UNIVERSIDADE DE SÃO PAULO

FACULDADE DE ECONOMIA, ADMINISTRAÇÃO E CONTABILIDADE DEPARTAMENTO DE ADMINISTRAÇÃO PROGRAMA DE PÓS-GRADUAÇÃO EM ADMINISTRAÇÃO

MODELO DE ALTA CAPACIDADE DE INOVAÇÃO PARA PMES

José Roberto de Araújo Cunha Neto

Orientador: Prof. Dr. Moacir de Miranda Oliveira Júnior

SÃO PAULO

2016 
Prof. Dr. Marco Antonio Zago

Reitor da Universidade de São Paulo

Prof. Dr. Adalberto Américo Fischmann

Diretor da Faculdade de Economia, Administração e Contabilidade

\author{
Prof. Dr. Roberto Sbragia
}

Chefe do Departamento de Administração

Prof. Dr. Moacir de Miranda Oliveira Júnior

Coordenador do Programa de Pós-Graduação em Administração 


\section{MODELO DE ALTA CAPACIDADE DE INOVAÇÃO PARA PMEs}

Tese apresentada ao Departamento de Administração da Faculdade de Economia, Administração e Contabilidade da Universidade de São Paulo como requisito para obtenção do título de Doutor em Ciências.

Orientador: Prof. Dr. Moacir de Miranda Oliveira Júnior

Versão Original

SÃO PAULO 
FICHA CATALOGRÁFICA

Elaborada pela Seção de Processamento Técnico do SBD/FEA/USP

Cunha Neto, José Roberto de Araújo

Modelo de alta capacidade de inovação para PMEs / José Roberto de Araújo Cunha Neto. - São Paulo, 2016.

$197 \mathrm{p}$.

Tese (Doutorado) - Universidade de São Paulo, 2016.

Orientador: Moacir de Miranda Oliveira Júnior.

1. Inovaç̃es tecnológicas - Administração 2. Determinantes 3. Capacidade de inovação 4 . Modelo 5 . Pequenas e médias empresas I. Universidade de São Paulo. Faculdade de Economia, Administração e Contabilidade. II. Título.

CDD -658.514 
A todos que superaram desafios. 


\section{AGRADECIMENTOS}

Meu profundo agradecimento a Deus (de Spinoza), pai vida, pai amor, pai consciência criativa o qual sempre senti presente em minha vida e me ajudou a superar todos os desafios que apareceram em meu caminho. Estou certo que assim continuaremos a caminhada.

Agradeço à minha família cujos membros contribuíram cada um à sua maneira para todas as minhas conquistas. Agradecimento especial ao meu irmão pelo apoio físico, mental e espiritual no processo de elaboração do presente estudo. Compartilho com ele quaisquer louros decorrentes desse trabalho.

Agradeço também à academia representada aqui pelo meu orientador Prof. Dr Moacir de Miranda Oliveira Júnior, Prof. Dr Felipe Mendes Borini, Prof. Cesar Akira Yokomizo, Prof. Dr José Afonso Mazzon e professores membros da banca. Agradeço ainda a todos envolvidos no projeto NAGI $P \& G$, quais sejam os gestores, membros da FIESP, CIESP, SENAI, consultores, bolsistas e empresas participantes que viabilizaram a condução da pesquisa de campo.

Agradeço, por fim, a todos que de alguma forma, por menor que tenha sido, contribuíram para meu progresso físico, mental e espiritual que foi fundamental para a conclusão da presente pesquisa. Agradeço aos parentes, amigos, meus colaboradores, colegas de trabalho, sem mencioná-los individualmente a fim de não incorrer na injustiça de deixar de citar alguém. \# Gratidão! 
"Me, we."

Mohammed Ali

"Ele não sabia que era impossível.

Foi lá e fez."

Jean Cocteau

"O futuro já está aqui, só está desigualmente distribuído entre as pessoas."

William Gibson

"Criatividade é a inteligência se divertindo."

Albert Einstein

"Aprenda as regras como um profissional, para que possa quebra-las como um artista."

Pablo Picasso 


\section{RESUMO}

Sob as condições presentes de competitividade global, rápido avanço tecnológico e escassez de recursos, a inovação tornou-se uma das abordagens estratégicas mais importantes que uma organização pode explorar. Nesse contexto, a capacidade de inovação da empresa enquanto capacidade de engajar-se na introdução de novos processos, produtos ou ideias na empresa, é reconhecida como uma das principais fontes de crescimento sustentável, efetividade e até mesmo sobrevivência para as organizações. No entanto, apenas algumas empresas compreenderam na prática o que é necessário para inovar com sucesso e a maioria enxerga a inovação como um grande desafio. A realidade não é diferente no caso das empresas brasileiras e em particular das Pequenas e Médias Empresas (PMEs). Estudos indicam que o grupo das PMEs particularmente demonstra em geral um déficit ainda maior na capacidade de inovação. Em resposta ao desafio de inovar, uma ampla literatura emergiu sobre vários aspectos da inovação. Porém, ainda considere-se que há poucos resultados conclusivos ou modelos compreensíveis na pesquisa sobre inovação haja vista a complexidade do tema que trata de um fenômeno multifacetado impulsionado por inúmeros fatores. Além disso, identifica-se um hiato entre o que é conhecido pela literatura geral sobre inovação e a literatura sobre inovação nas PMEs. Tendo em vista a relevância da capacidade de inovação e o lento avanço do seu entendimento no contexto das empresas de pequeno e médio porte cujas dificuldades para inovar ainda podem ser observadas, o presente estudo se propôs identificar os determinantes da capacidade de inovação das PMEs a fim de construir um modelo de alta capacidade de inovação para esse grupo de empresas. O objetivo estabelecido foi abordado por meio de método quantitativo o qual envolveu a aplicação da análise de regressão logística binária para analisar, sob a perspectiva das PMEs, os 15 determinantes da capacidade de inovação identificados na revisão da literatura. Para adotar a técnica de análise de regressão logística, foi realizada a transformação da variável dependente categórica em binária, sendo grupo 0 denominado capacidade de inovação sem destaque e grupo 1 definido como capacidade de inovação alta. Em seguida procedeu-se com a divisão da amostra total em duas subamostras sendo uma para análise contendo 60\% das empresas e a outra para validação (holdout) com os $40 \%$ dos casos restantes. A adequação geral do modelo foi avaliada por meio das medidas pseudo $\mathrm{R}^{2}$ (McFadden), chi-quadrado (Hosmer $\mathrm{e}$ Lemeshow) e da taxa de sucesso (matriz de classificação). Feita essa avaliação e confirmada a adequação do fit geral do modelo, foram analisados os coeficientes das variáveis incluídas no modelo final quanto ao nível de significância, direção e magnitude. Por fim, prosseguiu-se com a validação do modelo logístico final por meio da análise da taxa de sucesso da amostra de validação. Por meio da técnica de análise de regressão logística, verificou-se que 4 variáveis apresentaram correlação positiva e significativa com a capacidade de inovação das PMEs e que, portanto diferenciam as empresas com capacidade de inovação alta das empresas com capacidade de inovação sem destaque. Com base nessa descoberta, foi criado o modelo final de alta capacidade de inovação para as PMEs composto pelos 4 determinantes: base de conhecimento externo (externo), capacidade de gestão de projetos (interno), base de conhecimento interno (interno) e estratégia (interno).

Palavras-chave: Determinantes. Capacidade de inovação. Modelo. PMEs. 


\begin{abstract}
Under the current circumstances of global competition, fast technological improvement and scarcity of resources, innovation became one of the most important approaches that an organization can explore. In this context, the company's innovation capability, meaning its capacity to introduce new processes, products or ideas in the company, is recognized as one of the main sources of sustainable growth, effectiveness and survival for organizations. However, just a few companies understood in a practical manner what is required to successfully innovate and most of them see innovation as a big challenge. This reality is not different in the case of Brazilian companies and Small and Medium Size Enterprises (SMEs) in particular. Studies show that the group of SMEs particularly demonstrates in general a deficit even bigger in terms of innovation capacity. In response to the challenge to innovate, a broad literature arose about many aspects of innovation. Although it is considered that only a few results are conclusive or presented comprehensive models in the research about innovation due to the complexity of the theme that deals with a multidimensional phenomenon boosted by several factors. Besides that, there is a gap between what is known by the literature in general about innovation and the literature about innovation at SMEs. The relevance of the innovation capacity and the slow progress of its knowledge base in the context of small and medium size companies which the difficulties to innovate can still be observed, the present study proposed to identify the determinants innovation capacity for SMEs in order to build a high innovation capacity framework for this group of enterprises. The approach for the established goal was through a quantitative method which involved the application of a binary logistic regression to analyze, under the SME perspective, the 15 determinants of innovation capacity identified in the literature review. A transformation of the categorical dependent variable into binary, being group 0 named innovation capacity without highlight and group 1 called high innovation capacity, was done to allow adopting the logistic regression analysis technique. Following this, a procedure was conducted to divide the sample in two subgroups, being one for the analysis containing $60 \%$ of the companies and the other for validation (holdout) with the remaining $40 \%$ of the cases. The general model fit was assessed by the measures pseudo $\mathrm{R}^{2}$ (McFadden), chi-squared (Hosmer e Lemeshow) and the hit ratio (classification matrix). After this evaluation that confirmed the general model fit, the coefficients of the variables included in the final model were analyzed in terms of its significance level, direction and magnitude. By the end, the final logistic model was validated through the hit ratio of the holdout sample. With the logistic regression analysis, it was able to verify that 4 variables presented positive and significant correlation with the SMEs innovation capacity and, therefore distinguished the high innovation capacity companies from those with innovation capacity without highlight. Based on this discovery, a final high innovation capacity model was built for the SMEs composed by the 4 determinants: external knowledge base (external), project management capacity (internal), internal knowledge base (internal) and strategy (internal).
\end{abstract}

Keywords: Determinants. Innovation Capacity. Model. SMEs. 


\section{LISTA DE SIGLAS E ABREVIATURAS}

ABCD - Santo André, São Bernardo, São Caetano e Diadema

ANPEI - Associação Nacional de Pesquisa e Desenvolvimento das Empresas Inovadoras

CEO - Chief Executive Officer

CIESP - Confederação das Indústrias do Estado de São Paulo

DI - Difusão da Inovação

FIESP - Federação das Indústrias do Estado de São Paulo

IBGE - Instituto Brasileiro de Geografia e Estatística

MBA - Master of Business Administration

NAGI P\&G - Núcleo de Apoio à Gestão da Inovação Petróleo \& Gás

OCDE - Organização para Cooperação e Desenvolvimento Econômico

OI - Organizational Innovation

PMEs - Pequenas e Médias Empresas

PT - Process Theory

P\&D - Pesquisa \& Desenvolvimento

SEBRAE - Serviço de Apoio às Micro e Pequenas Empresas

SENAI - Serviço Nacional de Aprendizagem Industrial

TQM - Total Quality Management 


\section{LISTA DE FIGURAS}

Figura 1 - Evolução da inovação e capacidade da inovação . 31

Figura 2 - Três principais polos da literatura sobre inovação e respectivos e respectivos

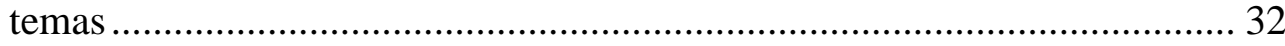

Figura 3 - Fluxo para aplicação da regressão logística.............................................. 97 


\section{LISTA DE TABELAS}

Tabela 1 - Questões, abordagem e foco das pesquisas sobre inovação

Tabela 2 - Determinantes da capacidade de inovação das empresas classificados em internos e externos.

Tabela 3 - Variáveis independentes do modelo: códigos, operacionalizações, referências e escalas

Tabela 4 - Variáveis latentes independentes do modelo: códigos, itens, operacionalizações, referências e escalas

Tabela 5 - Variável latente dependente do modelo: códigos, itens, operacionalizações, referências e escalas

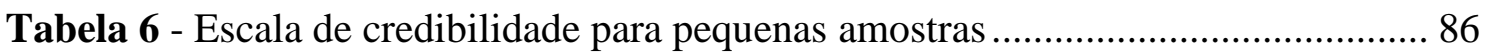

Tabela 7 - Grau de instrução dos respondentes ............................................................. 88

Tabela 8 - Distribuição das empresas por setor de atuação ........................................... 90

Tabela 9 - Distribuição da amostra por porte e setor de atuação ................................... 90

Tabela 10 - Distribuição das empresas por núcleo (localização geográfica)................. 91

Tabela 11 - Teste de igualdade de médias para a amostra de validação...................... 109

Tabela 12 - Análise de regressão logística por variável para a amostra de validação. 110

Tabela 13 - Precisão da estimação do modelo nulo.

Tabela 14 - Resultado do modelo de regressão logística estimado com 4 variáveis e respectivo McFadden $\mathrm{R}^{2}$ (adequação geral do modelo) ......................... 112

Tabela 15 - Resultado da estatística chi-quadrado (teste Hosmer Lemeshow) para o modelo estimado com 4 variáveis ............................................................ 113

Tabela 16 - Precisão da estimação do modelo logístico ................................................ 114

Tabela 17 - Precisão da estimação do modelo logístico para a amostra de análise $\mathrm{x}$ amostra de validação

Tabela 18 - Variáveis do modelo logístico final e seus respectivos coeficientes (originais e exponencializados). 


\section{LISTA DE GRÁFICOS}

Gráfico 1 - Crescimento da literatura sobre inovação ............................................... 28

Gráfico 2 - Distribuição dos respondentes por cargo que ocupa na empresa ................. 88

Gráfico 3 - Distribuição das empresas por porte (número de colaboradores) ................ 89 


\section{LISTA DE QUADROS}

Quadro 1 - Critérios e orientação para análise da validade teórica.............................. 95

Quadro 2 - Apresentação do modelo final de regressão logística ............................... 131 


\section{LISTA DE ESQUEMAS}

Esquema 1 - Modelo teórico apresentando as relações hipotéticas entre a capacidade de inovação e seus determinantes . 60 


\section{SUMÁRIO}

1 INTRODUÇÃO

1.1 Definição da Situação-problema e Justificativa ................................................. 19

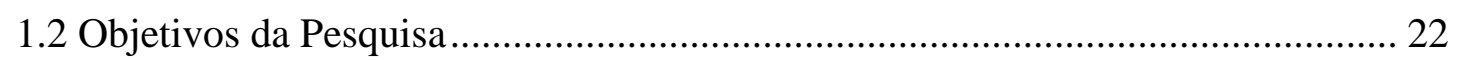

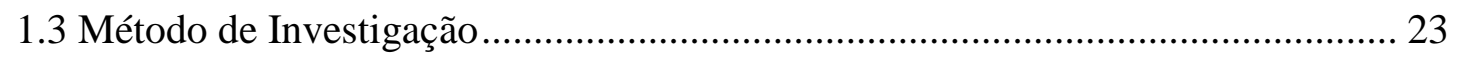

1.4 Contribuições Potenciais da Pesquisa ............................................................... 24

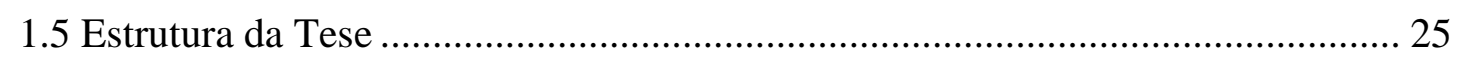

2 REVISÃO BIBLIOGRÁFICA ..................................................................................... 27

2.1 Evolução Histórica da Pesquisa sobre Inovação ................................................. 27

2.2 Identificação dos Determinantes da Capacidade de Inovação............................. 33

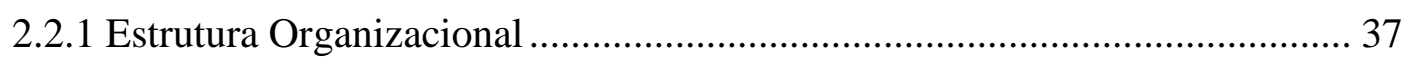

2.2.2 Disponibilidade de Recursos Financeiros Internos para Inovação ................ 39

2.2.3 Comunicação Interna............................................................................ 40

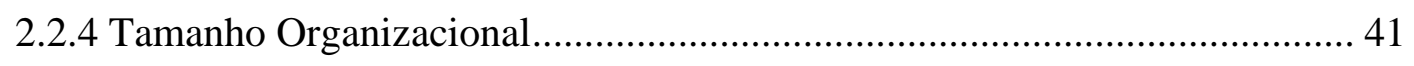

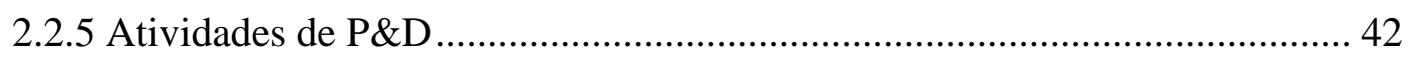

2.2.6 Investimento em Máquinas e Equipamentos .............................................. 44

2.2.7 Tempo de Existência da Organização ........................................................ 44

2.2.8 Cultura Organizacional......................................................................... 45

2.2.9 Capacidade de Gestão de Projetos............................................................... 46

2.2.10 Base de Conhecimento Interno............................................................ 47

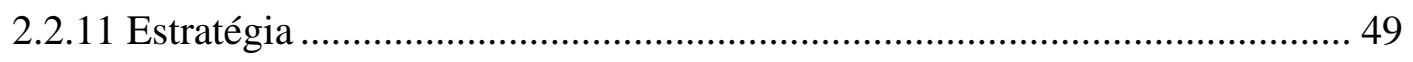

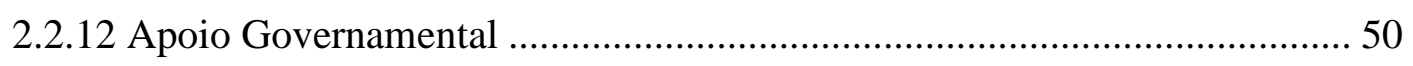

2.2.13 Localização Geográfica ..................................................................... 51

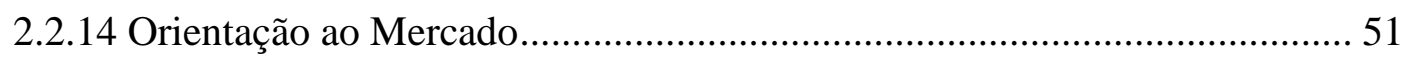

2.2.15 Base de Conhecimento Externo.............................................................. 53

2.3 Mensuração da Capacidade de Inovação............................................................. 55

3 MODELO TEÓRICO E FORMULAÇÃO DE HIPÓTESES.................................. 60

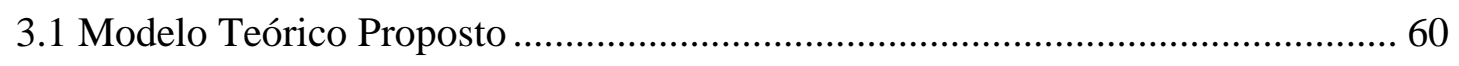

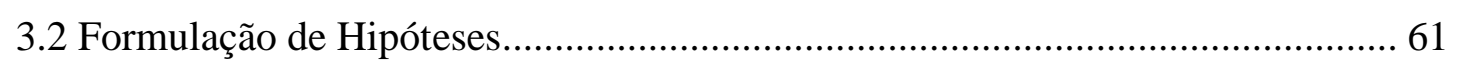

3.2.1 Formulação de Hipóteses: Estrutura Organizacional ................................. 61

3.2.2 Disponibilidade de Recursos Financeiros Internos para Inovação ................ 62

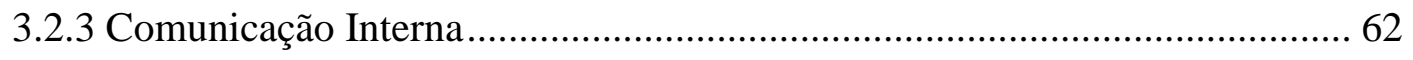

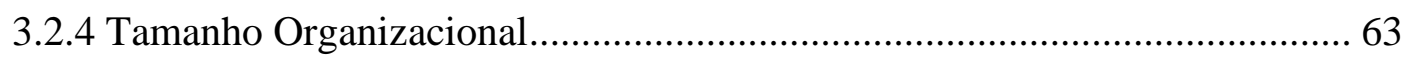

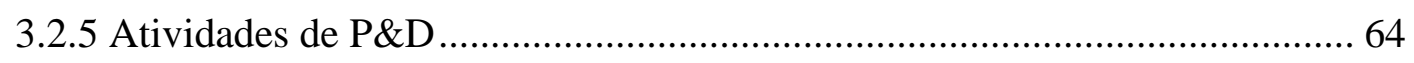

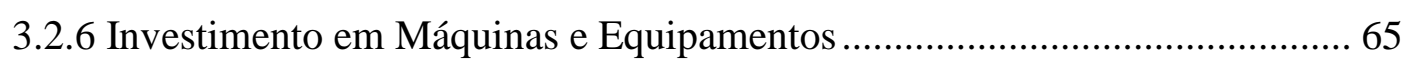




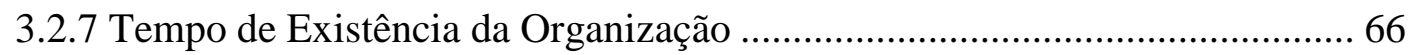

3.2.8 Formulação de Hipóteses: Cultura Organizacional ...................................... 67

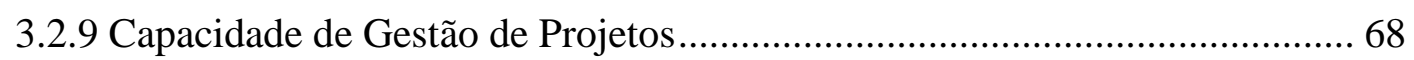

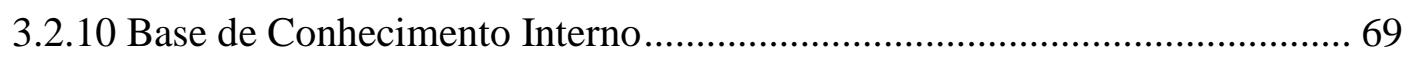

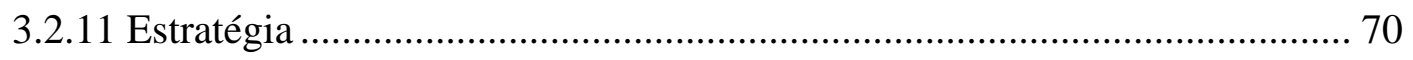

3.2.12 Apoio Governamental ...................................................................... 71

3.2.13 Localização Geográfica ...................................................................... 71

3.2.14 Orientação ao Mercado......................................................................... 72

3.2.15 Base de Conhecimento Externo........................................................... 73

4 METODOLOGIA DA PESQUISA................................................................... 74

4.1 O Questionário e a Geração de Escala................................................................. 74

4.1.1 Validade de Conteúdo e Pré-teste............................................................... 82

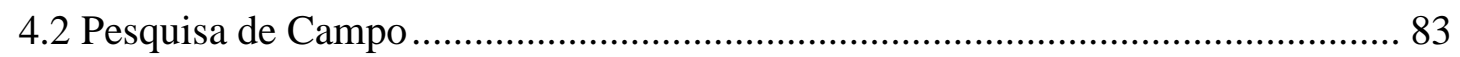

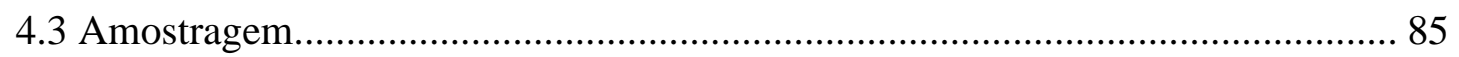

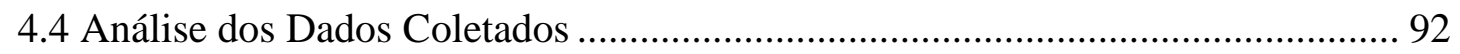

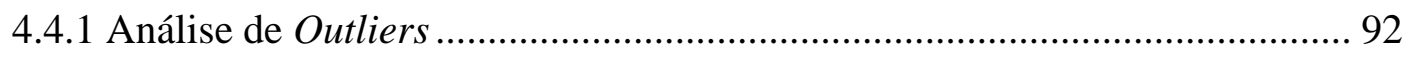

4.4.2 Análise de Validade e Confiabilidade ........................................................ 93

4.4.3 Método de Análise das Relações entre Variáveis.......................................... 96

5 APRESENTAÇÃO E ANÁLISE DOS RESULTADOS ........................................ 108

5.1 Construção do Modelo de Regressão Logística .................................................. 108

5.1.1 Resultado e Análise do Teste de Igualdade de Médias .............................. 109

5.1.2 Resultado e Análise da Regressão Logística por Variável Independente ... 109

5.1.3 Resultado e Análise do Modelo Nulo........................................................ 111

5.1.4 Resultado e Análise do Modelo Estimado................................................. 112

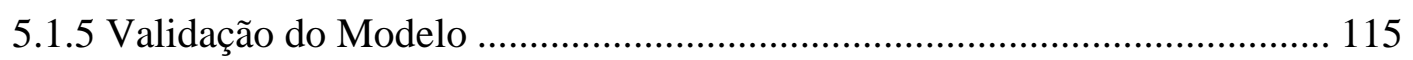

5.2 Interpretação e Análise das Variáveis do Modelo .............................................. 116

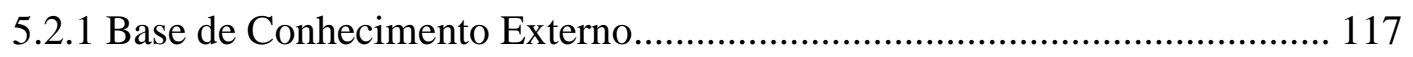

5.2.2 Capacidade de Gestão de Projetos............................................................ 118

5.2.3 Base de Conhecimento Interno................................................................. 119

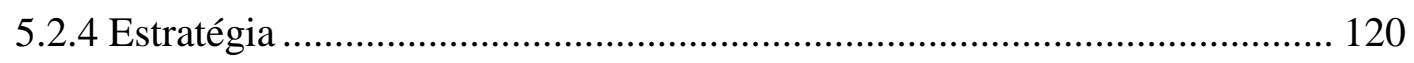

5.3 Análise das Variáveis Excluídas do Modelo .................................................... 121

5.3.1 Investimento em Máquinas e Equipamentos ............................................. 121

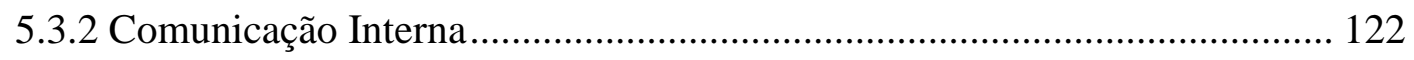

5.3.3 Disponibilidade de Recursos Financeiros Internos ................................. 123

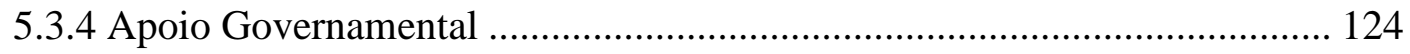

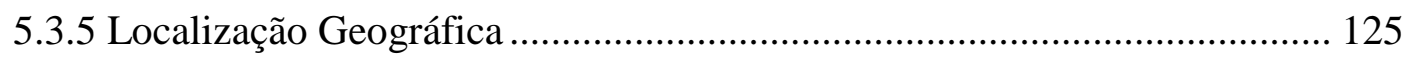

5.3.6 Tamanho Organizacional.................................................................. 125 


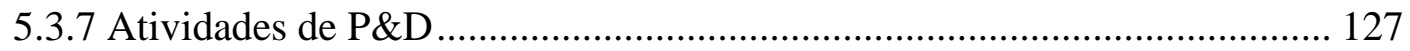

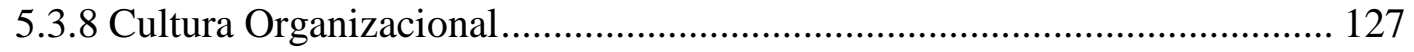

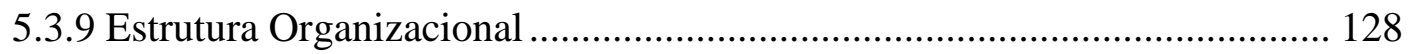

5.3.10 Tempo de Existência ........................................................................ 129

5.3.11 Orientação ao Mercado........................................................................ 130

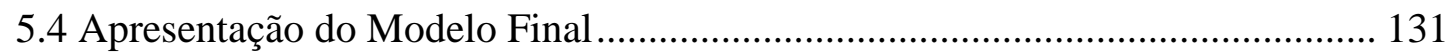

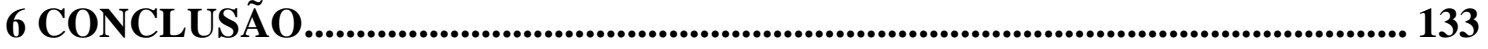

6.1 Contribuições da Pesquisa ............................................................................... 135

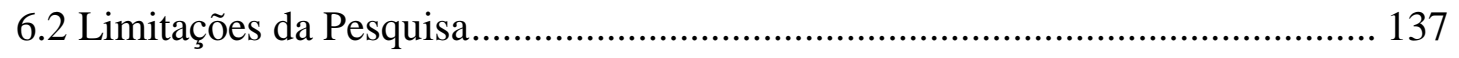

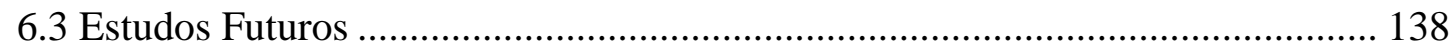

REFERÊNCIAS BIBLIOGRÁFICAS ............................................................... 140

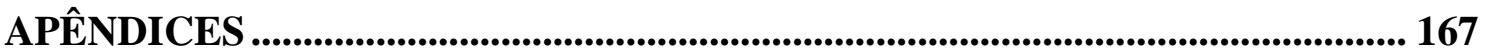




\section{INTRODUÇÃO}

A inovação tem transformado a economia mundial desde a Revolução Industrial (Department for Business Innovation \& Skills, 2014) e sob as condições presentes de competitividade global (BERKHOUT et al., 2006; LIN et al., 2015), rápido avanço tecnológico (HAMID e ROSMAINI, 2013) e escassez de recursos em que as organizações operam (DAMANPOUR e WISCHNEVSKY, 2006), passou a ser reconhecida como uma das principais fontes de crescimento sustentável, efetividade e até mesmo sobrevivência para as empresas (DAMANPOUR e SCHNEIDER, 2006; O'REGAN et al., 2005; RODRÍGUEZ-POSE E CRESCENZI, 2008, WATKINS et al, 2015). Nesse contexto, a inovação tornou-se uma das abordagens estratégicas mais significativas que uma organização pode explorar (ASA et al., 2013).

A relevância atribuída à inovação decorre do fato de que se trata de uma vantagem competitiva para a empresa (DAMANPOUR e ARAVIND, 2012; HOTHO e CHAMPION, 2011; KOC e CEYLAN, 2007; MAES e SELS, 2013; TEECE et al., 1997; TIDD et al., 2005) haja vista ter sido reconhecida como valiosa, complexa e até mesmo um recurso escasso, específico e que, portanto não pode ser facilmente transferido ou imitável por outras firmas (HULT et al., 2002). Dessa forma, um componente-chave do sucesso das organizações é a extensão de sua capacidade de inovação que se refere à capacidade da organização de se engajar em inovação, ou seja, introduzir novos processos, produtos ou ideias na empresa (HURLEY e HULT, 1998; PORTER, 1990; SCHUMPETER, 1934). Essa capacidade tem sido destacada como um fator crítico para produtividade e competitividade (OECD, 2005; SAKAMOTO, 2011) e é reconhecida como um conjunto de habilidades essencial para a sobrevivência e sucesso da empresa (FACÓ, 2009; FIGUEIREDO, 2014; WANG e AHMED, 2004).

No caso particular das Pequenas e Médias Empresas (PMEs), por sua vez, a importância da capacidade de inovação pode ser ainda maior do que para as grandes organizações (FRITZ, 1989). Mudanças nos mercados e nas estratégias competitivas das grandes organizações aumentaram a pressão sobre as PMEs para focar na capacidade de inovação (MCADAM et al., 2004). O desenvolvimento acelerado tecnológico e 
científico e os ciclos de vida de produtos cada vez mais curtos (HAMID e ROSMAINI, 2013) também geraram um particular imperativo para inovação, bem como oportunidades, para as PMEs (KEIZER et al., 2002; O'REGAN et al., 2005). Tal fato requer uma abordagem mais estratégica da capacidade de inovação para que a inovação seja efetiva e essas empresas sobrevivam e prosperem no longo prazo (CEFIS e MASILI, 2003; TIDD et al., 2005) contribuindo para reduzir a taxa de mortalidade das PMEs (CAVES, 1998).

No entanto, apenas algumas empresas compreenderam na prática o que é necessário para inovar com sucesso (CHRISTENSEN e RAYNOR, 2003; ASSINK, 2006) e as organizações brasileiras corroboram essa realidade. De acordo com dados apurados pela Pesquisa de Inovação Tecnológica (Pintec 2011²), realizada pelo IBGE (2013), apenas $35,7 \%$ das empresas pesquisadas declararam ter implementado inovações de produto ou processo entre 2009 e 2011. Estudos indicam que o grupo das PMEs particularmente demonstra em geral um déficit ainda maior na capacidade de inovação (O'REGAN et al., 2005) devido, em parte, ao baixo grau de complexidade tecnológica que possuem, além dos principais obstáculos como falta de conhecimento especializado, dificuldade de acesso à tecnologia, insumos, mercados, informação, créditos financeiros e aquisição de serviços externos (LEÓN e VALENZUELA, 2014) o que explica a alta gerência dessas empresas enxergar a gestão da inovação como um grande desafio (TIDD et al., 2005).

Em resposta a esse desafio, uma ampla literatura emergiu, particularmente nos anos recentes, sobre vários aspectos da inovação (FAGERBERG, 2003). Porém, ainda considera-se que há poucos resultados conclusivos ou modelos compreensíveis na pesquisa sobre inovação que é considerada demasiadamente estática ou tratada de forma inadequada (TIDD, 2001; EDWARDS et al. 2005). No caso específico das PMEs, a

\footnotetext{
${ }^{1}$ Os dados apurados pela Pintec 2011 correspondem ao período 2009-2011, sendo que do universo de 128.699 empresas pesquisadas (com 10 ou mais pessoas ocupadas), somente 45.950 implementaram produtos ou processos novos ou significativamente aprimorados, representando uma taxa geral de inovação de $35,7 \%$. A referida taxa é menor quando comparada aos dados fornecidos pela Pintec 2008 que apuraram uma taxa de $38,6 \%$ sugerindo que as empresas brasileiras foram ainda menos inovadoras nos últimos 03 anos.
} 
literatura cresce rapidamente, mas ainda apresenta uma abordagem genérica (HOFFMAN et al., 1998; KEIZER et al., 2002; EDWARDS et al, 2005) ao invés de diretrizes de gestão contextualizadas e muitas vezes inadequada por ser tratada a partir de perspectivas teóricas desenvolvidas para empresas maiores, o que pode ser considerado uma extrapolação perigosa (SAKAMOTO, 2011).

Nesse contexto, a inovação configura-se em um fator-chave para as empresas sobreviverem e crescerem no longo prazo, em especial para as PMEs. O processo de inovação envolve a transformação de oportunidades em utilidades práticas (TIDD et al., 2005) e, para tanto, a mera presença de conhecimento tecnológico dentro da empresa é insuficiente (COBBENHAGEN, 2000). A capacidade de inovação é reconhecida como a habilidade de gerir e explorar novas ideias e conceitos e gerar soluções para oportunidades potenciais que atendam as necessidades do mercado e as tornem em soluções viáveis (ASSINK, 2006, HULT et al., 2004). O desafio de compreender a relação complexa entre as dimensões da capacidade de inovação e a capacidade de inovação das PMEs será tratado ao longo do presente estudo uma vez que esse grupo de empresas conseguirá ganhar vantagem competitiva sustentável por meio da utilização contínua e investimento assertivo em recursos para inovação (BARNEY, 1991).

\subsection{Definição da Situação-problema e Justificativa}

Apesar de mais de 40 anos de estudo sobre inovação nas organizações que resultaram em uma volumosa literatura, a avaliação das dimensões ou conjunto de práticas, características ou atributos que contribuem para fortalecer a capacidade de inovação das empresas persiste como grande preocupação não só para a academia como também para administradores de empresas (BOLY et al., 2014). Pouco se sabe realmente sobre como fomentar a inovação e quais suas variáveis incentivadoras especialmente no contexto das PMEs (HAMID e ROSMAINI, 2013), sendo que no Brasil em particular a inovação ainda é restrita como fator de estudo e divulgação de sua reprodução (MACHADO, 2004). Dessa forma, as áreas de inovação e PMEs ainda apresentam oportunidades de pesquisa e lacunas a serem exploradas. 
Entre as principais causas do pouco conhecimento acerca das características que envolvem a capacidade de inovação das PMEs estão: limitações e deficiências das pesquisas sobre capacidade de inovação (VALLADARES, 2012; WOLFE, 1994), bem como sobre as PMEs (MULLEN et al., 2009), pouco esforço de pesquisa que tem sido dedicado à construção de teorias sobre PMEs a partir de seu próprio ambiente (SAKAMOTO, 2011), pouco espaço, na literatura sobre inovação, dedicado à exploração do comportamento inovador das organizações e como o mesmo é influenciado por agentes internos e externos (FACÓ, 2009) e o alto grau de complexidade do tema capacidade de inovação (ASA et al., 2013).

Os estudos sobre a capacidade de inovação evoluíram significativamente desde a crítica de Wolfe (1994) que contribuiu para reorientar a pesquisa neste campo (VALLADARES, 2012), contudo alguns problemas ainda persistem e dificultam a produção de teorias compatíveis que possam guiar práticas de gestão (TIDD, 2001). Até agora, os estudos empíricos sobre capacidade de inovação são limitados a estudos de caso (VALLADARES, 2012) o que resulta na imprecisão quanto à natureza e relação entre seus diversos determinantes (APAYDIN e CROSSAN, 2010). Outro fator que gera inconsistências nos resultados refere-se à adoção de diferentes medidas para capacidade de inovação (FIGUEIREDO, 2014). Ademais, para tratar a dificuldade de inferência de regras gerais sobre capacidade de inovação (RADAS e BOZIC, 2009) foram desenvolvidas nas pesquisas sobre esse tema teorias de contingência para tipos de inovação (ASSINK, 2006; PAVITT, 1984), tipos organizacionais (DAMANPOUR e WISCHNEVSKY, 2006) e por tipo de empresa, a título de exemplo, high tech (HOFFMAN et al., 1998). Essa tendência de limitar a pesquisa não configura por si só uma barreira à pesquisa cumulativa, porém impede generalizações em função da visão fragmentada do objeto de estudo. No caso das pesquisas sobre PMEs, os métodos de pesquisa apresentam deficiências tais como falta de foco e falha em explorar os múltiplos níveis de análise (MULLEN, et al., 2009).

Com relação à inovação no âmbito das PMEs, por sua vez, a literatura internacional é escassa no que diz respeito ao estudo sobre comportamento inovador das PMEs (HAMID e ROSMAINI, 2013; OAKEY, 1993; O’REGAN et al., 2006). Os resultados obtidos nas poucas pesquisas existentes sobre o tema apresentam dificuldade de 
generalização devido ao foco estreito desses trabalhos, concentrando em empresas com uso de tecnologia intensiva e setores de base tecnológica. Além disso, a procedência desses estudos é majoritariamente de economias desenvolvidas (KAUFMANN e TODTLING, 2002) e em virtude do processo de inovação em países em desenvolvimento ter características muito diferentes das de países desenvolvidos (GOEDHUYS e VEUGELERS, 2012) sua aplicabilidade torna-se limitada. Há ainda a prática nos estudos das PMEs de tomar muitas vezes como base perspectivas teóricas desenvolvidas para empresas maiores (SAKAMOTO, 2011) o que se trata de um equívoco dado que uma PME não é uma empresa de grande porte em escala reduzida. Nesse contexto, identifica-se um hiato entre o que é conhecido pela literatura geral sobre inovação e a literatura sobre inovação nas PMEs e estudos de inovação nas PMEs falharam em refletir avanços na literatura sobre inovação (EDWARDS et al., 2005).

No caso específico da literatura dedicada à análise das características que diferenciem empresas mais e menos inovadoras, o tema permanece pouco explorado (FACÓ, 2009) e apresenta lacunas, como é o caso das relações entre as PMEs e ambiente externo (EDWARDS et al., 2005). Tal fato decorre em parte devido aos padrões de estudos prévios que indicam que a literatura permaneceu durante muito tempo com forte foco no impacto de $\mathrm{P} \& \mathrm{D}$, quase excluindo aspectos relacionados à inovação e seus mecanismos (O'REGAN et al., 2005). No entanto, as pesquisas sobre tópicos de inovação vêm crescendo e muitos pesquisadores estão incorporando elementos do negócio como determinantes da capacidade de inovação (HAMID e ROSMAINI, 2013) tais como capacidade de marketing e administrativa que começaram a ganhar destaque na academia.

Por fim, a própria complexidade inerente ao tema capacidade de inovação se constitui em um obstáculo a ser superado para evolução do conhecimento dos seus determinantes. Entre as principais dificuldades está a própria falta de definição clara sobre quais dimensões ou fatores compõe o conceito de capacidade de inovação (YOKOMIZO, 2014) e sua dependência de um conjunto complexo de fatores (FRANCINI, 2012). Com relação ao primeiro ponto, há ainda uma ausência de definição comum e amplamente aceita de capacidade de inovação relacionada principalmente à inconsistência semântica do conceito. No caso do segundo ponto, o 
problema é que a capacidade de inovação não é um conceito simples ou composto por um único fator, haja vista envolver diversos aspectos de gestão e liderança, aspectos técnicos, bem como alocação estratégica de recursos, conhecimento de mercado, incentivos organizacionais, entre outros (ASA et al., 2013). Ou seja, trata-se de um fenômeno multifacetado impulsionado por inúmeros fatores (BECHEIKH et al., 2006) o que justifica em parte a contínua inconsistência dos resultados sobre os principais determinantes da inovação (FIGUEIREDO, 2014; YAM et al., 2010).

Identificar os aspectos que conduzem à inovação nas organizações é essencial para a construção da capacidade de inovação que proporciona o potencial para inovação efetiva (ASA et al., 2013). Tendo em vista o lento avanço no entendimento da capacidade de inovação no contexto das PMEs (HAMID e ROSMAINI, 2013) cujas fraquezas nas tentativas de inovar ainda podem ser observadas (NIETO e SANTAMARIA, 2006), o presente estudo propõe o seguinte problema de pesquisa:

Qual o modelo de alta capacidade de inovação para PMEs e como se comportam as variáveis que compõe o modelo?

Esta tese visa somar-se aos esforços da escassa literatura que assume o desafio de explorar a capacidade de inovação e que urge por mais estudos sobre o tópico (VALLADARES, 2012). Será adotado foco nas PMEs que em virtude da literatura escassa sobre o comportamento inovador desse grupo de empresas, em particular no caso dos países em desenvolvimento, permanecem com muitas perguntas sem resposta (NIETO e SANTAMARIA, 2006).

\subsection{Objetivos da Pesquisa}

Com base no contexto apresentado, o presente trabalho tem por objetivo geral construir um modelo de alta capacidade de inovação para as PMEs e compreender como se comportam as variáveis que compõe o modelo a fim de responder ao problema de pesquisa proposto. 
Esse objetivo geral pode ser desdobrado em três objetivos específicos, conforme apresentado a seguir:

Objetivo Específico 1. Classificar as PMEs da amostra de acordo com seus respectivos graus de capacidade de inovação (capacidade de inovação alta e capacidade de inovação sem destaque).

Objetivo Específico 2. Testar a relação entre as variáveis identificadas na literatura e a capacidade de inovação das PMEs a fim de identificar aquelas que apresentam relação positiva e significante e dessa forma são determinantes para explicar a diferença entre PMEs com capacidade de inovação alta e sem destaque.

Objetivo Específico 3. Interpretar e analisar os determinantes da capacidade de inovação que compõe o modelo final e analisar as variáveis que foram excluídas desse modelo.

\subsection{Método de Investigação}

O objetivo estabelecido para a presente pesquisa foi abordado por meio de método quantitativo. Esse método envolveu a aplicação da análise de regressão logística binária para identificar as variáveis que apresentam correlação positiva e significante com a capacidade de inovação das PMEs. Essa técnica foi escolhida por ser adequada para tratar casos como o desse estudo em que a variável dependente (capacidade de inovação) é categórica e as variáveis independentes são métricas e não-métricas. Além disso, a regressão logística também possui a vantagem de ser menos sensível quando as premissas não forem cumpridas.

Para adotar a técnica de análise de regressão logística, foi realizada a transformação da variável dependente categórica em binária, sendo grupo 0 denominado capacidade de inovação sem destaque e grupo 1 definido como capacidade de inovação alta. Em seguida foi realizada a divisão da amostra total em duas subamostras sendo uma para 
análise contendo $60 \%$ das empresas e a outra para validação (holdout) com os $40 \%$ dos casos restantes.

Antes de rodar o modelo, foi realizado um stepwise que compreendeu um teste de igualdade das médias e uma regressão logística por variável independente. Essa análise permitiu identificar 4 variáveis que foram incluídas no modelo logístico inicial. A adequação geral do modelo foi avaliada por meio das medidas pseudo $\mathrm{R}^{2}$ (McFadden), chi-quadrado (Hosmer e Lemeshow) e da taxa de sucesso (matriz de classificação). Feita essa avaliação e confirmada a adequação do fit geral do modelo, foram analisados os coeficientes das variáveis incluídas no modelo final quanto ao nível de significância, direção e magnitude. Por fim, prosseguiu-se com a validação do modelo logístico final por meio da análise da taxa de sucesso da amostra de validação.

\subsection{Contribuições Potenciais da Pesquisa}

Do ponto de vista acadêmico, espera-se com os resultados da presente pesquisa, contribuir para a consistência da literatura internacional sobre inovação, particularmente sobre os determinantes da capacidade de inovação e somar-se aos esforços da escassa literatura sobre o comportamento de inovação das PMEs, em especial nos países em desenvolvimento, com base na adoção das melhores práticas de pesquisa sobre o tema, sugeridas pela literatura.

Segundo Keizer et al. (2002), conhecer os determinantes que influenciam a capacidade de inovação do grupo das PMEs é relevante não apenas desde uma perspectiva teórica, como também de uma perspectiva gerencial. Nesse sentido, a pesquisa acadêmica pode fazer contribuições práticas valiosas para promover a inovação nas empresas o que permanece um grande desafio para executivos (DAMANPOUR e WISCHNEVSKY, 2006). O presente estudo pretende proporcionar aos gestores das PMEs conhecimento a respeito dos determinantes da capacidade de inovação para que se tornem mais assertivos no direcionamento dos recursos a fim de gerar e alavancar as capacidades inovadoras desejadas uma vez que inovação requer recursos substanciais que são limitados para essas empresas. Com base nesse conhecimento, acredita-se que esse 
grupo de empresas poderá tornar-se mais competitivo uma vez que inovação proporciona produto com alto valor agregado aos stakeholders (HULT et al., 2004), a baixos preços (FERGUSON, 2005), enquanto simultaneamente reduz custos da operação (ROTHWELL, 1992).

Por fim, sob a ótica do setor público, tendo em vista a capacidade do Brasil de atuar, nos anos recentes, como um ator crescentemente importante no comércio internacional, produção e inovação (GOEDHUYS e VEUGELERS, 2012) e a relevância das PMEs como um grande grupo internacional (OECD, 2002), espera-se compreender esse fenômeno e que a partir dos resultados dessa pesquisa seja possível inferir conclusões úteis que sirvam de base para formulação de políticas públicas. As PMEs são importantes para inovação e crescimento da economia dos países e enfrentam com maior dificuldade as barreiras para inovação o que as torna foco de políticas públicas para inovação uma vez que empresas inovadoras crescem duas vezes mais rápido que as não inovadoras e são menos propensas ao fracasso (Department for Business Innovation \& Skills, 2014).

\subsection{Estrutura da Tese}

O presente projeto de pesquisa será estruturado em seis capítulos. O primeiro capítulo trata da introdução a qual compreende a contextualização do tema, a formulação do problema de pesquisa com base nas lacunas da literatura, bem como sua justificativa de escolha e o estabelecimento dos objetivos de pesquisa (geral e específicos). Em seguida é realizada uma breve descrição da metodologia adotada para abordar o problema de pesquisa e atingir o objetivo. Ao final desse capítulo são apresentadas as contribuições potenciais da pesquisa no âmbito da academia, das PMEs e do setor público.

O capítulo dois contempla a revisão teórica da literatura sobre inovação, a qual inclui a contextualização do tema na literatura, a identificação e compreensão das dimensões que influenciam a capacidade de inovação das empresas e a análise e definição da forma de mensuração da capacidade de inovação. 
Em seguida, o capítulo três apresenta no primeiro tópico o modelo conceitual elaborado e no segundo tópico as hipóteses formuladas ambos a partir da literatura, sendo que o primeiro contém as variáveis que influenciam a capacidade de inovação das PMEs (divididos em dois grandes blocos, internos e externos) e o segundo apresenta a análise individual dessas varáveis que compõe a capacidade de inovação.

Já o capítulo quatro discorre sobre a metodologia adotada para a presente pesquisa por meio da apresentação do questionário e do processo de geração de escala, descrição da amostra e da pesquisa de campo e descrição e análise dos dados coletados que incluiu análise dos outliers, análise da validade e confiabilidade e descrição do método de análise das relações entre as variáveis e a capacidade de inovação.

No caso do capítulo cinco, realiza-se o processo de construção do modelo de regressão logística, a análise e interpretação das variáveis incluídas no modelo estimado, bem como a análise das variáveis excluídas desse modelo e a apresentação do modelo final.

Por fim, no capítulo seis será apresentada a conclusão e considerações finais do estudo que inclui contribuições da pesquisa, limitações do trabalho e sugestões de estudos futuros de acordo com as descobertas realizadas durante a pesquisa. 


\section{REVISÃO BIBLIOGRÁFICA}

Revisões da literatura ajudam os pesquisadores a limitar o escopo de sua investigação e transmitem para os leitores a importância de estudar um tópico (CRESWELL, 2007). O presente capítulo tem como objetivo realizar uma revisão teórica sobre a literatura de inovação. Inicialmente é apresentada a evolução histórica da pesquisa sobre inovação a fim de contextualizar o estudo nessa literatura. Em seguida são identificadas e apresentadas as dimensões que influenciam a capacidade de inovação das empresas. Por fim, são analisadas as formas adotadas para mensuração da capacidade de inovação.

\subsection{Evolução Histórica da Pesquisa sobre Inovação}

A taxa de acúmulo de fatores não responde mais pela maior parte do crescimento econômico (AGHION e HOWITT, 1998). Nesse contexto, a inovação passa a ser reconhecida como o principal motor de crescimento econômico de longo prazo, configurando-se em um poderoso fator explicativo por trás das diferenças de performance entre empresas, regiões e países (FAGERBERG, 2003). Tal mudança causa reflexos no nível teórico em que a inovação substitui a eficiência como foco crucial na construção de muitas teorias, com a eficiência tornando-se um complemento necessário à inovação (CLARK e STAUNTON, 1989; KEIZER et al., 2002; EDWARDS et al. 2005).

O presente tópico tem por finalidade explorar o desenvolvimento e a rápida expansão dos estudos no campo científico emergente denominado inovação, a fim de contextualizar essa proposta de pesquisa na literatura. $\mathrm{O}$ referido campo compreende o estudo sobre como a inovação ocorre e quais são os fatores explicativos relevantes e suas consequências econômicas e sociais (FAGERBERG et al., 2012)

A inovação não se trata de um fenômeno novo e, apesar de sua importância óbvia, a academia nem sempre deu ao tema a atenção que merece (FAGERBERG, 2003). No entanto, a pesquisa sobre o papel da inovação na mudança econômica e social vem 
proliferando nos anos recentes conforme ilustrado no Gráfico 1, particularmente dentro das ciências sociais, acompanhada de uma orientação interdisciplinar visando estudar todos os aspectos da inovação sob diferentes perspectivas.

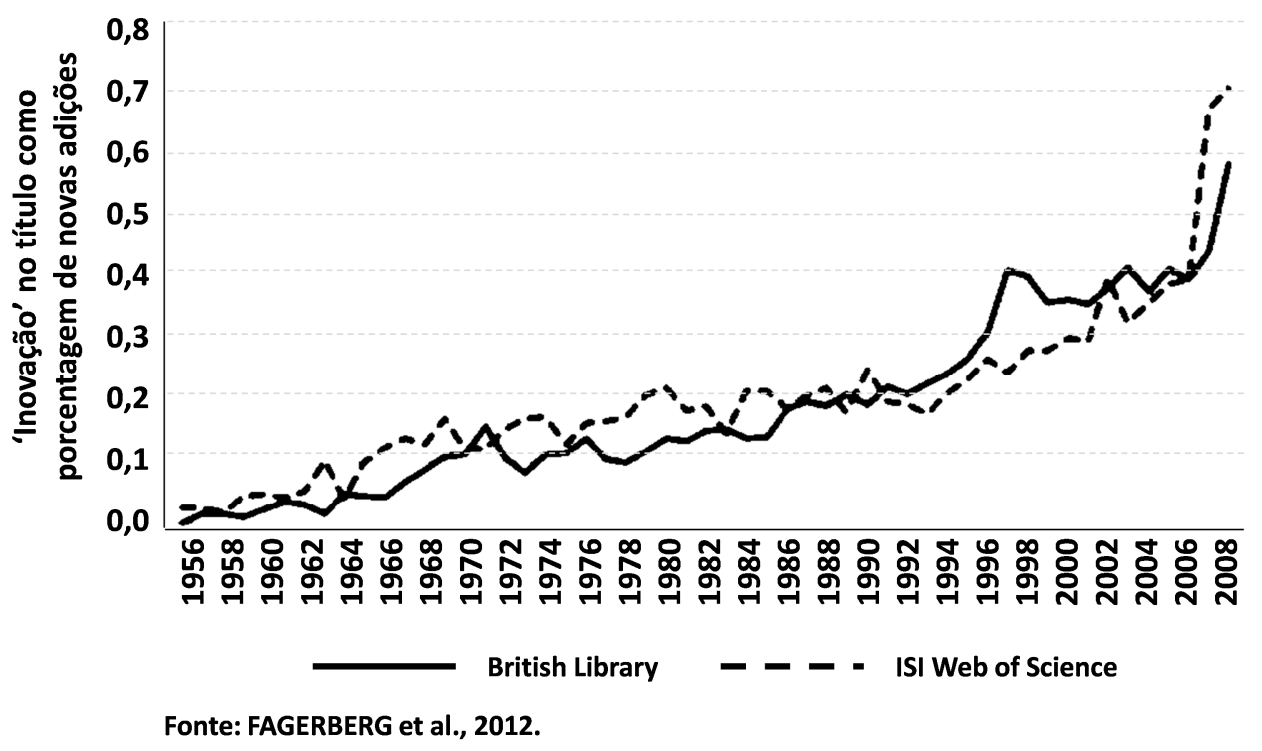

\section{Gráfico 1 - Crescimento da literatura sobre inovação}

A inovação está sob estudo acadêmico desde a década de 40, mas até 1960 as publicações científicas sobre inovação eram poucas e esparsas (FAGERBERG e VERSPAGEN, 2009). A partir da década de 60, o interesse acadêmico pela inovação apresentou crescimento sólido, com rápido aumento no volume de publicações particularmente no começo da década de 90 . Tendo em consideração a revisão dessa literatura é possível classificar os estudos sobre inovação em 04 fases evolutivas distintas e cronológicas (FERNANDES et al, 2013) que refletem a mudança do referido campo ao longo do tempo, sendo elas: origem, integração, distinção e sistematização.

$\mathrm{Na}$ primeira fase, denominada origem (1940-1960), pesquisadores detectaram a importância da necessidade da mudança e concluíram que mudança envolvia inovação (FERNANDES et al, 2013). Durante esse período, um trabalho que merece destaque é o do economista Joseph Schumpeter ${ }^{2}$ (1883-1950) que combinou conhecimentos sobre

\footnotetext{
${ }^{2}$ O economista austro-americano Joseph Schumpeter (1912/1934, 1942) avançou na construção de uma teoria em que as inovações e os agentes sociais que as sustentam eram vistos como força condutora do desenvolvimento econômico (ANDERSEN, 2009). Nessa teoria o autor descreve o processo de destruição
} 
economia, sociologia e história em uma abordagem original para o estudo da mudança econômica e social no longo prazo, focando em particular no papel crucial da inovação e dos fatores que a influenciam (FAGERBERG e VERSPAGEN, 2009). No entanto, a contribuição de trabalhos publicados entre 1950 e 1969 para o conhecimento central no campo da inovação é considerada relativamente modesta, uma vez que $85 \%$ desse conhecimento foi produzido depois de 1970 (FAGERBERG et al., 2012).

Em seguida, na segunda fase classificada como integração (1960-1985), o campo emergente dos estudos sobre inovação adentra um período de crescimento rumo ao desenvolvimento de um framework conceitual e teórico mais similar e coerente, bem como a uma agenda de pesquisa compartilhada (em especial pós década de 70 ). Todavia, a fragmentação do trabalho empírico ainda caracteriza o estado do conhecimento referente à gênese da inovação (NELSON e WINTER, 1977). Nesse período, a inovação é associada a equipamento e material tecnológico, sendo que os indicadores comumente utilizados para mensurar inovação eram as estatísticas de P\&D e patentes (PAVITT, 1984). Na literatura existente até o final dessa fase, já haviam sido explorados temas como os fatores que influenciam investimento em P\&D e inovação, as fontes de invenção e inovação, as diferenças entre indústrias e setores, entre outros. Schumpeter continuava sendo uma das principais fontes de inspiração sobre o tema, seguido de Richard Nelson e Christopher Freeman ${ }^{3}$ que também realizaram importantes contribuições para a literatura (FAGERBERG e VERSPAGEN, 2009). Sobre essa fase, pode-se concluir que a inovação estava ainda distante de ser um campo de análise desenvolvido e apresentava um considerável grau de sobreposição com relação aos estudos sobre tecnologia (BHUPATIRAJU et al., 2012).

A terceira fase, de distinção (1985-2000), por sua vez representa um momento mais maduro do campo da inovação (FAGERBERG et al., 2012). Os pesquisadores começaram a compreender a inovação como um processo que envolve a organização

criadora atribuindo-o como conceito primário condutor do capitalismo ressaltando a importância da necessidade das empresas se abrirem para novos mercados (FERNANDES et al, 2013). Schumpeter cunhou ainda a definição de inovação que permanece sendo utilizada nos estudos atuais sobre inovação (FAGERBERG et al., 2012).

${ }^{3}$ O economista inglês Christopher Freeman (1974, 1982 e 1985) é autor de um dos primeiros estudos a aplicar uma abordagem sistêmica do papel da inovação na mudança econômica e social de longo prazo, sendo que seus trabalhos se tornaram amplamente difundidos (FAGERBERG et al., 2012). 
como um todo enquanto simultaneamente condiciona o comportamento organizacional e passaram a utilizar-se das teorias de capacidade e recurso a fim de explicar as capacidades de inovação da empresa sendo novos produtos, processos e patentes os principais indicadores estudados para representar as capacidades de inovação existentes (FERNANDES et al., 2013). Trata-se de um enfoque importante haja vista que o comportamento inovador das empresas passou a ser em sua maioria avaliado de acordo com suas capacidades de inovação (COHEN AND LEVINTHAL, 1990; TEECE et al., 1997) tornando a capacidade em um fator fundamental para o estudo da inovação. Dessa forma, as pesquisas oriundas desse período promovem uma ruptura com os estudos da fase anterior uma vez que mudam a perspectiva de análise da inovação de tópicos econômicos industriais e macroeconômicos para uma orientação mais voltada para gestão e negócios (BHUPATIRAJU et al., 2012; FAGERBERG et al., 2012). Tal mudança de direcionamento teve início com Michael Porter que exemplifica essa realidade por ser um acadêmico com raízes na literatura de administração, mas que lida com assuntos relacionados à política em torno da vantagem competitiva das nações (BHUPATIRAJU e al., 2012). Ou seja, estudos sobre gestão e negócios começaram a assumir uma posição de destaque no campo dos estudos sobre inovação enquanto economia como disciplina desaparece da trajetória principal do campo e nesse contexto é possível inferir que o desenvolvimento da literatura ocorre de forma menos cumulativa e mais disruptiva.

Com relação à quarta e última fase, sistematização (a partir de 2000), os pesquisadores compreenderam que a aplicação individual de qualquer abordagem será insuficiente para qualquer explicação significativa a respeito das capacidades de inovação o que culminou na adoção de uma aplicação eclética e integradora de diversas teorias (FERNANDES et al., 2013). Ademais, parte das pesquisas desviou do foco de trabalhos sobre inovação em empresas e indústrias predominante na fase anterior para também atentar-se ao papel da inovação na economia como um todo e como as instituições e políticas podem ser ajustadas a fim de que a sociedade possa beneficiar-se da inovação e sua difusão (BHUPATIRAJU et al., 2012).

A Figura 1 apresenta as quatro fases descritas anteriormente e a consolidação dos principais acadêmicos que contribuíram para a literatura central no campo de estudos 
sobre inovação por período com base em Fagerberg e Verspagen (2009), Fernandes et al. (2013) e Bhupatiraju et al. (2012).

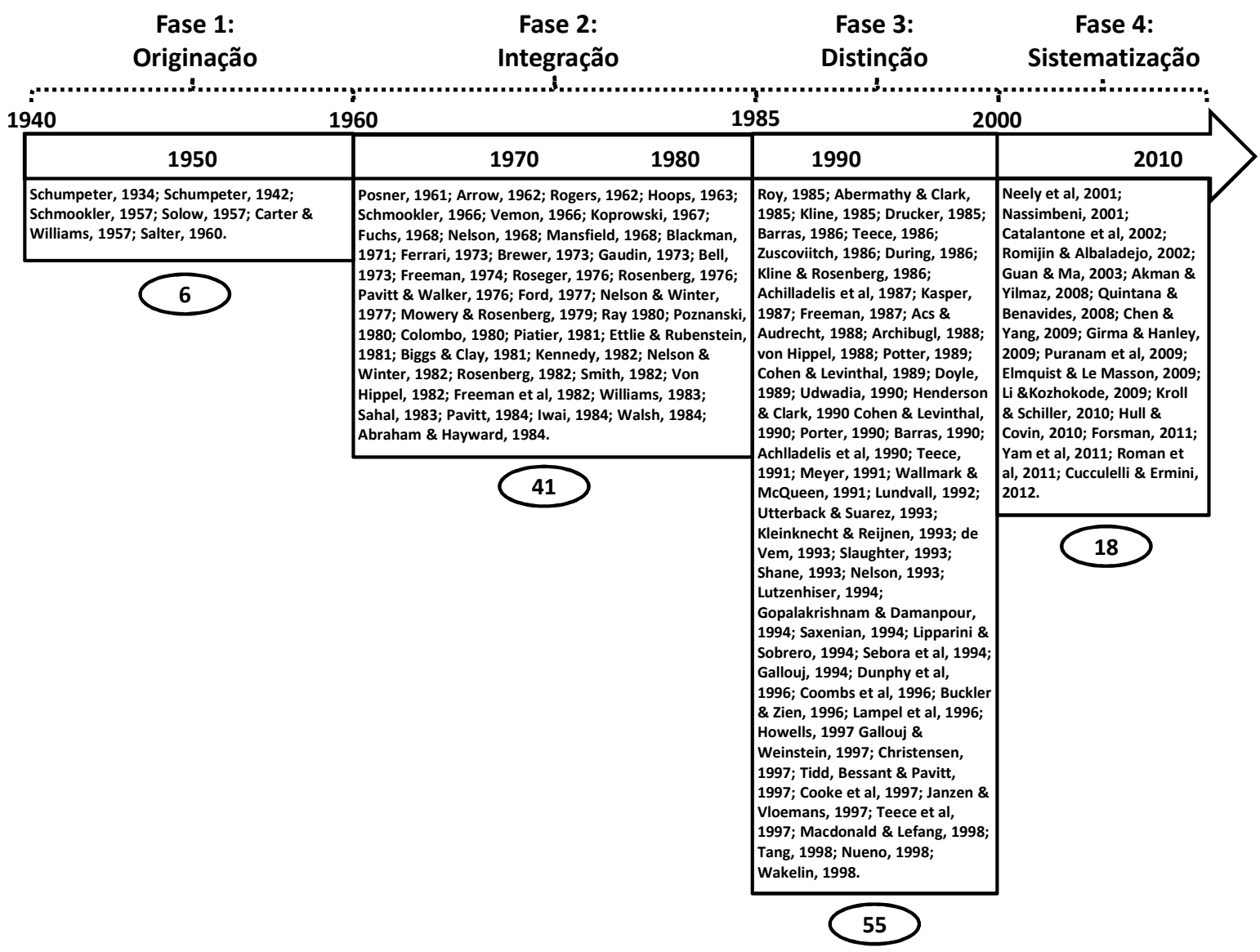

\section{Figura 1 - Evolução da inovação e capacidade da inovação}

Fonte: Elaboração própria.

O campo de estudo da inovação também pode ser analisado do ponto de vista temático. A literatura pode ser agrupada em dois principais polos (FAGERBERG et al., 2012), sendo um com foco na inovação dentro das empresas o qual é popular entre acadêmicos nas áreas de gestão e negócios, enquanto o outro enfatiza o papel exercido pela tecnologia e inovação na mudança econômica e social e é estudado em geral por pesquisadores em economia e outras ciências sociais. Há ainda a possibilidade de distinguir um terceiro polo, posicionado entre os dois principais, o qual possui forte apelo interdisciplinar e que contribui significativamente para conectar a base de conhecimento desses polos uma vez que a literatura desse cluster adota um foco 
compartilhado nos aspectos econômicos da tecnologia e inovação e tem um interesse comum com gestão e negócios (vide Figura 2).

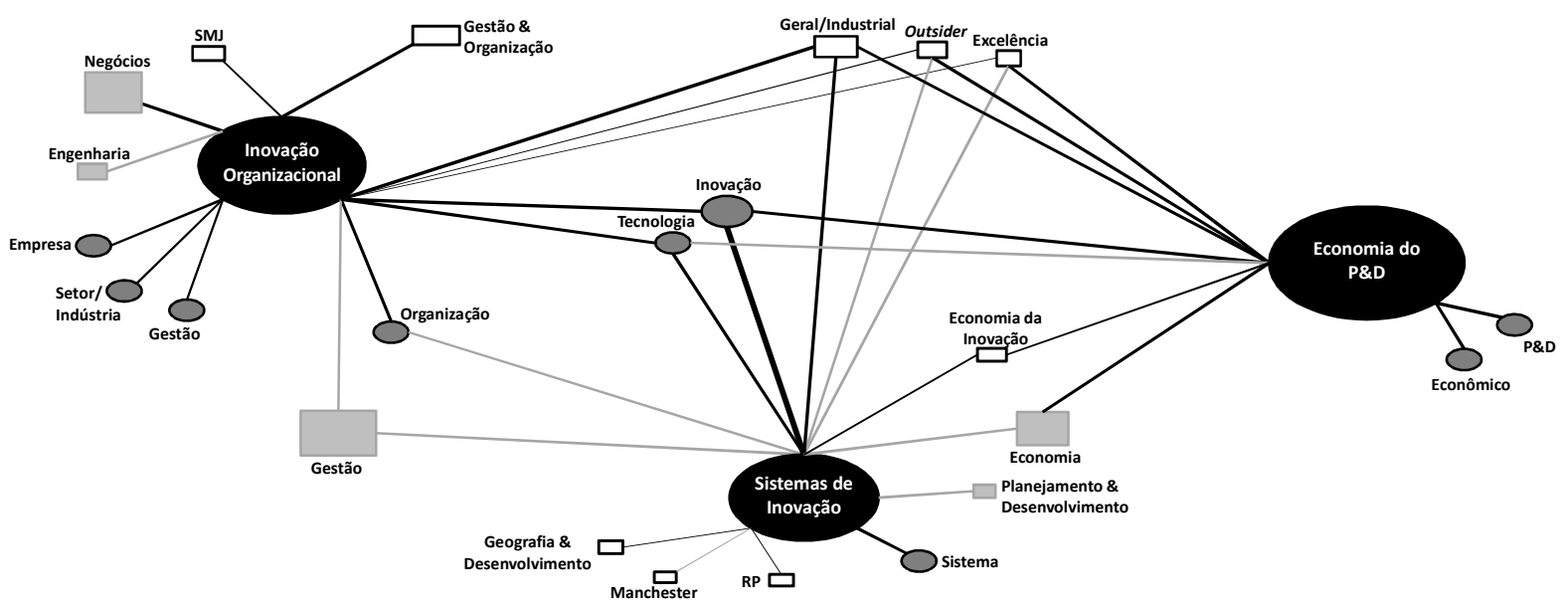

Fonte: FAGERBERG et al., 2012.

Figura 2 - Três principais polos da literatura sobre inovação e respectivos e respectivos temas

Outra classificação de pesquisas prévias em inovação apresenta a revisão conceitual da literatura por meio do resumo e organização dos estudos em três correntes de pesquisa relacionadas (WOLFE, 1994). Cada corrente foi desenvolvida de forma relativamente sequencial e apesar de as três correntes tratarem do fenômeno geral da inovação organizacional, elas apresentam focos diferentes haja vista proporem-se diferentes questões de pesquisa conforme Tabela $1 \mathrm{e}$, portanto apresentarem diferentes unidades de análise e diferentes variáveis dependentes.

Tabela 1 - Questões, abordagem e foco das pesquisas sobre inovação

\begin{tabular}{lll}
\hline Questão de Pesquisa & Abordagem da Pesquisa & Foco da Pesquisa \\
\hline $\begin{array}{l}\text { 1. Qual é o padrão da difusão de uma inovação a través } \\
\text { de uma população of potential adopter organizations? }\end{array}$ & Difusão da inovação (DI) pesquisa & $\begin{array}{l}\text { Endereça a difusão de uma inovação no } \\
\text { tempo e/ou espaço }\end{array}$ \\
\hline $\begin{array}{lll}\text { 2. O que determina a capacidade de inovação } \\
\text { organizacional? }\end{array}$ & $\begin{array}{l}\text { Capacidade de inovação } \\
\text { organizacional (OI) pesquisa }\end{array}$ & $\begin{array}{l}\text { Endereça os determinantes da capacidade } \\
\text { de inovação de organizações }\end{array}$ \\
\hline $\begin{array}{l}\text { 1. Quais são os processos que as organizações enfrentam } \\
\text { na implementação de inovações? }\end{array}$ & $\begin{array}{l}\text { Teoria de processo (PT) pesquisa } \\
\text { Fonte: WOLFE, 1994. }\end{array}$ & $\begin{array}{l}\text { Endereça o processo de inovação dentro de } \\
\text { uma organização }\end{array}$ \\
\hline
\end{tabular}


A primeira corrente corresponde à Difusão da Inovação (DI) que se refere à disseminação da inovação entre uma população de potenciais empresas com interesse em adotá-la e cujo objetivo é explicar ou prever taxas e padrões de adoção da inovação ao longo do tempo e espaço. A segunda corrente, por sua vez, é denominada Inovação Organizacional (OI) e tem como foco descobrir os determinantes da propensão de uma empresa em inovar, ou seja, nesse caso a unidade de análise é a organização. Com relação às pesquisas em OI, a variável dependente em geral é a inovação organizacional que é amplamente operacionalizada como base no número de inovações adotadas por uma organização (KIMBERLY e EVANISKO, 1981). Por fim, a terceira corrente conhecida como Modelos de Teoria de Processo (PT) investiga a natureza do processo de inovação por meio da análise de como e por que as inovações emergem, desenvolvem, crescem e terminam. Nessas pesquisas costuma-se estudar a sequência temporal de atividades relacionadas ao desenvolvimento da inovação.

Com base na evolução histórica da pesquisa sobre inovação apresentada é possível enquadrar o presente trabalho como parte da corrente de OI uma vez que o foco é a inovação dentro das empresas (no âmbito da organização) por meio da identificação e análise dos determinantes de sua capacidade de inovação. Tal enquadramento é essencial para definir a questão de pesquisa correta a fim de ser assertivo na escolha da literatura relevante a ser adotada (WOLFE, 1994).

\subsection{Identificação dos Determinantes da Capacidade de Inovação}

A inovação é um processo complexo impulsionado por inúmeros fatores (BECHEIKH et al., 2006). O presente tópico tem como objetivo identificar e selecionar, por meio de uma revisão da literatura, quais dimensões podem ser consideradas como possíveis preditoras da capacidade de inovação das empresas, ou seja, quais dimensões influenciam a habilidade das empresas de gerir e explorar novas ideias e conceitos e gerar soluções para oportunidades potenciais que atendam as necessidades do mercado e as tornem em soluções viáveis. 
Muito tem sido publicado acerca das dimensões que contribuem para o sucesso inovativo das empresas (HEELEY et al., 2007). Os pesquisadores ${ }^{4}$ que estudaram essas dimensões que influenciam a capacidade de inovação identificaram um número substancial de determinantes que se correlacionam com atividades conduzidas para inovação. Os autores argumentam que existem fatores internos e externos que pode condicionar positiva ou negativamente a realização de inovações (BARBIERI et al., 2003) e que um processo contínuo de geração de inovações depende tanto de fatores internos quanto externos à organização (BOLY et al., 2014; MACHADO, 2004).

A literatura indica ainda uma clara evolução na identificação dos fatores determinantes da capacidade de inovação, havendo uma convergência para certas dimensões. Há alguns temas que aparecem de forma mais proeminente na literatura e que aparentam compor uma base de requisitos para viabilizar a inovação em uma organização (ASA et al., 2013). No entanto, persistem algumas diferenças ${ }^{5}$ de conteúdo ou de classificação dessas dimensões, bem como casos de sobreposição de conteúdo entre dimensões (VALLADARES, 2012).

A partir das dimensões apontadas como relevantes pela literatura e considerando as diferenças de conteúdo, classificação e sobreposição de conteúdo entre dimensões, foram identificados, selecionados e consolidados na Tabela 2 os 15 determinantes que influenciam a capacidade de inovação das empresas os quais foram classificados ${ }^{6} \mathrm{em}$ internos e externos. Em virtude da sobreposição ${ }^{7}$ de conteúdo entre as dimensões

\footnotetext{
${ }^{4}$ Entre os principais pesquisadores que estudaram os fatores ou determinantes que influenciam a capacidade de inovação das empresas estão: ADAMS et al., 2006, AMABILE, 1988; BIRKINSHAW, 2001, CROSSAN e APAYDIN 2010, DAMANPOUR, 1991; DANNEELS, 2001, GERMAIN, 1996; HOFFMAN et al, 1998; HOTHO e CHAMPION, 2011, HULT et al., 2004; KEIZER et al., 2002; KIMBERLY e EVANISKO, 1981; NYSTROM et al., 2002; TIDD et al., 2005, VALLADARES, 2012.

${ }^{5}$ Segundo Valladares (2012), a título de exemplo, alguns autores elevam gestão de pessoas ao nível de uma dimensão e outros inserem as questões relativas à gestão de pessoas com um subfator dentro da dimensão cultura organizacional.

${ }^{6}$ Grande parte das pesquisas sobre determinantes da capacidade de inovação das empresas focam em fatores internos ou externos. Em linha com essa prática, o presente estudo adotou a definição de dimensões externas como sendo aquelas que se referem às oportunidades que uma empresa pode apropriar-se de seu ambiente e dimensões internas aquelas que se relacionam às características e políticas de uma empresa (KEIZER et al., 2002).

${ }^{7}$ A sobreposição de conteúdo entre liderança e cultura organizacional foi observada na literatura e ocorre a título de exemplo, no caso de variáveis que mensuram grau de autonomia dos colaboradores na empresa, tolerância ao erro, entre outras que são utilizadas para mensurar ambos os constructos.
} 
liderança e cultura organizacional mapeada na literatura, a dimensão liderança não foi incluída como fator isolado. Nesse caso, a dimensão liderança foi capturada por meio da inserção de algumas variáveis dentro do constructo Cultura Organizacional, conforme detalhado na metodologia apresentada no Capítulo 4, o que se configura em procedimento comum adotado na literatura (VALLADARES, 2012).

Tabela 2 - Determinantes da capacidade de inovação das empresas classificados em internos e externos

\begin{tabular}{|c|c|c|c|}
\hline & $\begin{array}{l}\text { Determinantes da capacidade } \\
\text { de inovação das empresas }\end{array}$ & Autores/Ano & $\begin{array}{c}\text { Classificação } \\
\text { Interno/Externo }\end{array}$ \\
\hline 1. & Estrutura Organizacional & $\begin{array}{l}\text { Apaydin e Crossan, 2010; Ashkenas, 1998; } \\
\text { Burgelman e Maidique, 1993; Choi e Chang, } \\
\text { 2009; Damanpour, 1991; Damanpour e } \\
\text { Gopalakrishnan, 1998; Kimberly e Evanisko, } \\
\text { 1981; Knox, 2002; Lawson e Samson, 2001; } \\
\text { Tidd et al., 2005; Valladares, } 2012 .\end{array}$ & Interno \\
\hline 2. & $\begin{array}{l}\text { Disponibilidade de Recursos } \\
\text { Financeiros Internos para } \\
\text { Inovação }\end{array}$ & $\begin{array}{l}\text { Amabile et al., 1996; Bourgeois, 1981; } \\
\text { Birkinshaw et al., 2011; Choi e Chang, 2009; } \\
\text { Geiger e Cashen, 2002; Hotho e Champion, } \\
\text { 2011; Katila e Shane, 2005; Kimberly e } \\
\text { Evanisko, 1981; Nystrom et al., 2002; } \\
\text { Oerlemans, 2001; Richtner e Ahlstrom, } \\
\text { 2006; Tornatzky e Fleischer, 1990; Voss e } \\
\text { Voss, 2008. }\end{array}$ & Interno \\
\hline 3. & Comunicação Interna & $\begin{array}{l}\text { Barbieri et al., 2003; Narula, 2004; Nonaka, } \\
\text { 1994; Nooteboom, 1994; Tornatzky e } \\
\text { Fleischer, 1990; Wan et al., } 2003 .\end{array}$ & Interno \\
\hline 4. & Tamanho Organizacional & $\begin{array}{l}\text { Barbieri et al., 2003; Bos-Brouwers, 2009; } \\
\text { Camison et al., 2004; Cohen, 1995; Capon et } \\
\text { al., 1992; Damanpour, 1991; Hobday, 2005; } \\
\text { Keizer et al., 2002; Kimberly e Evanisko, } \\
\text { 1981; Lee e Xia, 2006; Nieto e Santamaria, } \\
\text { 2006; Nystrom et al., 2002; Pavitt et al., } \\
\text { 1989; Rogers, 2004; Albaladejo e Romijn, } \\
\text { 2000; Tidd et al., 2005; Wan et al., 2003. }\end{array}$ & Interno \\
\hline 5. & Atividades de P\&D & $\begin{array}{l}\text { Akinci e Utlu, 2015; Birchall et al., 1996; Jha } \\
\text { e Bose, 2015; Bougrain e Haudeville, 2002; } \\
\text { Chudnovsky et al., 2006; Deeds, 2001; } \\
\text { Greve, 2003; Department for Business } \\
\text { Innovation \& Skills, 2014; Keizer et al., 2002; } \\
\text { Lokshin et al., 2008; Nelson e Winter, 1977; } \\
\text { Yam et al., 2010. }\end{array}$ & Interno \\
\hline 6. & $\begin{array}{l}\text { Investimento em Máquinas e } \\
\text { Equipamentos }\end{array}$ & $\begin{array}{l}\text { Keizer et al., 2002; Laforet, 2013; Nelson, } \\
2000 .\end{array}$ & Interno \\
\hline 7. & $\begin{array}{l}\text { Tempo de Existência da } \\
\text { Organização }\end{array}$ & $\begin{array}{l}\text { Acs e Audretsch, 1990; Bos-Brouwers, 2009; } \\
\text { Figueiredo, 2014; Hausman, 2005; } \\
\text { Henderson, 1999; Nystrom et al., 2002; } \\
\text { Albaladejo e Romijn, 2000; Sorensen e } \\
\text { Stuart, } 2000 .\end{array}$ & Interno \\
\hline
\end{tabular}

\section{Continua}




\section{Tabela 2 - Determinantes da capacidade de inovação das empresas classificados em internos e externos (continuação)}

\begin{tabular}{|c|c|c|c|}
\hline 8. & Cultura Organizacional & $\begin{array}{l}\text { Adams et al., 2006; Apaydin e Crossan, } \\
\text { 2010; Barbieri et al., 2003; Becheikh et al., } \\
\text { 2006; Birkinshaw et al., 2011; Hobday, } \\
\text { 2005; Jung et al., 2003; Choi e Chang, 2009; } \\
\text { Kimberly e Evanisko, 1981; Knox, 2002; } \\
\text { Lawson e Samson, 2001; Neely e Hii, 1998; } \\
\text { Nueno, 1998; O’Regan et al., 2006; Tidd et } \\
\text { al., 2005; Valladares, 2012; Wan et al., } \\
\text { 2003; Wind e Main, 2002. }\end{array}$ & Interno \\
\hline 9. & $\begin{array}{l}\text { Capacidade de Gestão de } \\
\text { Projetos }\end{array}$ & $\begin{array}{l}\text { Adams et al., 2006; Amabile et al., 1996; } \\
\text { Apaydin e Crossan, 2010; Barbieri et al., } \\
\text { 2003; Hotho e Champion, 2011; Kimberly e } \\
\text { Evanisko, 1981; Larson et al., 1991; Sáenz et } \\
\text { al., 2009; Tidd et al., 2005; Valladares, } 2012 .\end{array}$ & Interno \\
\hline 10. & Base de Conhecimento Interno & $\begin{array}{l}\text { Asa et al., 2013; Becheikh et al., 2006; } \\
\text { Birkinshaw et al., 2011; Freel, 2005; } \\
\text { Hoffman et al., 1998; Department for } \\
\text { Business Innovation \& Skills, 2014; Le Blanc } \\
\text { et al., 1997; Nelson, 2000; Nonaka e } \\
\text { Takeuchi, 1995; Nueno, 1998; Tidd et al., } \\
\text { 2005; Tornatzky e Fleischer, 1990. }\end{array}$ & Interno \\
\hline 11. & Estratégia & $\begin{array}{l}\text { Adams et al., 2006; Apaydin e Crossan, } \\
\text { 2010; Asa et al., 2013; Becheikh et al., 2006; } \\
\text { Berkhout, 2006; Birchall et al., 1996; Carrier, } \\
\text { 1994; Dodgson et al., 2008; Keizer et al., } \\
\text { 2002; Lawson e Samson, 2001; Mootee, } \\
\text { 2010; O'Regan et al., 2006; Valladares, } \\
\text { 2012; Yam et al., 2010. }\end{array}$ & Interno \\
\hline 12. & Apoio Governamental & $\begin{array}{l}\text { Becheikh et al., 2006; Bell e Pavitt, 1993; } \\
\text { Doloreux e Melancon, 2008; Hoffman et al., } \\
\text { 1998; Hotho e Champion, 2011; Keizer et } \\
\text { al., 2002; Tornatzky \& Fleischer, 1990; } \\
\text { Yokomizo, 2014. }\end{array}$ & Externo \\
\hline 13. & Localização Geográfica & $\begin{array}{l}\text { Cooke et al., 2004; Etzkowitz, 2009; } \\
\text { Hoffman et al., 1998; Keizer et al., 2002, Le } \\
\text { Blanc et al., 1997. }\end{array}$ & Externo \\
\hline 14. & Orientação ao Mercado & $\begin{array}{l}\text { Asa, et al., 2013; Berkhout, 2006; Cooper e } \\
\text { Edgett, 2007; Danneels, 2002; Deshpande et } \\
\text { al., 1993; Hoffman et al., 1998; Hult et al., } \\
\text { 2004; Kohli e Jaworski, 1990; Langerak et } \\
\text { al., 2004; Nystrom et al., 2002; Simpson et } \\
\text { al., 2006; Tidd et al., 2005; Valladares, 2012; } \\
\text { Yokomizo, } 2014 .\end{array}$ & Externo \\
\hline
\end{tabular}

continua 
Tabela 2 - Determinantes da capacidade de inovação das empresas classificados em internos e externos (conclusão)

\begin{tabular}{|c|c|c|c|}
\hline 15. & $\begin{array}{l}\text { Base de Conhecimento Externo } \\
\text { (Colaborações Externas) }\end{array}$ & $\begin{array}{l}\text { Akinci e Utlu, 2015; Asa etl al., 2013; } \\
\text { Berkhout, 2006; Becheikh et al., 2006; } \\
\text { Birchall et al., 1996; Camisón e Villar-López, } \\
\text { 2012; Chesbrough, 2003; Danneels, 2002; } \\
\text { Edwards et al., 2005; Facó, 2009; Fagerberg, } \\
\text { 2003; Ferguson, 2005; Forsman, 2011; } \\
\text { Freel, 2005; Geffen e Rothemberg, 2000; } \\
\text { Grodal, 2004; Hewitt-Dundas, 2006; Hippel, } \\
\text { 2007; Hoffman et al., 1998; Department for } \\
\text { Business Innovation \& Skills, 2014; Jensen et } \\
\text { al., 2007; Kaminski et al., 2008; Keizer et al., } \\
\text { 2002; Le Blanc et al., 1997; Massa e Testa, } \\
\text { 2008; Nelson, 2000; Nieto e Santamaria, } \\
\text { 2006; Rogers, 2004; Tidd et al., 2005; Utlu, } \\
\text { 2015. }\end{array}$ & Externo \\
\hline
\end{tabular}

Fonte: Elaboração própria.

Dessa forma, o processo de criar algo novo que tenha valor significante para a unidade relevante que irá adotá-lo é afetado por determinantes (ASSINK, 2006) exógenos tais como apoio governamental, orientação ao mercado, base de conhecimento externo e localização geográfica e por determinantes endógenos como estrutura organizacional, cultura organizacional, capacidade de gestão de projetos, disponibilidade de recursos financeiros internos para inovação, comunicação interna, base de conhecimento interno, tamanho organizacional, atividades de $\mathrm{P} \& \mathrm{D}$, investimento em máquinas $\mathrm{e}$ equipamentos, tempo de existência da organização e estratégia.

\subsubsection{Estrutura Organizacional}

O termo estrutura organizacional é utilizado para designar a disposição de um conjunto de pessoas reunidas por uma rede de ligações de dependência ou cooperação, constituindo inicialmente grupos elementares que se integram em uma sucessão de conjuntos mais complexos (SIMERAY, 1970). De uma forma mais simplificada, a estrutura organizacional define como as tarefas em uma organização são formalmente distribuídas, agrupadas e coordenadas (ROBBINS, 2002). Essa estrutura é concebida para ser um processo de decisão que visa trazer coerência entre os objetivos e propósitos para os quais a organização existe, o modelo de divisão de trabalho e de coordenação entre unidades e as pessoas que farão o trabalho (GALBRAITH, 1977). Ou seja, a estrutura organizacional trata de facilitar que um grupo de pessoas combine, coordene e 
controle recursos e atividades no intuito de produzir valor, de maneira apropriada ao ambiente no qual a empresa compete.

As organizações possuem estruturas distintas que consequentemente causam impactos distintos sobre as atitudes e comportamentos de seus colaboradores. A estrutura organizacional tradicional é geralmente associada a um modelo burocrático, com hierarquia, funções e regras bem definidas (SIMERAY, 1970). Intervenções na estrutura organizacional tratam de mudar elementos tais como a divisão de trabalho, a alocação dos poderes de decisão, escolhas dos mecanismos de coordenação, delineamento das fronteiras da organização e redes de relacionamentos informais (MYERS, 1996) visando buscar a estrutura mais apropriada ao negócio.

Na literatura sobre inovação, a estrutura organizacional é identificada como um dos temas-chave (CHOI e CHANG, 2009). A estrutura organizacional é considerada uma alavanca gerencial para estimular a inovação (APAYDAN e CROSSAN, 2010) e contribui para o encorajamento da geração de novas ideias (WAN et al., 2003). Damanpour e Gopalakrishnan (1998) ressaltam que as caraterísticas de estrutura de uma empresa facilitam a adoção de inovação. A não ser que essa estrutura e seus processos resultantes conduzam a um ambiente favorável à inovação, outros componentes do sistema de inovação são improváveis de ter êxito (LAWSON e SAMSON, 2001).

Conforme uma empresa cresce, há uma tendência de adicionar camadas, tornando-a mais mecanicista e institucionalizando a burocracia (KANTER, 1983). A criação de um ambiente favorável à inovação depende de uma estrutura organizacional com menor grau de departamentalização, menos formalização para aumentar a disseminação do conhecimento e a resposta às mudanças, como ocorre em estruturas "orgânicas" (VALLADARES, 2012). Estruturas inovativas podem ser caracterizadas a partir de cinco pontos: baixo nível de formalização, utilização de formas avançadas de departamentalização (centro de lucro, por projetos, estrutura matricial e estrutura celular), multiplicidade de comando (exemplo, na estrutura matricial), diversificação elevada da equipe e utilização da comunicação horizontal e vertical (VASCONCELLOS e HAMSLEY, 2002). 
Com relação à estrutura organizacional, vale ressaltar que as PMEs em particular costumam apresentar uma hierarquia plana (SEBORA et al., 1994), ou seja, com poucos níveis hierárquicos o que permite maior flexibilidade (NORD e TUCKER, 1987; WOLFF e PETT, 2006) e agilidade na tomada de decisão (TIDD et al., 2005). Além disso, empresas com esse porte costumam ser informais, ou seja, com poucas regras e comunicações por escrito.

\subsubsection{Disponibilidade de Recursos Financeiros Internos para Inovação}

As atividades de inovação exigem recursos. A disponibilidade (ou folga) de recursos para inovação consiste na fonte de recursos que estão disponíveis à empresa e que vão além daqueles necessários para se atingir as necessidades imediatas da organização e executar suas atividades, programas e objetivos cotidianos (HEROLD et al., 2006) e que, portanto podem ser empregadas nas atividades de inovação. Na visão de Bourgeois (1981) disponibilidade de recursos refere-se a uma margem extra de recursos atuais ou potenciais que permite uma organização adaptar-se com sucesso às pressões internas para ajustes, ou pressões externas de mudança na política, bem como para iniciar mudanças na estratégia em resposta ao ambiente externo. Ou seja, trata-se de recursos não utilizados que podem ser direcionados para inovação.

$\mathrm{Na}$ visão de alguns autores, esses recursos disponíveis podem ser humanos, operacionais, relacionados a clientes (VOSS e VOSS, 2008), estoque e capital de giro (LOVE e NOHRIA, 2005). Outros pesquisadores incluem até mesmo a disponibilidade de tempo (RICHTNER e AHLSTROM, 2006). Para Facó (2009), a disponibilidade de recursos organizacionais pode ser dividida em dois grupos sendo eles a folga absorvida caracterizada pela menor facilidade de realocação dos recursos disponíveis que as compõe (a título de exemplo, máquinas dedicadas e pessoal especializado) e não absorvida referente à maior facilidade de realocação dos recursos disponíveis que as compõe (a título de exemplo, recursos financeiros e pessoal não dedicado).

Porém, grande parte dos autores considera como recurso disponível para inovação a disponibilidade de capital para financiar uma determinada inovação (FACÓ, 2009). 
Esses autores dão maior ênfase à dimensão financeira relacionada à disponibilidade de recursos na firma (BOURGEOIS, 1981; KATILA e SHANE, 2005) uma vez que se trata de um recurso que pode ser facilmente realocado em qualquer projeto e que, dessa forma constitui uma fonte possível de financiamento para a inovação (HEROLD et al., 2006).

De acordo com a literatura, há evidências de que a disponibilidade de recursos internos pode facilitar a inovação, a criatividade e a tomada de risco de uma organização provendo os recursos necessários para essa atividade (LOVE e NOHRIA, 2005). Nesse sentido, essa disponibilidade de recursos financeiros possibilita à empresa experimentar novas posturas frente ao ambiente por meio da introdução de novos produtos ou de inovações nos negócios (BOURGEOIS, 1981), estimulando e contribuindo para a capacidade de inovação das empresas (CHOI e CHANG, 2009).

Apesar de ser um fator importante para a inovação, vale ressaltar que há um consenso na literatura acadêmica de que as PMEs apresentam escassez de recursos internos (CHEN e CHEN, 2013; FAGERBERG, 2003; FREEL, 2000; KEIZER et al., 2002, ROTHWELL, 1991). Empresas com esse porte não têm capacidade para financiar projetos de alto risco ou longo prazo (TIDD et al., 2005), nem recursos intangíveis tais como competências de gestão, recursos estratégicos, entre outros (CHEN e CHEN, 2013).

\subsubsection{Comunicação Interna}

A comunicação interna compreende o processo de intercâmbio de informações e conhecimento dentro de uma organização. Esse processo deve criar um ambiente propício para o fluxo correto de informações entre todos os níveis hierárquicos. O requisito 5.5.3 da ISO 9001:2008 prevê que "A alta administração deve assegurar que sejam estabelecidos, na organização, os processos de comunicação apropriados". 
Um processo de comunicação interno adequado e frequente contribui para a construção da capacidade de inovação da empresa (ASA et al., 2013) e configura-se até como prérequisito para a organização inovadora (MACHADO, 2004). Bons canais de comunicação e comunicação interna frequente favorecem a inovação haja vista facilitarem a dispersão de ideias dentro da organização e aumentarem o montante e a diversidade de informações, que por sua vez resultam na fertilização cruzada de ideias (NONAKA, 1994; WAN et al., 2003).

Como ferramenta de gestão, a comunicação interna também é fundamental para assegurar o sucesso na implementação de processos de melhoria contínua e de gestão da qualidade (FILIPE, 2007) os quais implicam em mudanças e estão muitas vezes relacionados diretamente com inovação. O investimento que as organizações realizam na comunicação interna e a forma como procuram envolver os seus públicos nas suas decisões estratégicas, são fatores determinantes para a melhoria da sua competitividade.

Quanto maior o porte da empresa, mais complexo fica o processo de comunicação (MACHADO, 2004). Já a comunicação interna nas PMEs costuma ser fácil e ágil (TIDD et al., 2005). Tal fato decorre em grande parte do fato dessas empresas apresentarem poucos níveis hierárquicos e baixo nível de formalidade. Por essa razão, pequenas e médias empresas frequentemente não necessitam de estratégias formais usadas em empresas de grande porte para assegurar comunicação e coordenação (TIDD et al., 2005).

\subsubsection{Tamanho Organizacional}

O tamanho organizacional pode ser definido por meio de recursos organizacionais, volumes de transação e número de colaboradores (KIMBERLY e EVANISKO, 1981). No Brasil, o BNDES, por exemplo, adota a faixa de faturamento bruto anual para definir o porte da empresa e as classifica com base em cinco faixas ${ }^{8}$ de faturamento. $\mathrm{O}$

\footnotetext{
${ }^{8}$ Faixas de faturamento adotadas pelo BNDES para definir o porte das empresas: menor que R $\$ 2,4$ milhões (micro), entre $R$ \$ 2,4 milhões e $R$ \$ 16 milhões (pequena), entre $R$ \$ 16 milhões e $R$ \$ 90 milhões (média), entre $\mathrm{R} \$ 90$ milhões e $\mathrm{R} \$ 300$ milhões (média-grande) e maior que $\mathrm{R} \$ 300$ milhões (grande).
} 
IBGE e o SEBRAE por sua vez utilizam o número de colaboradores ${ }^{9}$ para classificar as empresas. Na literatura, observou-se que o tamanho organizacional é normalmente mensurado pelo número de colaboradores (KIMBERLY e EVANISKO, 1998; TIDD et al., 2005) ou faturamento (TIDD et al., 2005), em consonância com o mercado.

A relação entre o tamanho da empresa e a atividade de inovação recebeu bastante atenção dos acadêmicos (NIETO e SANTAMARIA, 2006). O tamanho organizacional é considerado um dos mais importantes determinantes que afetam a capacidade de inovação (CAPON et al., 1992; ROGERS, 2004). Para Damanpour (1992), Kimberly and Evanisko (1981) e Wan et al. (2003) o tamanho da organização influencia a adoção de mais inovações sendo que empresas de maior porte tendem a adotar mais inovações que as de menor porte. Esta adoção é, em geral, atribuída à maior disponibilidade de recursos nas empresas de maior porte (MACHADO, 2004).

No entanto, ainda não foi possível estabelecer uma relação forte entre tamanho organizacional e inovação (NIETO e SANTAMARIA, 2006). Alguns pesquisadores encontraram inclusive correlação negativa (UTTERBACK, 1994) e até mesmo não significativa (LEE e XIA, 2006). Dessa forma, o tamanho organizacional continua sendo uma dimensão polêmica e importante desde a perspectiva da capacidade de inovação e, por isso permanece sendo incluída em diversos estudos que avaliam a capacidade de inovação das empresas.

\subsubsection{Atividades de P\&D}

A atividade de P\&D é a mais clássica das atividades inovativas e assume um papel de destaque na literatura. Essa dimensão compreende um conjunto de atividades que consiste de trabalho criativo, empreendido de forma sistemática, com a finalidade de aumentar o acervo de conhecimentos visando aplica-los no desenvolvimento de novos processos, novos produtos ou serviços, produtos tecnologicamente aprimorados,

\footnotetext{
${ }^{9}$ Faixas de número de colaboradores adotadas pelo IGBE e SEBRAE por setor para definir o porte das empresas: na indústria de 0 a 19 (micro), 20 a 99 (pequena), 100 a 499 (média), acima de 499 (grande) e no comércio ou serviço de 0 a 09 (micro), 10 a 49 (pequena), 50 a 99 (média), acima de 99 (grande).
} 
soluções para problemas (JHA e BOSE, 2015), entre outras aplicações. De acordo com a ANPEI, as atividades de P\&D são estruturadas por meio de projetos e em geral são conduzidas por unidades especializadas ou centros de pesquisa de empresas, universidades ou agências do Estado.

Várias empresas incorporaram atividades de P\&D. Como exemplo disso, as atividades internas de P\&D foram consideradas de alta e média importância para $22 \%$ das empresas que implementaram alguma inovação no período de 2003 a 2005 no Brasil (IBGE, 2007). A estruturação de um departamento específico para essas atividades permite sistematizar os processos de $\mathrm{P} \& \mathrm{D}$ criando um recurso específico que concentra ativos tangíveis e intangíveis vistos como estratégicos pela empresa e para o desenvolvimento de capacidades organizacionais.

Diversos estudos demonstram a relação entre as atividades de P\&D e o desempenho da inovação nas empresas (FRANCINI, 2012). A literatura indica que as atividades de P\&D praticadas pela organização apresentam relação próxima com o resultado da inovação tanto de forma quantitativa, quanto qualitativa (ADNER e LEVINTHAL, 2001). Essas atividades são um componente central da inovação e são reconhecidas como um dos gastos mais importantes de uma empresa (YAM et al., 2010) que contribuem para sua capacidade de inovação (LOKSHIN et al., 2008). No entanto, alguns autores afirmam que uma das características das empresas inovadoras de sucesso é realizar atividades internas de $\mathrm{P} \& \mathrm{D}$ de forma não só intensa como também profissional (BOUGRAIN e HOUDVILLE, 2002). Akinci e Utlu (2015) chegam a sugerir que inovação só é possível com atividades regulares (sistemáticas) de P\&D.

Os gastos com P\&D não costumam ser mensurados e as atividades de $\mathrm{P} \& \mathrm{D}$ são, em geral, informais nas PMEs (TIDD et al., 2005). Empresas enquadradas nesse grupo não são capazes de separar gastos com P\&D de outros custos operacionais e consequentemente a atividade de inovação voltada para conhecimento ocorre nos módulos informais (CEGARRA et al., 2011; RENKO, 2012). Dessa forma, é importante ressaltar que dentro desse grupo de empresas há uma maior probabilidade de que as atividades de P\&D sejam conduzidas de maneira informal. 


\subsubsection{Investimento em Máquinas e Equipamentos}

O investimento em máquinas e equipamentos representa quanto uma empresa está empregando seus recursos na aquisição desses itens a fim de modificar, modernizar e melhorar seus processos visando aumento da produtividade, redução de custo, melhoria da qualidade entre outros motivos. Esses investimentos implicam em adaptações dos processos e dos recursos exigindo a capacidade de absorção das organizações.

Investimento em máquinas e equipamentos configura-se em um importante input que produz mudança tecnológica (NELSON, 2000). Esse tipo de investimento como parte de uma estratégia de implementação do estado da arte na tecnologia de produção e automação exerce influência direta na capacidade de inovação das PMEs (KEIZER et al., 2002) uma vez que a aquisição de máquinas e equipamentos contribui para o processo de "learning by doing" o qual é componente integral no processo de realização de inovações incrementais (NELSON, 2000). Ademais, a literatura também indica associação específica entre nível de investimento em sistema e tecnologia na promoção do desenvolvimento de novos produtos (LAFORET, 2013).

\subsubsection{Tempo de Existência da Organização}

Além de classificar as empresas pelo porte, para analisar a capacidade de inovação organizacional, muitos autores incluem o tempo de existência da empresa (NIETO e SANTAMARIA, 2006) que compreende o período de tempo entre sua data de fundação e a data presente. Em linha com o tamanho organizacional, o tempo de existência da organização também é considerado um determinante que afeta a capacidade de inovação das empresas (AUDRETSCH, 1990; BOS-BROUWERS, 2009; SORENSEN, 2000), no entanto esse fator recebeu menos atenção dos pesquisadores sobre o tema (NYSTROM, 2002).

A literatura indica que há uma correlação positiva entre a idade da empresa e capacidade de inovação (ALBALADEJO e ROMIJN, 2000) em função da premissa de 
que organizações que existem há mais tempo tendem a serem maiores e apresentarem melhor situação financeira, mas nem todas as organizações continuam a crescer e aumentar sua receita com o passar do tempo (MINTZBERG, 1983). Além disso, quanto maior o tempo de existência da empresa, mais sólida tende a ser sua experiência e aprendizado (COHEN e LEVINTHAL, 1990). Entretanto, alguns autores identificaram o efeito contrário no caso das PMEs. Nesse grupo de empresas, identificou-se que as mais jovens são mais inovadoras que as mais antigas (HAUSMAN, 2005).

Dessa forma, o tempo de existência da empresa influencia a sua capacidade de inovação. Ainda que não haja consenso sobre o efeito dessa relação, quanto maior o tempo de existência da empresa, maior deve ser seu acumulo de conhecimento o que consequentemente causa impacto nas atividades organizacionais relacionadas à inovação.

\subsubsection{Cultura Organizacional}

Cultura é um conceito complexo de definir e mensurar, mas essas tarefas são facilitadas quando realizada a distinção entre cultura nacional, organizacional, funcional e de grupo. No caso da presente pesquisa, a cultura tratada é a organizacional. A cultura organizacional pode ser definida como sendo os valores e crenças compartilhados pelos membros de uma organização e de uma maneira simplificada como a forma como as coisas são feitas na organização (MACHADO, 2004; TIDD et al., 2005). Toda empresa tem sua cultura própria que emerge como resultado de experimentos e experiências repetidas.

A cultura organizacional é considerada uma variável que influencia a capacidade de inovação da empresa (APAYDIN e CROSSAN, 2010; BIRKINSHAW et al., 2011; BECHEIKH et al., 2006; NUENO, 1998; NEELY e HII, 1998), sendo que a cultura apropriada é de vital importância para o sucesso da inovação (LAWSON e SAMSON, 2001). Esse é um dos principais fatores determinantes da capacidade de inovação das empresas (O’REGAN et al., 2006; FACÓ, 2009) e para Wind e Main (2002) a principal questão a levar uma organização a ser inovadora ou não. 
Os estudos publicados sobre cultura organizacional como determinante da capacidade de inovação (BECHEIKH et al., 2006) sugerem que uma cultura organizacional de apoio à inovação propicia estímulo (VALLADARES, 2012), autonomia (LAWSON e SAMSON, 2001) e reconhecimento (WAN et al., 2003) aos colaboradores para inovar. Além disso, nesse tipo de cultura os erros são minimizados (desestigmatizados) e assume-se riscos (WAN et al., 2003), valoriza-se o aprendizado (BARBIERI et al., 2003) e celebra-se o sucesso (BIRKINSHAW et al., 2011). Culturas inovadoras são inspiradas também no total quality management (TQM) e melhoria contínua (BECHEIKH et al., 2006). Ou seja, os colaboradores participam do processo de tomada de decisão e têm a percepção de que suas ideias são encorajadas, coletadas e implementadas com apoio formalizado e sistematizado (JUNG et al., 2003; TIDD et al., 2005). Muitos autores apontam ainda que companhias inovadoras adotam uma abordagem de trabalho em equipe multifuncional, abrangendo diversos níveis hierárquicos e direcionada a projetos e solução de problemas (YOKOMIZO, 2014).

Dessa forma, a cultura organizacional é uma dimensão ampla que abarca fatores relacionados à gestão de pessoas, aprendizagem organizacional e liderança. Em termos de liderança, Yokomizo (2014) ressalta que o chefe executivo demonstre um comprometimento pessoal com a inovação, possua visão e entusiasmo e encoraje a mudança.

\subsubsection{Capacidade de Gestão de Projetos}

A gestão de projetos é amplamente reconhecida como uma capacidade organizacional (TIDD et al., 2005). Rotinas organizacionais devem existir para a gestão de projetos ou pesquisa de novos produtos. A gestão de projetos envolve um conjunto complexo de atividades tais como planejamento, seleção de equipe, monitoramento e execução de tarefas, replanejamento, entre outras (TIDD, et al., 2005). Empresas com boas rotinas de gestão de projetos são capazes de codificar informações relevantes e passa-las adiante por meio de procedimentos e sistemas e ferramentas de gestão de projetos asseguram redução de risco com base na atualização diária em relação às metas e relatórios consistentes sobre o progresso do projeto (HOTHO e CHAMPION, 2011). 
Enquanto parte da literatura enfatiza a importância da capacidade de gestão de projetos como variável que influencia positivamente a capacidade de inovação das empresas (KIMBERLY e EVANISKO, 1981; LARSON et al., 1991; TIDD et al., 2005), alguns autores argumentam que essas práticas são desnecessariamente burocráticas e afetam negativamente o sucesso de projetos criativos e da inovação (HOTHO e CHAMPION, 2011). Tais autores afirmam que as rotinas de gestão de projetos são positivas para o trabalho comercial da empresa, proporcionando maior eficiência na execução das tarefas, porém controles rígidos e contabilidade têm efeitos ambíguos em projetos de inovação e, portanto são contra-produtivos. Essa visão deu origem ao "paradoxo da gestão e organização da criatividade” (DE FILLIPI et al., 2007).

No entanto, diversos estudos empíricos mostraram que o gerenciamento dos projetos de inovação é valioso e que as melhores companhias são aquelas que aprenderam a sistematizar os processos relativos à gestão de projetos (VALLADARES, 2012). A gestão eficiente de projetos de inovação reforça claramente as dimensões custo e prazo, além da própria geração de ideias (SÁENZ et al., 2009) contribuindo para uma inovação mais efetiva.

Inovação efetiva exige ainda identificar, avaliar e controlar riscos e para tanto, ferramentas e processos de gestão de projetos contribuem para a atividade de inovação como um todo (ASA et al., 2013). Dessa forma, gestão de projetos é pré-requisito para uma organização inovadora (MACHADO, 2004) e permanece sendo incluída como dimensão em diversos estudos que avaliam a capacidade de inovação das empresas tais como Adams et al. (2006), Facó (2009) e Valladares (2012).

\subsubsection{Base de Conhecimento Interno}

A base de conhecimento interno de uma organização é definida como o conhecimento coletivo dos indivíduos que compõe a empresa (NONAKA e TAKEUCHI, 1995) e pode ser considerada uma maneira informal de P\&D (TIDD et al., 2005). A capacidade de aprendizagem, por sua vez, é conceituada como a habilidade da empresa de reconhecer, avaliar e aplicar novos conhecimentos do ambiente (YAM et al., 2010). Essa capacidade 
faz parte da base de conhecimento uma vez que a competência de absorver conhecimento externo é construída sobre e depende da base de conhecimento e, por essa razão os dois termos são frequentemente utilizados de forma intercambiável (COHEN e LEVINTHAL, 1990). O presente trabalho adota a definição de base de conhecimento interno apresentada a qual abrange a capacidade de absorção.

Tendo em vista que a base de conhecimento interna é fundamentalmente representada pelos indivíduos dentro da organização, sua qualidade depende do nível da sua mão de obra, ou seja, de um quadro de colaboradores qualificados (DANNEELS, 2002). A literatura sugere que a qualidade da base de conhecimento interno é evidenciada por meio do número de cientistas, engenheiros e matemáticos qualificados, colaboradores alocados em P\&D e o nível de educação formal dos colaboradores (DOCTER e STOCKMAN, 1988; HOFFMAN et al., 1998; Department for Business Innovation \& Skills, 2014; LE BLANC et al., 1997). Entre as variáveis internas, essa é considerada um dos determinantes mais importantes da atividade de inovação uma vez que contribui de forma direta para os esforços de P\&D por meio do conhecimento e ideias dos colaboradores (HOFFMAN et al., 1998), além de que a mão de obra qualificada apresenta maior capacidade de reconhecer valor da nova informação e aplica-lo para fins comerciais (Department for Business Innovation \& Skills, 2014). A qualidade da mão de obra também apresenta um componente dinâmico, em adição aos elementos estáticos comumente mensurados, o qual se refere a (programa) de treinamento (FREEL, 2005; BECHEIKH et al., 2006; TIDD et al., 2005).

No caso particular das PMEs há dificuldade de contratação de cientistas, engenheiros e matemáticos qualificados e alocação de colaboradores em $\mathrm{P} \& \mathrm{D}$, o que torna essas aproximações padrão limitadas (FREEL, 2005). Além disso, a responsabilidade de gerar e buscar novas ideias era frequentemente restrita a um grupo seleto de colaboradores (designers, engenheiros e cientistas), no entanto atualmente inovação tornou-se responsabilidade de toda a organização (BIRKINSHAW et al., 2011). Dessa forma, o nível de educação formal dos colaboradores e a intensidade de treinamento qualificam a base de conhecimento interno das PMEs. 


\subsubsection{Estratégia}

A capacidade da empresa relacionada à estratégia envolve a sua habilidade de identificar as forças e fraquezas internas e oportunidades e ameaças externas, formular planos formais alinhados com a visão e missão corporativa e frequentemente reavalialos, estabelecer indicadores estratégicos e respectivas metas e criar as condições para implementação dos planos (YAM et al., 2010). A estratégia deve abranger também o tema inovação envolvendo aspectos como a análise do ambiente competitivo e tecnológico, a priorização e o desenvolvimento focado de inovações tecnológicas corretas ao assegurar que os recursos, competências e processos apropriados sejam aplicados da melhor forma para gerar valor e atender os objetivos da organização (FRANCINI, 2012).

A estratégia tem papel dominante para inovação efetiva (BERKHOUT et al., 2006). Essa dimensão está entre os principais determinantes da capacidade de inovação (APAYDIN e CROSSAN, 2010; O'REGAN et al., 2006; VALLADARES, 2012). Sem alguma forma de planejamento estratégico torna-se difícil avaliar se uma inovação irá conduzir a empresa na direção correta. Dessa forma, é mandatório que inovação tenha um plano estratégico para dar as diretrizes que permitirão um bom desempenho das inovações (ASA et al., 2013). Para Valladares (2012) quando a estratégia é definida e comunicada e as metas são estabelecidas, é criada uma referência que orienta a ação de toda a empresa e se a inovação ocupa lugar de destaque nessa estratégia, a organização volta-se para a geração de ideias. A estratégia torna-se um passo crítico para institucionalizar a inovação (YOKOMIZO, 2014).

No caso particular das PMEs, as estratégias, quando existem, não costumam ser explícitas. Em geral, essas empresas apresentam deficiências em seu planejamento (BARBER et al., 1989) e estratégias informais e reativas para responder às condições diferentes e adversas de mercado (CHEN e CHEN, 2013). Tal fato decorre especificamente devido ao porte desse grupo de firmas que segundo a literatura sobre estratégia propicia a vantagem de organizações menores de se ajustar às mudanças no ambiente mais rápido que as maiores devido à hierarquia menor e rápida tomada de 
decisão, porém apresenta a desvantagem de tratar-se de um processo com alto grau de informalidade.

\subsubsection{Apoio Governamental}

A inovação é entendida como não apenas o trabalho de empresas individuais, mas sim um esforço coletivo que requer um conjunto diverso e substantivo de conhecimento, além de recursos (WATKINS et al., 2015). Governos têm um papel central em orquestrar a geração e difusão da inovação na economia nacional. Políticas de governo efetivas direcionadas à construção de uma capacidade de inovação em nível nacional estão entre os principais fatores que separaram os Tigres Asiáticos das economias latino-americanas com menor desempenho industrial (BELL e PAVITT, 1993).

O apoio governamental compreende apoio financeiro por meio de subsídios para a inovação que incluem recursos financeiros e regulações de apoio, disponibilidade de fundos públicos para P\&D, prêmios e empréstimos (KEIZER et al., 2002; BECHEIKH et al., 2006), definição de padrões e financiamento de pesquisa básica (BELL e PAVITT, 1993) e políticas tais como substituição de importações, apoio a setores estratégicos, parcerias público-privado, entre outras (BECHEIKH et al., 2006). As políticas de incentivo e apoio governamental à inovação são fundamentais (DOLOREUX e MELANCON, 2008). A título de exemplo, programas governamentais para promoção de design nas PMEs por meio de consultores subsidiados apresentaram uma alta taxa de sucesso (HOFFMAN et al., 1998).

A dimensão denominada apoio governamental encoraja as empresas a inovarem mais (BECHEIKH et al., 2006) e exerce influencia sobre a capacidade de inovação das organizações uma vez que políticas efetivas contribuem para proporcionar os recursos necessários para geração e implementação das inovações. Companhias inovadoras têm conhecimento sobre as propostas de legislação do governo que podem afetá-las e participam de procedimentos para definição de padrões (em seus setores), além de influenciar procedimentos regulatórios, ou seja, essas empresas tendem a trabalhar em parceria com o governo (YOKOMIZO, 2014). 


\subsubsection{Localização Geográfica}

A localização geográfica refere-se ao contexto físico no qual a empresa está inserida. Esse contexto inclui, a título de exemplo, proximidade aos stakeholders o que permite criar relação de cooperação com esses atores (BECHEIKH et al., 2006), proximidade com universidades que proporciona acesso a recursos humanos qualificados, proximidade à agências governamentais que oferecem incentivos e apoio à inovação e presença de fornecedores e concorrentes que estimulam a competitividade. Localizações favoráveis à inovação como, por exemplo, o Vale do Silício representam a aplicação prática do conceito de hélice tríplice em que há uma inteiração adequada entre universidades, empresas e governo, criando condições ideais para promoção da inovação (ETZKOWITZ, 2009).

Com relação à localização geográfica, alguns pesquisadores notaram diferenças do impacto desse fator na capacidade de inovação das empresas (COOKE et al., 2004; HOFFMAN et al., 1998, LE BLANC et al., 1997). Em parte, essa diferença de impacto segundo a localização geográfica pode ser explicada uma vez que um dos fatores críticos de sucesso encontrados na literatura é a colaboração externa e essa colaboração depende do contexto geográfico (KEIZER et al., 2002). Localizações com baixa ou inexistente relação entre universidades, empresas e governo tendem a ser ambientes compostos por empresas com baixa capacidade de inovação.

\subsubsection{Orientação ao Mercado}

A orientação ao mercado pode ser definida como sendo um conjunto de comportamentos e atividades relacionadas à geração, disseminação e resposta à inteligência de mercado (KOHLI e JAWORSKI, 1993). Em linha com essa definição está o conceito de que a orientação ao mercado compreende comportamentos e processos por meio da sensibilidade de mercado e relacionamento com o cliente (DAY, 1994). Desses conceitos, depreende-se que orientação ao mercado é um aspecto cultural e um constructo latente cujos indicadores são valores, crenças e símbolos que demonstram uma preocupação com o mercado (NYSTROM et al., 2002), ou seja, 
refere-se a uma cultura que prioriza a criação de valor ao cliente, enquanto considera outros stakeholders e enfatiza a resposta às informações do mercado (NARVER e SLATER, 1990).

Uma organização orientada ao mercado possui processos para coletar inteligência de mercado e integra-la ao processo de tomada de decisão estratégica (DAY, 1994) que resulta no desenvolvimento e adaptação de produtos, serviços e processos que vão de encontro às necessidades da evolução do mercado. Por essa razão, orientação ao mercado envolve fazer algo novo ou diferente em resposta às condições de mercado e deve ser vista como uma forma de comportamento inovador (KOHLI e JAWORSKI, 1993).

A dimensão orientação ao mercado também abrange competências relacionadas a clientes que são extremamente relevantes uma vez que inovações de sucesso são geradas por empresas que costumam ter compreensão das necessidades dos clientes (DANNEELS e KLEINSCHMIDT, 2001; NYSTROM et al., 2002) e são proativas em relação a eles (YOKOMIZO, 2014). Ou seja, empresas inovadoras têm a habilidade de antecipar e responder às necessidades de clientes melhor que seus competidores (SIMPSON et al., 2006) e se apropriam dos benefícios de aprender com seus erros a partir de feedbacks do mercado o que é uma propriedade muito importante da inovação (BERKHOUT et al., 2006).

Dessa forma, a orientação ao mercado contribui para fortalecer a capacidade de inovação das empresas (DESHPANDE et al., 1993; KOHLI e JAWORSKI, 1990; LANGERAK et al., 2004) sendo um dos seus principais determinantes. Os comportamentos e atividades relacionados à orientação de mercado proporcionam acesso a conhecimento e ideias que são recursos primários para o processo de inovação (ASA et al., 2013; YAM et al., 2010). Valladares (2012) demonstrou que conhecer profundamente o mercado e o cliente, ou seja, buscar identificar os requisitos e as necessidades do cliente, analisar como os clientes usam os produtos e serviços e analisar essas necessidades identificadas para o desenvolvimento de novos produtos e serviço, contribui diretamente para a capacidade inovadora das empresas. 
2.2.15 Base de Conhecimento Externo

As atividades de inovação nas empresas apresentam grande dependência de fontes externas (FAGERBERG, 2003). Nenhuma organização pode mais se permitir depender exclusivamente de suas próprias ideias para progredir, consequentemente a inovação está envolta em parcerias (BERKHOUT et al., 2006). A jornada da inovação passa a ser uma conquista coletiva que requer papéis chaves de inúmeros empreendedores tanto do setor público como do setor privado (VAN DE VEN e POLLEY, 1992) e o sucesso das companhias inovadoras está diretamente vinculado à qualidade e longevidade de suas relações colaborativas (FERGUSON, 2005).

Nesse contexto, surge o novo paradigma da inovação aberta que permite as empresas lucrarem com suas ideias, bem como as ideias de terceiros. Esse paradigma exige uma nova lógica da organização do $\mathrm{P} \& \mathrm{D}$ nas empresas que as transforme em um veículo efetivo para se apropriar da base de conhecimento externo, bem como gerar conhecimento (CHESBROUGH, 2013). Muitas empresas inovadoras passaram a adotar uma estratégia que envolve o uso de uma ampla gama de fontes e atores externos para ajuda-las a alcançar e sustentar a inovação (CHESBROUGH, 2003).

A base de conhecimento externo compreende relações com outras empresas (HOFFMAN et al., 1998; MASSA e TESTA, 2008), centros de conhecimento que incluem profissionais consultores, universidades, institutos de pesquisa públicos e privados (HOFFMAN et al., 1998; LAURSEN e SALTER, 2006; LE BLANC et al, 1997; NELSON, 2000; OERLEMANS, 1998; ROTHWELL, 1991; TIDD et al., 2005), fornecedores (BERKHOUT et al., 2006; FACÓ, 2009; GEFFEN e ROTHENBERG, 2000; HIPPEL, 2007; KAMINSKI, 2008) e até mesmo competidores (LAWSON e SAMSON, 2001).

A interação com a base de conhecimento externo e a transferência desse conhecimento, por sua vez, podem ocorrer de diversas formas, entre elas a simples comunicação e troca de conhecimento (HIPPEL, 2007), pela compra de licenças, por meio de parcerias e contratação (NELSON, 2000). Cooper e Edgett (2007) segmentam ainda mais os 
modelos de parcerias externas tais como joint venture $^{10}$, co-desenvolvimento ${ }^{11}$, aquisição de tecnologia ${ }^{12}$ e capital de risco e fomento. No caso particular das PMEs, essas empresas também podem adquirir ou receber $P \& D$, ideias, patentes e invenções de terceiros (OECD, 2005).

Com base na revisão da literatura, foi possível identificar que a habilidade de explorar a base de conhecimento externo configura-se dessa forma em um componente crítico da capacidade de inovação das empresas (COHEN e LEVINTHAL, 1990; BECHEIIKH et al., 2006). Quanto maior a interação da empresa com sua rede externa, maior será sua capacidade de inovação (FORSMAN, 2011; TIDD et al., 2005). As redes externas de conhecimento (interação com universidades, fornecedores, centros de pesquisa e outros atores presentes no ambiente em que a empresa está inserida) reforçam a competitividade das empresas por meio do acesso a novos conhecimentos, fontes de assistência técnica, expertise, tecnologia sofisticada, além de estrategicamente reduzir os custos do processo de inovação (BOUGRAIN e HOUDEVILLE, 2002; FREEL, 2005). A título de exemplo, estudos comprovam que associação com fornecedores contribui para o desenvolvimento de novos produtos (reduzindo inclusive o tempo de oferta do produto ou serviço ao mercado), redução de custos, diluição de riscos, melhorias na integração de componentes tecnológicos, além de permitir às empresas de menor porte superar limitações inerentes ao seu tamanho (AKINCI e UTLU, 2015; FERGUSON, 2005; KEIZER et al., 2002; TIDD et al. 2005).

Apesar da construção teórica no campo dos relacionamentos externos no caso particular das PMEs ter sido menor quando comparado às empresas de maior porte (SAKAMOTO, 2011), a literatura existente indica que a base de conhecimento externo é crítica para o processo de inovação das PMEs (NIETO e SANTAMARIA, 2006). Segundo Hoffman et al. (1998) as PMEs dependem ainda mais de uma rede de contatos

\footnotetext{
${ }^{10}$ Denomina-se joint venture um arranjo formal legal entre parceiros em um desenvolvimento conjunto e/ou iniciativa de negócio, sendo que os riscos e recompensas são negociados e compartilhados formalmente.

11 Co-desenvolvimento refere-se ao trabalho com parceiros externos no desenvolvimento de novos produtos e/ou serviços. Pode ser um subconjunto de uma iniciativa de joint venture ou de inovação aberta e pode incluir o co-desenvolvimento por meio de empresas pares ou de fornecedor/cliente.

${ }^{12} \mathrm{Na}$ aquisição de tecnologia, uma grande empresa compra uma pequena empresa de alta tecnologia a fim de aprender mais sobre uma tecnologia, adquirir a tecnologia ou obter uma primeira entrada com baixo custo.
} 
externa, ou seja, de uma base de conhecimento externo densa e em geral há uma associação positiva entre inputs externos científicos, técnicos e profissionais e a capacidade de inovação das PMEs (TIDD et al., 2005). Dessa forma, a colaboração com atores externos permite as empresas de menor porte aproximarem-se aos níveis de inovação das organizações de maior porte. As organizações devem, portanto melhorar suas redes colaborativas externas as quais são essenciais para inovação (ASA et al., 2013).

\subsection{Mensuração da Capacidade de Inovação}

O presente tópico tem como objetivo definir, por meio da revisão da literatura, o constructo capacidade de inovação que se configura na variável explicada ou dependente do estudo. Tal tarefa é relevante uma vez que resultados conflitantes e muitas vezes inconclusivos entre estudos que examinaram a relação entre determinantes da capacidade de inovação e capacidade de inovação decorreram em grande parte de problemas advindos de uma definição restrita do constructo capacidade de inovação (SUBRAMANIAN e NILAKANTA, 1996) ou ainda devido à adoção de diferentes definições ou formas de mensuração dessa capacidade (FIGUEIREDO, 2014). Considerando os problemas citados, foi realizada a seguir uma análise dos conceitos de capacidade de inovação e da evolução das formas de mensuração dessa capacidade a fim de definir, a partir dessas informações, o conceito mais adequado para essa pesquisa e alinhar a melhor forma para mensura-lo.

Ainda não há uma definição comum a respeito do que exatamente constitui a capacidade de inovação de uma empresa (YOKOMIZO, 2014). De forma abrangente, o conceito de capacidade de inovação refere-se ao potencial organizacional de converter novas ideias em valor comercial (ASA, et al., 2013). Especificando quanto ao grau de inovação, a capacidade inovadora refere-se à habilidade de realizar melhorias relevantes

e modificações em tecnologias existentes, e criar novas tecnologias (WONGLIMPIYARAT, 2010). Um conceito um pouco mais detalhado e gerencial estabelece capacidade de inovação como um conjunto de conhecimentos e habilidades gerenciais que representam o potencial interno de gerar novas ideias, identificar novas 
oportunidades de mercado e implementar inovações por meio da exploração dos recursos e capacidades existentes na empresa. O problema desse conceito é que se restringe aos recursos internos da empresa. Para o presente trabalho, a capacidade de inovação é reconhecida como a habilidade de gerir e explorar novas ideias e conceitos e gerar soluções para oportunidades potenciais que atendam as necessidades do mercado e as tornem em soluções viáveis (ASSINK, 2006, HULT et al., 2004).

Com relação à mensuração da capacidade de inovação, estudos prévios revelam diversas sugestões para mensurar essa capacidade (BOLY et al., 2014). A revisão da literatura permitiu identificar que essa capacidade era inicialmente conceitualizada e mensurada como um constructo unidimensional (SUBRAMANIAN e NILAKANTA, 1996). A capacidade de inovação costumava ser mensurada por medidas tradicionais como investimento em P\&D (input) ou número de patentes registradas (output) (ARCHIBUGI e SIRILLI, 2001; YAM et al., 2011). A mensuração da capacidade de inovação com base em indicadores únicos como investimento em P\&D e número de patentes foram as proxies mais populares e amplamente adotadas durante as últimas décadas (WAN et al., 2003; FRANCINI, 2012).

No entanto, indicadores como investimento em $\mathrm{P} \& \mathrm{D}$ e número de patentes registradas passaram a ser questionados (KLEINKNECHT et al., 2002; MANSFIELD, 1985) uma vez que permanece difícil correlacionar esforços de $\mathrm{P} \& \mathrm{D}$ com resultados de $\mathrm{P} \& \mathrm{D}$ (BOLY et al., 2014). Essas métricas podem talvez tornar-se úteis quando empresas construírem suas capacidades de inovação a ponto de envolverem atividades mensuráveis de P\&D ou registrarem patentes (FIGUEIREDO, 2014) o que não é o caso da maioria das PMEs (KLEINKNECHT et al., 2002; MICHIE, 1998) que não têm costume de registrar patente e praticam $P \& D$ de maneira informal ${ }^{13}$ e ocasional o que torna essa medida muito simplista (KEIZER et al., 2002).

\footnotetext{
${ }^{13}$ Empresas de pequeno e médio não possuem em geral uma área de P\&D formalizada (FRANCINI, 2012) tornando investimento em $P \& D$ como uma métrica representativa inadequada e imperfeita das atividades de inovação.
} 
Muitos pesquisadores apontam que as empresas variam em sua propensão à geração de patentes $^{14}$ (PAVITT et al., 1989) e outros argumentam ainda que no caso particular das patentes, esse indicador representa um resultado intermediário do processo de desenvolvimento de um novo produto e, dessa forma, muitas patentes podem não chegar a serem comercializadas (patentes adormecidas) (BOLY et al., 2014). Além disso, o processo de inovação é um fenômeno complexo caracterizado por diversos estágios que compreendem desde a pesquisa básica até a penetração do produto em um novo mercado (WAN et al., 2003) e, portanto é importante considerar uma ampla gama de indicadores de inovação a fim de capturar de forma mais precisa o nível de inovação das empresas (ROGERS, 1995) e não depender apenas de uma única métrica que reflita apenas uma fração da capacidade de inovação da organização (FIGUEIREDO, 2014).

Recentemente, o constructo capacidade de inovação organizacional vem sendo amplamente operacionalizado, de acordo com a literatura, com base no número de inovações adotadas por uma organização (KIMBERLY e EVANISKO, 1981; NYSTROM et al., 2002; SUBRAMANIAN e NILAKANTA, 1996). Uma razão para a adoção dessa alternativa de mensuração refere-se ao fato de que inovações em produtos e serviços são tangíveis e menos ambíguas, o que contribui para sua validade. Além disso, medir o número de inovações em produtos e serviços efetivamente comercializadas evita incorrer em distorções inerentes às mensurações de inovação comumente utilizadas, sendo que a mensuração direta do output inovador é preferível à métodos de mensuração que envolvam patentes ou P\&D (input) (KLEINKNECHT et al., 2002). Tal fato também se aplica às PMEs (ACS e AUDRETSCH, 1990).

Porém, o teste real para o sucesso da inovação não é o êxito de apenas uma inovação no curto prazo, mas o crescimento sustentável por meio de invenções e adaptações contínuas, ou seja, a habilidade de inovar consistentemente, o que requer considerar a perspectiva de tempo (TIDD et al., 2005) quando se trata da mensuração da capacidade de inovação. A capacidade de inovação, por definição, é um traço organizacional duradouro e organizações verdadeiramente inovadoras são aquelas que exibem

\footnotetext{
${ }^{14}$ Segundo Pavitt (1988) um número significativo de inovações ocorre for ado âmbito das áreas e atividades de $\mathrm{P} \& \mathrm{D}$ nas empresas e não são patenteadas e dessa maneira, não são consideradas nas medidas de inovações que fazem uso exclusivo de patentes.
} 
comportamento inovador consistente ao longo do tempo e, portanto qualquer medida válida de capacidade de inovação deve capturar a dimensão temporal da capacidade de inovação (SUBRAMANIAN e NILAKANTA, 1996).

Em linha com essa consideração, alguns pesquisadores avaliaram a capacidade de inovação organizacional baseado no número de inovações adotadas por uma organização dentro de um dado período de tempo (DAMANPOUR e GOPALAKRISHNAN, 2001). As pesquisas sobre inovação realizadas pelo Departament for Business, Innovation \& Skills britânico ${ }^{15}$ assumem como medida o número de novos produtos lançados no período dos últimos 03 anos. Freel (2005) também adota o mesmo período ao categorizar as empresas em "novel innovators" quando introduzem pelo menos 01 novo produto/serviço ou processo nos últimos 03 anos, "incremental innovators" quando introduzem 01 novo produto/serviço ou processo nos últimos 03 anos e "no innovators" quando não introduzem novos produtos/serviços ou processos nos últimos 03 anos.

Ainda assim, muitos autores ressaltam a necessidade de conceitualizar e operacionalizar a capacidade de inovação como um constructo multidimensional (incluindo outros indicadores de inovação) uma vez que as relações entre fatores organizacionais e a capacidade de inovação organizacional são complexas e só podem ser detectadas se a capacidade de inovação for uma medida "multi itens" (SUBRAMANIAN e NILAKANTA, 1996). A partir dessa premissa, alguns autores analisam a introdução de novos processos ${ }^{16}$, produtos/serviços ou ideias no nível organizacional a fim de melhor capturar o conceito de capacidade de inovação da empresa (DAS e JOSHI, 2007; HURLEY e HULT, 1998; WAN et al., 2003). Outros pesquisadores incluem também além desses itens, abertura de novos mercados (WANG e AHMED, 2004), inovações em marketing (WONGLIMPIYARAT, 2010), entre outras inovações administrativas e tecnológicas.

\footnotetext{
${ }^{15}$ Fonte: site https://www.gov.uk/government/organisations/department-for-business-innovation-skills

16 A título de exemplo, a introdução de um sistema just-in-time pode ser considerada uma inovação tecnológica de processo, pelos efeitos diretos sobre a produção de bens para o mercado (OCDE, 1997), assim como implantação de práticas como total quality management (TQM) e melhoria contínua (BECHEIKH et al., 2006), kaizan, kanban, ferramentas de benchmarking, ferramentas para solução de problemas, ISO 9001, entre outras (O’REGAN, 2005).
} 
Com base na revisão da literatura sobre mensuração da capacidade de inovação organizacional, foi possível identificar que a maioria das abordagens propostas baseiase na avaliação de múltiplos fatores, sendo preferencialmente indicadores relacionados aos outputs da inovação. Nesse contexto, respeitando as considerações observadas na literatura, o presente estudo propõe adotar um constructo para capacidade de inovação composto por variáveis que capturem as dimensões produtos e serviços, processos e mercados em um horizonte de tempo que compreende os últimos 03 anos.

Assim como Valladares (2012) não serão utilizados indicadores relacionados a desempenho financeiro, pois esta medição é afetada por outras variáveis além da inovação propriamente dita. Essa abordagem específica adotada converte a capacidade de inovação em critérios métricos que podem ser diretamente observados e avaliados dentro da companhia durante o estágio de coleta de dados por meio de provas tangíveis ${ }^{17}$, conforme sugerido por Boly et al. (2014) o que está menos sujeito ao viés do observador, bem como do entrevistado. Espera-se dessa forma, adotar uma abordagem menos ambígua da capacidade de inovação organizacional o que certamente contribuirá para um melhor entendimento dos seus determinantes.

\footnotetext{
${ }^{17}$ A título de exemplo, Boly et al. (2014) sugere que se uma empresa inova em parceria com o departamento de uma universidade, o pesquisador deve verificar que há um contrato formal assinado por ambas as partes. Outro exemplo pode ser o uso de ferramentas metodológicas como análise funcional em que a verificação pode consistir em ler o documento de especificações do produto.
} 


\section{MODELO TEÓRICO E FORMULAÇÃO DE HIPÓTESES}

A revisão da literatura permitiu identificar dimensões apontadas como determinantes da capacidade de inovação das empresas e revelar como esses determinantes se comportam em relação a essa capacidade. Como resumo e organização da revisão da literatura, o presente capítulo apresenta o modelo teórico proposto e formula as hipóteses de pesquisa acerca de como esses determinantes afetam e influenciam a capacidade de inovação das companhias, conforme sugerido por Forza (2002).

\subsection{Modelo Teórico Proposto}

No modelo teórico elaborado a partir da literatura (Esquema 1), todas as 15 dimensões identificadas como determinantes da capacidade de inovação organizacional foram incluídas. Esses determinantes foram agrupados em dois grupos, sendo eles o grupo de determinantes internos (11) e determinantes externos (4). Vale ressaltar que o modelo teórico proposto direcionou a construção do questionário e a pesquisa de campo.

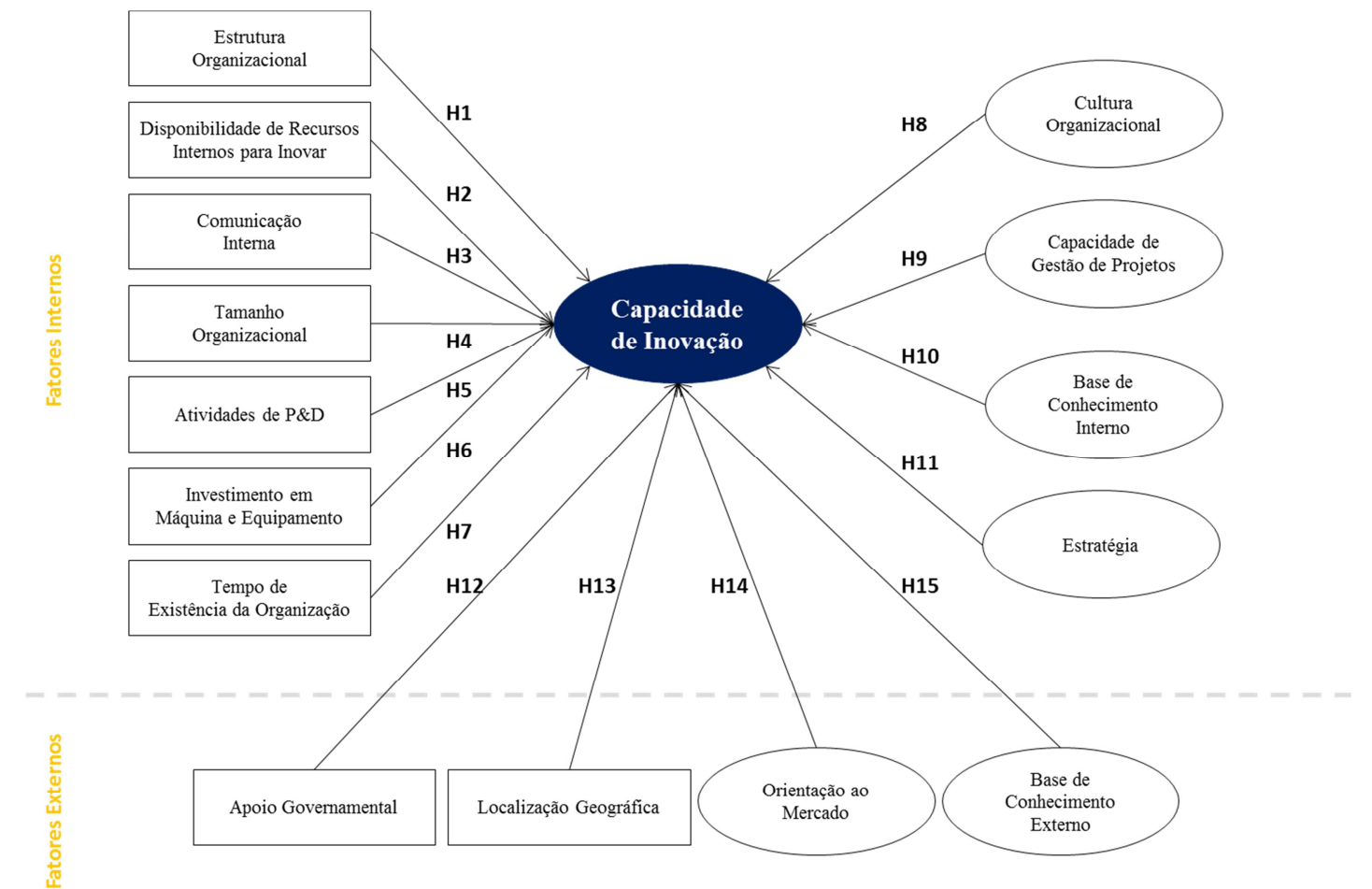

Esquema 1 - Modelo teórico apresentando as relações hipotéticas entre a capacidade de inovação e seus determinantes

Fonte: Elaboração própria. 


\subsection{Formulação de Hipóteses}

De acordo com a revisão da literatura e com o modelo teórico proposto, 15 hipóteses foram formuladas a seguir a fim de testar a relação em termos de direção e magnitude entre cada determinante e a capacidade de inovação organizacional. A revisão da literatura e formulação das hipóteses permitiu ainda uma melhor compreensão da natureza dos constructos, medidas, escalas e técnicas estatísticas a serem adotadas conforme apresentado na metodologia.

\subsubsection{Formulação de Hipóteses: Estrutura Organizacional}

O tipo de estrutura organizacional adotado por uma empresa causa impactos distintos na sua capacidade de inovação. Estruturas "orgânicas" tais como estrutura matricial, projetizada e celular, apresentam menor grau de departamentalização, baixo nível de formalização e multiplicidade de comando o que aumenta a disseminação do conhecimento e a resposta às mudanças (VALLADARES, 2012; VASCONCELLOS e HAMSLEY, 2002). Características típicas desses tipos de estruturas contribuem para o fortalecimento da capacidade de inovação das empresas. Em contrapartida, estruturas "mecanicistas" como a estrutura funcional estão associadas à centralização da tomada de decisão, da autoridade e da inovação e impactam de forma negativa o processo de inovação (WAN et al., 2003).

De acordo com esse raciocínio, depreende-se que a estrutura organizacional está associada à capacidade inovadora e que estruturas "orgânicas" são reconhecidas como sendo as mais adequadas para criar um ambiente favorável à inovação (LAWSON e SAMSON, 2001), o que permite traçar a seguinte hipótese:

Hipótese 1: A estrutura organizacional apresenta relação significativa com a capacidade de inovação, sendo que essa relação é positiva no caso das estruturas orgânicas. 
3.2.2 Disponibilidade de Recursos Financeiros Internos para Inovação

A disponibilidade de recursos internos afeta as atividades de inovação da empresa uma vez que essas atividades requerem recursos para poderem financiar projetos de alto risco ou longo prazo (TIDD et al., 2005), experimentar novas posturas frente ao ambiente em que está inserida (BOURGEOIS, 1981) e facilitar a inovação, a criatividade e a tomada de risco de uma organização (LOVE e NOHRIA, 2005). Entre os recursos que estimulam a inovação, identificados na literatura, estão os recursos humanos (CHOI e CHANG, 2009), operacionais (VOSS e VOSS, 2008), estoque e capital de giro (LOVE e NOHRIA, 2005), tempo (RICHTNER e AHLSTROM, 2006), entre outros. No entanto, a literatura em geral adota a dimensão financeira como principal indicador para avaliar a disponibilidade de recursos na firma (BOURGEOIS, 1981; FACÓ, 2009; KATILA e SHANE, 2005).

Segundo esse pensamento, infere-se que a disponibilidade de recursos financeiros internos para inovação se correlaciona com a capacidade de inovação das organizações, tornando possível formular a seguinte hipótese:

Hipótese 2: A disponibilidade de recursos financeiros internos para inovação possui relação significativa e positiva com a capacidade de inovação.

\subsubsection{Comunicação Interna}

O tipo de comunicação interna adotado por organizações inovadoras compreende processos, estruturas e ferramentas que permitam uma comunicação frequente (regular) para facilitar a dispersão e diversidade de ideias dentro da organização (WAN et al., 2003). Estudos indicam que a comunicação interna favorável à inovação proporciona também os canais e meios necessários para interação entre os indivíduos e consequente compartilhamento de informações e conhecimento haja vista que a comunicação entre diferentes departamentos estimula a inovação (ASA et al., 2013). O processo de comunicação deve ainda ser aberto com clientes e colaboradores (YOKOMIZO, 2014). 
Além disso, é importante que o fluxo de comunicação seja eficiente e apresente baixo nível de formalidade (TIDD et al., 2005) para que a comunicação seja completa, ou seja, para que a informação chegue a todos colaboradores e possa ocorrer entre os níveis hierárquicos (ISO 9001).

Em linha com o resultado dos estudos analisados, postula-se que a comunicação interna de uma organização influencia sua capacidade de inovação viabilizando a formulação da seguinte hipótese:

Hipótese 3: A comunicação interna possui relação significativa com a capacidade de inovação, sendo que essa relação é positiva no caso de comunicação aberta por meio de processos eficientes.

\subsubsection{Tamanho Organizacional}

A diferença de tamanho entre as organizações implica em distintas condições econômicas e de capital intelectual para investir em novas ideias. Em geral atribui-se melhores condições a empresas de maior porte, enquanto as empresas de menor porte possuem seus recursos financeiros e de capital intelectual mais super-utilizados e consequentemente com maior dificuldade em disponibilizá-los para a inovação (MACHADO, 2004). Por essa razão, em geral, esse determinante é relacionado positivamente à capacidade de inovação (KIMBERLY e EVANISKO, 1981; DAMANPOUR, 1991; YAM et al., 2010). No entanto alguns pesquisadores encontraram correlação negativa (UTTERBACK, 1994) e até mesmo não significativa (LEE e XIA, 2006, ROGERS, 2004). Estudiosos demonstram ainda que tamanho organizacional afeta a performance de inovação no caso particular das PMEs, apesar dos efeitos em alguns casos ser ambíguo (BOS-BROUWERS, 2009).

Dessa forma, a relação entre tamanho organizacional e atividades de inovação recebeu grande atenção por parte da academia (NIETO e SANTAMARIA, 2006). Vale ressaltar que a literatura indica que as pesquisas classificam o tamanho organizacional por meio 
do número de colaboradores, recursos organizacionais, volumes de transação (KIMBERLY e EVANISKO, 1981) ou faturamento (TIDD et al., 2005).

O tamanho organizacional é, portanto considerado um dos mais importantes determinantes que afetam a capacidade de inovação (CAPON et al., 1992; ROGERS, 2004), sendo que o tamanho da empresa influencia a adoção de mais inovações, ou seja, proporcionalmente, organizações maiores tendem a adotar mais inovações que organizações menores. Conforme a literatura, apesar do efeito esperado dessa variável ser marginal no caso das PMEs, espera-se que o tamanho da organização influencia a capacidade de inovação resultando na formulação da seguinte hipótese:

Hipótese 4: O tamanho organizacional possui relação significativa e positiva com a capacidade de inovação.

\subsubsection{Atividades de P\&D}

Organizações inovadoras praticam regularmente atividades de P\&D (AKINCI e UTLU, 2015) que compreendem um conjunto de atividades relacionadas ao trabalho criativo, empreendido de forma sistemática, com a finalidade de acumular conhecimento visando sua aplicação no desenvolvimento de novos processos, novos produtos ou serviços, produtos tecnologicamente aprimorados ou soluções para problemas (JHA e BOSE, 2015). Várias empresas incorporaram atividades de P\&D, mas o estado da arte dessas práticas envolve a estruturação de um departamento específico para essas atividades o que permite sistematizar os processos de $P \& D$ e realizar essas atividades de forma intensa e profissional (FREEMAN E SOETE, 1982) criando um recurso específico que concentra ativos tangíveis e intangíveis vistos como estratégicos pela empresa e para o desenvolvimento de capacidades organizacionais (ANPEI).

A literatura contém muitos estudos que demonstram a relação entre as atividades de P\&D e o desempenho da inovação nas empresas (FRANCINI, 2012). As pesquisas indicam em sua maioria que as atividades de P\&D praticadas pela organização 
apresentam relação próxima com o resultado da inovação tanto de forma quantitativa, quanto qualitativa (ADNER e LEVINTHAL, 2001). No entanto, alguns autores como Bougrain e Haudeville (2002) argumentam que a intensidade das atividades de P\&D não discriminam o sucesso ou fracasso das inovações.

No caso particular das PMEs, a relação entre P\&D e capacidade de inovação é baixa (AKINCI e UTLU, 2015). Esse resultado pode possivelmente decorrer do fato de que empresas de pequeno e médio porte podem não ter uma área de P\&D formalizada e consequentemente a atividade de inovação tem maior probabilidade de ocorrer nos módulos informais (CEGARRA et al., 2011; RENKO, 2012) e não costuma ser mensurada (TIDD et al., 2005). Sendo a prática de P\&D nessas empresas informal e ocasional (KLEINKNECHT et al., 2002), além de evidências de relatórios com gastos de P\&D subdimensionados nas PMEs (FREEL, 2005), o emprego dessa medida padrão torna-se menos apropriado para PMEs e o que detecta-se com essa estatística é apenas a ponta de um iceberg muito maior (HOFFMAN et al., 1998), sendo considerado muito menos importante (TIDD et al., 2005).

Com base no raciocínio exposto por meio da literatura, reconhece-se a relação entre atividades de $P \& D$ e a capacidade de inovação organizacional o que permite estabelecer a seguinte hipótese:

Hipótese 5: As atividades de P\&D possuem relação significativa e positiva com a capacidade de inovação.

\subsubsection{Investimento em Máquinas e Equipamentos}

O investimento em máquinas e equipamentos permite modificar, modernizar e melhorar os processos de uma organização visando aumento da produtividade, redução de custo, melhoria da qualidade, entre outros objetivos. Esse tipo de investimento constitui-se em um importante input que produz mudança tecnológica tendo em vista que a aquisição de máquinas e equipamentos contribui para o processo de "learning by doing" o qual é 
componente integral no processo de realização de inovações incrementais (NELSON, 2000).

A literatura indica associação entre nível de investimento em máquinas e equipamentos e a capacidade de inovação das organizações. Esse tipo de investimento como parte de uma estratégia de implementação do estado da arte na tecnologia de produção e automação também exerce influência direta na capacidade de inovação das empresas de pequeno e médio porte (KEIZER et al., 2002).

Nesse contexto, verifica-se que o determinante investimento em máquinas e equipamentos tem influência na capacidade de inovação das companhias o que estimula a formulação da seguinte hipótese:

Hipótese 6: Os investimentos em máquinas e equipamentos apresentam relação significativa e positiva com a capacidade de inovação.

\subsubsection{Tempo de Existência da Organização}

O tempo de existência de uma organização pode refletir sua situação financeira, seu grau de maturidade em termos de processos e a solidez da sua base de conhecimento. Organizações que existem há mais tempo tendem a serem maiores e apresentarem melhor situação financeira, apesar de nem todas as organizações continuarem a crescer e aumentar sua receita com o passar do tempo (MINTZBERG, 1983). Ademais, quanto maior o tempo de existência da empresa, mais sólida tende a ser sua experiência e aprendizado (COHEN e LEVINTHAL, 1990; NIETO e SANTAMARIA, 2006), componentes importantes para o processo de inovação.

Nesse sentido, muitos autores consideram o tempo de existência da empresa como um determinante que afeta a capacidade de inovação das empresas (ACS e AUDRETSCH, 1990; BOS-BROUWERS, 2009; SORENSEN e STUART, 2000) de forma positiva (ALBALADEJO e ROMIJN, 2000). Porém, alguns autores identificaram o efeito 
contrário nas empresas de pequeno e médio porte. No grupo das PMEs, identificou-se que as mais jovens são mais inovadoras que as mais antigas (HAUSMAN, 2005).

Ainda que não haja consenso sobre o efeito dessa relação, parte-se do pressuposto que quanto maior o tempo de existência da empresa, maior deve ser seu acumulo de conhecimento o que consequentemente causa impacto positivo nas atividades organizacionais relacionadas à inovação e conduz à elaboração da seguinte hipótese:

Hipótese 7: O tempo de existência da organização apresenta relação significativa e positiva com a capacidade de inovação.

\subsubsection{Formulação de Hipóteses: Cultura Organizacional}

O tipo de cultura organizacional que favorece a inovação encoraja o empreendedorismo individual (MACHADO, 2004), tolera e minimiza erros, apresenta maior propensão em assumir riscos (WAN et al., 2003), cria a percepção dos colaboradores de que suas ideias sejam encorajadas, coletadas e implementadas com apoio de um sistema (JUNG et al., 2003; TIDD et al., 2005) e celebra o sucesso (BIRKINSHAW et al., 2011). A cultura organizacional é uma dimensão ampla e abarca ainda fatores relacionados à gestão de pessoas, aprendizagem organizacional e liderança.

Em termos de gestão de pessoas, adotar um sistema de recompensa atrelado a inovações (ASA et al., 2013; FACÓ, 2009), proporcionar os recursos adequados para explorar novas ideias (WAN et al., 2003) e encorajar o trabalho em times ${ }^{18}$ (MACHADO, 2004) são práticas que estimulam a inovação. Com relação à aprendizagem organizacional, esse tipo de cultura valoriza o aprendizado (BARBIERI et al., 2003) e a prática de utilização do conhecimento com aplicação concreta para a organização (ASA et al., 2013), além de serem inspiradas também no total quality management (TQM) e melhoria contínua (BECHEIKH et al., 2006). Do ponto de vista da liderança, os líderes (em especial o chefe executivo no caso das PMEs) devem demonstrar um

\footnotetext{
${ }^{18}$ Companhias inovadoras adotam uma abordagem de trabalho em equipe multifuncional, abrangendo diversos níveis hierárquicos e direcionada a projetos e solução de problemas (YOKOMIZO, 2014).
} 
comprometimento pessoal com a inovação, possuir visão e entusiasmo, introduzir novas ideias, encorajar a mudança (YOKOMIZO, 2014), conceder autonomia aos colaboradores para inovar (LAWSON e SAMSON, 2001; VALLADARES, 2012) e definir metas específicas de inovação (ASA et al., 2013).

Dessa forma, a cultura organizacional é considerada uma variável que influencia a capacidade de inovação da empresa (ADAMS et al., 2006; APAYDIN e CROSSAN, 2010; BIRKINSHAW et al., 2011; BECHEIKH et al., 2006; NUENO, 1998; NEELY e HII, 1998, VALLADARES, 2012), sendo que a cultura apropriada é de vital importância para o sucesso da inovação (LAWSON e SAMSON, 2001). Verifica-se que esse é um dos principais fatores determinantes da capacidade de inovação das empresas (O’REGAN et al., 2006; FACÓ, 2009; WIND e MAIN, 2002) e de acordo com o exposto é possível gerar a seguinte hipótese:

Hipótese 8: A cultura organizacional de apoio à inovação apresenta relação significativa e positiva com a capacidade de inovação.

\subsubsection{Capacidade de Gestão de Projetos}

Projetos de inovação envolvem riscos e incertezas, além das questões típicas de projeto como prazo e custo. A capacidade de gestão de projetos contribui para que a inovação seja mais efetiva por meio de atividades como identificação, avaliação e controle de riscos (ASA et al, 2013), gestão eficiente dos custos, do prazo e da própria geração de ideias (SÁENZ et al., 2009), além do planejamento, seleção de equipe, monitoramento e execução de tarefas, replanejamento, entre outras (TIDD, et al., 2005).

Uma ampla parte da literatura enfatiza a importância da capacidade de gestão de projetos como variável que influencia positivamente a capacidade de inovação das empresas (KIMBERLY e EVANISKO, 1981; LARSON et al., 1991; TIDD et al., 2005). Em contrapartida, alguns autores argumentam que essas práticas são desnecessariamente burocráticas e rígidas, causando efeitos ambíguos e até mesmo 
afetando negativamente o sucesso de projetos criativos e da inovação (HOTHO e CHAMPION, 2011) o que deu origem ao "paradoxo da gestão e organização da criatividade" (DE FILLIPI et al., 2007).

Ainda assim, diversos estudos empíricos corroboraram que as melhores companhias aprenderam a sistematizar os processos relativos à gestão de projetos (VALLADARES, 2012). Os resultados dessas pesquisas reforça que gestão de projetos é pré-requisito para uma organização inovadora (MACHADO, 2004) e deve ser incluída como determinante nos estudos que avaliam a capacidade de inovação das empresas (ADAMS et al. 2006), FACÓ, 2009 e VALLADARES, 2012) o que permite formular a seguinte hipótese:

Hipótese 9: A capacidade de gestão de projetos apresenta relação significativa e positiva com a capacidade de inovação.

\subsubsection{Base de Conhecimento Interno}

A base de conhecimento interno composta por mão de obra qualificada apresenta maior capacidade de reconhecer, assimilar e explorar o valor da nova informação ou conhecimento e aplica-lo para fins comerciais (Department for Business Innovation \& Skills, 2014; YAM et al., 2010). Trata-se de um dos determinantes internos considerados como mais relevantes para a atividade de inovação uma vez que contribui de forma direta para os esforços de P\&D da organização (HOFFMAN et al., 1998).

A literatura reconhece majoritariamente a base de conhecimento interno como uma variável que influencia positivamente a capacidade de inovação das empresas (FREEL, 2005; HOFFMAN et al., 1998; Department for Business Innovation \& Skills, 2014; LE BLANC et al., 1997; BECHEIKH et al., 2006; NUENO, 1998; TIDD et al.; 2005). Entretanto alguns autores não encontrarem essa correlação entre base de conhecimento interno e a capacidade de inovar das companhias (KEIZER et al., 2002). 
De acordo com a ampla parte dos pesquisadores que apresentou evidências de que a base de conhecimento interno favorece a capacidade de inovação organizacional, sugere-se a criação da seguinte hipótese:

Hipótese 10: A base de conhecimento interno apresenta relação significativa e positiva com a capacidade de inovação.

\subsubsection{Estratégia}

A estratégia enquanto práticas relacionadas a identificar as forças e fraquezas internas e oportunidades e ameaças externas, formular planos formais alinhados com a visão e missão corporativa e frequentemente reavalia-los, estabelecer indicadores estratégicos e respectivas metas e criar as condições para implementação dos planos (YAM et al., 2010) contribui para um melhor desempenho da empresa em termos de inovação. Organizações inovadoras incluem ainda o tema inovação com destaque nessa estratégia (VALLADARES, 2012) o que implica na análise do ambiente competitivo e tecnológico, a priorização e o desenvolvimento focado de inovações tecnológicas corretas, alinhadas aos objetivos da organização (FRANCINI, 2012).

Com base na literatura, conclui-se que a estratégia tem papel dominante para inovação efetiva (BERKHOUT et al., 2006) sendo que essa dimensão está entre os principais determinantes da capacidade de inovação organizacional (APAYDIN e CROSSAN, 2010; ASA et al., 2013; O'REGAN et al., 2006; VALLADARES, 2012) o que sustenta a proposta da seguinte hipótese:

Hipótese 11: A estratégia apresenta relação significativa e positiva com a capacidade de inovação. 


\subsubsection{Apoio Governamental}

O apoio governamental por meio de subsídios para a inovação tais como recursos financeiros e regulações de apoio, disponibilidade de fundos públicos para P\&D, prêmios e empréstimos (KEIZER et al., 2002; BECHEIKH et al., 2006), definição de padrões e financiamento de pesquisa básica (BELL e PAVITT, 1993) e políticas públicas (BECHEIKH et al., 2006), fomentam a geração e difusão da inovação na economia (WATKINS et al., 2015).

Conforme identificado na literatura, as políticas de incentivo e apoio governamental à inovação são fundamentais (DOLOREUX e MELANCON, 2008). Empresas inovadoras tendem a trabalhar em parceria com o governo (YOKOMIZO, 2014) uma vez que estão cientes de que esse apoio lhes estimula a inovar mais e de forma mais efetiva (BECHEIKH et al., 2006).

Em consonância com esse pensamento, ressalta-se que o apoio governamental exerce influencia sobre a capacidade de inovação das organizações, pois contribui para proporcionar os recursos necessários para geração e implementação das inovações o que suporta a elaboração da seguinte hipótese:

Hipótese 12: O apoio governamental apresenta relação significativa e positiva com a capacidade de inovação.

\subsubsection{Localização Geográfica}

Um contexto geográfico favorável à inovação efetiva proporciona proximidade com universidades, agências governamentais, além de fornecedores e concorrentes o que facilita a criação de uma relação de cooperação com esses atores (BECHEIKH et al., 2006). Esse tipo de localizações representa a aplicação prática do conceito de hélice tríplice em que há uma inteiração adequada entre universidades, empresas e governo, criando condições ideais para promoção da inovação (ETZKOWITZ, 2009). 
No que diz respeito à localização geográfica, alguns pesquisadores notaram diferenças do impacto desse determinante na capacidade de inovação das empresas (COOKE et al., 2004; HOFFMAN et al., 1998, LE BLANC et al., 1997). Localizações com relação baixa ou inexistente entre universidades, empresas e governo tendem a ser ambientes compostos por empresas com baixa capacidade de inovação. Já localizações que criam as condições necessárias para a colaboração entre as empresas e atores externos tais como governo, universidade, fornecedores e concorrentes fortalecem a capacidade de inovação das companhias instaladas em seu território (KEIZER et al., 2002).

Segundo esse contexto, identifica-se que a localização geográfica é vista pela academia como um dos fatores críticos de sucesso para a capacidade de inovação das organizações o que ampara a elaboração da seguinte hipótese:

Hipótese 13: A localização geográfica apresenta relação significativa com a capacidade de inovação, sendo positiva onde há maior proximidade com atores externos.

\subsubsection{Orientação ao Mercado}

O conhecimento detalhado das necessidades e expectativas do mercado e dos clientes proporciona acesso a conhecimento e ideias que são recursos primários para o processo de inovação (ASA et al., 2013; YAM et al., 2010) e contribui diretamente para a capacidade inovadora das empresas (VALLADARES, 2012). Os comportamentos e atividades relacionados à orientação de mercado fazem parte do perfil da empresa inovadora posto que envolvem fazer algo novo ou diferente em resposta às condições de mercado (KOHLI e JAWORSKI, 1993).

Em linha com essas considerações, a literatura indica que a orientação ao mercado contribui para o fortalecimento da capacidade de inovação das empresas (DESHPANDE et al., 1993; KOHLI e JAWORSKI, 1990; LANGERAK et al., 2004). Nesse sentido, atribui-se um papel de destaque a essa dimensão para as atividades de inovação, o que a 
faz ser considerada um dos principais determinantes das organizações inovadoras e legitima a formulação da seguinte hipótese:

Hipótese 14: A orientação ao mercado apresenta relação significativa e positiva com a capacidade de inovação.

\subsubsection{Base de Conhecimento Externo}

Companhias inovadoras possuem relações colaborativas qualitativas e duradouras com a base de conhecimento externo (FERGUSON, 2005) tendo em vista que a jornada da inovação é uma conquista coletiva (VAN DE VEN e POLLEY, 1992). A interação com

redes externas de conhecimento tais como universidades, fornecedores, centros de pesquisa e outros atores externos proporcionam meios de acesso a novos conhecimentos, fontes de assistência técnica, expertise, tecnologia sofisticada, podendo inclusive reduzir os custos do processo de inovação (BOUGRAIN e HOUDEVILLE, 2002; FREEL, 2005).

A partir da revisão da literatura, infere-se que a habilidade de explorar a base de conhecimento externo configura-se em um componente crítico da capacidade de inovação organizacional (COHEN e LEVINTHAL, 1990; BECHEIIKH et al., 2006). Ou seja, quanto maior a interação da empresa com sua rede externa, maior será sua capacidade de inovação (FORSMAN, 2011; TIDD et al., 2005).

Pesquisas acadêmicas indicam ainda que a base de conhecimento externo é indispensável para o processo de inovação nas PMEs (NIETO e SANTAMARIA, 2006). Uma base de conhecimento externo densa tem peso ainda maior para esse grupo de empresas (HOFFMAN et al., 1998) que apresentam maior dependência de uma rede de contatos externa haja vista suas limitações em função do porte. Nesse contexto, também se encontra uma associação positiva entre inputs externos e os outputs inovadores das PMEs (TIDD et al., 2005), o que fundamenta a seguinte hipótese:

Hipótese 15: A base de conhecimento externo apresenta relação significativa e positiva com a capacidade de inovação. 


\section{METODOLOGIA DA PESQUISA}

Uma boa base teórica e um plano metodológico adequado são necessários para coletar o tipo correto de dados e interpreta-los apropriadamente (FORZA, 2002). Após a revisão da literatura sobre inovação, um modelo conceitual para os determinantes da capacidade de inovação foi elaborado e apresentado ao final do capítulo anterior. A partir desse modelo e dos objetivos de pesquisa foram definidos os procedimentos metodológicos adequados para dar continuidade ao estudo. O presente capítulo tem como finalidade apresentar esses procedimentos os quais contemplam as seguintes etapas: questionário e geração de escala, amostragem e análise dos dados coletados.

\subsection{O Questionário e a Geração de Escala}

Com base na revisão da literatura foram identificados 15 determinantes da capacidade de inovação organizacional. Ainda de acordo com a literatura, foi possível observar que enquanto alguns determinantes são passíveis de mensuração direta, objetiva e precisa, outros são mais abstratos e complexos de serem mensurados de forma precisa, o que ocorre em especial quando envolvem múltiplas facetas, atitudes, percepções ou sentimentos das pessoas. No caso dos determinantes de difícil mensuração direta, a literatura recomenda a adoção de constructos que implicam em uma definição operacional e inclui múltiplos elementos (FORZA, 2002), caso contrário podem ser utilizadas variáveis com uma única questão direta.

Dessa forma, os determinantes foram convertidos em 09 variáveis e 06 constructos (vide Apêndices B, C, D, E, F, G), além do constructo (variável latente) dependente capacidade de inovação (vide Apêndice $\mathrm{H}$ ), para mensuração, conforme modelo teórico representado anteriormente no Esquema 1. Para mensurar as referidas variáveis e constructos foi elaborado um questionário (vide Apêndice A) contendo 64 questões e dividido em 04 seções: (I) Perfil do Respondente, (II) Perfil da Empresa, (III) Avaliação dos Determinantes da Inovação e (VI) Avaliação da Capacidade de Inovação. As seções I e II do questionário contêm perguntas para coletar dados utilizados para estatística descritiva e mensuração de algumas variáveis independentes. A seção III inclui 
perguntas para mensurar as demais variáveis e variáveis latentes (constructos) independentes. A seção IV consiste em questões para mensurar a variável latente dependente capacidade de inovação.

A construção do questionário ocorreu, sempre que possível, a partir de definições operacionais, questões e escalas extraídas da literatura que já foram desenvolvidas, usadas e testadas a fim de mitigar problemas de validade ${ }^{19}$ do instrumento de coleta de dados. Dessa forma, parte do questionário foi desenvolvida com base nas questões que mensuram as dimensões da inovação que deram origem ao modelo denominado "Innovation Radar"20" de Sawhney ${ }^{21}$ (2006). No entanto, nem sempre essas informações estão disponíveis. Nesses casos, foi necessário criar medidas próprias ou adapta-las, sempre em acordo com a literatura, visando complementar o questionário para atender os objetivos de pesquisa. A Tabela 3 a seguir apresenta as 09 variáveis independentes do modelo e seus respectivos códigos, localizações no questionário (operacionalização), referências teóricas utilizadas para adotar ou desenvolver o item e a escala do item.

\section{Tabela 3 - Variáveis independentes do modelo: códigos, operacionalizações, referências e escalas}

\begin{tabular}{|c|c|c|c|c|}
\hline Variável & Código da Variável & Operacionalização & Referência(s) & Escala do Item \\
\hline Estrutura Organizacional & ESTRUT_ORG & Seção III, Item 2 & $\begin{array}{l}\text { Item desenvolvido com } \\
\text { base na revisão da literatura } \\
\text { (e.g. Kanter, 1983; Martins, } \\
\text { e Terblanche, 2003; } \\
\text { Robbins, 2002; Valladares, } \\
\text { 2012; Vasconcellos e } \\
\text { Hamsley, 2002) }\end{array}$ & \begin{tabular}{|l} 
Tipos: \\
0 - Funcional \\
1 - Matricial \\
2 - Projetizada
\end{tabular} \\
\hline
\end{tabular}

(continua)

\footnotetext{
${ }^{19}$ Validade está associada ao grau que um instrumento realmente mede a variável que pretende medir. Ou seja, validade diz respeito à adequação do instrumento em relação aquilo que se propõe medir.

${ }^{20} \mathrm{O}$ "Innovation Radar" foi elaborado por meio do resultado de entrevistas com gestores responsáveis por atividades relacionadas à inovação em diversas empresas de uma ampla gama de indústrias (SAWHNEY et al., 2006). O autor também realizou a revisão a literatura acadêmica sobre inovação a fim de identificar as doze dimensões que compõe o radar. Para medir essas dimensões, foram compiladas cum conjunto de questões fechadas com 03 pontos de acordo com as melhores práticas aceitas em termos de métricas e design de questionário. Esse questionário passou por dois pré-testes, com 16 e 54 gerentes respectivamente. $\mathrm{O}$ modelo de mensuração e estrutural foi estimado com base na técnica dos mínimos quadrados parciais que contribuiu para confirmar a validade do framework proposto.

${ }^{21}$ Mohanbir Sawhney é professor de tecnologia da McCormick Tribune e Diretor do Centro de Pesquisa em Tecnologia e Inovação na Northwestern University's Kellogg School of Management em Illinois (MIT Sloan Management Review - Sloanselect collection winter 2011).
} 
Tabela 3 - Variáveis independentes do modelo: códigos, operacionalizações, referências e escalas (conclusão)

\begin{tabular}{|c|c|c|c|c|}
\hline $\begin{array}{l}\text { Disponibilidade de } \\
\text { Recursos Financeiros } \\
\text { Internos para Inovação }\end{array}$ & DISP_REC_INT & Seção II, Item 9 & $\begin{array}{l}\text { Item desenvolvido com } \\
\text { base na revisão da literatura } \\
\text { (e.g. Bourgeois, 1981; Facó, } \\
\text { 2009; Katila e Shane, 2005) }\end{array}$ & $\begin{array}{l}\text { Faixa de Faturamento: } \\
1 \text { - Micro } \\
2 \text { - Pequena } \\
3 \text { - Média } \\
4 \text { - Média-grande } \\
5 \text { - Grande }\end{array}$ \\
\hline Comunicação Interna & COMUNIC_INT & Seção III, Item 14 & \begin{tabular}{|l|} 
Item desenvolvido com \\
base na revisão da literatura \\
(e.g. Akinci e Utlu, 2015; \\
Boly et al., 2014; Filipe, \\
2007; Wan et al., 2003)
\end{tabular} & $\begin{array}{l}0 \text { - Não } \\
1 \text { - Manual da } \\
\text { Qualidade } \\
2 \text { - Sim }\end{array}$ \\
\hline $\begin{array}{l}\text { Tamanho } \\
\text { Organizacional }\end{array}$ & TAM_ORG & Seção II, Item 8 & Kimberly e Evanisko, 1981 & $\begin{array}{l}\text { № de Colaboradores: } \\
1 \text { - Micro } \\
2 \text { - Pequena } \\
3 \text { - Média } \\
4 \text { - Grande } \\
\end{array}$ \\
\hline Atividades de P\&D & ATIV_P\&D & Seção III, Item 19 & \begin{tabular}{|l|} 
Item adaptado de Akinci e \\
Utlu, 2015; Boly et al., 2014; \\
Chester, 1994; Cohen e \\
Levinthal, 1990 \\
\end{tabular} & $\begin{array}{l}0 \text { - Não realiza P\&D } \\
1 \text { - P\&D esporádico } \\
2 \text { - P\&D regular }\end{array}$ \\
\hline $\begin{array}{l}\text { Investimento em } \\
\text { Máquinas e } \\
\text { Equipamentos }\end{array}$ & INVEST_MAQ & Seção II, Item 10 & \begin{tabular}{|l|} 
Item desenvolvido com \\
base na revisão da literatura \\
(e.g. Facó, 2009; Wang e \\
Ahmed, 2004)
\end{tabular} & $\begin{array}{l}\text { Investimento/ } \\
\text { Faturamento (em \%) }\end{array}$ \\
\hline $\begin{array}{l}\text { Tempo de Existência da } \\
\text { Organização }\end{array}$ & TEMP_EXIST & Seção II, Item 4 & $\begin{array}{l}\text { Albaladejo e Romijn, 2000; } \\
\text { Nieto e Santamaria, } 2006\end{array}$ & Idade em anos \\
\hline Apoio Governamental & AP_GOV & Seção III, Item 24 & $\begin{array}{l}\text { Item adaptado de Amabile } \\
\text { et al., 1996; Facó, } 2009\end{array}$ & $\begin{array}{l}0 \text { - Não } \\
1 \text { - Obteve apoio } \\
\text { financeiro ou fiscal } \\
2 \text { - Obteve apoio } \\
\text { financeiro e fiscal } \\
\end{array}$ \\
\hline Localização Geográfica & LOCALIZ_GEO & Seção II, Item 5 & $\begin{array}{l}\text { Item adaptado da divisão de } \\
\text { núcleos do Projeto NAGI } \\
\text { P\&G }\end{array}$ & $\begin{array}{l}9 \text { Núcleos: } \\
1 \text { - ABCD } \\
2 \text { - Campinas } \\
3 \text { - Mogi das Cruzes } \\
4 \text { - Piracicaba } \\
5 \text { - Ribeirão Preto } \\
6 \text { - São Carlos } \\
7 \text { - São Paulo/Santos } \\
\text { 8- Sorocaba } \\
\text { 9- Vale do Paraíba } \\
\end{array}$ \\
\hline
\end{tabular}

Fonte: Elaboração própria.

A estrutura organizacional foi mensurada por meio do enquadramento em um dos três tipos de estruturas identificados na literatura que abrangem variações relevantes para o estudo. No caso de disponibilidade de recursos financeiros internos para inovação, o faturamento da empresa foi utilizado como proxy em acordo com a literatura. Cada empresa foi classificada em uma das cinco faixas adotadas tanto pelo IBGE, como pelo SEBRAE, com base no seu faturamento dos últimos 12 meses. A comunicação interna 
também foi mensurada por meio de uma proxy representada pela certificação da ISO 9001 que conforme identificado na revisão da literatura exige, entre outros, requisitos para garantir uma comunicação interna adequada. Já o tamanho organizacional foi mensurado diretamente a partir do número de colaboradores segundo faixa de classificação adotada pela Receita Federal. A regularidade das atividades de P\&D foi mensurada por meio da existência de um departamento específico para lidar com essas atividades como proxy o que demonstra que a prática é perene. Com relação aos investimentos em máquinas e equipamentos, a mensuração ocorreu pelo cálculo do porcentual investido sobre o total do faturamento a fim de relativizar os gastos. O tempo de existência da organização é representado pela idade da empresa contada a partir de sua data de fundação. No caso do apoio governamental, foi identificado se a empresa recebeu algum tipo de apoio, financeiro ou fiscal, do governo para suas atividades de inovação. Por fim, a localização geográfica foi atribuída com base na divisão em 09 núcleos proposta pelo projeto NAGI $\mathrm{P} \& \mathrm{G}$ do qual as empresas faziam parte.

As 06 variáveis latentes independentes (constructos) do modelo são apresentadas na Tabela 4 abaixo com seus respectivos códigos, itens, localizações no questionário (operacionalização), referências teóricas utilizadas para adotar ou desenvolver o item e a escala do item.

Tabela 4 - Variáveis latentes independentes do modelo: códigos, itens, operacionalizações, referências e escalas

\begin{tabular}{|c|c|c|c|c|c|c|}
\hline Constructo & $\begin{array}{l}\text { Código do } \\
\text { Constructo }\end{array}$ & Item de Likert & Operacionalização & Referência(s) & $\begin{array}{c}\text { Escala } \\
\text { do Item }\end{array}$ & $\begin{array}{l}\text { Escala do } \\
\text { Constructo }\end{array}$ \\
\hline \multirow{3}{*}{$\begin{array}{l}\text { Cultura } \\
\text { Organizacional }\end{array}$} & \multirow{3}{*}{ CULT_ORG } & Decisão Participativa & Seção III, Item 3 & $\begin{array}{l}\text { Item adaptado de Martins, } \\
\text { e Terblanche, 2003; } \\
\text { Mumford et al., 2002; } \\
\text { Sawhney et al., 2006; Tang, } \\
1999\end{array}$ & $\begin{array}{l}0 \text { - Não } \\
1 \text { - Parcial } \\
2 \text { - Sim }\end{array}$ & \multirow{3}{*}{ Likert 10 pontos } \\
\hline & & Política de Autonomia & Seção III, Item 4 & $\begin{array}{l}\text { Item desenvolvido com } \\
\text { base na revisão da } \\
\text { literatura (e.g. Amabile et } \\
\text { al., 2004; Martins, e } \\
\text { Terblanche, 2003; } \\
\text { Mumford et al., 2002; } \\
\text { Shalley e Gilson, 2004) } \\
\end{array}$ & $\begin{array}{l}0 \text { - Não } \\
1 \text { - Parcial } \\
2 \text { - Sim }\end{array}$ & \\
\hline & & Coleta de Ideias & Seção III, Item 5 & $\begin{array}{l}\text { Item adaptado de Amabile } \\
\text { et al., 2004; Boly, 2014; } \\
\text { Sawhney et al., 2006; } \\
\text { Wang e Ahmed, 2004 }\end{array}$ & $\begin{array}{l}0 \text { - Não } \\
1 \text { - Parcial } \\
2 \text { - Sim }\end{array}$ & \\
\hline
\end{tabular}

(continua) 
Tabela 4 - Variáveis latentes independentes do modelo: códigos, itens, operacionalizações, referências e escalas (continuação)

\begin{tabular}{|c|c|c|c|c|c|c|}
\hline \multirow{5}{*}{$\begin{array}{l}\text { Cultura } \\
\text { Organizacional }\end{array}$} & \multirow{5}{*}{ CULT_ORG } & Sistema de recompensas & Seção III, Item 6 & $\begin{array}{l}\text { Item adaptado de Boly, } \\
\text { 2014; Gupta e Shingal, } \\
\text { 1993; Martins, e } \\
\text { Terblanche, 2003; } \\
\text { Mumford et al., 2002; } \\
\text { Sawhney et al., 2006; } \\
\text { Shalley e Gilson, 2004 } \\
\end{array}$ & $\begin{array}{l}0 \text { - Não } \\
1 \text { - Parcial } \\
2 \text { - Sim }\end{array}$ & \multirow{5}{*}{ Likert 10 pontos } \\
\hline & & $\begin{array}{l}\text { Profissionais com } \\
\text { múltiplas competências }\end{array}$ & Seção III, Item 7 & $\begin{array}{l}\text { Item desenvolvido com } \\
\text { base na revisão da } \\
\text { literatura (e.g. Neely e Hii, } \\
\text { 1998; Yokomizo, 2014) }\end{array}$ & $\begin{array}{l}0 \text { - Não } \\
1 \text { - Parcial } \\
2 \text { - Sim }\end{array}$ & \\
\hline & & Tolerância ao erro & Seção III, Item 8 & $\begin{array}{l}\text { Item desenvolvido com } \\
\text { base na revisão da } \\
\text { literatura (e.g. Amabile et } \\
\text { al., 1996; Gupta, e Singhal, } \\
\text { 1993; Martins, e } \\
\text { Terblanche, 2003; Wan et } \\
\text { al., 2003) }\end{array}$ & $\begin{array}{l}0 \text { - Não } \\
1 \text { - Parcial } \\
2 \text { - Sim }\end{array}$ & \\
\hline & & Times Multidisciplinares & Seção III, Item 9 & $\begin{array}{l}\text { Item desenvolvido com } \\
\text { base na revisão da } \\
\text { literatura (e.g. Ahmed, } \\
\text { 1998; Mumford, 2000; } \\
\text { Shalley e Gilson, 2004) }\end{array}$ & $\begin{array}{l}0 \text { - Não } \\
1 \text { - Parcial } \\
2 \text { - Sim }\end{array}$ & \\
\hline & & $\begin{array}{l}\text { Apoio da Alta } \\
\text { Administração }\end{array}$ & Seção III, Item 10 & $\begin{array}{l}\text { Item adaptado de Amabile } \\
\text { et al, 2004; Cooper, e } \\
\text { Kleinschmidt, 2007; } \\
\text { Rothwell, 1994; Sawhney } \\
\text { et al., 2006; Tang, } 1999\end{array}$ & $\begin{array}{l}0 \text { - Não } \\
1 \text { - Parcial } \\
2 \text { - Sim }\end{array}$ & \\
\hline \multirow{3}{*}{$\begin{array}{l}\text { Capacidade de } \\
\text { Gestão de } \\
\text { projetos }\end{array}$} & \multirow{3}{*}{ GEST_PROJ } & $\begin{array}{l}\text { Portfólio de Projetos de } \\
\text { Inovação }\end{array}$ & Seção III, Item 11 & $\begin{array}{l}\text { Item adaptado de Ahmed, } \\
\text { 1998; Boly, 2014; Mumford } \\
\text { et al., } 2002\end{array}$ & $\begin{array}{l}0 \text { - Não } \\
1 \text { - Parcial } \\
2 \text { - Sim }\end{array}$ & \multirow{3}{*}{ Likert 10 pontos } \\
\hline & & $\begin{array}{l}\text { Controle e } \\
\text { Acompanhamento }\end{array}$ & Seção III, Item 12 & $\begin{array}{l}\text { Item adaptado de Boly, } \\
\text { 2014; Mumford, 2000; } \\
\text { Rothweel, 1994; } \\
\text { Soderquist et al., 1997; } \\
\text { Tidd, Bessant e Pavitt, } 2008\end{array}$ & $\begin{array}{l}0 \text { - Não } \\
1 \text { - Parcial } \\
2 \text { - Sim }\end{array}$ & \\
\hline & & $\begin{array}{l}\text { Software ou Ferramenta } \\
\text { de Gestão da inovação }\end{array}$ & Seção III, Item 13 & $\begin{array}{l}\text { Item adaptado de Ahmed, } \\
\text { 1998; Boly, 2014; Sawhney } \\
\text { et al., 2006; Soderquist et } \\
\text { al., 1997; Tang, } 1999\end{array}$ & $\begin{array}{l}0 \text { - Não } \\
1 \text { - Parcial } \\
2 \text { - Sim }\end{array}$ & \\
\hline \multirow{4}{*}{$\begin{array}{l}\text { Base de } \\
\text { Conhecimento } \\
\text { Interno }\end{array}$} & \multirow{4}{*}{ CONHEC_INT } & $\begin{array}{l}\text { Competências } \\
\text { Necessárias na Equipe }\end{array}$ & Seção III, Item 15 & $\begin{array}{l}\text { Item adaptado de Boly, } \\
\text { 2014; Daghfous, 2004; } \\
\text { Prajogo e Ahmed, } 2006\end{array}$ & $\begin{array}{l}0 \text { - Não } \\
1 \text { - Parcial } \\
2 \text { - Sim }\end{array}$ & \multirow{4}{*}{ Likert 10 pontos } \\
\hline & & $\begin{array}{l}\text { Política de Educação e } \\
\text { treinamento }\end{array}$ & Seção III, Item 16 & $\begin{array}{l}\text { Item adaptado de Akinci e } \\
\text { Utlu, 2015; Boly, 2014; } \\
\text { Mumford et al., 2002; } \\
\text { Shalley e Gilson, 2004; } \\
\text { Soderquist, 1997; Tang, } \\
1999 .\end{array}$ & $\begin{array}{l}0 \text { - Não } \\
1 \text { - Parcial } \\
2 \text { - Sim }\end{array}$ & \\
\hline & & $\begin{array}{l}\text { Qualificação do Quadro } \\
\text { gerencial }\end{array}$ & Seção III, Item 17 & $\begin{array}{l}\text { Item desenvolvido com } \\
\text { base na revisão da } \\
\text { literatura (e.g. Docter e } \\
\text { Stock, 1988; Hoffman et al., } \\
\text { 1998; Innovation Report } \\
\text { 2014; Le Blanc et al., 1997) }\end{array}$ & $\begin{array}{l}0 \text { - Não } \\
1 \text { - Parcial } \\
2 \text { - Sim }\end{array}$ & \\
\hline & & $\begin{array}{l}\text { Avaliação de } \\
\text { desempenho }\end{array}$ & Seção III, Item 18 & $\begin{array}{l}\text { Item desenvolvido com } \\
\text { base na revisão da } \\
\text { literatura (e.g. Gupta e } \\
\text { Shingal, 1993; Mumford et } \\
\text { al., 2002; Shalley e Gilson, } \\
\text { 2004) }\end{array}$ & $\begin{array}{l}0 \text { - Não } \\
1 \text { - Parcial } \\
2-\operatorname{Sim}\end{array}$ & \\
\hline
\end{tabular}




\section{Tabela 4 - Variáveis latentes independentes do modelo: códigos, itens, operacionalizações, referências e escalas (conclusão)}

\begin{tabular}{|c|c|c|c|c|c|c|}
\hline \multirow{4}{*}{ Estratégia } & \multirow{4}{*}{ ESTRAT } & $\begin{array}{l}\text { Planejamento } \\
\text { Estratégico }\end{array}$ & Seção III, Item 20 & $\begin{array}{l}\text { Item adaptado de Boly, } \\
\text { 2014; Chester, 1994; Yam et } \\
\text { al., } 2010\end{array}$ & $\begin{array}{l}0 \text { - Não } \\
1 \text { - Parcial } \\
2 \text { - Sim }\end{array}$ & \multirow{4}{*}{ Likert 10 pontos } \\
\hline & & $\begin{array}{l}\text { Conceito e estratégia de } \\
\text { inovação }\end{array}$ & Seção III, Item 21 & $\begin{array}{l}\text { Item adaptado de Ahmed, } \\
\text { 1998; Chester, 1994; } \\
\text { Cooper, e Kleinschmidt, } \\
\text { 2007; Rothwell, 1994; } \\
\text { Sawhney et al., 2006; } \\
\text { Soderquist et al., 1997; } \\
\text { Tang, } 1999 \\
\end{array}$ & $\begin{array}{l}0 \text { - Não } \\
1 \text { - Parcial } \\
2-\operatorname{Sim}\end{array}$ & \\
\hline & & Avaliação da estratégia & Seção III, Item 22 & $\begin{array}{l}\text { Item adaptado de Boly, } \\
\text { 2014; Mumford, } 2000\end{array}$ & $\begin{array}{l}0 \text { - Não } \\
1 \text { - Parcial } \\
2 \text { - Sim } \\
\end{array}$ & \\
\hline & & Indicadores estratégicos & Seção III, Item 23 & $\begin{array}{l}\text { Item desenvolvido com } \\
\text { base na revisão da } \\
\text { literatura (e.g. Cottam, } \\
\text { Ensor e Band, 2001) }\end{array}$ & $\begin{array}{l}0 \text { - Não } \\
1 \text { - Parcial } \\
2-\operatorname{Sim}\end{array}$ & \\
\hline \multirow{6}{*}{$\begin{array}{l}\text { Orientação ao } \\
\text { Mercado }\end{array}$} & \multirow{6}{*}{ ORIENT_MERC } & Avaliação da marca & Seção III, Item 25 & $\begin{array}{l}\text { Item adaptado de Sawhney } \\
\text { et al., } 2006\end{array}$ & $\begin{array}{l}0 \text { - Não } \\
1 \text { - Parcial } \\
2 \text { - Sim }\end{array}$ & \multirow{6}{*}{ Likert 10 pontos } \\
\hline & & $\begin{array}{l}\text { Coleta de Manifestações } \\
\text { dos Clientes }\end{array}$ & Seção III, Item 26 & $\begin{array}{l}\text { Item adaptado de Boly, } \\
\text { 2014; Sawhney et al., 2006; } \\
\text { Soderquist et al., } 1997\end{array}$ & $\begin{array}{l}0 \text { - Não } \\
1 \text { - Parcial } \\
2-\operatorname{Sim}\end{array}$ & \\
\hline & & $\begin{array}{l}\text { Uso das Manifestações } \\
\text { dos clientes (processo } \\
\text { de inovação) } \\
\text { Monitoramento do } \\
\text { mercado }\end{array}$ & $\begin{array}{l}\text { Seção III, Item } 27 \\
\text { Seção III, Item } 28\end{array}$ & $\begin{array}{l}\text { Item adaptado de Boly, } \\
\text { 2014; Sawhney et al., 2006; } \\
\text { Soderquist et al., 1997; } \\
\text { Yam et al., } 2010 \\
\text { Item adaptado de Boly, } \\
\text { 2014; Mumford et al., 2002; } \\
\text { Sawhney et al., } 2006\end{array}$ & $\begin{array}{l}0 \text { - Não } \\
1 \text { - Parcial } \\
2 \text { - Sim } \\
0 \text { - Não } \\
1 \text { - Parcial } \\
2 \text { - Sim }\end{array}$ & \\
\hline & & $\begin{array}{l}\text { Relacionamento com } \\
\text { clientes }\end{array}$ & Seção III, Item 29 & $\begin{array}{l}\text { Item adaptado de Boly, } \\
\text { 2014; Sawhney et al., 2006; } \\
\text { Yam et al., } 2010\end{array}$ & $\begin{array}{l}0 \text { - Não } \\
1 \text { - Parcial } \\
2 \text { - Sim } \\
\end{array}$ & \\
\hline & & Diálogo com o cliente & Seção III, Item 30 & $\begin{array}{l}\text { Item adaptado de Ahmed, } \\
\text { 1998; Boly, 2014; Sawhney } \\
\text { et al., } 2006\end{array}$ & $\begin{array}{l}0 \text { - Não } \\
1 \text { - Parcial } \\
2 \text { - Sim } \\
\end{array}$ & \\
\hline & & Pesquisa de mercado & Seção III, Item 31 & $\begin{array}{l}\text { Item adaptado de Boly, } \\
\text { 2014; Facó, } 2009\end{array}$ & $\begin{array}{l}0 \text { - Não } \\
1 \text { - Parcial } \\
2-\operatorname{Sim}\end{array}$ & \\
\hline \multirow{7}{*}{$\begin{array}{l}\text { Base de } \\
\text { Conhecimento } \\
\text { Externo }\end{array}$} & \multirow{7}{*}{ CONHEC_EXT } & Parceria & Seção III, Item 32 & $\begin{array}{l}\text { Item adaptado de Akinci e } \\
\text { Utlu, 2015; Boly, 2014; } \\
\text { Pittaway et al. 2004; } \\
\text { Sawhney et al., 2006 }\end{array}$ & $\begin{array}{l}0 \text { - Não } \\
1 \text { - Parcial } \\
2-\operatorname{Sim}\end{array}$ & \multirow{7}{*}{ Likert 10 pontos } \\
\hline & & Projeto cooperado & Seção III, Item 33 & $\begin{array}{l}\text { Item adaptado de Pittaway } \\
\text { et al. 2004; Sawhney et al., } \\
2006\end{array}$ & $\begin{array}{l}0 \text { - Não } \\
1 \text { - Parcial } \\
2 \text { - Sim }\end{array}$ & \\
\hline & & $\begin{array}{l}\text { Relacionamento externo } \\
\text { (com universdades) }\end{array}$ & Seção III, Item 34 & $\begin{array}{l}\text { Item adaptado de Akinci e } \\
\text { Utlu, 2015; Boly, 2014; } \\
\text { Pittaway et al. 2004; } \\
\text { Soderquist et al., 1997; } \\
\text { Sawhney e tal., } 2006\end{array}$ & $\begin{array}{l}0 \text { - Não } \\
1 \text { - Parcial } \\
2-\operatorname{Sim}\end{array}$ & \\
\hline & & $\begin{array}{l}\text { Relacionamento externo } \\
\text { (cadeia de } \\
\text { fornecimento) }\end{array}$ & Seção III, Item 35 & $\begin{array}{l}\text { Item adaptado de Boly, } \\
\text { 2014; Sawhney e tal., } 2006\end{array}$ & $\begin{array}{l}0 \text { - Não } \\
1 \text { - Parcial } \\
2 \text { - Sim } \\
\end{array}$ & \\
\hline & & $\begin{array}{l}\text { Consultoria e } \\
\text { Instituições de Apoio }\end{array}$ & Seção III, Item 36 & $\begin{array}{l}\text { Item adaptado de Akinci e } \\
\text { Utlu, 2015; Pittway et al. } \\
\text { 2004; Sawhney e tal., } 2006\end{array}$ & \begin{tabular}{|l|}
$0-$ Não \\
1 - Parcial \\
2 - Sim \\
\end{tabular} & \\
\hline & & Eventos e Associações & Seção III, Item 37 & $\begin{array}{l}\text { Item adaptado de Boly, } \\
\text { 2014; Sawhney e tal., } 2006\end{array}$ & $\begin{array}{l}0 \text { - Não } \\
1 \text { - Parcial } \\
2 \text { - Sim }\end{array}$ & \\
\hline & & $\begin{array}{l}\text { Aquisição de patentes e } \\
\text { know-how }\end{array}$ & Seção III, Item 38 & $\begin{array}{l}\text { Item adaptado de Facó, } \\
\text { 2009; Sawhney e tal., } 2006\end{array}$ & $\begin{array}{l}0 \text { - Não } \\
1 \text { - Parcial } \\
2-\operatorname{Sim}\end{array}$ & \\
\hline
\end{tabular}

Autor: Elaboração própria. 
Cada item dos constructos representa uma afirmação para a qual o entrevistado tem três opções de resposta, sendo elas: $0=$ Não; $1=$ Parcial; $2=$ Sim. A opção "Não" indica a ausência de determinada prática, atributo ou fator relacionado à empresa. Já a opção "Parcial" consiste na presença de algum aspecto de determinada prática, atributo ou fator referido na afirmação. No caso da opção "Sim" significa que foi confirmada a presença de determinada prática, atributo ou fator que está sendo mensurado. Para cada resposta, foram exigidas evidências que comprovem a opção escolhida a fim de minimizar o viés do(a) respondente, conforme previsto na pesquisa de campo detalhada no item 4.2. As respostas foram somadas por constructo e tendo em vista que cada constructo possui um número diferente de itens, o resultado final da soma foi nivelado em uma escala de 0 a 10. Dessa forma, cada constructo é composto pela somatória de um conjunto de itens e recebe uma pontuação de 0-10 de acordo com a avaliação objetiva de cada item. Vale ressaltar que todos os constructos foram mensurados com pelo menos três itens conforme sugerido pela literatura (DE VELLIS, 2011).

A Tabela 5 abaixo apresenta a variável latente dependente (constructo) do modelo e seus respectivos códigos, itens, localizações no questionário (operacionalização), referências teóricas utilizadas para adotar ou desenvolver o item e a escala do item.

Tabela 5 - Variável latente dependente do modelo: códigos, itens, operacionalizações, referências e escalas

\begin{tabular}{|c|c|c|c|c|c|c|}
\hline Constructo & $\begin{array}{l}\text { Código do } \\
\text { Constructo }\end{array}$ & Item de Likert & Operacionalização & Referência(s) & $\begin{array}{c}\text { Escala } \\
\text { do Item }\end{array}$ & Medida do Constructo \\
\hline \multirow[t]{2}{*}{$\begin{array}{l}\text { Capacidade de } \\
\text { Inovação }\end{array}$} & \multirow[t]{2}{*}{ CAP_INOV_DEP } & Novos produtos/serviços & Seção IV, Item 1 & $\begin{array}{l}\text { Item adaptado de } \\
\text { Damanpour e } \\
\text { Gopalakrishnan, 2001; } \\
\text { Das e Joshi, 2007; } \\
\text { Department for } \\
\text { Business Innovation \& } \\
\text { Skills, 2014; Freel, 2005; } \\
\text { Hurley e Hult, 1998; } \\
\text { Sawhney et al., 2006; } \\
\text { Subramanian e } \\
\text { Nilakanta, 1996; } \\
\text { Nystrom et al., 2002; } \\
\text { Wan et al., 2003; Yam et } \\
\text { al., 2010 }\end{array}$ & $\begin{array}{l}0 \text { - Não } \\
1 \text { - Parcial } \\
2 \text { - Sim }\end{array}$ & \multirow[t]{2}{*}{$\begin{array}{c}\text { Binária (categórica): } \\
0 \text { - Capacidade de } \\
\text { Inovação sem destaque } \\
1 \text { - Capacidade de } \\
\text { Inovação Alta }\end{array}$} \\
\hline & & $\begin{array}{l}\text { Soluções } \\
\text { complementares } \\
\text { (produtos) }\end{array}$ & Seção IV, Item 2 & $\begin{array}{l}\text { Item adaptado de } \\
\text { Damanpour e } \\
\text { Gopalakrishnan, 2001; } \\
\text { Freel, 2005; Sawhney e } \\
\text { tal., 2006; Subramanian } \\
\text { e Nilakanta, } 1996\end{array}$ & $\begin{array}{l}0 \text { - Não } \\
1 \text { - Parcial } \\
2 \text { - Sim }\end{array}$ & \\
\hline
\end{tabular}

(continua) 
Tabela 5 - Variável latente dependente do modelo: códigos, itens, operacionalizações, referências e escalas (conclusão)

\begin{tabular}{|c|c|c|c|c|c|c|}
\hline \multirow{6}{*}{$\begin{array}{l}\text { Capacidade de } \\
\text { Inovação }\end{array}$} & \multirow{6}{*}{ CAP_INOV_DEP } & $\begin{array}{l}\text { Soluções } \\
\text { complementares } \\
\text { (serviços) }\end{array}$ & Seção IV, Item 3 & $\begin{array}{l}\text { Item adaptado de } \\
\text { Damanpour e } \\
\text { Gopalakrishnan, 2001; } \\
\text { Freel, 2005; Sawhney e } \\
\text { tal., 2006; Subramanian } \\
\text { e Nilakanta, } 1996\end{array}$ & $\begin{array}{l}0 \text { - Não } \\
1 \text { - Parcial } \\
2 \text { - Sim }\end{array}$ & \multirow{6}{*}{$\begin{array}{l}\text { Binária (categórica): } \\
0 \text { - Capacidade de } \\
\text { Inovação sem destaque } \\
1 \text { - Capacidade de } \\
\text { Inovação Alta }\end{array}$} \\
\hline & & $\begin{array}{l}\text { Sistema de produção } \\
\text { flexível }\end{array}$ & Seção IV, Item 4 & $\begin{array}{l}\text { Item adaptado de Freel, } \\
\text { 2005; OECD, 2005; } \\
\text { O'Regan et al., 2005; } \\
\text { Rogers, 1998; Sawhney } \\
\text { e tal., } 2006\end{array}$ & $\begin{array}{l}0 \text { - Não } \\
1 \text { - Parcial } \\
2 \text { - Sim }\end{array}$ & \\
\hline & & Inovações em processo & Seção IV, Item 5 & \begin{tabular}{|l|} 
Item adaptado de \\
Damanpour e \\
Gopalakrishnan, 2001; \\
Das e Joshi, 2007; \\
Department for \\
Business Innovation \& \\
Skills, 2014; Freel, 2005; \\
Hurley e Hult, 1998; \\
Sawhney e tal., 2006; \\
Subramanian e \\
Nilakanta, 1996; \\
Nystrom et al., 2002; \\
Wan et al., 2003; Yam et \\
al., 2010
\end{tabular} & $\begin{array}{l}0 \text { - Não } \\
1 \text { - Parcial } \\
2 \text { - Sim } \\
\end{array}$ & \\
\hline & & $\begin{array}{l}\text { Sistemas de gestão da } \\
\text { qualidade }\end{array}$ & Seção IV, Item 6 & $\begin{array}{l}\text { Item adaptado de } \\
\text { Becheikh et al., 2006; } \\
\text { OECD, 2005; O'Regan et } \\
\text { al., 2005; Sawhney e } \\
\text { tal., 2006 }\end{array}$ & $\begin{array}{l}0 \text { - Não } \\
1 \text { - Parcial } \\
2 \text { - Sim }\end{array}$ & \\
\hline & & $\begin{array}{l}\text { Identificação de novos } \\
\text { mercados }\end{array}$ & Seção IV, Item 7 & $\begin{array}{l}\text { Item adaptado de } \\
\text { Sawhney e tal., 2006; } \\
\text { Wang e Ahmed, 2004; } \\
\text { Wonglimpiyarat, 2010 }\end{array}$ & $\begin{array}{l}0 \text { - Não } \\
1 \text { - Parcial } \\
2 \text { - Sim }\end{array}$ & \\
\hline & & $\begin{array}{l}\text { Inserção em novos } \\
\text { mercados }\end{array}$ & Seção IV, Item 8 & $\begin{array}{l}\text { Item adaptado de } \\
\text { Sawhney e tal., 2006; } \\
\text { Wang e Ahmed, 2004; } \\
\text { Wonglimpiyarat, 2010 }\end{array}$ & $\begin{array}{l}0 \text { - Não } \\
1 \text { - Parcial } \\
2 \text { - Sim }\end{array}$ & \\
\hline
\end{tabular}

Autor: Elaboração própria.

Foram identificados 08 indicadores na revisão da literatura para compor o constructo capacidade de inovação. Assim como nos constructos referente às variáveis latentes independentes, os itens do constructo que mensura a capacidade de inovação são afirmações para a qual o entrevistado tem três opções de resposta, sendo elas: $0=$ Não; $1=$ Parcial; 2 = Sim. Com base nos valores obtidos para cada item, foi calculada uma média simples por empresa e a partir dessa pontuação foi realizado o processo de transformação da variável dependente em variável binária segundo descrito detalhadamente no tópico 4.4.3.2. 
O instrumento de coleta de dados apresentado foi desenhado com critérios de avaliação para orientar o(a) entrevistador(a) e com campos de evidências onde devem ser apontadas as provas tangíveis que amparam as respostas fornecidas pelos(as) entrevistados(as) conforme pode ser observado no Apêndice A. Buscou-se dessa forma, não só padronizar a intepretação das respostas, como também torna-la imparcial visando mitigar o viés de ambos entrevistados(as) e entrevistador(a) (FURMAN et al., 2002). Além disso, o questionário final também passou por um pré-teste, descrito em detalhe no tópico a seguir, em que foi avaliada a clareza das perguntas e o formato do questionário a fim de garantir a validade de conteúdo e revisar questões, formatos e escalas.

\subsubsection{Validade de Conteúdo e Pré-teste}

A validade de conteúdo está relacionada à clareza das perguntas e o formato do questionário. Para avaliar o instrumento de pesquisa, foi realizado um pré-teste que consiste em um teste inicial por meio da revisão das questões, formatos, escalas, e outros componentes do questionário visando reforçar a validade de conteúdo. O préteste foi conduzido em três etapas e abrangeu acadêmicos (colegas e professor), especialistas e empresários do público-alvo, conforme sugerido por Forza (2002), totalizando 09 pessoas. Todos participantes do pré-teste foram selecionados com base na conveniência por conhecerem o escopo do projeto de pesquisa.

Na primeira etapa, o pré-teste foi realizado com 03 acadêmicos sendo 01 professor, 01 doutorando e 01 mestrando. O questionário foi entregue aos participantes e foi solicitado que individualmente avaliassem se o instrumento permite atingir o objetivo do estudo, bem como comentários sobre a qualidade e interpretação das questões e clareza das instruções fornecidas ao entrevistador. A partir dos feedbacks recebidos, foram feitos ajustes mínimos nos textos de algumas afirmações. Foi também implementada a sugestão de atribuir exemplos de evidências a fim de contribuir para alinhamento da intepretação das respostas e estimular o entrevistado a resgatar e apresentar provas tangíveis (vide Apêndice A). 
Para a segunda etapa, foram convidados 03 especialistas, um de cada entidade a seguir: FIESP, CIESP e SENAI. Foi realizada uma apresentação do instrumento de pesquisa aos especialistas, seguida de um debate sobre a qualidade e interpretação das perguntas e o formato do instrumento de pesquisa. Com base nos comentários dos especialistas, foram realizados alguns ajustes de palavras de alguns itens.

Por fim, na terceira etapa, 03 empresas da amostra foram selecionadas aleatoriamente para realizar o pré-teste com o público-alvo. Os empresários foram entrevistados normalmente e durante a entrevista foram avaliados o tempo da entrevista, o entendimento das perguntas e a disponibilidade dos dados solicitados como evidências. Esse pré-teste serviu como piloto que permitiu o refinamento final do instrumento de coleta de dados e resultou na reordenação de alguns itens do questionário a fim de reduzir o tempo da entrevista. O tempo médio de entrevista foi reduzido de 6 para 4 horas. Ao final do pré-teste foi possível constatar que em geral as questões estavam claras e as respostas puderam ser interpretadas de forma objetiva e padronizada, sendo que o pré-teste permitiu identificar algumas oportunidades de melhoria marginais no instrumento de coleta reforçando a validade do questionário.

\subsection{Pesquisa de Campo}

A pesquisa de survey pode ser usada vantajosamente no exame de muitos temas sociais (BABBIE, 1999). No entanto, há certa dificuldade de se coletar dados em quantidade sobre a capacidade de inovação das empresas (CHO e PUCIK, 2005). Esse problema ocorre em parte pelo fato de que a inovação é um tema que não deve ser pesquisado à distância, como é frequentemente feito, uma vez que a distância do fenômeno prejudica a habilidade de análise do pesquisador (GATIGNON et al., 2002). Em uma pesquisa presencial, o entrevistador solicita informações diretamente ao respondente o que proporciona vantagens ${ }^{22}$ que aumentam a confiabilidade do processo de coleta de dados. Além disso, entrevistas in loco também proporcionam uma abordagem que permite

\footnotetext{
${ }^{22}$ Entre as vantagens da pesquisa presencial estão: flexibilidade no sequenciamento das questões, possibilidade de detalhamento e explicações de ambas as partes (entrevistador e respondente), facilidade de contactar populações de difícil acesso, altas taxas de resposta e aumento da confiabilidade de que as instruções para coleta de dados foram seguidas (FORZA, 2002).
} 
observar provas tangíveis de que a resposta a uma afirmação (item) seja válida o que consequentemente isenta a sensibilidade em relação ao julgamento do observador e minimiza o viés da opinião pessoal do respondente (BOLY et al., 2014).

Considerando as recomendações da literatura, a presente pesquisa adotou um survey interseccional em que os dados são colhidos in loco num determinado momento de uma amostra selecionada para determinar relações entre variáveis na época do estudo. A pesquisa de campo teve início com um agendamento de uma entrevista presencial com um representante da empresa que ocupasse pelo menos o nível gerencial e estivesse na empresa há no mínimo 03 anos, visto que muitas questões envolvem ocorrências que especificam esse período de tempo.

As entrevistas foram conduzidas por um entrevistador que inicialmente explicava o objetivo da pesquisa e apresentava um Termo de Confidencialidade para ser assinado entre as partes visando oferecer a garantia de sigilo das informações. Em seguida, o entrevistador alinhava com o respondente o conceito de inovação adotado no estudo. No caso foi considerada inovação o que é novo para a organização (OECD, 2005; VACCARO et al., 2012) para que o nível de análise seja a empresa e viabilize a pesquisa $^{23}$ (LIN et al., 2015). A partir dessa instrução, iniciava-se a coleta de dados de acordo com os itens do questionário. Cada resposta foi analisada segundo os critérios de avaliação para o entrevistador e eram solicitadas provas tangíveis (evidências) que corroborassem as respostas fornecidas. Ao final, o entrevistador comunicava o encerramento da entrevista, realizava o agradecimento e informava que o resultado seria entregue quando da conclusão da pesquisa, conforme previsto no protocolo da entrevista.

Dessa forma, foi possível garantir que todos os entrevistados ocupavam no mínimo cargo gerencial e estavam há mais de 03 anos na empresa. Além disso, todas as empresas agendadas foram visitadas e houve um aproveitamento de $100 \%$ das respostas (nenhum questionário apresentou campo sem preenchimento). Por fim, a qualidade das respostas foi assegurada por meio da obtenção de provas tangíveis (evidências) que

\footnotetext{
${ }^{23}$ Caso o conceito de inovação adotado fosse "novo para o mercado" seria difícil obter um tamanho de amostra suficiente para testar as hipóteses formuladas no estudo.
} 
mitigaram a subjetividade do entrevistador, bem como do respondente. Essas observações demonstram a força do método de coleta de dados baseado na entrevista pessoal (FORZA, 2002).

\subsection{Amostragem}

O presente tópico tem como objetivo especificar características da população e o procedimento da amostra adotada para aplicação da survey. A população dessa pesquisa é composta por PMEs no âmbito do estado de São Paulo. A amostra, por sua vez, é nãoprobabilística (ou amostra de conveniência) uma vez que os respondentes são participantes do projeto NAGI P\&G e escolhidos com base em sua conveniência. A amostra obtida foi de 80 empresas o que é suficiente para análises multivariadas, cujo tamanho mínimo da amostra deve ser de 30 observações. Amostras menores apresentam desvio significativo da normalidade e podem ocasionar impacto substancial nos resultados, sendo que o mesmo pode ocorrer com amostras superiores a 200 observações (HAIR et al, 2010).

Há sempre uma preocupação com amostras especiais como, por exemplo, as amostras de conveniência uma vez que podem causar um viés na análise. No entanto, para evitar a pesquisa à distância e viabilizar o método de coleta de dados por meio de entrevista presencial com uma quantidade minimamente adequada, optou-se pela oportunidade de adotar a amostra formada por participantes do projeto. Ainda assim, foi decidido checar a credibilidade da amostra disponível por meio da escala de Sudman (1983), Tabela 6. 
Tabela 6 - Escala de credibilidade para pequenas amostras

\begin{tabular}{|c|c|}
\hline Características & Pontuação \\
\hline Generalização e Dispersão & Local único (0); combinação de locais com geografia limitada (4); combinação de \\
\hline Geográfica & locais com geografia dispersa (6); universo total (10) \\
\hline Discussão de Limitações & Sem discussão (0); breve discussão (3); discussão detalhada (5) \\
\hline Uso de Amostras Especiais & $\begin{array}{l}\text { Amostra com viés óbvio que afete os resultados (-5); usado por conveniência sem } \\
\text { viés óbvio (0); necessário para testar teoria (5); população geral (5) }\end{array}$ \\
\hline Tamanho da Amostra & $\begin{array}{l}\text { Muito pequena para análise (0); adequada para algumas, mas não todas análises } \\
\text { (3); adequado para fins do estudo (5) }\end{array}$ \\
\hline Execução da Amostra & $\begin{array}{l}\text { Amostra casual (-3); baixa taxa de retorno (0); alguma evidência de trabalho de } \\
\text { campo sem rigor (3); taxa de retorno razoável e operação de campo controlada (5) }\end{array}$ \\
\hline Uso de Recursos & Pouco uso de recursos (0); Uso justo de recursos (3), ótimo uso de recursos (5) \\
\hline Intervalo da Pontuação & de -5 a 35 \\
\hline
\end{tabular}

Fonte: Elaboração própria.

De acordo com os critérios e pontuações dessa escala, uma nota no intervalo entre -5 e 5 equivale a uma credibilidade muito baixa da amostra. Uma pontuação entre 6 e 15 refere-se a uma credibilidade limitada. Já uma pontuação entre 16 e 25 indica uma boa credibilidade da amostra. E uma nota entre 26 e 35 classifica a credibilidade da amostra como sendo muito boa. Essas pontuações são atribuídas por meio de julgamentos qualitativos e não avaliações quantitativas e, portanto incorrem em certo grau de arbitrariedade, mas permitem discriminar de forma consistente entre diferentes níveis de credibilidade da amostra (FORZA, 2002).

Com base nos critérios da Tabela 6, foi possível atribuir uma pontuação total de 19 pontos para a amostra do presente estudo, uma vez que a pesquisa envolve uma combinação 09 núcleos (4 pontos), não foi feita discussão de limitações em virtude da amostra ( 0 pontos), foi realizada a partir de uma amostra por conveniência sem viés óbvio (0 pontos), com um tamanho de amostra adequado para fins de análise multivariada (5 pontos), uma taxa de retorno de $100 \%$ e operação de campo controlada (5 pontos) e ótima disponibilidade de recursos para realizar a pesquisa de campo (5 pontos). Dessa forma, pode-se afirmar que a amostra apresenta uma boa credibilidade.

Além da avaliação da credibilidade da amostra, também foi inserido intencionalmente na Seção II do questionário, o item 11 que tem como objetivo identificar o principal motivo da empresa para participar do projeto NAGI P\&G. Do total de participantes, 
94\% das empresas alegaram motivos não relacionados a problemas para inovar, sendo $81 \%$ relacionado a oportunidades de negócios. Tal fato proporciona um respaldo inicial de que a amostra não consiste apenas de empresas com problemas para inovar ou com baixa capacidade de inovação o que também poderia prejudicar a qualidade da amostra.

Com relação às características da amostra, foi realizada uma análise descritiva tanto dos respondentes, como das empresas. O perfil dos respondentes foi descrito com base nos dados coletados na Seção I do questionário. Já o perfil das empresas foi mapeado a partir das informações coletadas na Seção II do instrumento de pesquisa. O objetivo de analisar essas características foi o de compreender a amostra, identificar problemas com a mesma e usar os dados como base para tomada de decisão de eliminar eventuais outliers que apareçam nos testes da amostra.

No caso dos respondentes, é importante avaliar se os mesmos têm maturidade adequada para fornecer respostas precisas aos itens do questionário. Quanto maior o grau de maturidade do entrevistado, melhor ou mais qualificada espera-se que seja sua resposta. Entende-se como possíveis critérios para analisar maturidade, a posição que o respondente ocupa na empresa, seu grau de instrução e o tempo de empresa. Tendo em vista que o instrumento de coleta desenvolvido abordou temas complexos, diversificados e continha itens com um horizonte de tempo de 03 anos, é interessante e desejável que o(a) respondente tenha uma visão ampla da empresa, podendo ser o proprietário, o principal executivo, um diretor ou um gerente e que tenha completado no mínimo 03 anos de empresa. Espera-se também que um maior grau de instrução do entrevistado contribua para responder com propriedade a um questionário dessa natureza.

Conforme ilustra o Gráfico 2 a seguir, 100\% da amostra ocupa pelo menos um cargo gerencial. Desse total, 64\% dos respondentes é proprietário (único dono) ou sócio dirigente. Esses valores indicam um perfil de respondente capacitado para prover respostas adequadas aos itens do questionário. 

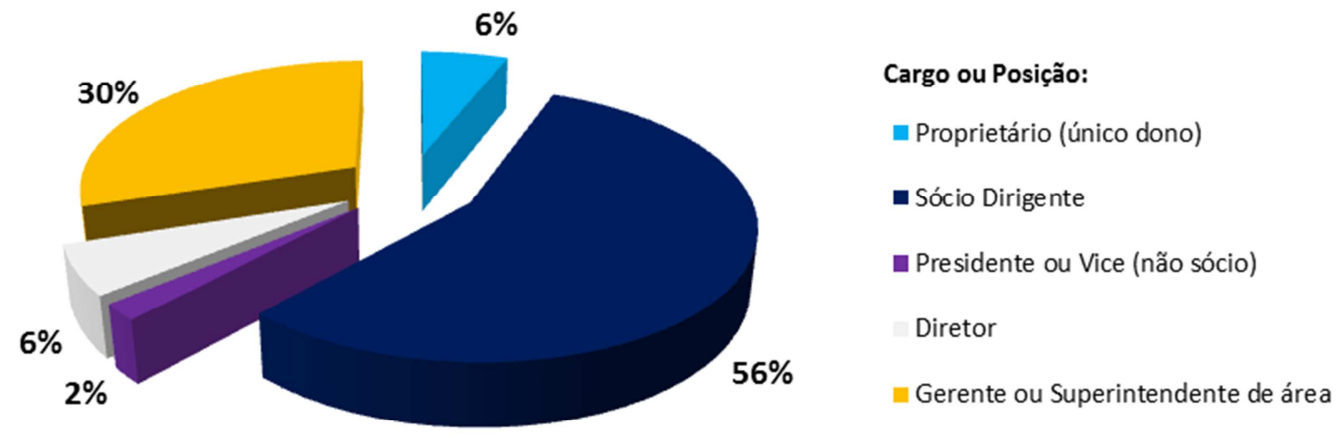

Autor: Elaboração Própria.

\section{Gráfico 2 - Distribuição dos respondentes por cargo que ocupa na empresa}

Ademais de ocuparem posições que lhes proporcionem uma visão ampla da empresa, 93\% dos entrevistados possuíam pelo menos curso superior completo, sendo que $33 \%$ concluíram MBA ou especialização, $10 \%$ mestrado stricto sensu, 1\% doutorado e $1 \%$ pós-doutorado. O grau de instrução dos respondentes também foi adequado para fins de aplicação do questionário, conforme pode ser observado na Tabela 7.

Tabela 7 - Grau de instrução dos respondentes

\begin{tabular}{lr}
\hline Grau de Instrução & Respondentes (em \%) \\
\hline Ensino & $1 \%$ \\
Superior incompleto & $6 \%$ \\
Superior completo & $48 \%$ \\
MBA/especialização & $33 \%$ \\
Mestrado & $10 \%$ \\
Doutorado & $1 \%$ \\
Pós-doutorado & $1 \%$ \\
\hline Total & $\mathbf{1 0 0 \%}$ \\
\hline
\end{tabular}

Fonte: Elaboração própria.

Vale ressaltar ainda que $100 \%$ da amostra tinham no mínimo 03 anos de permanência na empresa o que também é positivo para a qualidade das respostas. Ou seja, do ponto de vista da maturidade dos respondentes, não foram identificados problemas que pudessem comprometer os dados obtidos. 
A análise do perfil das empresas, por sua vez, é relevante para avaliar se houve um número apropriado de elementos de cada subconjunto refletindo uma proporção real de empresas, no caso, com relação ao porte (micro, pequena e média), ao setor (indústria, serviço, comércio ou mais de um setor) e localização (núcleos). Trata-se de um método que permite obter um maior grau de representatividade, reduzindo o provável erro amostral (BABBIE, 1999). Dessa forma, é possível mitigar viés da amostra, problema identificado como comum na literatura que contém pesquisas com amostra contendo maioria de micro empresas.

Ao final do processo, as 80 empresas que participaram do estudo apresentaram a distribuição segundo o porte (número de colaboradores) conforme exposto no Gráfico 3 a seguir.

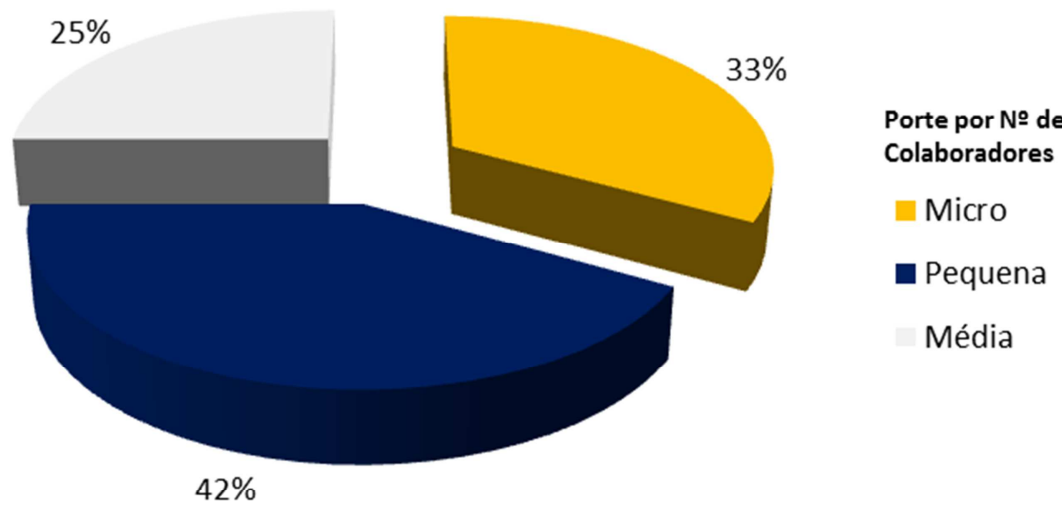

Autor: Elaboração Prórpia.

Gráfico 3 - Distribuição das empresas por porte (número de colaboradores)

A distribuição das empresas segundo o porte ficou equilibrada, com uma pequena predominância das empresas de pequeno porte de acordo com os dados apresentados no Gráfico 3 o que satisfaz a representatividade da amostra em termos de tamanho organizacional para fins do presente trabalho.

Quanto à proporção de empresas por setor de atividade (indústria, serviço, comércio e mais de um setor), foi elaborada a Tabela 8 para demonstrar a divisão da amostra segundo essa classificação. Como durante o pré-teste do questionário foi identificado 
que uma das empresas atuava tanto na indústria como no comércio sem predominância de um dos dois setores, optou-se pela inclusão da categoria "mais de 01 setor".

\section{Tabela 8 - Distribuição das empresas por setor de atuação}

\begin{tabular}{lc}
\hline Setor de Atividade & Distribuição (em \%) \\
\hline Indústria & $33 \%$ \\
Serviço & $31 \%$ \\
Comércio & $3 \%$ \\
Mais de 01 setor & $33 \%$ \\
\hline Total & $\mathbf{1 0 0 \%}$ \\
\hline
\end{tabular}

Autor: Elaboração própria.

Nota-se com base na Tabela 8 que a distribuição da amostra segundo o setor de atividade está equilibrada, exceto no caso do setor de comércio. No entanto, tendo em vista que as empresas classificadas no grupo "mais de um setor", compreendem em geral o setor de comércio como um dos setores de atuação (a título de exemplo, “indústria e comércio" ou "indústria serviço e comércio") é possível inferir que há uma representatividade satisfatória desse setor.

Vale ressaltar que a proporcionalidade mantém-se equilibrada, quando a distribuição é analisada desde a perspectiva que confronta o porte e o setor de atividade (vide Tabela 9) o que também é importante para mitigar viés da amostra.

Tabela 9 - Distribuição da amostra por porte e setor de atuação

\begin{tabular}{|c|c|c|c|c|c|}
\hline $\begin{array}{l}\text { Setor } \\
\text { Porte }\end{array}$ & Indústria & Serviço & Comércio & Mais de 01 Setor & Total Geral \\
\hline Micro & $6 \%$ & $15 \%$ & $1 \%$ & $11 \%$ & $33 \%$ \\
\hline Pequena & $16 \%$ & $10 \%$ & $1 \%$ & $15 \%$ & $42 \%$ \\
\hline Média & $11 \%$ & $6 \%$ & $1 \%$ & $7 \%$ & $25 \%$ \\
\hline Total Geral & $33 \%$ & $31 \%$ & $3 \%$ & $33 \%$ & $100 \%$ \\
\hline
\end{tabular}

Autor: Elaboração própria. 
Com relação ao segmento de atuação, a diversidade da amostra compreende mais de 30 segmentos. Alguns segmentos representados na amostra são: metal mecânico, refrigeração, materiais cerâmicos, industrialização de artefatos de borracha, molas e artefatos de arame, engenharia, construção, automação industrial, inspeção, entre outros.

Do ponto de vista da localização, a amostra apresenta uma dispersão geográfica no âmbito do estado de São Paulo, sendo que as empresas foram agrupadas em 09 núcleos, conforme distribuição apresentada na Tabela 10 a seguir. Os núcleos São Carlos e Vale do Paraíba estão subrepresentados, como pode ser observado na tabela, porém a diversidade de núcleos é suficiente para testar se a localização geográfica influencia a capacidade de inovação das empresas. Vale ressaltar ainda que em nível municipal, as empresas da amostra representam mais de 40 cidades.

Tabela 10 - Distribuição das empresas por núcleo (localização geográfica)

\begin{tabular}{lc}
\hline Núcleo & Distribuição (em \%) \\
\hline ABCD & $10 \%$ \\
Campinas & $18 \%$ \\
Mogi das Cruzes & $9 \%$ \\
Piracicaba & $9 \%$ \\
Ribeirão Preto & $11 \%$ \\
São Carlos & $1 \%$ \\
São Paulo/Santos & $25 \%$ \\
Sorocaba & $14 \%$ \\
Vale do Paraíba & $3 \%$ \\
\hline Total & $\mathbf{1 0 0 \%}$ \\
\hline
\end{tabular}

Autor: Elaboração própria.

Em uma primeira análise foi possível constatar a credibilidade da amostra e com base na descrição em termos do perfil dos respondentes e do perfil das empresas não foram identificados problemas que invalidem ou ocasionem impactos substanciais nos resultados da pesquisa. Dessa forma, infere-se que a amostra é adequada para fins do objetivo proposto para o presente estudo. 


\subsection{Análise dos Dados Coletados}

Este é um estudo quantitativo baseado no uso de fonte de dados primários coletados por meio de questionário aplicado em entrevistas presenciais com executivos seniores de empresas participantes do projeto NAGI P\&G. O presente tópico explica como foi realizado o processo de análise dos dados coletados e está dividido em três partes. A primeira parte diz respeito à identificação e tratamento de outliers. A análise de validade e confiabilidade é o tema da segunda parte. A terceira parte aborda os seguintes tópicos relacionados ao método de análise das relações entre variáveis: definição do objetivo do método de análise, desenho da pesquisa, análise de premissas, estimação e avaliação do fit do modelo, interpretação e análise dos resultados e por fim, a validação dos resultados obtidos.

Vale ressaltar ainda que foi dispensada a necessidade de conduzir uma análise de dados faltantes e de detecção de viés entre os primeiros e últimos respondentes, uma vez que o método de coleta de dados adotado permitiu garantir o preenchimento completo de $100 \%$ dos questionários e mitigou o risco de diferença na motivação entre primeiros e últimos respondentes por meio da padronização do processo de pesquisa. Avaliar a normalidade e linearidade dos dados também não foi necessário tendo em vista que a técnica de análise selecionada não requer essas premissas, conforme será explicado no item 4.4.3.3.

\subsubsection{Análise de Outliers}

Um outlier pode ser definido como uma observação que é substancialmente diferente das demais observações em uma ou mais características (variáveis) (HAIR et al., 2010). Esse valor extremo ou combinação única de valores pode influenciar o resultado de qualquer análise multivariada. Por esse motivo, faz-se mister identificar e tratar (reter ou eliminar) esse tipo de observação.

Para avaliar a existência de outliers, pode ser adotada uma perspectiva univariada, bivariada e multivariada, com base no número de variáveis consideradas. No caso do 
presente estudo, procedeu-se com os métodos de diagnóstico univariado e multivariado. Esses métodos em conjunto proporcionam perspectivas complementares das observações para o enquadramento correto como outliers (HAIR et al., 2010).

$\mathrm{Na}$ identificação univariada de outliers, foram avaliadas as distribuições das observações para cada variável da análise a fim de identificar casos que se enquadrassem fora dos limites (superior e inferior) das respectivas distribuições. Já na análise multivariada é necessária uma forma de medir objetivamente a posição multidimensional de cada observação em relação a um ponto comum. Para tanto, adotou-se a medida Mahalanobis $D^{2}$ com o objetivo de realizar a avaliação multivariada de cada observação com relação ao conjunto de variáveis. De acordo com a sugestão de Hair et al. (2010) os valores da medida $D^{2} / d f$ devem ter como valor limite 2,5 para amostras pequenas, que aplica-se ao presente caso que compreende 80 empresas.

Após realizar as análises univariada e multivariada, buscou-se identificar a fonte que causa essa condição única e enquadrar o outlier em uma das seguintes classes: erros no procedimento, eventos extraordinários, observações extraordinárias e combinações únicas de valores. A partir dessa análise, foi tomada a decisão de reter ou eliminar o outlier da amostra.

\subsubsection{Análise de Validade e Confiabilidade}

Resultados pobres de pesquisa nem sempre ocorrem devido a problemas de mensuração, mas não há dúvidas que a presença de erros de mensuração distorce as relações observadas e enfraquecem as técnicas multivariadas (HAIR et al., 2010). Por essa razão, deve-se sempre buscar aumentar a validade e a confiabilidade, que por sua vez proporcionam um retrato mais preciso das variáveis de interesse.

A validade é a extensão em que uma medida representa corretamente o conceito do estudo (OLLAIK e ZILLER, 2012). Nesse sentido, verificar a validade de uma pesquisa significa determinar a proporção com que um item mede o que pretende medir. Com a 
validade assegurada, analisa-se a confiabilidade das medições. A confiabilidade representa o grau que uma variável observada mede o verdadeiro valor e está livre de erro (HAIR et al., 2010). Dessa forma, medidas mais confiáveis apresentam maior consistência quando aplicadas repetidamente. Considerou-se para essa pesquisa avaliar tanto a sua validade quanto a confiabilidade.

Enquanto julgamento avaliativo integrado, a validade pode ser classificada em diversos tipos que se complementam (MESSICK, 1989). Cada tipo de validade implica em uma determinada forma de validação que pode ser qualitativa ou quantitativa (DEVELLIS, 2011). Há três tipos de validades consolidados na literatura: validade de conteúdo, validade de critérios e validade de constructo (ADCOCK e COLLIER, 2001). Até o presente tópico, foi conduzida e apresentada a validade de conteúdo (vide item 4.1.1) e como complemento, optou-se por auferir a validade de constructo.

A validade de constructo é, em geral, aferida por meio de técnica estatística e pode ser subdividida em validade convergente e discriminante. Nesse caso, a validade é testada por meio da análise fatorial que agrupa os itens que apresentam alta correlação entre si (validade convergente) enquanto assegura que as variáveis que não se correlacionam estejam em grupos diferentes (validade divergente). No entanto, não é adequado realizar a análise fatorial no presente estudo tendo em vista a sobreposição de conteúdo entre determinantes da capacidade de inovação (VALLADARES, 2012) que pode resultar em agrupamentos indesejados e diferentes do referencial teórico adotado como base.

Por conseguinte, para aprofundar a validade da pesquisa, optou-se pela validade teórica dos constructos. A validade teórica avalia em que medida o constructo teórico desenvolvido em uma pesquisa é passível de ser aplicado no contexto empírico e, portanto pode ser considerado crível e justificável conferindo legitimidade à aplicação de modelos ou teorias (MAXWELL, 1992). Para tanto, existem dois aspectos necessários para que seja conferida a validade teórica a um constructo: a validade dos conceitos empregados na construção teórica e a validade dos relacionamentos existentes entre estes conceitos. A análise desses aspectos frequentemente ocorre a partir de um framework teórico (HANNES et al., 2010). O presente trabalho adotou o modelo de 
análise contido no Quadro 1 a fim de validar quão bem os constructos e suas relações foram fundamentados.

\begin{tabular}{|l|l|}
\hline Critérios de Validação & \multicolumn{1}{|c|}{ Orientação para Validação } \\
\hline Plausibilidade & $\begin{array}{l}\text { Analisar a validade de face dos conceitos e modelo conceitual o que pode ser } \\
\text { demonstrado pela corroboração ou dedução com base em teorias e pesquisa } \\
\text { passadas ou ainda desenvolvida a partir de observação ou indução. }\end{array}$ \\
\hline Factibilidade & $\begin{array}{l}\text { Avaliar a capacidade de operacionalização dos conceitos e do modelo conceitual } \\
\text { do ponto de vista verbal, gráfico, matemático e ilustrativo. }\end{array}$ \\
\hline Efetividade & $\begin{array}{l}\text { Analisar a qualidade dos conceitos e do modelo conceitual em termos de } \\
\text { descrição do fenômeno sob estudo e de guia e estímulo para outras pesquisas } \\
\text { científicas. }\end{array}$ \\
\hline Pragmatismo & $\begin{array}{l}\text { Certificar se os conceitos e o modelo abrangem de forma ampla (sem restrição) } \\
\text { estruturas conceituais prévias e possuem certo grau de abstração, consistência } \\
\text { lógica ou coerência como outros conceitos ou modelos na disciplina. }\end{array}$ \\
\hline Empirismo & $\begin{array}{l}\text { Analisar se os conceitos e o modelo conceitual podem ser empiricamente } \\
\text { testados (observação direta, não só lógica) por meio da habilidade de coletar } \\
\text { dados empíricos para corrobora-los. }\end{array}$ \\
\hline Previsibilidade & $\begin{array}{l}\text { Avaliar a capacidade dos conceitos e do modelo de cobrir todo o espectro do } \\
\text { fenômeno observado e demonstrar que de acordo com certas condições } \\
\text { antecedentes, é esperada a ocorrência do fenômeno correspondente. }\end{array}$ \\
\hline Intersubjetividade & $\begin{array}{l}\text { Certificar que os conceitos e o modelo conceitual são objetivos podendo serem } \\
\text { testados por diferentes investigadores. }\end{array}$ \\
\hline Intermetodológico & $\begin{array}{l}\text { Analisar se investigadores utilizando diferentes metodologias de pesquisa } \\
\text { conseguem testar a veracidade dos conceitos e do modelo e prever a ocorrência } \\
\text { do mesmo fenômeno. }\end{array}$ \\
\hline
\end{tabular}

\section{Quadro 1 - Critérios e orientação para análise da validade teórica}

Fonte: Elaborado a partir de Khazanchi (1996).

Não há, portanto, um teste único que permita conferir a validade absoluta de uma pesquisa. Ressalta-se ainda que quanto mais processos de validação forem aplicados, maior é o potencial de um conceito ou modelo ser válido. As validações realizadas são adequadas às circunstâncias da pesquisa e satisfatórias para seus propósitos.

No caso da confiabilidade, trata-se de uma avaliação do grau de consistência entre diversas mensurações de uma variável (HAIR et al., 2010). Ou seja, quanto maior a consistência entre os valores para uma variável ou um conjunto de variáveis e o que se tem a intenção de medir, maior a confiabilidade. O coeficiente Alpha de Cronbach foi adotado como medida de confiabilidade e procedeu-se com uma análise desse coeficiente para avaliar a consistência da escala de todos os constructos do modelo a fim 
de contribuir para aumentar o grau de confiabilidade do mesmo. Segundo Hair et al. (2010), um coeficiente elevado indica a existência da consistência interna de um constructo, sendo que um valor igual ou superior à 0,7 sugere boa confiabilidade. No entanto, por convenção, um Alpha de Cronbach acima de 0,6 é tido com amplamente aceitável pela literatura e adequado para indicar a confiabilidade dos constructos contidos no presente estudo.

\subsubsection{Método de Análise das Relações entre Variáveis}

Em qualquer campo que busca a aplicação prática de conhecimento, se um problema não for tratado como multivariado, será tratado superficialmente (FORZA, 2002). Os métodos de análise multivariada permitem aos pesquisadores analisar simultaneamente múltiplas medidas sobre cada objeto de investigação (MALHOTRA, 2001). A regressão, por sua vez, é um método de análise com processo flexível e apropriado quando o problema de pesquisa envolve a compreensão das relações entre uma única variável dependente e duas ou mais variáveis independentes (HAIR et al., 2010) como é o caso da presente pesquisa.

Tendo em vista que o modelo proposto no presente estudo contém variáveis independentes métricas e não-métricas e uma variável latente dependente composta por itens com escala categórica, as técnicas de regressão multivariada adequadas para este estudo foram restringidas à uma única opção: regressão logística (logit). Além disso, a logit não possui restrições em relação a premissas tais como normalidade multivariada e matrizes de variância-covariância iguais entre grupos que são difíceis de cumprir em muitas situações e é muito mais robusta quando essas premissas não são cumpridas (HAIR et al., 2010). A logit é, ainda, preferida por muitos pesquisadores pelo fato de proporcionar uma análise similar à regressão múltipla no sentido de fornecer testes estatísticos diretos, abordagem similar para incorporar variáveis métricas e não-métricas e uma ampla variedade de diagnósticos.

A regressão logística com variável dependente binária é uma forma especializada de regressão adotada para prever e explicar uma variável categórica composta por dois 
grupos. Essa técnica estatística pode ser descrita como a estimativa das relações entre uma única variável categórica dependente e um conjunto de variáveis independentes métricas e não-métricas e sua forma geral pode ser expressada da seguinte maneira:

$$
\underset{\text { (não-métrica binária) }}{Y_{1}}=\begin{gathered}
X_{1}+X_{2}+X_{3}+\ldots . .+X_{n} \\
\text { (não-métricas e métricas) }
\end{gathered}
$$

Como na regressão múltipla, a variação na variável dependente representa uma relação multivariada única com coeficientes de regressão que indicam o impacto relativo de cada variável independente (preditora).

Sendo assim, trata-se de um estudo quantitativo no qual foi aplicada uma análise de regressão logística por meio do programa E-Views 7 a fim de testar as hipóteses constantes do modelo teórico proposto uma vez que essa técnica apresentou o fit mais adequado para identificar os determinantes da capacidade de inovação das PMEs. Para detalhar o método escolhido, o presente tópico foi dividido em 06 estágios conforme sugerido por Hair et al. (2010) para aplicação da regressão logística os quais foram consolidados no fluxo ilustrado na Figura 3.

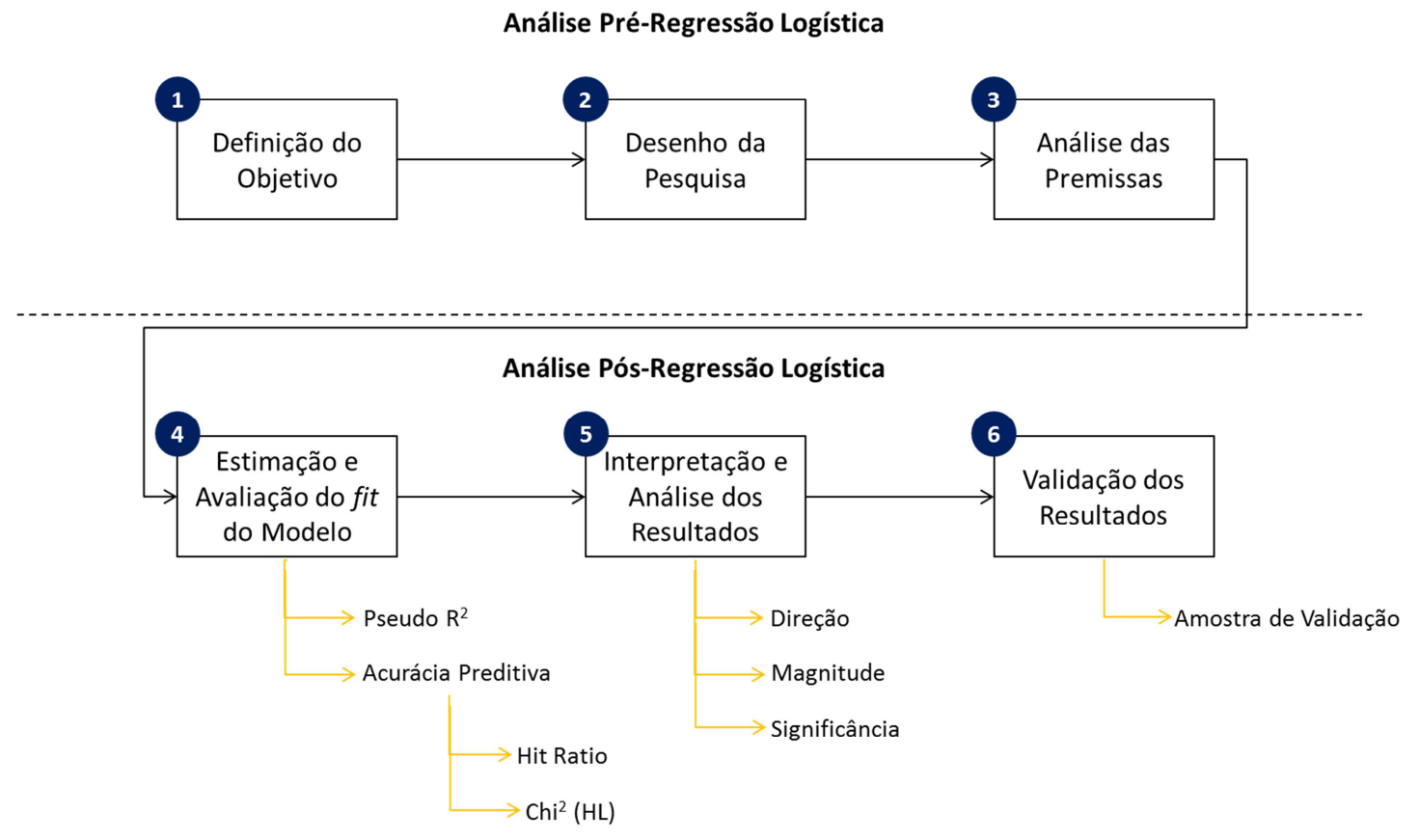

Figura 3 - Fluxo para aplicação da regressão logística

Fonte: Elaborado a partir de Hair et al. (2010). 


\subsubsection{Definição do Objetivo}

A regressão logística é uma técnica estatística apropriada para tratar dois objetivos básicos (HAIR et al., 2010). O primeiro objetivo é identificar as variáveis independentes que impactam no enquadramento do objeto (observação) em um dos dois grupos da variável dependente. Um segundo objetivo é o de criar um sistema de classificação baseado no modelo logístico para determinar (prever) a qual grupo um objeto fora da amostra pertence, o que requer que a observação reúna os dados para todas as variáveis independentes do modelo.

O objetivo da presente pesquisa está alinhado com o primeiro objetivo da técnica qual seja o de identificar as variáveis independentes selecionadas pelo pesquisador que causam impacto na variável dependente. A partir dessa análise é possível criar um modelo que contemple apenas variáveis que sejam capazes de determinar o enquadramento dos objetos em um dos grupos da variável dependente.

Dessa forma, a regressão logística foi aplicada para analisar a natureza e o grau de associação entre os determinantes da capacidade de inovação e a capacidade de inovação das PMEs a fim de identificar aquelas que causam impacto na capacidade de inovação das empresas com esse porte. Com base no resultado dessa análise, foi criado um modelo contendo os determinantes que explicam as diferenças no grau da capacidade de inovação das PMEs e sirva de referência para aquelas que queiram aprimorar sua capacidade de inovação.

\subsubsection{Desenho da Pesquisa}

O desenho de pesquisa para aplicação da análise de regressão logística deve tratar dois assuntos principais para contribuir para a robustez do modelo (HAIR et al., 2010). O primeiro assunto diz respeito à natureza única da variável dependente binária que afeta a especificação e estimação do modelo. Já o segundo assunto compreende o tamanho da amostra que impacta a técnica de estimação e a validação dos resultados obtidos. 
Com relação à natureza da variável dependente, a regressão logística adota uma abordagem que está limitada a prever apenas medida dependente binária, ou seja, uma variável dependente dividida em dois grupos de interesse. Os grupos são codificados com os valores 0 e 1 sendo que não importa a qual grupo é atribuído cada número desde que seja anotado para fins de interpretação dos coeficientes. Os grupos podem ser divididos em função de características, eventos, resultados, entre outros fatores. Tendo em vista que a variável dependente apresenta apenas os valores 0 e 1 , o valor previsto (probabilidade) tem que estar contido nesse intervalo o que implica na adoção da curva logística (curva S) para representar a relação entre as variáveis independente e dependente.

Devido à natureza binária requerida para a variável dependente, foi necessário transformar a variável latente capacidade de inovação em uma variável dicotômica e atribuir os valores 0 e 1 para cada grupo. Para tanto, esse processo de transformação da variável dependente em binária foi dividido em duas partes. Inicialmente foi calculada para cada empresa uma média simples dos itens que compõe o constructo capacidade de inovação. Em seguida as empresas foram divididas em dois grupos com base na pontuação individual obtida a partir da média simples que reflete a qualidade das empresas em termos de capacidade de inovação. Para empresas com pontuação menor ou igual a 1 foi atribuído o valor 0 e para empresas com pontuação maior que 1 foi designado o valor 1 .

A divisão dos grupos obedeceu ao valor limite que teve como referência objetiva a escala individual dos itens do constructo que apresentavam 3 pontos sendo eles 0 (não), 1 (parcial) e 2 (sim). $\mathrm{O}$ valor 0 indicava baixa capacidade de inovação, o valor 1 média capacidade de inovação e o valor 2 alta capacidade de inovação. Logo empresas com uma média simples menor ou igual a 1 foram enquadradas no grupo codificado com o valor 0 denominado "capacidade de inovação sem destaque". Já as empresas com pontuação acima de 1 foram classificadas no grupo com valor 1 nomeado "capacidade de inovação alta". Essa divisão resultou em um total de 52 empresas contidas no grupo 0 e 28 empresas no grupo 1. 
No caso do tamanho da amostra, examina-se o tamanho geral da amostra e tamanho da amostra por categoria da variável dependente. Com relação ao primeiro aspecto, as regressões em geral requerem um tamanho mínimo de amostra com 30 casos, porém recomenda-se uma amostra maior para realizar a regressão logística (HAIR et al., 2010). Em parte, essa exigência decorre do fato de que há o costume de dividir a amostra total em uma amostra para análise e uma amostra de validação (holdout) para testar com a segunda amostra, o modelo gerado a partir da primeira a fim de validar o resultado final. Para o segundo aspecto, espera-se um número mínimo de 10 observações para cada grupo por parâmetro estimado.

Conforme descrito no item 4.3, a amostra do presente estudo é composta por 80 empresas. Ainda no referido item, foi realizado o detalhamento das características dessa amostra que apresentou equilibrou em termos de porte, setor e localização geográfica. Entre as sugestões de Hair et al. (2010) para trabalhos com amostras pequenas, há a opção de aplicar a regressão logística na amostra total, no caso de 80 empresas, e realizar um teste alternativo à amostra de validação denominado teste jackknife baseado no princípio leave-one-out que não requer a divisão da amostra total para validação do resultado final.

Tendo em vista que as análises prévias à estimação do modelo (teste de igualdade das médias por parâmetro e regressão logística por variável independente) descritas no item 4.4.3.3 a seguir permitiram identificar variáveis independentes que puderam ser dispensadas de inclusão no modelo, o que reduziu o número de parâmetros presentes no mesmo, tornou-se possível adotar o teste com amostra de validação. Dessa forma, optou-se na presente pesquisa pela realização do teste com amostra de validação que implicou na divisão da amostra total em uma amostra de análise com 60\% dos casos (48 empresas) e uma amostra de validação com os demais $40 \%$ dos casos (32 empresas).

Ainda que esse procedimento tenha implicado na divisão da amostra total em duas amostras menores, procedeu-se dessa maneira uma vez que o teste de validação com uma amostra separada da amostra de análise confere maior credibilidade ao modelo e proporciona com maior segurança a possibilidade de generalização do modelo. Segundo 
Hair et al. (2010), o processo de validação adequado compensa problemas com amostras menores. Além disso, o fato de a regressão logística ser menos afetada que as demais técnicas quando premissas básicas como tamanho da amostra não são respeitadas (HAIR et al., 2010) também contribuiu para a decisão de trabalhar com uma amostra de análise menor aliada ao teste com amostra de validação, em detrimento à opção de trabalhar com amostra maior e adotar o teste de validação jackknife.

\subsubsection{Análise das Premissas}

A falta geral de premissas requeridas para aplicação da regressão logística configura-se em uma das suas principais vantagens. Essa técnica não requer nenhuma forma de distribuição específica para as variáveis independentes, nem a análise de assuntos relacionados à heterocedasticidade. A regressão logística tampouco prescinde de relações lineares entre variáveis independentes e variável dependente. Em virtude desses motivos, não foram incluídos na metodologia de pesquisa testes para as variáveis com o propósito de verificar normalidade, homocedasticidade e linearidade.

\subsubsection{Estimação e Avaliação do fit do Modelo}

A regressão adotada no presente estudo usa a relação logística baseada na curva logística (com formato de $\mathrm{S}$ ) com intervalo entre 0 e 1 para estimar tanto o modelo logístico, como estabelecer as relações entre a variável dependente e as variáveis independentes. A estimação do modelo de regressão logística ocorre por meio da adequação da curva de valores previstos para as observações à curva de dados reais, sendo que os valores previstos correspondem a 0 ou 1 e são resultados da probabilidade baseada nos valores das variáveis independentes e nos coeficientes estimados. De acordo com esse método de estimação, a regressão logística proporciona uma abordagem para avaliar o fit geral do modelo a partir de medidas similares ao $\mathrm{R}^{2} \mathrm{e}$ medidas de acurácia preditiva (HAIR et al., 2010). 
Entre as principais medidas de pseudo $\mathrm{R}^{2}$ desenvolvidas e indicadas na literatura estão Cox e Snell, Nagelkerke e McFadden. A medida de Nagelkerke é, em verdade, uma modificação (correção) da medida de Cox e Snell que não atingia o valor máximo de 1. Em todos os casos, maiores valores de pseudo $\mathrm{R}^{2}$ indicam melhor adequação do modelo, sendo que o valor 1 representa o fit perfeito do modelo. Apesar de não haver um consenso sobre qual a melhor medida para o poder preditivo, McFadden é a medida para pseudo $\mathrm{R}^{2}$ que melhor satisfaz os critérios para um bom $\mathrm{R}^{2}$ (MENARD, 2000). A título de parâmetro, valores de McFadden entre 0,2 e 0,4 são considerados muito bons em termos de fit do modelo e quanto maior o valor, melhor o ajuste (LOUVIERE et al., 2003) equivalendo o intervalo de 0,7 a 0,9 para uma função linear (DOMENCICH e MCFADDEN, 1975). Dessa forma, McFadden foi a medida de pseudo $\mathrm{R}^{2}$ adotada para o presente estudo.

Com relação à acurácia preditiva, uma abordagem comum é a matriz de classificação. A matriz de classificação mensura o nível de precisão da estimativa por meio da medida de hit ratio (taxa de sucesso) do resultado da aplicação do modelo. Dessa forma, a matriz apresenta um percentual geral de casos corretamente classificados, bem como um percentual de acerto no nível dos grupos, no caso grupo 0 (verdadeiro positivo) e grupo 1 (verdadeiro negativo). A qualidade da acurácia preditiva do modelo depende da melhora da taxa de acerto do modelo estimado em relação à taxa de acerto do modelo inicial (modelo nulo) o qual considera apenas a constante. Além de analisar a melhora no percentual geral dos casos corretamente classificados com base no modelo estimado, deve-se verificar também se ambas as taxas de sucesso por grupo são altas.

Outra medida amplamente adotada para avaliar a validade preditiva do modelo de regressão são as medidas de fit baseadas no chi-quadrado. O teste Hosmer-Lemeshow é um teste de classificação que implica na divisão dos casos em aproximadamente 10 classes iguais e posterior comparação do número de eventos reais e previstos por cada classe com base na estatística chi-quadrado. A hipótese nula é de que o modelo estimado é adequado e, portanto p-valores entre 0,7 e 0,8 já são aceitáveis para não rejeitar a hipótese nula (HOSMER E LEMESHOW, 2000). 
Seguindo a orientação de Hair et al. (2010), um pesquisador deve examinar tantas medidas de avaliação do fit do modelo quanto possível. Nesse sentido, também foram analisados na presente pesquisa a matriz de classificação e o teste Hosmer-Lemeshow como complemento à medida pseudo $\mathrm{R}^{2}$ a fim de avaliar o fit do modelo estimado. Com base nessas três medidas adotadas nesse estudo, buscou-se demonstrar a convergência dos indicadores o que permite inferir que o modelo estimado apresenta níveis aceitáveis de significância estatística e prática.

Antes de iniciar a estimação do modelo, foi realizada com base na amostra de análise de 48 empresas um stepwise que compreendeu a exploração individual das variáveis independentes com o objetivo de avaliar os resultados univariados em termos de capacidade de diferenciação entre os dois grupos. Conforme sugerido por Hair et al. (2010), procedeu-se com um teste de igualdade de médias para as variáveis métricas o qual indicou que 04 variáveis apresentaram nível de significância abaixo de $0,05^{24}$ que permite rejeitar a hipótese nula de igualdade das médias, ou seja, essas variáveis distinguem os grupos de forma significativa. Como reforço ao resultado desse teste, optou-se também pela execução da regressão logística para cada uma das 15 variáveis. A regressão também indicou que apenas as mesmas 04 variáveis apresentaram coeficientes com nível de significância abaixo de 0,05 e consequentemente as demais variáveis independentes não apresentaram correlação com a variável dependente. $\mathrm{O}$ resultado dessa análise foi adotado como ponto de partida para iniciar o processo de estimação do modelo logístico.

O processo de estimação para a amostra de análise teve início com um modelo nulo também denominado baseline o qual é calculado apenas com uma constante e sem a adição de nenhuma variável independente. Esse modelo nulo apresenta uma taxa de sucesso que serve como referência para avaliar o incremento na taxa de sucesso proporcionado pelo modelo estimado. Dessa forma, espera-se que o modelo de regressão logística irá ser mais assertivo na classificação das empresas do que o percentual de acerto apresentado no modelo nulo.

\footnotetext{
${ }^{24}$ Por convenção o nível de significância de 0,05 (5\%) é utilizado como limite de significância.
} 
Em seguida, foi rodado um modelo com a entrada forçada das 04 variáveis identificadas no teste de igualdade das médias, bem como na regressão logística individual. A partir dos resultados desse modelo, foram analisadas as medidas do pseudo $\mathrm{R}^{2}$, da matriz de classificação e do teste Hosmer-Lemeshow de acordo com os parâmetros especificados anteriormente no presente tópico. O modelo gerado a partir das 04 variáveis cumpriu todas as medidas, sendo que todos os coeficientes individuais apresentaram nível de significância abaixo de 0,05 . Havia a possibilidade de restringir o modelo por meio da eliminação de variáveis, porém a omissão de variáveis relevantes pode resultar no viés da análise (WOOLDRIDGE, 2007). O modelo final compreendeu, portanto, quatro variáveis as quais foram interpretadas e analisadas de acordo com o disposto no tópico a seguir.

\subsubsection{Interpretação e Análise dos Resultados}

O modelo de regressão logística resulta em coeficientes para as variáveis independentes. Os coeficientes são medidas difíceis de interpretar em sua forma original haja vista serem expressos em termos logarítmicos. Dessa forma, muitos programas de computador também proporcionam um coeficiente logístico exponencializado que é a transformação (antilog) do coeficiente logístico original. Os resultados podem ser interpretados a partir de qualquer um dos dois coeficientes, mas é importante ressaltar que eles diferem na forma em que refletem a relação da variável independente com a variável dependente. O coeficiente original reflete mudança no log das probabilidades e o coeficiente exponencializado por sua vez reflete mudança na probabilidade em si.

A interpretação dos coeficientes deve ser realizada do ponto de vista de direção e magnitude (HAIR et al., 2010). A direção indica se a relação entre a variável independente e a variável dependente é positiva ou negativa. Uma relação positiva significa que o aumento da variável independente está associado a um aumento na probabilidade preditiva e vice versa no caso da relação negativa. A interpretação da direção pode ocorrer a partir do sinal do coeficiente original, ou seja, sinal positivo indica relação positiva e sinal negativo corresponde a uma relação negativa. No caso do coeficiente exponencializado, o mesmo não possui valor negativo o que exige outra 
forma de interpretação. Para a análise da direção a partir de coeficiente exponencializado deve considerar-se o valor do coeficiente, sendo que coeficiente maior que 1 significa probabilidade positiva e menor que 1 indica probabilidade negativa. Segundo Hair et al. (2010) o coeficiente original é mais apropriado para interpretar a direção da relação entre as variáveis dependente e independente.

Já a magnitude da relação entre a variável independente e a variável dependente referese ao impacto na probabilidade da empresa pertencer a um grupo em relação ao outro da variável dependente, dada uma mudança em uma unidade da variável independente. De acordo com Hair et al. (2010) o coeficiente logístico original é menos útil para interpretar a magnitude dessa relação. Segundo o autor, a melhor opção para medir esse impacto é o coeficiente logístico exponencializado que reflete diretamente a razão (proporção) da chance ${ }^{25}$, sendo a razão da chance representada pela seguinte fórmula:

\begin{tabular}{|c|c|c|c|}
\hline \multirow{4}{*}{ Razão da Chance } & \multirow{2}{*}{ Chance $_{\text {ponto } a+1}$} & Probabilidade (grupo 1$)_{\text {ponto } a+1}$ & Probabilidade (grupo 1$)_{\text {ponto } a+1}$ \\
\hline & & Probabilidade (grupo 0$)_{\text {ponto } a+1}$ & $(1 \text { - Probabilidade (grupo1) })_{\text {ponta } a+1}$ \\
\hline & \multirow{2}{*}{ Chance $_{\text {ponto a }}$} & Probabilidade (grupo 1) ponto a & Probabilidade (grupo 1) ponta a \\
\hline & & Probabilidade (grupo 0$)_{\text {ponto a }}$ & (1 - Probabilidade (grupo1) $)_{\text {ponta } a}$ \\
\hline
\end{tabular}

Com base no valor do coeficiente exponencializado, que representa a razão da chance, é possível calcular o percentual de mudança no valor da chance de acordo com a seguinte fórmula:

\section{Percentual de Mudança na Chance $=$ (Coeficiente Exponencializado $-1,0) \times 100$}

Dessa forma, o coeficiente exponencializado das variáveis independentes métricas torna possível identificar o percentual de mudança na chance o qual permite inferir que a cada aumento de uma unidade da variável independente, há um aumento na chance, determinado pelo valor percentual de mudança estimado a partir do coeficiente exponencializado, da empresa ser considerada do grupo 1 em relação ao grupo 0. No caso das variáveis independentes não-métricas coeficiente exponencializado representa

\footnotetext{
${ }^{25} \mathrm{O}$ termo chance foi adotado na presente pesquisa como tradução para a palavra "odds" e a razão da
} chance equivale à tradução de "odds ratio". 
diretamente o nível relativo da variável dependente para o grupo representado em relação ao grupo omitido.

Com base no exposto, a intepretação e análise dos resultados teve início com a identificação da direção de cada uma das 04 variáveis independentes que apresentaram nível de significância abaixo de 0,05 e, portanto foram incluídas no modelo estimado. A direção foi analisada por meio do sinal do coeficiente original de cada variável independente. Em seguida, a magnitude das relações foi avaliada por meio do cálculo do coeficiente exponencializado que consiste no método mais direto para esse exame.

\subsubsection{Validação dos Resultados}

Apesar da regressão logística não ser tão suscetível ao overfit do resultado como outras técnicas, o processo de validação é essencial em especial no caso de amostras pequenas (HAIR et al., 2010). Para realizar a validação do resultado, estão disponíveis técnicas de validação cruzada que consistem no particionamento do conjunto de dados em subconjuntos mutuamente exclusivos a fim de estimar os parâmetros do modelo com alguns subconjuntos e validar o modelo com os demais. Dessa forma, a validação cruzada avalia a precisão de um modelo por meio do seu desempenho para um novo conjunto de dados o que permite inferir a capacidade de generalização do modelo.

Entre as principais técnicas de validação cruzada estão: o método de amostra de validação (holdout), bootstrapping, k-fold e leave-one-out. O método de amostra de validação implica na divisão da amostra em dois subconjuntos mutuamente exclusivos, sendo que um é utilizado para análise (estimar os parâmetros) e o outro para teste do modelo resultante da análise. Uma proporção comum entre os subconjuntos é considerar 2/3 da amostra para análise e 1/3 restante para teste (KOHAVI, 1995). As demais técnicas aplicam o teste de validade utilizando múltiplos subconjuntos por meio de variações nas técnicas de reamostragem de subconjuntos da amostra disponível. Essas técnicas utilizam o procedimento que processa repetidamente a amostra estimada e, em geral, são indicadas para situações em que há poucos dados disponíveis. 
O método para estabelecer a validação dos resultados da análise do presente estudo foi o da amostra de validação (holdout). A opção escolhida tem como justificativa o fato de essa técnica proporcionar maior robustez ao resultado uma vez que avalia o nível de acurácia preditiva do modelo logístico por meio de uma amostra separada daquela que foi utilizada no processo de estimação. Ainda que esse teste seja mais adequado para situações em que haja maior disponibilidade de dados, o desenho da pesquisa permitiu separar aleatoriamente o conjunto total de dados em uma amostra de análise com $60 \%$ dos casos (48 empresas) e uma amostra de validação com 40\% dos casos (32 empresas) sem impactar de forma significativa no cumprimento das premissas para aplicação da técnica de regressão logística.

Dessa forma, a abordagem para validação dos resultados por meio do método holdout envolveu a construção da matriz de classificação para a amostra de validação com base no modelo logístico estimado. Em seguida, foi realizada a avaliação das taxas de sucesso obtidas para essa amostra de validação em relação às taxas do modelo nulo, bem como do modelo estimado. A validade é reforçada quando as taxas de sucesso da matriz de classificação excederem os padrões de comparação que representam o modelo nulo e forem similares às taxas de sucesso resultantes do modelo estimado (HAIR et al., 2010). 


\section{APRESENTAÇÃO E ANÁLISE DOS RESULTADOS}

O presente capítulo tem como objetivo apresentar e analisar os resultados obtidos por meio da execução dos procedimentos metodológicos descritos no capítulo anterior e está estruturado em três blocos. O primeiro bloco compreende a apresentação e análise de todas as etapas do processo de construção do modelo. Já o segundo bloco contempla a interpretação e análise das variáveis incluídas no modelo estimado. Por fim, o terceiro bloco contém a análise das variáveis que foram excluídas do modelo logístico.

\subsection{Construção do Modelo de Regressão Logística}

O processo de construção do modelo de regressão logística foi executado conforme a sequência de etapas descrita no capítulo 4. Tendo em vista que não foram detectados outliers, a amostra de 80 empresas foi dividida aleatoriamente em 2 partes, sendo que a amostra de análise ou treinamento compreende 48 empresas (60\% dos casos) e a amostra de validação ou holdout contém as demais 32 empresas (40\% dos casos). O objetivo do presente tópico é construir um modelo que explique por meio das variáveis independentes a classificação das empresas em um dos grupos ${ }^{26}$ da variável dependente (CAP_INOV_DEP), ou seja, um modelo com os determinantes da capacidade de inovação das PMEs.

O tópico está dividido em cinco partes, sendo que a primeira compreende o resultado da análise prévia no nível individual das variáveis por meio do teste de igualdade de médias. A segunda parte apresenta o resultado e a análise da regressão logística por variável independente como complemento ao teste de igualdade de médias descrito no item anterior. A terceira parte, por sua vez, contém a descrição e análise da estimação do modelo nulo. A quarta parte aborda o resultado e a análise do modelo estimado. A quinta parte contempla, por fim, o resultado do teste de validação do modelo final.

\footnotetext{
${ }^{26}$ O grupo 0 representa o grupo de empresas com capacidade de inovação sem destaque e o grupo 1 representa o grupo de empresas com capacidade de inovação alta.
} 
5.1.1 Resultado e Análise do Teste de Igualdade de Médias

De acordo com o previsto no item 4.4.3.4, foi realizado um procedimento de stepwise por meio do teste de igualdade de médias que precedeu o início do processo de estimação do modelo logístico. O referido teste foi executado para as 8 variáveis métricas identificadas na literatura com base na amostra de validação e apresenta-se o resultado na Tabela 11 a seguir.

Tabela 11 - Teste de igualdade de médias para a amostra de validação

\begin{tabular}{|c|c|c|c|c|}
\hline \multirow[b]{2}{*}{ Variáveis Independentes } & \multicolumn{2}{|c|}{ Média: } & \multirow[b]{2}{*}{ T-Valor } & \multirow[b]{2}{*}{ Significância } \\
\hline & $\begin{array}{c}\text { Grupo } 0 \\
(n=30)\end{array}$ & $\begin{array}{c}\text { Grupo } 1 \\
(n=18)\end{array}$ & & \\
\hline INVEST_MAQ & 0,008 & 0,004 & 1,215 & 0,231 \\
\hline TEMP_EXIST & 23,283 & 23,944 & $-0,145$ & 0,886 \\
\hline CULT_ORG & 6,104 & 6,354 & $-0,472$ & 0,639 \\
\hline GEST_PROJ & 0,389 & 1,389 & $-2,794$ & 0,008 \\
\hline CONHEC_INT & 5,083 & 7,431 & $-2,915$ & 0,005 \\
\hline ESTRAT & 1,542 & 3,611 & $-3,063$ & 0,004 \\
\hline ORIENT_MERC & 3,810 & 3,849 & $-0,053$ & 0,958 \\
\hline CONHEC_EXT & 3,190 & 4,603 & $-2,824$ & 0,007 \\
\hline
\end{tabular}

Ao examinar as diferenças entre os dois grupos com relação as 8 variáveis (vide Tabela 11) foi possível identificar que 4 variáveis (GEST_PROJ, CONHEC_INT, ESTRAT e CONHEC_EXT) apresentaram diferenças estatísticas significantes (abaixo de 0,05) entre os dois grupos. Essas 4 variáveis foram candidatas lógicas para compor o modelo de regressão logística por demonstrarem as maiores diferenças entre os grupos.

5.1.2 Resultado e Análise da Regressão Logística por Variável Independente

Como complemento ao teste de igualdade das médias apresentado no item anterior, foi realizada uma análise de regressão logística para cada uma das 15 variáveis independentes em relação à variável dependente. O resultado dessa regressão logística individual foi consolidado na Tabela 12. 
Tabela 12 - Análise de regressão logística por variável para a amostra de validação

\begin{tabular}{|c|c|c|c|c|}
\hline & Coeficiente & & & \\
\hline Variáveis Independentes & (Original) & Erro Padrão & Estatística Z & Significância \\
\hline \multicolumn{5}{|l|}{ Métricas } \\
\hline INVEST_MAQ & $-37,838$ & 33,132 & $-1,142$ & 0,253 \\
\hline TEMP_EXIST & 0,003 & 0,020 & 0,148 & 0,883 \\
\hline CULT_ORG & 0,083 & 0,174 & 0,480 & 0,631 \\
\hline GEST_PROJ & 0,703 & 0,304 & 2,313 & 0,021 \\
\hline CONHEC_INT & 0,341 & 0,134 & 2,548 & 0,011 \\
\hline ESTRAT & 0,384 & 0,147 & 2,615 & 0,009 \\
\hline ORIENT_MERC & 0,006 & 0,120 & 0,054 & 0,957 \\
\hline CONHEC_EXT & 0,508 & 0,205 & 2,482 & 0,013 \\
\hline \multicolumn{5}{|l|}{ Não-métricas } \\
\hline \multicolumn{5}{|l|}{ AP_GOV } \\
\hline AP_GOV_0* & - & - & - & - \\
\hline AP_GOV_1 & 0,560 & 1,048 & 0,534 & 0,593 \\
\hline AP_GOV_2** & - & - & - & - \\
\hline \multicolumn{5}{|l|}{ ATIV_P\&D } \\
\hline ATIV_P\&D_0* & - & - & - & - \\
\hline ATIV_P\&D_1 & 1,242 & 0,805 & 1,543 & 0,123 \\
\hline ATIV_P\&D_2** & - & - & - & - \\
\hline \multicolumn{5}{|l|}{ COMUNIC_INT } \\
\hline COMUNIC_INT_0* & - & - & - & - \\
\hline COMUNIC_INT_1 & 1,179 & 0,997 & 1,182 & 0,237 \\
\hline COMUNIC_INT_2 & 1,386 & 0,755 & 1,835 & 0,066 \\
\hline \multicolumn{5}{|l|}{ DISP_REC_INT } \\
\hline DISP_REC_INT_1 & $-2,197$ & 1,173 & $-1,874$ & 0,061 \\
\hline DISP_REC_INT_2 & 0,383 & 0,695 & 0,551 & 0,581 \\
\hline DISP_REC_INT_3* & - & - & - & - \\
\hline DISP_REC_INT_4** & - & - & - & - \\
\hline DISP_REC_INT_5** & - & - & - & - \\
\hline \multicolumn{5}{|l|}{ ESTRUT_ORG } \\
\hline ESTRUT_ORG_0* & - & - & - & - \\
\hline ESTRUT_ORG_1 & 0,442 & 0,664 & 0,665 & 0,506 \\
\hline ESTRUT_ORG_2 & 0,182 & 0,849 & 0,215 & 0,830 \\
\hline \multicolumn{5}{|l|}{ LOCALIZ_GEO } \\
\hline LOCALIZ_GEO_1* & - & - & - & - \\
\hline LOCALIZ_GEO_2 & $-1,792$ & 1,443 & $-1,241$ & 0,214 \\
\hline LOCALIZ_GEO_3 & $-1,792$ & 1,443 & $-1,241$ & 0,214 \\
\hline LOCALIZ_GEO_4 & $-2,015$ & 1,426 & $-1,413$ & 0,158 \\
\hline LOCALIZ_GEO_5 & 0,511 & 1,238 & 0,413 & 0,680 \\
\hline LOCALIZ_GEO_6** & - & - & - & - \\
\hline LOCALIZ_GEO_7 & $-0,560$ & 1,069 & $-0,523$ & 0,601 \\
\hline LOCALIZ_GEO_8 & $-2,197$ & 1,414 & $-1,554$ & 0,120 \\
\hline LOCALIZ_GEO_9** & - & - & - & - \\
\hline \multicolumn{5}{|l|}{ TAM_ORG } \\
\hline TAM_ORG_1 & $-1,705$ & 1,211 & $-1,408$ & 0,159 \\
\hline TAM_ORG_2 & 0,860 & 0,737 & 1,168 & 0,243 \\
\hline TAM_ORG_3* & - & - & - & - \\
\hline TAM_ORG_4** & - & - & - & - \\
\hline
\end{tabular}


Com base nos coeficientes originais expostos na Tabela 12, pode-se inferir que apenas as mesmas 4 variáveis (GEST_PROJ, CONHEC_INT, ESTRAT e CONHEC_EXT) que foram significantes no teste de igualdade de médias, também apresentaram coeficientes originais com nível de significância abaixo de 0,05 na regressão logística binária por variável independente ${ }^{27}$. Esse resultado reforça as variáveis independentes que devem ser inicialmente incluídas no modelo logístico.

\subsubsection{Resultado e Análise do Modelo Nulo}

O modelo nulo foi estimado a partir dos dados da amostra de validação e contendo apenas uma constante, ou seja, nenhuma variável independente foi incluída no modelo. O resultado da estimação do modelo nulo pode ser observado na Tabela 13.

Tabela 13 - Precisão da estimação do modelo nulo MATRIZ DE CLASSIFICAÇÃOO $0^{a, b}$

\begin{tabular}{|c|c|c|c|}
\hline \multirow[b]{3}{*}{ Observado (real) } & \multicolumn{3}{|c|}{ Previsto } \\
\hline & \multicolumn{2}{|c|}{ CAP_INOV_DEP } & \multirow[b]{2}{*}{$\begin{array}{c}\text { Porcentagem } \\
\text { Correta }\end{array}$} \\
\hline & $\begin{array}{c}\text { Grupo } 0 \\
(n=30)\end{array}$ & $\begin{array}{c}\text { Grupo } 1 \\
(n=18)\end{array}$ & \\
\hline Capacidade de Inovação sem Destaque (Grupo 0) & 30 & 18 & $100 \%$ \\
\hline Capacidade de Inovação Alta (Grupo 1) & 0 & 0 & $0 \%$ \\
\hline Porcentagem Geral & & & $62,5 \%$ \\
\hline
\end{tabular}

Tendo em vista que a amostra de validação é composta por 62,5\% de empresas com capacidade de inovação sem destaque, se arbitrariamente todas as empresas fossem consideradas com capacidade de inovação sem destaque, a taxa de sucesso corresponde a exatamente esse percentual. O modelo de regressão logística estimado com as

\footnotetext{
${ }^{27}$ As variáveis independentes categóricas precisam que uma de suas categorias seja adotada como base. Não há nenhuma exigência para que uma categoria específica seja considerada base. Alguns programas adotam uma categoria como base de forma automática (por exemplo, por ordem alfabética). Já outros programas permitem que o usuário faça a escolha. A presente pesquisa adotou o programa E-Views 7 que permitiu a escolha das categorias base, as quais foram escolhidas pelo autor por meio dos seguintes critérios: i) Para variáveis que capturam qualidade da empresa, a qualidade mais fraca foi considerada com base; ii) Para variáveis que capturam tamanho da empresa, o porte médio foi considerado; iii) Para as demais variáveis, a categoria base foi escolhida por ordem alfabética.
} 
variáveis que representam os determinantes da capacidade de inovação das PMEs apresentado no tópico a seguir deve ser mais assertivo na classificação das empresas do que esse percentual. Dessa forma, o modelo nulo é adotado como base comparativa, sendo que os pontos de corte $^{28}$ adequados devem ser de 62,5\% para empresas com capacidade de inovação sem destaque e 37,5\% para as empresas com capacidade de inovação alta.

\subsubsection{Resultado e Análise do Modelo Estimado}

A avaliação do fit geral do modelo de regressão logística foi realizada por meio de três abordagens (vide item 4.4.3.4): medida pseudo $\mathrm{R}^{2}$ (MacFadden), estatística chiquadrado (teste Hosmer e Lemeshow) e taxa de sucesso expressa na matriz classificatória. Cada uma dessas medidas foi analisada para o modelo inicial de regressão logística estimado com as 4 variáveis independentes identificadas no resultado do procedimento de stepwise.

Todas as 4 variáveis independentes incluídas no modelo inicial apresentaram nível de significância abaixo de 0,05 , sendo que o McFadden $\mathrm{R}^{2}$ obteve valor de 0,527 conforme indicado na Tabela 14.

Tabela 14 - Resultado do modelo de regressão logística estimado com 4 variáveis e respectivo McFadden $\mathbf{R}^{2}$ (adequação geral do modelo)

\begin{tabular}{lcccc}
\hline Variáveis Independentes & $\begin{array}{c}\text { Coeficiente } \\
\text { (Original) }\end{array}$ & Erro Padrão & Estatística Z & Significância \\
\hline Constante & $-10,384$ & 3,225 & $-3,220$ & 0,001 \\
GEST_PROJ & 0,929 & 0,427 & 2,177 & 0,029 \\
CONHEC_INT & 0,607 & 0,249 & 2,440 & 0,015 \\
ESTRAT & 0,465 & 0,234 & 1,984 & 0,047 \\
CONHEC_EXT & 1,050 & 0,394 & 2,666 & 0,008 \\
\hline & & & & \\
Adequação Geral do Modelo & Valor & & & \\
McFadden $\mathbf{R}^{2}$ & 0,527 & & & \\
\hline
\end{tabular}

\footnotetext{
${ }^{28}$ Quando não se conhece a proporção, convenciona-se na literatura usar o ponto de corte de $50 \%$ o qual define probabilidades iguais para os dois grupos.
} 
Um valor de McFadden entre 0,2 e 0,4 corresponde a um fit muito bom do modelo (vide item 4.4.3.4) e quanto maior o valor melhor a adequação do modelo. Dessa forma, o valor de 0,527 expresso na Tabela 14 permitiu inferir uma ótima adequação geral do modelo de regressão logística estimado tendo em vista que equivale a um valor de $\mathrm{R}^{2}$ superior a 0,9 em uma função linear (DOMENCICH e MCFADDEN, 1975).

O fit geral do modelo estimado também foi avaliado com relação a sua acurácia preditiva. O teste Hosmer e Lemeshow cujo resultado consta na Tabela 15 permitiu avaliar, por meio da estatística chi-quadrado, a acurácia preditiva do modelo de regressão logística com as 4 variáveis independentes.

Tabela 15 - Resultado da estatística chi-quadrado (teste Hosmer Lemeshow) para o modelo estimado com 4 variáveis

\begin{tabular}{|c|c|c|c|c|c|c|}
\hline \multirow[b]{2}{*}{ Passo } & \multicolumn{2}{|c|}{ Grupo 0} & \multicolumn{2}{|c|}{ Grupo 1} & \multirow{2}{*}{$\begin{array}{c}\text { Total } \\
\text { Observações }\end{array}$} & \multirow[b]{2}{*}{ Valor H-L } \\
\hline & Observado & Esperado & Observado & Esperado & & \\
\hline 1 & 4 & 3,989 & 0 & 0,011 & 4 & 0,011 \\
\hline 2 & 5 & 4,954 & 0 & 0,046 & 5 & 0,046 \\
\hline 3 & 5 & 4,832 & 0 & 0,168 & 5 & 0,174 \\
\hline 4 & 5 & 4,726 & 0 & 0,274 & 5 & 0,290 \\
\hline 5 & 4 & 4,079 & 1 & 0,921 & 5 & 0,008 \\
\hline 6 & 2 & 2,924 & 2 & 1,076 & 4 & 1,085 \\
\hline 7 & 3 & 2,461 & 2 & 2,539 & 5 & 0,232 \\
\hline 8 & 2 & 1,451 & 3 & 3,549 & 5 & 0,293 \\
\hline 9 & 0 & 0,530 & 5 & 4,470 & 5 & 0,593 \\
\hline 10 & 0 & 0,053 & 5 & 4,947 & 5 & 0,053 \\
\hline Total & 30 & 30 & 18 & 18 & 48 & 2,784 \\
\hline \multirow{2}{*}{\multicolumn{3}{|c|}{ Acurácia Preditiva do Modelo }} & Valor & Significância & & \\
\hline \multicolumn{2}{|c|}{ Estatística H-L (chi-quadrado) } & & 2,784 & 0,947 & & \\
\hline
\end{tabular}

A hipótese nula $\left(\mathrm{H}_{0}\right)$ do teste Hosmer e Lemeshow é a de que o fit do modelo é bom, logo se espera um nível de significância alto a fim de aceitar $\mathrm{H}_{0}$ e corroborar a adequação do modelo de regressão logística estimado. Valores de nível de significância entre 0,7 e 0,8 (videm item 4.4.3.4) já são aceitáveis para não rejeitar $\mathrm{H}_{0 .} \mathrm{O}$ nível de significância encontrado de 0,947 possibilitou, portanto aceitar $\mathrm{H}_{0}$ e reforçar a 
adequação geral do modelo uma vez que a estatística H-L indicou apenas pequenas diferenças entre a classificação prevista e a observada.

O nível de acurácia preditiva do modelo logístico foi avaliado por meio da taxa de sucesso (percentual de casos corretamente classificados) obtida na matriz de classificação apresentada na Tabela 16 para completar a análise do fit geral do modelo estimado.

Tabela 16 - Precisão da estimação do modelo logístico MATRIZ DE CLASSIFICAÇÃO

\begin{tabular}{lccc}
\hline & \multicolumn{3}{c}{ Previsto } \\
\cline { 2 - 3 } & \multicolumn{2}{c}{ CAP_INOV_DEP } \\
\cline { 2 - 3 } Observado (real) & $\begin{array}{c}\text { Grupo 0 } \\
(\mathrm{n}=30)\end{array}$ & $\begin{array}{c}\text { Grupo 1 } \\
(\mathrm{n}=18)\end{array}$ & $\begin{array}{c}\text { Porcentagem } \\
\text { Correta }\end{array}$ \\
\hline Capacidade de Inovação sem Destaque (Grupo 0) & $\mathbf{2 5}$ & 5 & $83,3 \%$ \\
Capacidade de Inovação Alta (Grupo 1) & 5 & $\mathbf{1 3}$ & $\mathbf{7 2 , 2 \%}$ \\
Porcentagem Geral & & & $\mathbf{7 9 , 2 \%}$ \\
\hline
\end{tabular}

A taxa de sucesso geral do modelo logístico contendo as 4 variáveis independentes para as 48 empresas da amostra de análise (treinamento) foi de 79,2\% o que pode ser considerado um nível satisfatório de acerto. Essa taxa de acerto do modelo estimado foi superior em comparação com a taxa geral de sucesso do modelo nulo, que considerava apenas a constante, adotada como referência $(62,5 \%)$. Além disso, a taxa de sucesso do grupo capacidade de inovação sem destaque (0) foi de 83,3\% e no caso do grupo capacidade de inovação alta (1) foi de $72,2 \%$. Essas taxas de acerto demonstraram uma melhora substancial em relação às taxas de sucesso dos mesmos grupos 0 e 1 do modelo nulo que eram de respectivamente $62,5 \%$ e $37,5 \%$, em especial no caso do grupo de capacidade de inovação alta (1) que é o mais relevante para a presente pesquisa.

A partir desse estágio, houve a tentativa de inclusão forçada, no modelo estimado, de cada uma das variáveis que ficaram de fora do modelo similar a um stepwise avançar. Esse procedimento implicou na inclusão de uma variável inicialmente excluída do modelo, seguida da estimação e análise do modelo com 5 variáveis independentes e 
exclusão da nova variável para dar lugar a inclusão de outra variável inicialmente excluída do modelo. O resultado indicou que cada nova variável incluída apresentou nível de significância acima de 0,05 o que justificou manter o modelo apenas com as 4 variáveis iniciais. Optou-se por não estimar um novo modelo com a eliminação de alguma dessas 4 variáveis (equivalente a um stepwise retroceder) uma vez que a omissão de variável relevante pode causar viés na análise do resultado (WOOLDRIDGE, 2007).

\subsubsection{Validação do Modelo}

Para validação do resultado do modelo logístico estimado, foi adotado o teste com amostra de validação (holdout) conforme mencionado no item 4.4.3.2. Esse teste implicou no particionamento da amostra total em duas subamostras extraídas por meio da geração de números aleatórios, sendo uma para análise contendo $60 \%$ dos casos (48 empresas) e outra para validação com os $40 \%$ dos casos restantes (32 empresas). O resultado do teste com amostra de validação foi consolidado na Tabela 17 que apresenta um quadro comparativo com a matriz de classificação e respectivas taxas de acerto para ambas as amostras.

Tabela 17 - Precisão da estimação do modelo logístico para a amostra de análise $\mathrm{x}$ amostra de validação

MATRIZ DE CLASSIFICAÇÃO

\begin{tabular}{|c|c|c|c|c|c|c|}
\hline \multirow[b]{4}{*}{ Observado (real) } & \multicolumn{6}{|c|}{ Previsto } \\
\hline & \multicolumn{3}{|c|}{ AMOSTRA DE ANÁLISE ${ }^{a}$} & \multicolumn{3}{|c|}{ AMOSTRA DE VALIDAÇÃO ${ }^{b}$} \\
\hline & \multicolumn{2}{|c|}{ CAP_INOV_DEP } & \multirow[b]{2}{*}{$\begin{array}{c}\text { Porcentagem } \\
\text { Correta }\end{array}$} & \multicolumn{2}{|c|}{ CAP_INOV_DEP } & \multirow[b]{2}{*}{$\begin{array}{c}\text { Porcentagem } \\
\text { Correta }\end{array}$} \\
\hline & $\begin{array}{c}\text { Grupo } 0 \\
(n=30)\end{array}$ & $\begin{array}{c}\text { Grupo } 1 \\
(n=18)\end{array}$ & & $\begin{array}{c}\text { Grupo } 0 \\
(n=22)\end{array}$ & $\begin{array}{c}\text { Grupo } 1 \\
(n=10)\end{array}$ & \\
\hline Capacidade de Inovação sem Destaque (Grupo 0) & 25 & 5 & $83,3 \%$ & 18 & 2 & $81,8 \%$ \\
\hline Capacidade de Inovação Alta (Grupo 1) & 5 & 13 & $72,2 \%$ & 4 & 8 & $80,0 \%$ \\
\hline Porcentagem Geral & & & $79,2 \%$ & & & $81,3 \%$ \\
\hline
\end{tabular}

${ }^{a} 79,2 \%$ da a mostra e análise foi classificada corretamente

${ }^{b} 81,3 \%$ da amostra de validação foi classificada corretamente

As taxas de sucesso (geral e por grupo) da amostra de validação e as taxas de acerto da amostra de análise são superiores às taxas do modelo nulo apresentado anteriormente e muito próximas quando comparadas entre si (vide Tabela 17), salvo a taxa de sucesso 
do grupo 1 da amostra de validação (80\%) que foi ainda maior do que a taxa de sucesso do mesmo grupo na amostra de análise $(72,2 \%)$ o que é positivo para o modelo. Dessa forma, foram encontradas evidências de que o modelo de regressão logística possui suporte empírico para ambas as amostras (análise e validação) o que confere maior credibilidade ao modelo e proporciona possibilidade de generalização do mesmo.

Com o fit geral do modelo aceito, prosseguiu-se com interpretação e análise das 4 variáveis contidas no modelo estimado. Todas essas variáveis apresentaram relações significantes que afetam a classificação das empresas nos grupos da variável dependente e faz-se necessário avaliar a direção e magnitude dessas relações como será realizado no item a seguir.

\subsection{Interpretação e Análise das Variáveis do Modelo}

O modelo de regressão logística final permitiu identificar 4 variáveis independentes (determinantes) que impactam na classificação da capacidade de inovação das empresas em "sem destaque" ou "alta". Em referência à Lei de Pareto ${ }^{29}$ é possível notar que o modelo se enquadra no princípio $80 / 20$ uma vez que aproximadamente $27 \%$ das variáveis independentes (4 variáveis, do total de 15 variáveis) explicam em torno de $90 \%$ do resultado do modelo (vide item 5.1.4) o que indica seu alto poder explicativo a partir de poucas variáveis de análise. A Tabela 18 apresenta os coeficientes originais e exponencializados obtidos para cada variável independente contida no modelo final.

Tabela 18 - Variáveis do modelo logístico final e seus respectivos coeficientes (originais e exponencializados)

\begin{tabular}{|c|c|c|c|c|c|}
\hline Variáveis Independentes & $\begin{array}{c}\text { Coeficiente } \\
\text { (Original) }\end{array}$ & Erro Padrão & Estatística Z & $\begin{array}{c}\text { Coeficiente }^{a} \\
\text { (Exponencializado) }\end{array}$ & Significância \\
\hline Constante & $-10,384$ & 3,225 & $-3,220$ & 0,000 & 0,001 \\
\hline CONHEC_EXT & 1,050 & 0,394 & 2,666 & 2,857 & 0,008 \\
\hline GEST_PROJ & 0,929 & 0,427 & 2,177 & 2,531 & 0,029 \\
\hline CONHEC_INT & 0,607 & 0,249 & 2,440 & 1,835 & 0,015 \\
\hline ESTRAT & 0,465 & 0,234 & 1,984 & 1,592 & 0,047 \\
\hline
\end{tabular}

${ }^{a}$ Antilog do coeficiente logístico original

\footnotetext{
${ }^{29}$ A Lei de Pareto, também conhecida como Princípio 80/20, é uma proposição devida ao engenheiro e economista franco-italiano Vilfredo Frederico Damaso Pareto e atesta que para muitos fenômenos, $80 \%$ das consequências advêm de $20 \%$ das causas (KOCH, 2000).
} 
A interpretação e análise dessas variáveis compreendeu o exame dos coeficientes logísticos (vide Tabela 18) de cada variável independente para avaliar a direção e a magnitude que cada uma dessas variáveis tem na probabilidade prevista e na classificação dos grupos da variável dependente.

\subsubsection{Base de Conhecimento Externo}

A variável CONHEC_EXT representa a base de conhecimento externo e foi uma das variáveis significantes do modelo. Essa variável apresentou um coeficiente original de 1,050 e um coeficiente exponencializado de 2,857. O sinal positivo do valor do coeficiente original indica que a relação entre a base de conhecimento externo e a variável dependente capacidade de inovação é positiva. Com base no valor superior a 1 do coeficiente exponencializado é possível corroborar a direção positiva da relação. Dessa forma, quanto maior o valor da variável CONHEC_EXT, maior a probabilidade preditiva, aumentando a chance de uma empresa ser classificada com capacidade de inovação alta.

Com relação à magnitude, o coeficiente exponencializado encontrado permitiu estimar (vide fórmula no item 4.4.3.5) o percentual de mudança na chance no valor de $186 \%$. Esse percentual torna possível inferir que a cada unidade de aumento na base de conhecimento externo, há um aumento de $186 \%$ na chance da empresa ser considerada do grupo com capacidade de inovação alta em relação ao grupo de capacidade de inovação sem destaque. A variável CONHEC_EXT apresentou o maior coeficiente exponencializado o que lhe confere o status de determinante com maior impacto na capacidade de inovação das PMEs.

Conforme previsto na literatura, a base de conhecimento externo tem relação significante e positiva com a capacidade de inovação das empresas. Nesse sentido, a inovação deve ser vista em termos de aquisição e não simplesmente presença de competências (ALBALADEJO e ROMIJN, 2000; FREEL, 2005). Além disso, sua grande magnitude para as PMEs pode ser explicada, em parte, em função da escassez de recursos internos (tecnológicos, mão de obra, financeiro, entre outros) inerente a 
empresas desse porte (NIETO e SANTAMARIA, 2006), o que exige que essas empresas busquem recursos externos para inovar com sucesso. Portanto, busca por parcerias externas, participação em projetos cooperados (por exemplo, por meio de plataformas de open innovation), formas sistemáticas de relacionamentos externos com fornecedores, universidades e clientes, entre outras práticas, são importantes para melhorar a capacidade de inovação das PMEs.

\subsubsection{Capacidade de Gestão de Projetos}

A capacidade de gestão de projetos, variável codificada como GEST_PROJ, também foi significante para o modelo final. Seu coeficiente original foi de 0,929 o que correspondeu a um valor para o coeficiente exponencializado de 2,531. De acordo com o sinal positivo do coeficiente original determinou-se que a relação entre a capacidade de gestão de projetos e a variável dependente capacidade de inovação é positiva. $\mathrm{O}$ valor superior a 1 identificado para o coeficiente exponencializado reforça a direção positiva dessa relação. Nesse sentido, quanto maior o valor da variável GEST_PROJ, maior a probabilidade preditiva, aumentando a chance de uma empresa ser classificada com capacidade de inovação alta.

No caso da magnitude, o percentual de mudança na chance foi de $153 \%$ conforme calculado a partir do coeficiente exponencializado. Esse percentual permite atestar que a cada unidade de aumento na capacidade de gestão de projetos, há um aumento de $153 \%$ na chance da empresa ser considerada do grupo com capacidade de inovação alta em relação ao grupo de capacidade de inovação sem destaque. Essa magnitude conferiu à capacidade de gestão de projetos o segundo lugar em termos de impacto na capacidade de inovação das PMEs.

Dessa forma, a capacidade de gestão de projetos tem relação significante e positiva com a capacidade de inovação das empresas confirmando o que foi identificado na literatura. Uma inovação de sucesso passa por diversos estágios que incluem desde a geração e concretização de uma nova ideia até a avaliação de seu resultado. As práticas de gestão de projetos aumentam a efetividade do processo de inovação e consequentemente 
contribuem para o sucesso da mesma (ASA et al., 2013; MACHADO, 2004). Logo, a adoção de um portfólio de projetos de inovação, práticas de controle e acompanhamento de projetos (tais como reunião de status report, criação de Comitê de Gestão da Inovação, etc) e utilização de ferramentas ou softwares de gestão da inovação (a título de exemplo, funil da inovação como ferramenta e MS Project como software) impactam positivamente na capacidade de inovação das PMEs.

\subsubsection{Base de Conhecimento Interno}

O nível de significância da variável CONHEC_INT também garantiu a inclusão da base de conhecimento interno no modelo logístico final. O coeficiente final estimado foi de 0,607 o que resultou no valor de 1,835 para o coeficiente exponencializado. A relação entre a base de conhecimento interno e a variável dependente capacidade de inovação é positiva, conforme se aufere pelo sinal positivo do coeficiente original e de acordo com o valor superior a 1 obtido para o coeficiente exponencializado. Essa análise indica que quanto maior o valor da variável CONHEC_INT, maior a probabilidade preditiva, aumentando a chance de uma empresa ser classificada com capacidade de inovação alta.

Sob a perspectiva da magnitude, o coeficiente exponencializado deu origem a um percentual de mudança na chance no valor de $83 \%$. A partir desse percentual de mudança na chance, torna-se possível afirmar que a cada unidade de aumento na base de conhecimento interno, há um aumento de $83 \%$ na chance da empresa ser considerada do grupo com capacidade de inovação alta em relação ao grupo de capacidade de inovação sem destaque. De acordo com essa magnitude, a base de conhecimento interno ocupou o terceiro lugar entre as variáveis que causam maior impacto na capacidade de inovação das PMEs.

A partir dessa análise conclui-se que a base de conhecimento interno tem relação significante e positiva com a capacidade de inovação das PMEs o que está alinhado com a hipótese formulada com base na revisão da literatura. Atualmente, a inovação é considerada responsabilidade de todos os colaboradores da organização (BIRKINSHAW et al., 2011). Nesse contexto, a base de conhecimento interno, 
enquanto conhecimento coletivo dos indivíduos que compõe a empresa, contribui diretamente para os esforços de inovação da companhia (HOFFMAN et al., 1998). Uma capacidade de inovação alta para uma PME depende, portanto, de um quadro de colaboradores qualificados em todos os níveis e com competências adequadas à função que cada um exerce, o que requer processo de seleção adequado, política de educação e treinamento (contínuos), avaliação de desempenho dos colaboradores, entre outras práticas que contribuem para assegurar qualidade da mão de obra da empresa.

\subsubsection{Estratégia}

A estratégia, representada pela variável ESTRAT, foi a última variável significante a compor o modelo logístico final. Os coeficientes, original e exponencializado, estimados para essa variável apresentaram respectivamente os valores de 0,465 e 1,592. No que diz respeito à direção, observa-se que a relação entre estratégia e a variável dependente capacidade de inovação é positiva de acordo com o sinal positivo do coeficiente original. Ainda segundo o valor superior a 1 estimado para o coeficiente exponencializado, é possível confirmar a direção positiva dessa relação. A relação positiva encontrada determina que quanto maior o valor da variável ESTRAT, maior a probabilidade preditiva, aumentando a chance de uma empresa ser classificada com capacidade de inovação alta.

Para análise da magnitude, foi calculado com base no coeficiente exponencializado o percentual de mudança na chance que resultou no valor de $59 \%$. Segundo o percentual de mudança na chance encontrado, pode-se interpretar que a cada unidade de aumento na estratégia, há um aumento de 59\% na chance da empresa ser considerada do grupo com capacidade de inovação alta em relação ao grupo de capacidade de inovação sem destaque. Esse valor de magnitude conferiu para estratégia o quarto lugar entre as variáveis que causam maior impacto na capacidade de inovação das PMEs.

De acordo com o exposto, depreende-se que a estratégia possui relação significante e positiva com a capacidade de inovação das PMEs o que permite aceitar a hipótese extraída da literatura. A estratégia tem papel dominante na efetividade da inovação 
(BERKHOUT et al., 2006) proporcionando as diretrizes necessárias para um bom desempenho das inovações (ASA et al., 2013; VALLADARES, 2012), além de tornarse um passo crítico para institucionalizar a inovação (YOKOMIZO, 2014). Conclui-se que a capacidade das pequenas e médias empresas de realizar um planejamento estratégico abrangendo um conceito e estratégia de inovação, reavalia-lo periodicamente, estabelecer indicadores estratégicos e respectivas metas e criar as condições para implementação dos planos oriundos desse planejamento favorece a capacidade de inovação das PMEs. Tal determinante merece especial atenção visto que no caso particular das PMEs, as estratégias, quando existem, costumam ser informais e reativas para responder às condições diferentes e adversas de mercado (CHEN e CHEN, 2013).

\subsection{Análise das Variáveis Excluídas do Modelo}

As variáveis independentes excluídas da análise não apresentaram coeficientes logísticos significantes (a um nível de significância de 0,05 ) indicando que não há impacto dessas variáveis na capacidade de inovação. O presente tópico tem como objetivo realizar breves considerações acerca de cada variável independente excluída do modelo final com base nas respostas dos questionários, na revisão da literatura e na análise empírica feita durante a entrevista, a fim de apresentar algumas possíveis razões para o resultado encontrado. Vale ressaltar que essa análise tem caráter exploratório e de forma alguma tem a intenção de esgotar o assunto, visando apenas contribuir para estudos futuros.

\subsubsection{Investimento em Máquinas e Equipamentos}

Julgou-se interessante iniciar a análise a partir da variável independente que apresentou coeficiente negativo qual seja a variável INVEST_MAQ. Essa relação negativa é contrária às evidências encontradas na literatura que apontam que investimentos em máquinas e equipamentos exerce influência direta na capacidade de inovação das PMEs (KEIZER et al., 2002) uma vez que contribuem para o processo de "learning by doing" 
o qual é componente integral no processo de realização de inovações incrementais (NELSON, 2000).

O resultado contraditório obtido pode decorrer da deficiência na análise sob a ótica da qualidade e do retorno do investimento realizado tendo em vista que a variável referiuse apenas ao percentual de investimento em máquinas e equipamentos sobre o total do faturamento. Tal fato pode haver ocasionado distorção na relação dessa variável com a capacidade de inovação o que foi apontado como limitação da pesquisa. Ademais, o fato da variável não ser significante pode estar relacionado à observação de Nelson (2000) que indica uma relação de INVEST_MAQ principalmente com inovações incrementais, sendo que a variável latente dependente capacidade de inovação não se restringiu a esse tipo de inovação.

Contudo, a variável pode também não ter apresentado significância em função do fato de que um investimento em máquinas e equipamentos sem uma estratégia tecnológica definida ou uma base de conhecimento interno capaz de aprender e absorver a nova tecnologia pode não causar o reflexo esperado na capacidade de inovação da PME. A título de exemplo, foi detectado em uma entrevista que uma empresa havia investido na aquisição de um software para a área comercial o qual estava inutilizada devido à incapacidade da equipe de operar o programa ainda que tenham recebido um treinamento. Esses argumentos explicam possivelmente, em parte, o resultado dessa pesquisa não ter corroborado os achados na literatura.

\subsubsection{Comunicação Interna}

Segundo a literatura, a variável COMUNIC_INT contribui para fortalecer a capacidade de inovação da empresa (ASA et al., 2013). Bons processos de intercâmbio de informações e conhecimento dentro de uma organização facilitam a dispersão de ideias e aumentam o montante e a diversidade de informações, que por sua vez resulta na fertilização cruzada de ideias (NONAKA, 1994; WAN et al., 2003). 
A comunicação interna pode não ter apresentado significância devido à própria natureza das PMEs que em função do seu porte já apresentam um padrão que compreende poucos níveis hierárquicos e baixo nível de formalidade o que faz com que a comunicação interna nessas empresas costume ser fácil e ágil (TIDD et al., 2005). Como informação complementar, com base nas respostas do item 1 da seção III do questionário, 92\% da amostra possui no máximo até 3 níveis hierárquicos o que é considerado uma hierarquia plana (ROBBINS, 2002). Esse fato pode justificar o resultado obtido para essa variável não ter sido significante no caso de empresas com esse porte.

\subsubsection{Disponibilidade de Recursos Financeiros Internos}

A variável DISP_REC_INT não apresentou relação significante com a capacidade de inovação das PMEs. As atividades de inovação exigem recursos, consequentemente a disponibilidade (ou folga) de recursos (financeiro, humano, operacional, tempo, entre outros) facilita a inovação, a criatividade e a tomada de risco de uma organização (LOVE e NOHRIA, 2005). Assim como grande parte da literatura, a presente pesquisa considerou como recurso disponível para inovação a disponibilidade de capital para financiar uma determinada inovação (FACÓ, 2009) uma vez que se trata de um recurso que pode ser facilmente realocado em qualquer projeto (HEROLD et al., 2006) e suprir a necessidade dos demais recursos.

Há um consenso na literatura acadêmica de que as PMEs apresentam escassez de recursos internos (CHEN e CHEN, 2013; FAGERBERG, 2003; FREEL, 2000; KEIZER et al., 2002; LEÓN e VALENZUELA, 2014; ROTHWELL, 1991). Se a folga de recursos financeiros fosse essencial para inovação, não haveria pequenas e médias empresas inovadoras como se pode observar na literatura e nessa própria pesquisa em que foram identificadas 28 empresas com capacidade de inovação alta. A disponibilidade de recursos internos, quando não aliada a um planejamento estratégico e a uma capacidade de gestão de projetos, tampouco garante que o mesmo seja alocado de forma adequada maximizando o resultado do investimento para a empresa. 
Por fim, as PMEs podem compensar a falta de recursos internos com a base de conhecimento externo e até mesmo por meio de apoio governamental o que faz com que a escassez de recursos não seja um impeditivo para uma capacidade de inovação alta. Dessa forma, explica-se em parte o resultado para essa variável não ter sido significante.

\subsubsection{Apoio Governamental}

A variável AP_GOV apresentou relação positiva, porém não significante no que tange a capacidade de inovação. Esse resultado contradiz as evidências extraídas da literatura as quais apontam que apoio governamental exerce influencia positiva e significante sobre a capacidade de inovação das organizações (BECHEIKH et al., 2006) por meio de políticas que contribuem para proporcionar os recursos necessários para geração e implementação das inovações. A título de exemplo, foi citado o caso dos Tigres Asiáticos que conseguiram melhorar a capacidade de inovação de suas empresas adotando políticas de governo efetivas (BELL e PAVITT, 1993). Dessa forma, as políticas de incentivo e apoio governamental à inovação são fundamentais (DOLOREUX e MELANCON, 2008).

Um primeiro ponto a ser ressaltado sobre essa variável é que apenas 10 empresas do total de uma amostra de 80 empresas obteve alguma forma de apoio financeiro do governo. A maior parte das empresas da amostra enquadra-se no regime tributário Simples Nacional ou Lucro Presumido o que já as exclui da possibilidade de beneficiarem-se de um dos principais incentivos fiscais oferecidos pelo governo, a Lei do Bem, que exige o enquadramento da empresa no regime tributário Lucro Real. As dificuldades relatadas por algumas empresas com relação à participação dos editais abertos pelo governo para inovação, entre elas dificuldades relacionadas à complexidade do processo e de atender aos requisitos do edital, também são alguns indícios que sugerem que as políticas do governo não estão atingindo o público das PMEs.

Além da dificuldade de acesso das empresas de pequeno e médio porte aos apoios governamentais, também pode ser questionada a efetividade dessas políticas. Como o 
presente trabalho não contemplou uma avaliação da efetividade do apoio governamental à inovação, não é possível inferir conclusões a esse respeito. Mas a efetividade das políticas de apoio do governo à inovação é um fator que pode ter impacto no nível de significância obtido para essa variável. A importância do apoio governamental como fator externo também pode ser relativizada quando comparada à base de conhecimento externo que se demonstrou muito efetiva para a capacidade de inovação das PMEs.

\subsubsection{Localização Geográfica}

Com relação à variável LOCALIZ_GEO, seu coeficiente não apresentou relação significativa com a capacidade de inovação, sendo que o grau de significância, assim como para as demais variáveis excluídas do modelo final, foi acima de 0,05. Alguns pesquisadores notaram diferenças do impacto da localização geográfica na capacidade de inovação das empresas (COOKE et al., 2004; HOFFMAN et al., 1998, LE BLANC et al., 1997) devido ao fato de a proximidade física aos stakeholders permitir estabelecer uma relação de cooperação com esses atores (BECHEIKH et al., 2006).

Apesar de a amostra compreender empresas de mais de 40 cidades agrupadas em 9 núcleos que representam distintas regiões do estado de São Paulo, é possível que haja certa homogeneidade entre essas localizações quando comparadas a outros estados. Tal fato pode ter relativizado a importância da localização geográfica para a capacidade de inovação das empresas o que também foi apontado como uma limitação da pesquisa. Esse fator pode ter causado impacto no nível de significância obtido para a variável LOCALIZ_GEO.

\subsubsection{Tamanho Organizacional}

A variável TAM_ORG apresentou coeficiente original que indica relação positiva com a capacidade de inovação das PMEs, porém o resultado encontrado não foi significante. O tamanho organizacional foi classificado no presente estudo por meio de número de colaboradores (KIMBERLY e EVANISKO, 1981) de acordo com as faixas adotadas 
pelo IBGE e pelo SEBRAE. Apesar da hipótese referente ao tamanho organizacional formulada a partir da revisão da literatura ter considerado a relação entre essa variável e a capacidade de inovação positiva e significativa, o fato é que esse ainda não foi possível estabelecer uma relação forte entre tamanho organizacional e inovação (NIETO e SANTAMARIA, 2006).

Enquanto o tamanho organizacional configura-se em um dos mais importantes determinantes que afetam a capacidade de inovação para alguns autores (CAPON et al., 1992; ROGERS, 2004) resultado esse, em geral, atribuído à maior disponibilidade de recursos nas empresas de maior porte (MACHADO, 2004), outros pesquisadores encontraram correlação negativa (UTTERBACK, 1994) e até mesmo não significativa (LEE e XIA, 2006). A disponibilidade de recursos já foi refutada como determinante da capacidade de inovação das PMEs, conforme justificado no item 5.3.3 o que também pode explicar que uma empresa de maior porte não necessariamente implica em uma melhor capacidade de inovação.

Além disso, segundo Christensen (1997), conforme as empresas crescem, seus processos, sua estrutura e até mesmo a cultura organizacional tendem a se alinhar muitas vezes com objetivos voltados para a consolidação no mercado o que requer estratégias de redução de custo e melhoria da qualidade resultando em inovações incrementais, mas não disruptivas ou radicais. Como a presente pesquisa analisou a capacidade de inovação desde uma abordagem que inclui todos os tipos de inovação, é possível que o tamanho organizacional seja significante para um tipo de inovação, por exemplo, incremental, mas perca sua significância no caso de uma perspectiva mais abrangente de inovação. Nesse contexto, o tamanho organizacional permanece como uma dimensão polêmica, sendo que o resultado do presente estudo contribui para consolidar a vertente de que o tamanho organizacional não possui relação significativa com a capacidade de inovação das PMEs. 


\subsubsection{Atividades de P\&D}

A variável ATIV_P\&D apresentou um coeficiente que indicou uma relação positiva com a capacidade de inovação, no entanto esse resultado não foi estatisticamente significante. Apesar da atividade de P\&D estar entre as mais clássicas das atividades inovativas e a literatura sugerir amplamente que essas atividades apresentam relação próxima com o resultado da inovação tanto de forma quantitativa, quanto qualitativa (ADNER e LEVINTHAL, 2001), a sistematização das mesmas não apresentou relação significativa com a capacidade de inovação.

É importante ressaltar, nesse momento, que se constatou no trabalho de campo um alto grau de informalidade nas atividades de P\&D e ausência da mensuração dos gastos com essas atividades na ampla maioria da amostra, conforme previsto por Tidd et al. (2005) para as PMEs. Empresas com esse porte, em geral, não são capazes de separar gastos com $\mathrm{P} \& \mathrm{D}$ de outros custos operacionais e consequentemente a atividade de inovação voltada para conhecimento ocorre nos módulos informais (CEGARRA et al., 2011; RENKO, 2012).

Em virtude dessa realidade, a visão de que P\&D é uma das principais forças por trás da inovação deve ser reconsiderada quando a unidade de análise for empresas que constituem o grupo das PMEs (FREEL, 2005; TIDD et al., 2005). Dessa forma, é possível que dentro do contexto das PMEs, os módulos informais sejam efetivos do ponto de vista da capacidade de inovação e, portanto a prática formal das atividades de $P \& D$ pode ser significante para empresas de grande porte e não necessariamente essa relação é significante paras as empresas de pequeno e médio porte.

\subsubsection{Cultura Organizacional}

O resultado obtido no presente estudo para a relação entre a variável CULT_ORG e a capacidade de inovação das PMEs foi positivo, mas não significante. Embora a cultura organizacional tenha sido apontada pela literatura como um fator que influencia a 
capacidade de inovação da empresa (APAYDIN e CROSSAN, 2010; BIRKINSHAW et al., 2011; BECHEIKH et al., 2006; NUENO, 1998; NEELY e HII, 1998) essa relação não foi confirmada para empresas de pequeno e médio porte.

Uma cultura organizacional favorável (com autonomia, estímulo, reconhecimento, tolerância a erros dos colaboradores, entre outros fatores) não implica necessariamente em uma capacidade de inovação alta, em especial na ausência de uma base de conhecimento interno adequada. Tal fato pode ser ilustrado por meio de uma empresa da amostra que havia estabelecido diversas práticas de estímulo à cultura inovadora sugerida pela literatura e, não obstante apresentou capacidade de inovação sem destaque. Segundo o empresário, a baixa qualificação da mão de obra limitava a capacidade de inovação da empresa ainda que ele tentasse estimular de diversas formas o surgimento e implementação de novas ideias.

O exemplo citado a partir da pesquisa de campo não tem a intenção de minimizar a relevância de uma cultura organizacional favorável à inovação, mas justifica, em parte, o fato de a variável CULT_ORG não ter apresentado significância no nível individual quando incluída no modelo final em relação à cultura organizacional das PMEs. É provável que as práticas de estímulo à cultura organizacional inovadora, citadas na literatura, potencializem a capacidade de inovação na presença de uma base de conhecimento interno adequada.

\subsubsection{Estrutura Organizacional}

As diferentes estruturas organizacionais (mecanicista e orgânica) representadas pela variável ESTRUT_ORG não apresentaram resultados significantes em relação à capacidade de inovação. Segundo identificado na literatura, a estrutura organizacional pode estimular a capacidade de inovação (APAYDAN e CROSSAN, 2010), sendo que estruturas orgânicas (com menor grau de departamentalização e menor formalização conforme explicado por Valladares (2012)) são favoráveis à inovação em detrimento às estruturas mecanicistas. 
No que diz respeito ao contexto particular das PMEs, vale ressaltar que a estrutura organizacional dessas empresas costuma apresentar uma hierarquia plana (SEBORA et al., 1994), ou seja, com poucos níveis hierárquicos o que permite maior flexibilidade (NORD e TUCKER, 1987; WOLFF e PETT, 2006) e agilidade na tomada de decisão (TIDD et al., 2005). Essas empresas também têm como característica a informalidade (poucas regras e comunicações por escrito) o que foi reforçado na pesquisa de campo e por meio dos dados coletados no item 1 da seção III do questionário.

A partir dessa realidade é possível observar que as PMEs têm naturalmente uma estrutura organizacional que facilita a combinação, coordenação e controle dos recursos e atividades devido às suas características intrínsecas. Tal fato pode ter minimizado a relevância do tipo de estrutura organizacional para a capacidade de inovação das empresas de pequeno e médio porte o que justificaria o resultado da variável ESTRUT_ORG não ter sido significante.

\subsubsection{Tempo de Existência}

A variável TEMP_EXIST, que representa a idade da empresa, apresentou coeficiente positivo e não significante o que permitiu rejeitar a hipótese formulada com base na revisão da literatura de que o tempo de existência da organização é um determinante que afeta positivamente a capacidade de inovação das PMEs. A literatura indicou que há uma correlação positiva entre idade da empresa e capacidade de inovação (ALBALADEJO e ROMIJN, 2000), sendo que alguns autores adotaram como premissa que empresas mais velhas são, em geral, maiores e apresentam melhor situação financeira e que quanto maior o tempo de existência da empresa, mais sólida tende a ser sua experiência e aprendizado (COHEN e LEVINTHAL, 1990).

Contudo, a primeira premissa pode ser refutada uma vez que nem todas as organizações continuam a crescer e aumentar sua receita com o passar do tempo (MINTZBERG, 1983). Além disso, conforme já havia sido observado, na revisão da literatura, alguns autores identificaram o efeito contrário, ou seja, que as empresas mais jovens são mais inovadoras que as mais antigas (HAUSMAN, 2005). Dessa forma, ainda não há um 
consenso sobre a relação entre tempo de existência da empresa e capacidade de inovação e o resultado do presente estudo para essa variável contribui para acumular conhecimento da literatura sobre esse tema.

\subsubsection{Orientação ao Mercado}

A variável (latente) ORIENT_MERC obteve um coeficiente positivo, porém não significante na regressão individual e nem ao ser incluída no modelo final com as demais 4 variáveis independentes. De acordo com a literatura, esperava-se que a orientação ao mercado apresentasse correlação positiva e significante com a capacidade de inovação das PMEs. Algumas razões podem contribuir para o entendimento do resultado ocorrido.

A ausência de significância na relação entre orientação ao mercado e capacidade de inovação das PMEs não quer dizer que comportamentos e atividades relacionados à orientação de mercado não contribuem para a inovação. Essas práticas proporcionam acesso a conhecimento e ideias que são recursos primários para o processo de inovação (ASA et al., 2013; YAM et al., 2010), mas a compreensão das necessidades do mercado e do cliente sem uma estratégia definida, clara e disseminada pode não trazer o resultado positivo esperado.

A título de exemplo da situação exposta, foram identificados alguns casos durante as entrevistas de empresas da amostra que receberam sugestões ou pedidos de clientes que envolveram inovações em processo, inovações incrementais e até mesmo radicais em produtos ou serviços. Apesar de essas oportunidades não estarem alinhadas com o core business das empresas, os pedidos foram atendidos e não resultaram em sucesso comercial. Tal situação demonstrou-se recorrente no caso das PMEs que na ânsia de atender seus clientes, muitas vezes inovam sem realizar um alinhamento prévio da demanda com suas respectivas estratégias, além de em muitos casos a empresa nem ter uma estratégia formalizada. A coleta de inteligência de mercado deve estar integrada ao processo de tomada de decisão estratégica (DAY, 1994), servindo de subsídio para o mesmo. 
Além disso, os dados coletados pela inteligência de mercado também dependem da base de conhecimento interno e da capacidade de gestão de projetos da empresa para transforma-los em uma inovação efetiva. A título de ilustração desse argumento, duas empresas concorrentes podem ter acesso às mesmas informações dos clientes, sendo que uma pode converter esse dado em uma inovação efetiva e a outra não. Dessa forma, o conjunto de comportamentos e atividades relacionadas à geração, disseminação e resposta à inteligência de mercado é positivo para o processo de inovação, mas não diferencia as empresas com capacidade de inovação alta, das empresas com capacidade de inovação sem destaque e, portanto a orientação ao mercado não é considerada um determinante da capacidade de inovação das PMEs.

\subsection{Apresentação do Modelo Final}

Após avaliar a adequação do modelo de regressão logística, realizar sua validação e interpretar e analisar as variáveis contidas no mesmo, bem como as variáveis excluídas, buscou-se esquematizar o resultado do modelo final em um quadro referencial. Para tanto, foi elaborado o Quadro 2 para ilustrar o referido modelo. Conforme se pode observar, esse quadro contém as 4 variáveis independentes que impactam de forma significante e positiva a capacidade de inovação das PMEs.

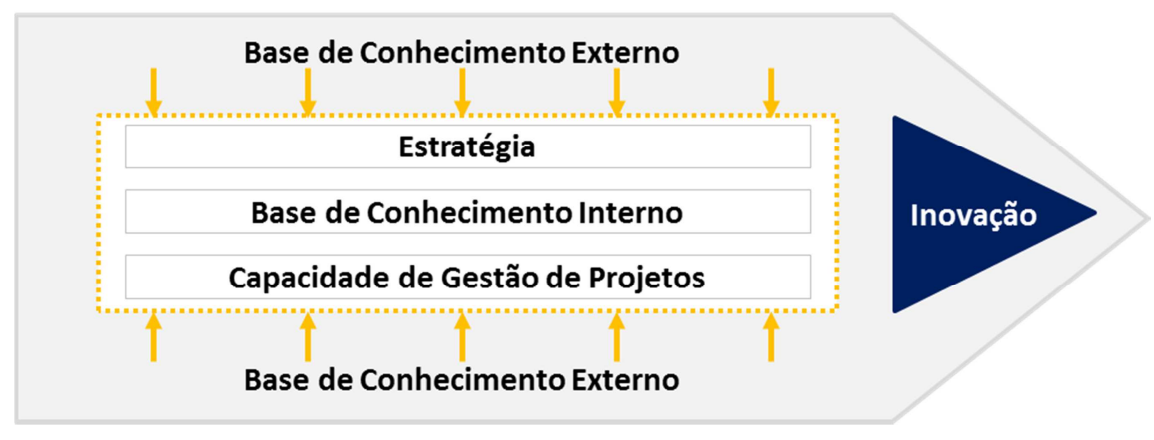

Quadro 2 - Apresentação do modelo final de regressão logística

O objetivo do modelo criado foi o de representar o fenômeno de maneira simplificada a fim de contribuir para a compreensão do resultado encontrado por meio da análise de 
regressão logística aplicada na presente pesquisa e atender ao princípio da parcimônia ${ }^{30}$. Dessa forma, base de conhecimento externo, estratégia, base de conhecimento interno e capacidade de estão de projetos realmente diferenciam a capacidade de inovação das pequenas e médias empresas e, portanto foram classificadas como determinantes da capacidade de inovação das PMEs e incluídas no modelo final. Pode-se observar que tanto fatores internos como externo são importantes para a capacidade de inovação das PMEs. As demais 11 variáveis não diferenciam as empresas com capacidade de inovação alta, das empresas com capacidade de inovação sem destaque e por essa razão não foram consideradas determinantes e consequentemente foram excluídas do modelo.

\footnotetext{
${ }^{30} \mathrm{O}$ princípio da parcimônia prevê que a simplicidade tanto na explicação do fenômeno ou problema como na aplicação das soluções aos problemas é sempre preferível em relação a frameworks de pesquisa complexos que consideram um número de fatores de difícil gerenciamento (FORZA, 2002).
} 


\section{CONCLUSÃO}

O presente estudo teve como objetivo construir um modelo de alta capacidade de inovação para as PMEs a partir dos 15 determinantes da capacidade de inovação identificados na literatura. Por meio da técnica de análise de regressão logística, verificou-se que 4 variáveis apresentaram correlação positiva e significativa com a capacidade de inovação das PMEs e que, portanto diferenciam as empresas com capacidade de inovação alta das empresas com capacidade de inovação sem destaque. Foi demonstrado dessa forma que base de conhecimento externo, capacidade de gestão de projetos, base de conhecimento interno e estratégia são determinantes da capacidade de inovação das PMEs e confirmou-se que tanto fatores internos, como externo são importantes para a capacidade de inovação dessas empresas.

Com base nessa descoberta, foi criado o modelo final de alta capacidade de inovação para as PMEs, apresentado no item 5.4, que atende ao princípio da parcimônia. O referido modelo compreende aproximadamente $27 \%$ das variáveis independentes (4 variáveis, do total de 15 variáveis) que explicam em torno de $90 \%$ de seu resultado. Essa proporção, comparada à Lei de Pareto (Princípio 80/20) indica seu alto poder explicativo a partir de poucas variáveis de análise. A simplicidade do modelo é importante visto que se torna uma orientação fácil para o direcionamento dos esforços das pequenas e médias empresas, cujos recursos são escassos, para melhorar sua capacidade de inovação.

O modelo de alta capacidade de inovação para as PMEs indica que práticas de gestão relacionadas à base de conhecimento externo, capacidade de gestão de projetos, base de conhecimento interno e estratégia são determinantes para a capacidade de inovação das empresas de pequeno e médio porte. Essas práticas contribuem para melhorar não só a efetividade das inovações, como também para um processo contínuo de geração das mesmas. Dessa forma, esse grupo de empresas poderá tornar-se mais competitivo uma vez que inovação pode resultar em produtos e serviços com alto valor agregado aos stakeholders, impactar na redução de preços e até mesmo contribuir para redução de custos da operação. 
Em nível individual dos determinantes da capacidade de inovação das PMEs, a base de conhecimento externo foi o que apresentou maior impacto. Nesse sentido, a inovação deve ser vista em termos de aquisição e não simplesmente presença de competências conforme já havia sido apontado na revisão da literatura. De acordo com as variáveis que mensuraram esse constructo depreende-se que parcerias externas com outras organizações nacionais ou internacionais e até mesmo concorrentes podem melhorar a capacidade de inovação das PMEs. A participação em projetos cooperados com universidades, fornecedores ou clientes, por exemplo, por meio de plataformas de open innovation também contribuem para o incremento da capacidade de inovações das empresas de pequeno e médio porte. Além disso, formas sistemáticas de relacionamentos externos (troca de ideias, informações ou conhecimento) com fornecedores, universidades e clientes, consultorias externas, participação em feiras, eventos e entidades de classe e aquisição de patentes ou know how de terceiros fortalecem a capacidade de inovação das PMEs.

No caso da capacidade de gestão de projetos, é importante reforçar que para uma inovação ser considerada de sucesso ela deve ter passado por diversos estágios que incluem desde a geração e concretização de uma nova ideia até a avaliação de seu resultado após seu lançamento no mercado. As práticas de gestão de projetos aumentam a efetividade desse processo e consequentemente contribuem para o sucesso da inovação nas PMEs. Entre as boas práticas inferidas a partir do constructo capacidade de gestão de projetos está a adoção de um portfólio de projetos de inovação que permita avaliar o balanceamento dos projetos de inovação, analisar o alinhamento desses projetos com a estratégia da empresa, listar os recursos necessários para executar os projetos e estabelecer um cronograma para os mesmo. As práticas de controle e acompanhamento de projetos tais como reunião de status report, criação de Comitê de Gestão da Inovação, entre outras, também contribuem para uma alta capacidade de inovação das PMEs. A utilização de ferramentas ou softwares de gestão da inovação, a título de exemplo, funil da inovação como ferramenta e MS Project como software, impactam positivamente na capacidade de inovação das empresas de pequeno e médio porte. 
Com relação à base de conhecimento interno, considerando, segundo a literatura, que a inovação é responsabilidade de todos os colaboradores da organização faz-se mister adotar práticas que fortaleçam o conhecimento coletivo dos indivíduos que compõe a empresa e que por sua vez contribui diretamente para os esforços de inovação da companhia. O fortalecimento da base de conhecimento interno, de acordo com o respectivo constructo, implica na identificação das competências necessárias para exercer cada função na equipe e um plano de desenvolvimento pessoal (PDP), por exemplo, que permita orientar o crescimento do colaborador dentro da organização. Uma política de educação e treinamento (contínuos) correspondentes a essas competências requeridas também é relevante para garantir uma base de conhecimento interno qualificada, assim como a avaliação de desempenho dos colaboradores que entre outras práticas contribuem para assegurar a qualidade da mão de obra da empresa e favorecer a capacidade de inovação das PMEs.

Por fim, a estratégia enquanto determinante da capacidade de inovação das PMEs proporciona as diretrizes necessárias para um bom desempenho das inovações, além de constituir-se um passo crítico para institucionalizar a inovação na empresa. Apesar das PMEs em geral não terem o costume de definir estratégias, aquelas empresas que realizam práticas formais relacionadas à estratégia apresentaram destaque na capacidade de inovação. Entre as práticas observadas por meio do constructo de estratégia estava a elaboração de um planejamento estratégico formal abrangendo um conceito e estratégia de inovação o qual é reavaliado periodicamente. Como complemento, há a adoção de indicadores estratégicos e respectivas metas para fins de monitoramento os quais eram comunicados para toda a empresa. Tais práticas demonstraram-se, portanto relevantes para a alta capacidade de inovação das pequenas e médias empresas.

\subsection{Contribuições da Pesquisa}

A partir dos resultados obtidos na presente pesquisa, foi possível realizar contribuições para a área acadêmica, o setor privado (em especial as PMEs) e o setor público. Com relação à contribuição acadêmica, a identificação, intepretação e análise dos determinantes da capacidade de inovação das pequenas e médias empresas realizada 
nesse trabalho somaram-se aos esforços da escassa literatura sobre as características que envolvem a capacidade de inovação das PMEs, em especial nos casos dos países em desenvolvimento.

No que diz respeito às contribuições da pesquisa para o setor privado, em especial para as PMEs, espera-se que o modelo final e o entendimento dos determinantes contidos no mesmo sirvam de orientação no processo fortalecimento da capacidade de inovação das empresas. Empresas com alta capacidade de inovação estão mais aptas a superar os desafios de inovar e empresas inovadoras oferecem melhores produtos e serviços e tornam-se mais competitivas frente aos concorrentes.

Foram demonstradas para os executivos e empreendedores diversas práticas relacionadas aos determinantes da capacidade de inovação. Gestores que querem melhorar sua base de conhecimento externo devem buscar parcerias com outras empresas (nacionais e internacionais), ampliar seus relacionamentos com fornecedores, universidades e clientes e participar de projetos cooperados com essas organizações, participar de eventos e associações buscar apoio de consultorias externas s instituições de apoio, entre outras práticas. No caso da capacidade de gestão de projetos, os líderes devem apoiar a elaboração de um portfólio de projetos de inovação, estabelecer práticas de controle e acompanhamento dos projetos e adotar software ou ferramentas de gestão da inovação. Para obter melhores resultados com sua base de conhecimento interno, os empresários devem identificar as competências necessárias em suas equipes, adotar políticas de educação e treinamento e efetuar avaliação de desempenho dos colaboradores a fim de contar com um quadro qualificado de mão de obra. Já melhorias no determinante estratégia implicam em elaborar um planejamento estratégico, incluindo o conceito e estratégia de inovação, estabelecer indicadores e metas estratégicas e monitorar e revisar o planejamento.

Como contribuição para o setor público, a compreensão dos determinantes da capacidade de inovação das PMEs a partir dos resultados dessa pesquisa permite inferir conclusões úteis para a formulação de políticas públicas adequadas de fomento à inovação no âmbito das pequenas e médias empresas. As PMEs constituem um grupo 
importante não só para a inovação, como também para o crescimento da economia dos países. Não obstante, empresas com esse porte enfrentam com maior dificuldade as barreiras para inovação, especialmente em virtude da escassez de recursos com que operam. Tendo em vista essa realidade, o apoio governamental efetivo para inovação focado nas PMEs pode contribuir para o sucesso e rápido crescimento dessas empresas.

\subsection{Limitações da Pesquisa}

As limitações do presente estudo estão relacionadas a três pontos, sendo eles: literatura, perfil da amostra em termos de localização geográfica e item 10 da seção III do questionário.

Com relação às limitações referentes à literatura, apesar da tentativa de buscar na revisão da literatura aprofundar o conhecimento sobre todos os temas abordados na pesquisa por meio de artigos seminais, nucleares e recentes, observou-se que alguns conceitos ainda não estão consolidados na literatura. Tendo em vista essa realidade, alguns conceitos foram adotados com base no critério de escolha do autor. Esses conceitos estão amparados pela literatura, mas suas diferentes intepretações podem gerar algumas inconsistências na análise.

No caso do perfil da amostra em termos de localização geográfica, a despeito de a amostra ter contemplado empresas de mais de 40 cidades agrupadas em 9 núcleos que representam distintas regiões do estado de São Paulo, é possível que haja certa homogeneidade entre essas localizações quando comparado a outros estados, conforme foi mencionado no item 5.3.5. Nesse sentido, há uma limitação de pesquisa com relação ao resultado obtido para a relação entre localização geográfica e a capacidade de inovação das PMEs.

Por fim, a deficiência apontada no item 5.3.1 em relação à análise da variável investimento em máquinas e equipamentos diz respeito ao item 10 da seção III do questionário. Esse item coleta o dado referente ao valor do total de investimento em 
máquinas e equipamentos nos últimos 12 meses sobre o valor do faturamento total nos últimos 12 meses. Esse valor é um percentual que retrata de forma relativa os investimentos destinados às máquinas e equipamentos, no entanto não captura a qualidade do investimento nem o retorno proporcionado por ele. A ausência dessa informação complementar pode ter enviesado o resultado obtido para essa variável.

\subsection{Estudos Futuros}

As inovações podem surgir em diversas formas (TIDD et al., 2005; LAFORET, 2013) e consequentemente serem classificadas em diferentes tipos (FAGERBERG, 2003). O presente estudo buscou construir um modelo abrangente e aceitável do ponto de vista dos diferentes tipos de inovação. No entanto, as competência e habilidade variam em função do tipo de inovação almejado pela empresa (FREEL, 2005). A literatura apresenta diferenças entre os tipos de inovação que existem entre empresas de diferentes tamanhos, tempo de existência e setores (LAFORET, 2013).

Com base nos fatos expostos é possível inferir a importância de adotar uma tipologia de inovação. A adoção de tipologia para analisar, em particular, a inovação nas empresas proporciona um framework com base empírica que auxilia na elaboração da teoria da inovação (PAVITT, 1984; ARCHIBUGI, 2001). Segundo Damanpour e Wischnevsky (2006) tipos de inovação devem ser discriminados na pesquisa sobre inovação a fim de contribuir para o entendimento do fenômeno da inovação e para a consistência dos resultados do estudo, além de serem relevantes para identificar que impactos econômicos e sociais variam de acordo com o tipo de inovação (FAGERBERG, 2003).

Em geral, as inovações são distinguidas nas pesquisas de acordo com as três principais classificações: técnica e administrativa; radical e incremental; e produto e processo (LAFORET, 2013). O presente estudo propõe, para estudos futuros, a adoção da tipologia de inovação utilizando a distinção entre inovação em produto e processo haja vista tratar-se de uma classificação amplamente adotada, com conceitos claros e precisos o que demonstra a maturidade da tipologia e proporciona robustez à pesquisa. 
O foco na distinção entre inovações em produto e processo permitirá avaliar eventuais determinantes específicos para inovações em produto e processo, bem como o impacto econômico e social resultante de cada tipo de inovação. Assume-se comumente que a introdução de novos produtos tem efeito positivo no crescimento da renda e emprego e argumenta-se que a inovação em processo, devido à sua natureza de redução de custo, tem um efeito mais ambíguo (FAGERBERG, 2003). A literatura existente tende a sugerir que novos produtos resultam em expansão em novas áreas e incremento em market share e margem de lucro, contribuindo dessa forma para a melhoraria da performance financeira e da vantagem competitiva da empresa (DANEELS e KLEINSCHMIDT, 2001) e, em contraste, inovação em processo é associada a melhoria na eficiência, produtividade e redução de custo, conforme mencionado anteriormente (LAFORET, 2013). Tais resultados são interessantes de serem analisados, em especial para as PMEs. 


\section{REFERÊNCIAS BIBLIOGRÁFICAS}

ABERNATHY, W. J.; UTTERBACK, J. M. Patterns of industrial innovation. Technology Review, Cambridge, v. 80, n. 7, p. 40-47, 1978.

ACS, Z.J.; AUDRETSCH, D.B. Innovation and Small Firms. The MIT Press, Cambridge, MA: MIT University Press, 1990.

ADAMS, R.; BESSANT, J.; PHELPS, R. Innovation management measurement: A review. International Journal of Management Reviews, v. 8, n. 1, p. 21- 47, 2006.

ADCOCK, R.; COLLIER, D. Measurement validity: a shared standard for qualitative and quantiative research. The American political science review, v. 95, n. 3, p. 529546, 2001.

ADNER, R.; LEVINTHAL, D. Demand heterogeneity and technology evolution: implications for product and process innovation. Management Science, v. 47, n. 5, p. 611-628, 2001.

AGHION, P.; HOWITT, P. Endogenous Growth Theory. The MIT Press, Cambridge, MA: MIT University Press, 1998.

AHMED, P. K. Culture and climate for innovation. European Journal of Innovation Management, v. 1, n. 1, p. 30-43, 1998.

AKINCI, G.; UTLU, Z. The reseach \& development and innovation capacity of small and medium sized enterprises. IMES Procedia - Social and Behavioral Sciences, v. 195, p. $790-798,2015$.

ALBALADEJO, M.; ROMIJN, H. Determinants of innovation capability in small UK firms: an empirical analysis. ECIS, Technische Universiteit Eindhoven, Eindhoven, 2000 .

ALVAREZ, S.; BUSINETIZ, L. The entrepreneurship of resource-based theory. Journal of Management, 2001.

AMABILE, T. M.; CONTI, R.; COON, H. Assessing the work environment for creativity. Academy of Management Journal, v. 39, n. 5, p. 1154-1184, 1996. 
AMABILE, T. M.; SCHATZEL, E. A.; MONETA, G. B.; KRAMER, S. J. Leader behaviors and the work environment for creativity: perceived leader support. The Leadership Quarterly, v. 15, n. 1, p. 5-32, 2004.

ANDERSEN, E. S. Schumpeter's evolutionary economics: a theoretical, historical and statistical analysis of the engine of capitalism. Anthem, London, 2009.

APAYDIN, M.; CROSSAN, M. A multi-dimensional framework of organizational innovation: a systematic review of the literature. Journal of Management Studies, v. 47, n. 6, p. 1154-1191, 2010.

ARCHIBUGI, D. Pavitt's taxonomy sixteen years on: a review article. Economic Innovation and New Technology, v. 10, p. 415-425, 2001.

ARCHIBUGI, D.; CESARATTO, S.; SIRILLI, G. Sources of innovative activities and industrial organization in Italy. Research Policy, v. 20, p. 299-313, 1991.

ARCHIBUGI, D.; SIRILLI, G. The direct measurement of technological innovation in business. European Commission (Eurostat), Innovation and Enterprise Creation: Statistics and Indicators, European Commission, 2001.

ARMBRUSTER, H.; BIKFALVI, A.; KINKEL, S.; LAY, G. Organizational innovation: the challenge of measuring non-technical innovation in largescale surveys. Technovation, v. 28, p. 644-657, 2008.

ASA R.; NAVNEEL S. P.; MAW, M. H. Exploring factors that construct innovation capability in services sector. International Journal of Contemporary Business Studies, v. 4, n. 4, p. 20-30, 2013. ISSN 2156-7506 Disponível em: http://www.akpinsight.webs.com

ASHKENAS, R. Real innovation knows no boundaries. The Journal for Quality and Participation, v. 21, n. 6, p. 34-38, 1998.

ASSINK, M. The inhibitors of disruptive innovation capability: a conceptual model. European Journal of Innovation Management, v. 9, n. 2, p. 215-233, 2006.

BABBIE, E. Métodos de pesquisa de survey. Ed. UFMG, Belo Horizonte, 1999.

BALACHANDRA, R.; FRIAR, J. H. Factors for success in R\&D projects and new product innovation: a contextual framework. Engineering Management, IEEE Transactions, v. 44, n. 3, p. 276-287, 1997. 
BANTEL, K. A.; JACKSON, S. E. Top management and innovations in banking: does composition of top management team make a difference? Strategic Management Journal, v. 10, p. 107-124, 1989.

BARBER, J.; METCALFE, J.; PORTEOUS, M. Barriers to growth: the ACARD study. Em: Barber, J., Metcalfe, J., Porteous, M. (Eds.), Barriers to Growth in Small Firms, Routledge, London, 1989.

BARBIERI, J. C. et al. Organizações inovadoras: estudos e casos brasileiros. Editora FGV, Rio de Janeiro, 2003.

BARNEY, J. Firm resources and sustained competitive advantage. Journal of Management, v. 17, p. 99-120, 1991.

BARRAS, R. Towards a theory of innovation in services. Research Policy, v. 15, p. 161-73, 1986.

BECHEIKH, N.; REJEAN, L.; NABIL, A. Lessons from innovation empirical studies in the manufacturing sector: a systematic review of the literature from 1993-2003. Technovation, v. 26, p. 644-664, 2006.

BELL, M.; PAVITT, K. Technological accumulation and industrial growth: contrasts between developed and developing countries. Industrial and Corporate Change, v. 2, n. 2, p. 157-211, 1993.

BENEITO, P. Choosing among alternative technological strategies: an empirical analysis of formal sources of innovation. Research Policy, v. 32, p. 693-713, 2003.

BERKHOUT, A. J.; DAP HARTMANN, P. D.; ROLAND, O. Innovating the innovation process. International Journal of Technology Management, v. 34, n. 3/4, 2006.

BHUPATIRAJU, S.; ÖNDER N.; TRIULZI, G.; VERSPAGENA, B. Knowledge flows: analyzing the core literature of innovation, entrepreneurship and science and technology studies. Research Policy, v. 41, p. 1205-1218, 2012.

BIRCHALL, D.W.; CHANARON, J.J.; SODERQUIST, K. Managing innovation in SMEs: a comparison of companies in the UK, France and Portugal. International Journal of Technology Management, v. 12, n. 3, p. 291-305, 1996.

BIRKINSHAW， J.; BOUQUET， C.; BARSOUX， J-L. The five myths of innovation. MIT Sloan Management Review, v. 52, n. 2, 2011. 
BIRKINSHAW, J.; GIBSON, C. Building ambidexterity into an organization. MIT Sloan Management Review, v. 45, p. 47-55, 2004.

BIRKINSHAW, J.; HAMEL, G.; MOL, M. J. Management Innovation. Academy of Management Review, v. 33, n. 4, p. 825-845, 2008.

BLUMENTRITT, T. Does small and mature have to mean dull? Defying the ho-hum at SMEs. Journal of Business Strategy, v. 25, n. 1, p. 27-33, 2004.

BOLY, V.; MOREL, L.; ASSIELOU, N. G.; CAMARGO, M. Evaluating innovative processes in french firms: methodological proposition for firm innovation capacity evaluation. Research Policy, v. 43, p. 608- 622, 2014.

BOOZ, A. New product management for the 1980s. Hamiton Inc, NY, 1982.

BOS-BROUWERS, H. E. J. Corporate sustainability and innovation in SMEs: Evidence of themes and activities in practice. Business Strategy and the Environment, v. 19, n. 7, 2009.

BOUGRAIN, F.; HAUDEVILLE, B. Innovation, collaboration and SMEs internal research capacities. Research Policy, v. 31, p. 735-747, 2002.

BOURGEOIS, L. J. On the measurement of organizational slack. Academy of Management Review, v. 6, n. 1, p. 29-39, 1981.

BRIDGE, S.; O’NEILL, K.; MARTIN, F. Understanding enterprise, entrepreneurship and small business. Basingstoke: Palgrave Macmillan, $3^{\text {rd }}$ ed., 2009.

BURGELMAN, R. A.; MODESTO, A. M. Strategic management of technology and innovation. Small Business Economics, v. 5, n. 4, p. 331-334, 1993.

CAMISÓN, C.; VILLAR-LÓPEZ, A. Organizational innovation as an enabler of technological innovation capabilities and firm performance. Journal of Business Research, 2012.

CAMISON, Z. C.; LAPIEDRA, A. R.; SEGARRA-CIPRES, M.; BORONAT, N. M. A meta-analysis of innovation and organizational size. Organization Studies, v. 25, p. 331-361, 2004.

CANNON, T. Innovation, creativity and small firm organization. International Small Business Journal, v. 4, n. 1, p. 33-41, 1985. 
CAPON, N.; FARLEY, J. U.; HOENIG, S. Determinants of financial performance: a meta-analysis. Management Science, v. 36, p. 1143-1159, 1990.

CAPON, N.; FARLEY, J. U.; LEHMAN, D. R.; HULBERT, J. M. Profiles of product innovators among large US manufacturers. Management Science, v. 38, p. 157-170, 1992.

CAPON, N.; HULBERT, J. Corporate Strategic Planning. Columbia University Press, New York, 1988.

CARRIER, C. Research note: intrapreneurship on large firms and SMEs: a comparative study. International Small Business Journal, v. 12, n. 3, p. 54-61, 1994.

CAVES, R.E. Industrial organization and new findings on the turnover and mobility of firms. Journal of Economic Literature, v. 36, n. 4, p. 1947-1982, 1998.

CEFIS, E.; MARSILI, O. Survivor: the role of innovation in firm's survival. WPT. Koopmans Institute, USE, Utrecht University, n. 03-18, 2003.

CEGARRA, N. J. G.; SÁNCHEZ, V. M. E.; CEGARRA, L. D. Balancing exploration and exploitation of knowledge through an unlearning context: an empirical investigation in SMEs. Management Decision, v. 49, n. 7, p. 1099-1119, 2011.

CHEN, C.-J.; HUANG, J.-W. Strategic human resource practices and innovation performance: the mediating role of knowledge management capacity. Journal of Business Research, v. 62, n. 1, p. 104-114, 2009.

CHEN, J.; CHEN, I. A theory of innovation resource synergy. Innovation: Management, Policy \& Practice, v. 15, n. 3, p. 368-392, 2013.

CHEN, Y.-S.; LIN, M.-J. J.; CHANG, C.-H The positive effects of relationship learning and absorptive capacity on innovation performance and competitive advantage in industrial markets. Industrial Marketing Management, v. 38, n. 2, p. 152-158, 2009.

CHESBROUGH, H W. Open Innovation: the new imperative for creating and profiting from technology. Harvard Business School Press, Boston, Massachussets 2003.

CHESTER, A. N. Aligning technology with business strategy. Research Technology Management, v. 37, n. 1, 1994. 
CHIESA, V.; COUGHLAN, P.; VOSS, C. A. Development of a technical innovation audit. Journal of Product Innovation Management, v. 13, p. 105-136, 1996.

CHO, H.; PUCIK, V. Relationship between innovativeness, quality, growth, profitability, and market value. Strategic Management Journal, v. 26, p.555- 575, 2005.

CHOI, J. N.; CHANG, J. Y. Innovation implementation in the public sector: an integration of institutional and collective dynamics. Journal of Applied Psychology, v. 94, p. 245-253, 2009.

CHOI, T. Y; KRAUSE, D.R. A supply base and its complexity: implications for transaction costs, risks, responsiveness, and innovation. Journal of Operations Management, v. 24, p.637-652, 2006.

CHRISTENSEN, C. M. The innovator's dilemma. Harvard Business School Press, Cambridge, 1997.

CHRISTENSEN, C. M.; RAYNOR, M. E. The innovator's solution: creating and sustaining successful growth. Harvard Business School Press, Cambridge, 2003.

CHUDNOVSKY, D.; LÓPEZ, A.; PUPATO, G. Innovation and productivity in developing countries: a study of Argentine manufacturing firms' behaviour (19922001). Research Policy, v. 35, p. 266-288, 2006.

CLARK, P. A.; STAUNTON, N. Innovation in technology and organisation. Routledge, London, 1989.

COBBENHAGEN, J. Successful innovation: towards a new theory for the management of small and medium-sized enterprises. Edward Elgar, Cheltenham, 2000.

COHEN, W. M. Empirical studies of innovative activity. Em STONEMAN, P., (eds.), Handbook of the Economics of Innovation and Technological Change, Oxford: Blackwell, p. 182-264, 1995.

COHEN, W. M.; LEVINTHAL, D. Absorptive capacity: a new perspective on learning and innovation. Administrative Science Quarterly, v. 35, p. 128-152, 1990.

COOKE, P.; HEIDENREICH, M.; BRACZYK, H. J. Regional systems of innovation. Routledge, London, 2004. 
COOMBS, R.; NARANDREN, P.; RICHARDS, A. A literature-based innovation output indicator. Research Policy, v. 25, p. 403-413, 1996.

COOPER, R. G.; EDGETT, S. Generating breakthrough new product ideas: feeding the innovation funnel. Product Development Institute, Canada, 2007.

COOPER, R. G.; KLEINSCHMIDT, E. J. Winning businesses in product development: the critical success factors. Research Technology Management, v. 50, n. 3, p. 52-66, 2007.

COTTAM, A.; ENSOR, J.; BAND, C. A benchmark study of strategic commitment to innovation. European Journal of Innovation Management, v. 4, n. 2, p. 88-94, 2001.

CRESWELL, J. W. Projeto de pesquisa: métodos qualitativos, quantitativos e misto. $2^{\text {a }}$ ed. Artmed, Porto Alegre, 2007.

DAFT, R. L. A dual-core model of organizational innovation. Academy of Management Journal, v. 21, p. 193-210, 1978.

DAGHFOUS, A. Absorptive capacity and the implementation of knowledge-intensive best practices. SAM Advanced Management Journal, Spring, p. 21-27, 2004.

DAMANPOUR, F. Organizational innovation: a meta-analysis of effects of determinants and moderators. Academy of Management Journal, v. 34, n. 3, p. 555590, 1991.

DAMANPOUR, F.; ARAVIND, D. Managerial innovation: conceptions, processes, and antecedents. Management and Organization Review, v. 8, n. 2, p. 423-454, 2012.

DAMANPOUR, F.; GOPALAKRISHNAN, S. The dynamics of the adoption of product and process innovations in organizations. Journal of Management Studies, v. 38, p. 45-65, 2001.

Theories of organizational structure and innovation adoption: the role of environmental change. Journal of Engineering and Technology Management, v. 15, p. 01-24, 1998.

DAMANPOUR, F.; SCHNEIDER, M. Phases of the adoption of innovation in organizations: effects of environment, organization and top managers. British Journal of Management, v. 17, n. 3, p. 215-236, 2006. 
DAMANPOUR, F.; SZABAT, K. A.; EVAN, W. M. The relationship between types of innovation and organizational performance. Journal of Management Studies, v. 26, n. 6, p. 587-602, 1989.

DAMANPOUR, F.; WISCHNEVSKY, J. D. Research on innovation in organizations: distinguishing innovation-generating from innovation-adopting organizations. Journal of Engineering and Technology Management, v. 23, p. 269-291, 2006.

DANNEELS, E. The dynamics of product innovation and firm competencies. Strategic Management Journal, v. 23, n. 12, p. 1095-121, 2002.

DANNEELS, E.; KLEINSCHMIDT, E. J. Product innovativeness from the firm's perspective: its dimensions and their relation with project selection and performance. Journal of Product Innovation Management, v. 18, n. 6, p. 357-373, 2001.

DAS, S. R.; JOSHI, M. P. Process innovativeness in technology services organizations: roles of differentiation strategy, operational autonomy and risk-taking propensity. Journal of Operations Management, v. 25, p. 643-660, 2007.

DAY, G. S. The capabilities of market-driven organizations. Journal of Marketing, v. 58, p. 37- 52, 1994.

DEEDS, D. The role of R\&D intensity, technical development and absorptive capacity in creating entrepreneurial wealth in high technology start-ups. Journal of Engineering and Technology Management, v. 18, p. 29-47, 2001.

DE FILLIPPI, R.; GRABHER, G.; JONES, C. Paradoxes of creativity: managerial and organizational challenges of the cultural economy. Journal of Organizational Behaviour, v. 28, p. 511-521, 2007.

Department for Business Innovation \& Skills. Innovation Report 2014: innovation research and growth. London, Mar. 2014.

DESHPANDE, R.; FARLEY, J. U.; WEBSTER, E. Corporate culture, customer orientation and innovativeness in Japanese firms: a quadrad analysis. Journal of Marketing, v. 57, p. 23-27, 1993.

DE VELLIS, R. F. Scale development: theory and applications. $3^{\text {rd }}$ ed. Sage Publications, North Carolina, 2011.

DEWAR, R. D.; DUTTON, J. E. The adoption of radical and incremental innovations: an empirical analysis. Management Science, v. 32, p. 1422-1433, 1986. 
DOCTER, H. J.; STOKMAN, C. T. M. Innovation in SMEs (Innovatie in het industrie"le midden en kleinbedrijf). Paper for symposium on Technology-Economics, [S.I.], 1988.

DODGSON, M.; GANN, D.; SALTER, A. The Management of technological innovation - strategy and practice. Completely Revised and Updated. Oxford University Press, Oxford, 2008.

DOLOREUX, D.; MELANCON, Y. On the dynamics of innovation in Quebec's coastal maritime industry. Technovation, v. 28, n. 4, p. 231-243, 2008.

DOMENCICH, T; MCFADDEN, D. Urban travel demand: a behavioral analysis. North Holland Press, Amsterdam, 1975.

EDWARDS, T.; DELBRIDGE, R.; MUNDAY, M. Understanding innovation in small and medium-sized enterprises: a process manifest. Technovation, v. 25, p. 1119-1127, 2005.

ETTLIE, J. E.; BRIDGES, W.P.; O'KEEFE, R. D. Organization strategy and structural differences for radical versus incremental innovation. Management Science, v. 30, p. 682-695, 1984.

ETZKOWITZ, H. Hélice Tríplice - Universidade - Indústria - Governo: Inovação em Movimento. Editora: EDIPUCRS, Rio Grande do Sul, 2009.

EVAN, W. M.; BLACK, G. Innovation in business organizations: some factors associated with success or failure of staff proposals. Journal of business, v. 40, p. 519530, 1967.

FACÓ, J. F. B. Capacidade de inovação organizacional: uma análise aplicada à indústria de transformação paulista. 2009. Tese - EAESP FGV, São Paulo, 2009.

FAGERBERG, J. Innovation: a guide to the literature. Centre for technology, innovation and culture, University of Oslo, 2003.

FAGERBERG, J.; FOSAAS, M.; SAPPRASERT, K. Innovation - exploring the knowledge base. Research Policy, v. 41, n. 7, p. 1132-1153, 2012.

FAGERBERG, J.; VERSPAGEN, B. Innovation studies: the emerging structure of a new scientific field. Research Policy, v. 38, p. 218-233, 2009. 
FERGUSON, D. Partnering for innovation and growth. Handbook of Business Strategy, v. 6, n. 1, p. 101-106, 2005.

FERNANDES, C. I.; FERREIRA, J. J. M.; RAPOSO, M. L. Drivers to firm innovation and their effects on performance: an international comparison. International Entrepreneurship Management Journal, v. 9, p. 557-580, 2013.

FIGUEIREDO, P. N. Beyond technological catch-up: an empirical investigation of further innovative capability accumulation outcomes in latecomer firms with evidence from Brazil. Journal of Eng. Technol. Management, v. 31, p. 73-102, 2014.

FILIPE, N. C. C. Comunicação interna vector estratégico para a qualidade: um ensaio sobre uma empresa do sector do retalho. Universidade Aberta, Lisboa, 2007.

FORSMAN, H. Innovation capacity and innovation development in small enterprises: a comparison between the manufacturing and service sectors. Research Policy, v. 40, n. 5, p. 739-750, 2011.

FORZA, C. Survey research in operations management: a process-based perspective. International Journal of Operations \& Production Management, v. 22, n. 2, p. 152194, 2002.

FRAMBACH, R. T. An integrated model of organizational adoption and diffusion of innovation. European Journal of Marketing, v. 27, n. 5, p. 22-41, 1993.

FRANCINI, W. S. Modelos de gestão da inovação: um estudo de casos em empresas brasileiras do setor petroquímico. 2012. Tese - EAESP-FGV. São Paulo, 2012.

FREEL, M. S. External linkages and product innovation in small manufacturing firms. Entrepreneurship and Regional Development, v. 12, p. 245-266, 2000.

FREEL, M. S. Patterns of innovation and skills in small firms. Technovation, v. 25, p. 123-134, 2005.

FREEL, M. S. Sectoral patterns of small firm innovation, networking and proximity. Research Policy, v. 32, p. 751-770, 2003.

FREEMAN, C. Innovation. Em: Kuper, A.; Kuper, J. The social science encyclopedia. Routledge \& Kegan Paul, London, p. 394-395, 1985. 
FREEMAN, C. The Economics of Industrial Innovation. Penguin, Harmondsworth, 1974.

FREEMAN, C.; CLARK, J.; SOETE, L. Unemployment and technical innovation: a study of long waves and economic development. Pinter, London, 1982.

FREEMAN, C.; SOETE, L. The economics of industrial innovation. $3^{\text {rd }}$ ed. The MIT Press, London, 1982.

FRITZ, W. Determinants of product innovation activities. European Journal of Marketing, v. 23, n. 10, p. 32-43, 1989.

FURMAN, J. L.; PORTER, M. E.; STERN, S. The determinants of national innovative capacity. Research Policy, v. 31, p. 899-933, 2002.

GALBRIGHT, J. Organizational Design. Addinson Wesley, USA, 1977.

Projetando a Organização Inovadora. Em: Starkey, K. (org). Como as Organizações Aprendem. Futura, São Paulo, 1997.

GATIGNON, H.; TUSHMAN, M. L.; SMITH, W.; ANDERSON, P. A structural approach to assessing innovation: construct development of innovation locus, type, and characteristics. Management Science, v. 48, p. 1103-1122, 2002.

GEFFEN, C. A.; ROTHENBERG, S. Suppliers and environmental process: the automotive paint process. International Journal of Operations \& Production Management, v.20, p.166-186, 2000.

GEIGER, S. W.; CASHEN, L. H. A multidimensional examination of slack and its impact on innovation. Journal of Managerial Studies, v.15, p.68-84, 2002.

GERMAIN, R. The role of context and structure in radical and incremental logistics innovation adoption. Journal of Business Research, v. 35, p. 117-127, 1996.

GOEDHUYS, M.; VEUGELERS, R. Innovation strategies, process and product innovations and growth: firm-level evidence from Brazil. Structural Change and Economic Dynamics, v. 23, p. 516- 529, 2012.

GOPALAKRISHNAN, S.; DAMANPOUR, F. The impact of organizational context on innovation adoption in commercial banks. IEEE Transactions on Engineering Management, v. 47, p. 14-25, 2000. 
GOVINDARAJAN, V.; KOPALLE, P. K. Disruptiveness of innovations: measurement and an assessment of reliability and validity. Strategic Management Journal, v. 27, p. 189-199, 2006.

GREVE, H. A behavioral theory of R\&D expenditures and innovations: evidence from shipbuilding. Academy of Management Journal, v. 46, p. 685-702, 2003.

GRODAL, S. Towards a dynamic model of networks and innovation. Paper apresentado na DRUID Summer Conference, Industrial Dynamics, Innovation and Development, Elsinore/Denmark, Jun., 2004.

GUPTA, A. K.; SINGHAL, A. Managing human resources for innovation and creativity. Research Technology Management, v. 36, p. 41-48, 1993.

HADJIMANOLIS, A. Barriers to innovation for SMEs in a small less developed country (Cyprus). Technovation, v. 19, p. 561-570, 1999.

HAGEDOORN, J.; CLOODT, M. Measuring innovative performance: is there an advantage in using multiple indicators? Research Policy, v. 32, n. 8, p. 1365-1379, 2003.

HAIR, J. F.; BLACK, W. C.; BABIN, B. J.; ANDERSON, R. E. Multivariate data analysis. $7^{\text {th }}$ ed. Pearson Prentice Hall, 2010.

HAMEL, G.; KIRKPATRICK, D. Innovation do's and don'ts. Fortune, v. 150, n. 5, p. 239-240, 2004.

HAMID, N. A. A.; ROSMAINI, T. The relationship of business innovation capabilities and technology innovation capabilities on SME organization performance: a conceptual framework proceedings. The 2nd International Conference On Global Optimization and Its Applications 2013 (ICoGOIA2013). Avillion Legacy Melaka Hotel, Malaysia 28-29 Aug. 2013.

HANNES, K.; LOCKWOOD, C.; PEARSON, A. A comparative analysis of three online appraisal instruments' ability to assess validity in qualitative research. Qualitative Health Research, v. 20, n. 12, p. 1736-1743, 2010.

HAUSMAN, A. Theory and propositions for future research. Industrial Marketing Management, v. 34, p. 773-782, 2005.

HAYES, R. H.; ABERNATHY, W. J. Managing for the long term: managing our way to economic decline. Harvard Business Review, p. 138-149, Jul./Aug., 2007. 
HEELEY, M. B; MATUSIK, S. F.; JAIN, N. Innovation, appropriability, and the underpricing of initial public offerings. Academy of Management Journal, v. 50, n. 1, p. 209-225, 2007.

HELFAT, C. E.; FILKELSTEIN, S.; MITCHELL, W.; PETERAF, M. A.; SINGH, H.; TEECE, D. J.; WINTER, S. G. Dynamic capabilities: understanding strategic change in organizations. Blackwell Publishing, Malden, MA, USA, 2007.

HENARD, D. H.; SZYMANSKI, D. M. Why some new products are more successful than others. Journal of Marketing Research, p. 38, n. 3, p. 362- 375, 2001.

HENDERSON, A.D. Firm strategy and age dependence: a contingent view of the liabilities of newness, adolescence, and obsolescence. Administrative Science Quarterly, v. 44, n. 2, p. 281-314, 1999.

HEROLD, D. M.; JAYARAMAN, N.; NARAYANASWAMY, C. R. What is the relationship between organizational slack and innovation? Journal of Managerial Issues, v. 28, p.372-392, 2006.

HEWITT, D. N. Resource and capability constraints to innovation in small and large plants. Small Business Economics, v. 26, p. 257-277, 2006.

HIPPEL, E. V. An emerging hotbed of user-centered innovation. Em: The HBR Brakthrough Ideas for 2007. Copresented by Harvard Business Review e World Economic Forum, p. 20-54, Feb., 2007.

HOBDAY, M. Firm-level innovation models: perspectives on research in developed and developing countries. Technology Analysis \& Strategic Management, v. 17, n. 2, p. 121-146, Jun. 2005.

HOFFMAN, K.; PAREJO, M.; BESSANT, J.; PERREN, L. Small firms, R\&D technology and innovation in the UK: a literature review. Technovation, v. 18, n. 1, p. 39-55, 1998.

HOSMER, D. W.; LEMESHOW, S. Applied logistic regression. 2nd ed. John Wiley \& Sons Inc., New York, NY, 2000.

HOTHO, S.; CHAMPION, K. Small businesses in the new creative industries: innovation as a people management challenge. Management Decision, v. 49, n. 1, p. 29-54, 2011. 
HUBER, J. Technological environmental innovations (TEIs) in a chain analytical and life-cycle-analytical perspective. Journal of Cleaner of Production, v. 16, 2008.

HULL, C. E.; COVIN, J. G. Learning capability, technological parity, and innovation mode use. Journal of Product Innovation Management, v. 27, n. 1, p. 97-114, 2010.

HULT, G. T. M.; HURLEY, R. F.; KNIGHT, G. A. Innovativeness: its antecedents and impact on business performance. Industrial Marketing Management, v. 33, n. 5, p. 429-438, 2004.

HULT, G. T. M; KETCHEN, D. J.; NICHOLS, E. L. An examination of cultural competitiveness and order fulfillment cycle time within supply chains. Academy of Management Journal, v. 45, p. 577-586, 2002.

HURLEY, R. F.; HULT, T. M. Innovation, market orientation, and organizational learning: an integration and empirical examination. Journal of Marketing, v. 62, p. 42-54, 1998.

Instituto Brasileiro de Geografia e Estatística (IBGE). PINTEC - Pesquisa de Inovação Tecnológica 2011. IBGE, Rio de Janeiro, 2013.

Tecnológica 2005. IBGE, Rio de Janeiro, 2007.

PINTEC - Pesquisa de Inovação

JAMBULINGAM, T.; KATHURIA, R.; DOUCETTE, W. R. Entrepreneurial orientation as a basis for classification within a service industry: the case of retail pharmacy industry. Journal of Operations Management, v. 23, p. 23-24, 2005.

JAWORSKI, B.; KOHLI, A. Market orientation: antecedents and consequences. Journal of Marketing, v. 57, p. 53-70, 1993.

JENSEN, M. B.; JOHSON, B.; LORENZ, E.; LUNDVALL, B. A. Forms of knowledge and modes of innovation. Research Policy, v. 36, p. 680-693, 2007.

JHA, A. K.; BOSE, I. Innovation in IT firms: an investigation of intramural and extramural R\&D activities and their impact. Information \& Management, v. 52, n. 6, 2015.

JUNG, D. I.; CHOW, C.; WU, A. The role of transformational leadership in enhancing organizational innovation: hypotheses and some preliminary findings. The Leadership Quarterly, v. 14, p. 525-544, 2003. 
KAMINSKI, P. C.; DE OLIVEIRA, A. C.; LOPES, T. M. Knowledge transfer in product development processes: a case study in small and medium enterprises (SMEs) of the metal-mechanic sector from São Paulo, Brazil. Technovation, v. 28, n. 1-2, p. 29-36, 2008.

KANTER, R. M. The Change Masters. Simon \& Schuster, New York, NY, 1983.

KAPLAN, A. The conduct of inquiry. Chandler Publ. Co., Scranton, PA, 1964.

KATILA, R.; SHANE, S. When does lack of resources make new firms innovative? Academy of Management Journal, v. 48, p. 814-829, 2005.

KAUFMANN, A.; TODTLING, F. How effective is innovation support for SMEs? An analysis of the region of Upper Austria. Technovation, v. 22, p. 147-159, 2002.

KEIZER, J.; DIJSTRA, L.; HALMAN, J. I. M. Explaining innovative efforts of SMEs. An exploratory survey among SMEs in the mechanical and electrical engineering sector in The Netherlands. Technovation, v. 22, p. 1-13, 2002.

KHAZANCHI, D. A. Framework for the validation of IS Concepts. Proceedings of the second annual association for information systems Americas conference. Phoenix, Arizona, 1996.

KIMBERLY, J. R.; EVANISKO, M. J. Organizational innovation: the influence of individual organizational, and contextual factors on hospital adoption of technological and administrative innovations. Academy of Management Journal, v. 24, p. 689-713, 1981.

KLEINKNECHT, A.; VANMONTFORT, K.; BROUWER, E. The non-trivial choice between innovation indicators. Economics of Innovation \& New Technology, v. 11, n. 2, p. 109-121, 2002.

KNOX, S. The boardroom agenda: developing the innovative organization. Corporate Governance, Bradford, UK, v. 2, n. 1, p. 27-36, 2002.

KOC, T.; CEYLAN, C. Factores impacting the innovative capacity in large-scale companies industry. Technovation, v. 28, p. 231-243, 2007.

$\mathrm{KOCH}, \mathrm{R}$. O princípio 80/20: o segredo de se realizar mais com menos. $1^{\mathrm{a}}$ ed. Rocco, Rio de Janeiro, 2000. 
KOHAVI, R. A study of cross-validation and bootstrap for accuracy estimation and model selection. Em: International joint Conference on artificial intelligence, v. 14, p. 1137-1145, 1995.

KOHLI, A.; JAWORSKI, B. J. Market orientation: the construct, research propositions, and managerial implications. Journal of Marketing, v. 54, p. 1-8, 1990.

LAFORET, S. Organizational innovation outcomes in SMES: effects of age, size, and sector. Journal of World Business, v. 48, p. 490-502, 2013.

LAFORET, S.; TANN, J. Innovative characteristics of small manufacturing firms. Journal of Small Business and Enterprise Development, v. 13, n. 3, p. 363-380, 2006.

LANGERAK, F.; HULTINK, E. J.; ROBBEN, H. S. J. The impact of market orientation, product advantage, and launch proficiency on new product performance and organizational performance. Journal of Product Innovation Management, v. 21, p. 79-94, 2004.

LARSON, E. W.; GOBELI, D. H.; GREY, C. F. Application of project management by small business to develop new products and services. Journal of Small Business Management, v. 29, n. 2, p. 31-41, 1991.

LAURSEN, K.; SALTER, A. Open for innovation: the role of openness in explaining innovation performance among U.K. manufacturing firms. Strategic Management Journal, v. 27, p. 131-150, 2006.

LAWSON, B.; SAMSON, D. Developing innovation capability in organizations: a dynamic capabilities approach. International Journal of Innovation Management, v. 5, n. 3, p. 377-400, 2001.

LE BLANC, L. J.; NASH, R.; GALLAGHER, D.; GONDA, K.; KAKIZAKI, F. A comparison of US and Japanese technology management and innovation. International Journal of Technology Management, v. 13, n. 5-6, p. 601-614, 1997.

LEE, G.; XIA, W. Organizational size and IT innovation adoption: a meta-analysis. Information \& Management, v. 43, p. 975-985, 2006.

LEE, T.; YIN, F.; NG, K.; HSIEN, V.; PEI, L.; GAN, L. The relationship between knowledge management practices and technological innovation: a conceptual framework. International Journal of Management, Knowledge and Learning, v. 1, n. 1, p. 71-78, 2012. 
LENDEL, V. L.; HITTMÁRA, Š; SIANTOVÁ, E. Management of Innovation Processes in Company. Procedia Economics and Finance, v. 23, p. 861 - 866, 2015.

LEÓN, J. G. M.; VALENZUELA, A. V. Aprendizaje, innovación y gestión tecnológica en la pequeña empresa. Un estudio de las industrias metalmecánica y de tecnologías de información en Sonora. Contaduría y Administración, v. 59, n. 4, p. 253-284, 2014.

LICHTENTHALER, U.; ECKHARD, L. A Capability-Based framework for open innovation: complementing absorptive capacity. Journal of Management Studies, v. 46, n. 8, 2009.

LIN, H.-F.; SU, J. -Q.; HIGGINS, A. How dynamic capabilities affect adoption of management innovations. Journal of Business Research, v. 52, n. 5, 2015.

LOKSHIN, B.; BELDERBOS, R.; CARREE, M. The productivity effects of internal and external R\&D: evidence from a dynamic panel data model. Oxford Bulletin of Economics and Statistics, v. 70, n. 3, p. 399-413, 2008.

LOUVIERE, J. J.; HENSHER, D. A.; SWAIT, J. D. Stated choice methods: analysis and applications. Cambridge University Press, United Kingdom, 2003.

LOVE, E.G.; NOHRIA, N. Reducing slack: the performance consequences of downsizing by large industrial firms. Strategic Management Journal, v. 26, p. 1087$1108,2005$.

MACHADO, D. P. N. Inovação e cultura organizacional: um estudo dos elementos culturais que fazem parte de um ambiente inovador. Tese - EAESP FGV. São Paulo, 2004.

MADRID, -G. A.; GARCIA, D.; VAN AUKEN, H. Barriers to innovation among Spanish manufacturing SMEs. Journal of Small Business Management, v. 47, n. 4, p. 465- 488, 2009.

MAES, J.; SELS, L. SMEs' radical product innovation: the role of internally and externally oriented knowledge capabilities. Journal of Small Business Management, p. n/a-n/a, Jul. 2013.

MALHOTRA, N.K. Pesquisa de marketing: uma orientação aplicada. $3^{\text {a }}$ ed. Bookman, Porto Alegre, 2001.

MANN, A.; TODTLING, F. How effective is innovation support for SMEs? An analysis of the region of Upper Austria. Technovation, v. 22, p. 147-159, 2002. 
MANSFIELD, E. How rapidly does new industrial technology leak out? The Journal of Industrial Economics, v. 34, p. 217-223, 1985.

MAROTTI-DE-MELLO, A.; DEMONEL-DE-LIMA, W.; VILAS BOAS, E.; SBRAGIA, R. Innovative capacity and advantage: a case study of Brazilian firms. Revista de Administração e Inovação, v. 5, p. 57-72, 2008.

MARTINS, E. C.; TERBLANCHE, F. Building organisational culture that stimulates creativity and innovation. European Journal of Innovation Management, v. 6, n. 1, p. 64-74, 2003.

MARTIS, M. S. Validation of simulation based models: a theoretical outlook. Research Methods, v. 4, n. 1, p. 39-46, 2006.

MASSA, S.; TESTA, S. Innovation and SMEs: misaligned perspectives and goals among entrepreneurs, academics, and policy makers. Technovation, v. 28, n. 7, p. 393407, 2008.

MAXWELL, J. A. Understanding and validity in qualitative research. Harvard Educational Review, v. 62, p. 279-299, 1992.

MCADAM, R.; MCCONVERY, T; ARMSTRONG, G. Barriers to innovation within small firms in a peripheral location. International Journal of Entrepreneurial Behaviour \& Research, v. 10, n. 3, p. 206-221, 2004.

MCEVILY, S. K.; EISENHARDT, K. M. M.; PRESCOTT, J. E. The global acquisition, leverage, and protection of technological competencies. Strategic Management Journal, v. 25, n. 8/9, p. 713-22, 2004.

MEER, W.; VAN DER TROMMELEN, G.; VLEGGNAAR, J.; VRIEZEN, P. Collaborative R\&D and European industry. Research Technology Management, v. 39, n. 5 , p. 15-18, 1996.

MENARD, S. Coefficients of determination for multiple logistic regression analysis. The American Statistician, v. 54, n. 17-24, 2000.

MESSICK, S. Validity. Em R. Linn (Org.), Educational measurement. $3^{\text {rd }}$ ed. New York: American Council on Education and Macmillan Publishing Company, 1989.

MICHIE, J. The internationalisation of the innovation process. International Journal of the Economics of Business, v. 5, n. 3, p. 261-277, 1998. 
MINTZBERG, H. Structures in five: designing effective organizations. PrenticeHall, Englewood Cliffs, NJ, 1983.

MOOTEE, I. Linking Innovation with Strategy. 2010. Disponível em: http://mootee.typepad.com/innovation_playground/2008/02/strategic-and-i.html Acesso em: 07 de maio de 2012

MOSEY, S. Understanding new-to-market product development in SMEs. International Journal of Operations \& Production Management, v. 25, p.114-130, 2005.

MULLEN, M. R.; BUDEVA, D. G.; DONEY, P M. Research methods in the leading Small Business-Entrepreneurship. Journals: A Critical Review with Recommendations for Future Research. Journal of Small Business Management, v. 47, n.3, p. 287-307, 2009.

MUMFORD, M. D. Managing creative people: strategies and tactics for innovation. Human Resource Management Review, v. 10, n. 3, p. 313-351, 2000.

MUMFORD, M. D.; SCOTT, G. M.; GADDIS, B.; STRANGE, J. M. Leading creative people: orchestrating expertise and relationships. The Leadership Quarterly, v. 13 n. 6, p. 705-750, 2002.

MYERS, P. S. Knowlodge management and organizational design. ButterworthHeinemann, USA, 1996.

NARULA, R. R\&D collaboration by SMEs: new opportunities and limitations in the face of globalization. Technovation, v. 24, p. 153-161, 2004.

NARVER, K.; SLATER, S. The effect a market orientation has on business profitability. Journal of Marketing, v. 54, p. 20-35, 1990.

NEELY, A.; HII, J. Innovation and business performance: a literature review. The Judge Institute of Management Studies. University of Cambridge, Cambridge, 1998.

NELSON, R. R. National innovation systems. Em: Acs, Z. (Ed.), Regional Innovation, Knowledge and Global Change. Pinter, London, p. 11-26, 2000.

NELSON, R. R.; WINTER, S. G. In search of a useful theory of innovation. Research Policy, v. 6, n. 1, p. 36-76, 1997. 
NIETO, M. J.; SANTAMARIA, L. Technological collaboration: bridging the innovation gap between small and large firms. Working Paper 06-66, Business Economics Series, 20 November, 2006.

NONAKA, I. A dynamic theory of organizational knowledge creation. Organization Science, v. 5, p. 14-37, 1994.

Redundant, overlapping organizations: a Japanese approach to managing the innovation process. California Management Review, p. 27-38, 1990.

NONAKA, I.; TAKEUCHI, H. The knowledge creating company. How Japanese companies create the dynamics of innovation. Oxford University Press, New York, 1995.

NOOTEBOOM, B. Innovation and diffusion in small firms: Theory and evidence. Small Business Economics, v. 6, n. 5, p. 327-347, 1994.

NORD, W. R.; TUCKER, S. Implementing routine and radical innovations. Lexington Books, Lexington, MA, 1987.

NUENO, P. La capacidad inovadora de las empresas. Economia Industrial, n. 324, p. 55-58, 1998.

NYSTROM, P. C.; RAMAMURTHY, K.; WILSON, A. L. Organizational context, climate and innovativeness: adoption of imaging technology. Journal of Engineering Technology Management, v. 19, p. 221-247, 2002.

OAKEY, R. Innovation and the management of marketing in high technology small firms. Journal of Marketing Management, v. 7, p. 343-356, 1991.

Predatory networking: the role of small firms in the development of the British biotechnology industry. International Small Business Journal, v. 11, n. 4, p. 9-22, 1993.

OERLEMANS, L. A.; BUYS, A.; PRETORIUS, M. Research design for the South African Innovation Survey. [S.I.], 2001.

OERLEMANS, L. A.; MEEUS, M. T. H.; BOEKEMA, F. W. M. Do networks matter for innovation: the usefulness of the economic network approach in analysing innovation. Journal of Economic and Social Geography, v. 89, n. 3, p. 298-309, 1998. 
OLLAIK, L. G; ZILLER H. M. Concepções de validade em pesquisas qualitativas. Educação e pesquisa, v. 38, n. 1, p. 229-241, 2012.

O'REGAN, N.; GHOBADIAN, A. Innovation in SMEs: the impact of strategic orientation and environmental perceptions. International Journal of Productivity and Performance Management, v. 54, n. 2, p. 81-97, 2005.

O'REGAN, N.; GHOBADIAN, A.; SIMS, M. Fast tracking innovation in manufacturing SMEs'. Technovation, v. 26, p. 251-261, 2006.

The link between leadership, strategy, and performance in manufacturing SMEs. Journal of Small Business Strategy, Retrieved August 16, 2012, from EBSCOhost database, 2005.

Organisation for Economic Cooperation and Development (OECD). OECD Small and Medium Enterprise Outlook. 2002 Edition. France, 2002.

OSLO MANUAL

2005. The measurement of scientific and technological activities: Guidelines for collecting and interpreting innovation data. $3^{\text {rd }}$ ed. Prepared by the working party of national experts on scientific and technology indicators, Paris, 2005.

PAVITT, K. Innovation Processes. Em: FAGERBERG, J.; MOWERY, D. C.; NELSON, R. R. The Oxford Handbook of Innovation. Oxford University Press, Oxford, 2006.

. Sectoral patterns of technical change: towards a taxonomy and a theory.

Research Policy, v. 13, n. 6, p. 343-373, 1984.

. Technologies, products and organization in the innovating firm: what Adam Smith tells us and Joseph Schumpeter doesn't. Industrial and Corporate Change, v. 7, n. 3, p. 433-452, 1998.

What we know about the strategic management of technology. California Management Review, v. 32, n. 3, p. 17-26, 1990.

PAVITT, K.; ROBSON, M. J.; TOWNSEND, J. F. Technological accumulation, diversification and organisation in UK companies, 1945-1983. Management Science, v. 35, n. 1, p. 81-99, 1989. 
PITTAWAY, L.; ROBERTSON, M.; MUNIR, K.; DENYER, D.; NEELY, A. Networking and innovation: a systematic review of the evidence. International Journal of Management Reviews, 5/6(3/4), p. 137-168, 2004.

POTTER, D. From experience: the customer's eye view of innovation. Journal of Product Innovation Management, v. 6, n. 1, p. 35-42, 1989.

PRAJOGO, D. I.; AHMED, P. K. Relationships between innovation stimulus, innovation capacity, and innovation performance. R\&D Management, v. 36, n. 5, p. 499-515, 2006.

RADAS, S.; BOZIC, L. The antecedents of SME innovativeness in an emerging transition economy. Technovation, v. 29, n. 6-7, p. 438-450, 2009.

RENKO, M. The role of market and technological knowledge in recognizing entrepreneurial opportunities. Management Decision, v. 50, n. 5, p. 797-816, 2012.

RICHTNER, A.; AHLSTROM, P. Influences on organisational slack in new product development projects. International Journal of Innovation Management, v. 10, p. 375-406, 2006.

ROBBINS, S. Comportamento Organizacional. Prentice Hall, São Paulo, 2002.

RODRÍGUEZ, -P. A.; CRESCENZI, R. Research and development, spillovers, innovation systems, and the genesis of regional growth in Europe. Reg. Stud., v. 42, n. 1, p. 51-67, 2008.

ROGERS, E. M. Diffusion of Innovations. Free Press, New York, 1995.

Networks, firm size and innovation. Small Business Economics, v. 22, p. 141-153, 2004.

ROPER, S.; LOVE, J. H. Innovation and export performance: evidence from the UK and German manufacturing plants. Research Policy, v. 31, p. 1087-1102, 2002.

ROTHWELL, R. External networking and innovation in small and medium-sized manufacturing firms. Technovation, v. 11, p. 93-112, 1991.

ROTHWELL, R. Successful industrial innovation: critical factors for the 1960s. R\&D Management, v. 22, p. 221-239, 1990. 
ROTHWELL, R. Successful industrial innovation: critical factors for the 1990s. R\&D Management, v. 22, n. 3, p. 221-239, 1992.

ROTHWELL, R. Towards the fifth-generation innovation process. International Marketing Review, v. 11, n. 1, p. 7-31, 1994.

SÁENZ, J.; ARAMBURU, N.; RIVERA, O. Knowledge sharing and innovation performance: a comparison between high-tech and low-tech companies. Journal of Intellectual Capital, v. 10, n. 1, p. 22-36, 2009.

SAKAMOTO, A. R. Inovação em rede de PMEs: fatores determinantes consequencias sociais. Tese - EAESP FGV, São Paulo, 2011.

SANTARELLI, E.; STERLACCHINI, A. Innovation, formal vs. informal R\&D, and firm size: some evidence from Italian manufacturing firms. Small Business Economics, v. 2, n. 3, p. 223-228, 1990.

SAWHNEY, M.; BALASUBRAMANIAN, S.; KRISHNAN, V. V. Creating growth with services. MIT Sloan Management Review, v. 45, n. 2, p. 34-43, 2004.

SAWHNEY, M.; WOLCOTT, R. C.; ARRONIZ, I. The 12 differente ways for companies to innovate. Em: Sloan Select Collection Winter 2011, p. 28-34. MIT Sloan Management Review, 2006.

SCHUMPETER, J. A. Capitalism Socialism and Democracy. Harper \& Row, New York, 1942.

Studies, Cambridge, 1934.

A. The Theory of Economic Development. Harvard Economic

SEBORA, T.; HARTMAN, C. E.; TOWER, A. C. B. Innovative activity in small businesses: competitive context and organization level. Journal of Engineering Technology Management, v. 11, n. 3/4, p. 253-272, 1994.

SHALLEY, C. E.; GILSON, L. L. What leaders need to know: a review of social and contextual factors that can foster or hinder creativity. The Leadership Quarterly, v. 15, n. 1, p. 33-53, 2004.

SIMERAY, J. P. Estrutura da Empresa: princípios e definições, tipos de estruturas e organogramas. Livros Técnicos, Rio de Janeiro, 1970. 
SIMPSON, P.; SIGUAW, J.; ENZ, C. Innovation orientation outcomes: the good and the bad. Journal of Business Research, v. 59, n. 10/11, p. 1133-1141, 2006.

SLATER, S.; NARVER, J. C. Does competitive environment moderate the market orientation-performance relationship. Journal of Marketing, v. 57, p. 46-55, 1994.

Market orientation and the learning organization.

Journal of Marketing, v. 59, p. 63-74, 1995.

SMITH, M.; BUSI, M.; BALL, P.; MEER, R. V. D. Factors influencing an organisation's ability to manage innovation: a structured literature review and conceptual model. International Journal of Innovation Management, v. 12, n. 4, p. 655-676, 2008.

SODERQUIST, K.; CHANARON, J. J.; MOTWANI, J. Managing innovation in French small and medium- sized enterprises: an empirical study. Benchmarking: An International Journal, v. 4, n. 4, p. 259-272, 1997.

SORENSEN, J. B.; STUART, T. E. Aging, obsolescence, and organizational innovation. Administrative Science Quarterly, v. 45, p. 81-112, 2000.

SOUITARIS, V. Firm-specific competencies determining technological innovation. A survey in Greece. R\&D Management, v. 32, p. 61-77, 2002.

Technological trajectories as moderators of firm-level determinants of innovation. Research Policy, v. 31, p. 877-898, 2002a.

STREET T. C.; CAMERON, A. External relationships and small business: a review of small business alliance and network research. Journal of Small Business Management, v. 45, n. 2, p. 239-266, 2007.

SUBRAHMANYA, M. H. Pattern of technological innovations in small enterprises: a comparative perspective of Bangalore (India) and Northeast England (UK). Technovation, v. 25, n. 3, p. 269-280, 2005.

SUBRAMANIAN, A.; NILAKANTA, S. Organizational innovativeness: exploring the relationship between organizational determinants of innovation, types of innovations, and measures of organizational performance. Omega, v. 24, p. 631-647, 1996.

SUDMAN, S. Applied sampling. Em: ROSSI, P. H.; WRIGHT, J. D.; ANDERSON, A. B. Handbook of Survey Research, Academic Press, New York, NY, p. 144-94, 1983. 
TAN, J.; FISCHER, E.; MITCHELL, R.; PHAN, P. At the center of the acton: innovation and technology strategy research in the small business setting. Journal of Small Business Management, v. 47, n. 3, p. 233-262, 2009.

TANG, H. K. An inventory of organizational innovativeness. Technovation, v. 19, n. 1, p. 41-51, 1999.

TEECE, D. J.; PISANO, G.; SHUEN, A. Dynamic capabilities and strategic management. Strategic Management Journal, v. 18, n. 7, p. 509-533, 1997.

TIDD, J. Innovation management in context: environment, organization and performance. International Journal of Management Review, v. 3, n. 3, p. 169-183, 2001.

TIDD, J.; BESSANT, J.; PAVITT, K. Managing innovation, integrating technological, market and organizational change. $3^{\text {rd }}$ ed. John Wiley \& Sons Ltd., Southern Gate, Chichester, England, 2005.

TORNATZKY, L. G.; FLEISCHER, M. The process of technological innovation. Lexington Books, Lexington, MA, 1990.

TUSHMAN, M. L.; ANDERSON, P. Technological discontinuities and organizational environments. Administrative Science Quarterly, v. 31, p. 439-465, 1986.

TYAGI, R. K.; SAWHNEY, M. S. High-performance product management: the impact of structure, process, competencies, and role definition. Journal of Product Innovation Management, v. 27, n. 1, p. 83-96, 2010.

UTLU, Z. Investigation of the potential for heat recovery at low, medium, and high stages in the Turkish industrial sector (TIS): an application . Elsevier, v. 81, p. 394-405, 2015.

UTTERBACK, J. M. Mastering the dynamics of innovation. Harvard Business School Press, Boston, 1994.

The process of innovation. A paper presented at the Conference on Technological Forecasting: Concepts and Methods. Patrocinado por Industrial Management Center, Inc. at Hilton Head Island, S. C., Jun. 8-12, 1969.

UTTERBACK, J. M.; ABERNATHY, W. J. A dynamic model of process and product innovation. Omega, v. 3, p. 639-656, 1975. 
VACCARO, I. G.; JANSEN, J. J. P.; VAN DEN BOSCH, F. A. J.; VOLBERDA, H. W. Management innovation and leadership: the moderating role of organizational size. Journal of Management Studies, v. 49, n. 1, p. 28-51, 2012.

VALLADARES, P. S. D. A. Capacidade de inovação: análise estrutural e o efeito moderador da organicidade da estrutura organizacional e da gestão de projetos. Tese - EAESP - FGV, São Paulo, 2012.

VAN DE VEN, A. H. Central problems in the management of innovation. Management Science, v. 32, n. 5, p. 590-607, 1986.

VAN DE VEN, A. H.; POLLEY, D. Learning while innovating. Organization Science, v. 3, n. 1, p. 92-116, 1992.

VASCONCELLOS, E. P. G.; HEMSLEY, J. Estrutura das organizações. $4^{\mathrm{a}}$ ed. Pioneira Thomson, São Paulo, 2002.

VOS, J. P. Case-study business typology. Internal report of the Eindhoven University of Technology, Eindhoven, 2000.

VOSS, G. B.; SIRDESHMUKH, D.; VOSS, Z. G. The effects of slack resources and environmental: threat on product exploration and exploitation. Academy of Management Journal, v. 51, p.147-164, 2008.

VOSSEN, R. W. Relative strengths and weaknesses of small firms in innovation. International Small Business Journal, v. 16, n. 3, p. 88-94, 1998.

WAN, D.; ONG, C. H.; LEE, F. Determinants of firm innovation in Singapore. Technovation, v. 25, n. 3, p. 261-268, 2005.

WANG, C. L.; AHMED, P. K. The development and validation of the organisational innovativeness construct using confirmatory factor analysis. European Journal of Innovation Management, v. 7, n. 4, p. 303-313, 2004.

WATKINS, A.; PAPAIOANNOU, T.; MUGWAGWA, J.; KALE, D. National innovation systems and the intermediary role of industry associations in building institutional capacities for innovation in developing countries: a critical review of the literature. Research Policy, v. 44, p. 1407-1418, 2015.

WEERAWARDENA, J.; MAVONDO, F. T. Capabilities, innovation and competitive advantage. Industrial Marketing Management, v. 40, n. 8, p. 1220-1223, 2011. 
WIND, J. Y.; MAIN, J. Provocar mudanças: como as melhores empresas estão se preparando para o século XXI. Qualitymark Ed., Rio de Janeiro, 2002.

WOLFE, R. A. Organizational innovation: review, critique, and suggested research directions. Journal of Management Studies, v. 31, p. 405-431, 1994.

WOLFF, J. A.; PETT, T. L. Small-firm performance: modeling the role of product and process improvements. Journal of Small Business Management, v. 44, n. 2, p. 268284, 2006.

WONGLIMPIYARAT, J. Innovation index and the innovative capacity of nations. Futures, v. 42, n. 3, p. 247-253, 2010.

WOOLDRIDGE, J. M. Introdução à econometria: uma abordagem moderna. Thomson Learning, São Paulo, 2007.

YAM, R. C. M.; LO, W.; TANG, E. P. Y.; LAU, A. K. W. Analysis of sources of innovation, technological innovation capabilities, and performance: an empirical study of Hong Kong manufacturing industries. Research Policy, v. 40, n. 3, p. 391- 402, 2011.

YAM, R. C. M.; LO, W.; TANG, E. P. Y.; LAU, A. K. W. Technological Innovation Capabilities and Firm Performance. World Academy of Science, Engineering and Technology, v. 4, 2010.

YOKOMIZO, C. A. The relationship between innovation and internationalization, and business performance: evidence from companies operations in Brazil. Tese FEA USP, São Paulo, 2014.

ZMUD, R. W. Diffusion of modern software practices: influence of centralization and formalization. Management Science, v. 28, p. 1421-1431, 1982. 


\section{APÊNDICES}

APÊNDICE A - QUESTIONÁRIO

APÊNDICE B - CONSTRUCTO CULTURA ORGANIZACIONAL

APÊNDICE C - CONSTRUCTO CAPACIDADE DE GESTÃO DE PROJETOS

APÊNDICE D - CONSTRUCTO BASE DE CONHECIMENTO INTERNO

APÊNDICE E - CONSTRUCTO ESTRATÉGIA

APÊNDICE F - CONSTRUCTO ORIENTAÇÃO AO MERCADO

APÊNDICE G - CONSTRUCTO BASE DE CONHECIMENTO EXTERNO

APÊNDICE H - CONSTRUCTO CAPACIDADE DE INOVAÇÃO 


\section{APÊNDICE A - QUESTIONÁRIO}

Local/Data:

Consultor:

Orientação ao entrevistador antes de iniciar a entrevista: Este estudo tem como objetivo identificar e compreender os determinantes da capacidade de inovação das PMEs. 0 questionário está dividido em 04 partes e a entrevista dura em torno de 4 horas. As informações fornecidas e documentos apresentados não poderão ser divulgados de forma individual, conforme previsto no Termo de Confidencialidade assinado entre as partes.

Seção I. PERFIL DO RESPONDENTE

\begin{tabular}{|l|l|}
\hline 1. Nome completo: \\
\hline 2. E-mail corporativo: & $\begin{array}{l}\text { 3. Telefone: } \\
\text { ( ) }\end{array}$ \\
\hline 4. Área de trabalho na empresa: & 5. Ano de ingresso na empresa: \\
\hline \begin{tabular}{l} 
6. Cargo ou posição que ocupa: \\
( ) 1 - Proprietário da empresa (único dono) \\
( ) 2 - Sócio dirigente \\
( ) 3 - Presidente ou vice (mas não é sócio) \\
( ) 4 - Diretor ou C-Level \\
( ) 5 - Gerente ou Superintendente de Área \\
( ) 6 - Analista ou Operador \\
\hline 7. Grau de Instrução: \\
( ) 1 - Ensino médio \\
( ) 2 - Ensino profissionalizante \\
( ) 3 - Superior incompleto \\
( ) 4 - Superior completo \\
( ) 5 - MBA/especialização lato sensu \\
( ) 6 - Mestrado \\
( ) 7 - Doutorado \\
( ) 8 - Pós-doutorado
\end{tabular} \\
\hline
\end{tabular}


Seção II. PERFIL DA EMRPESA

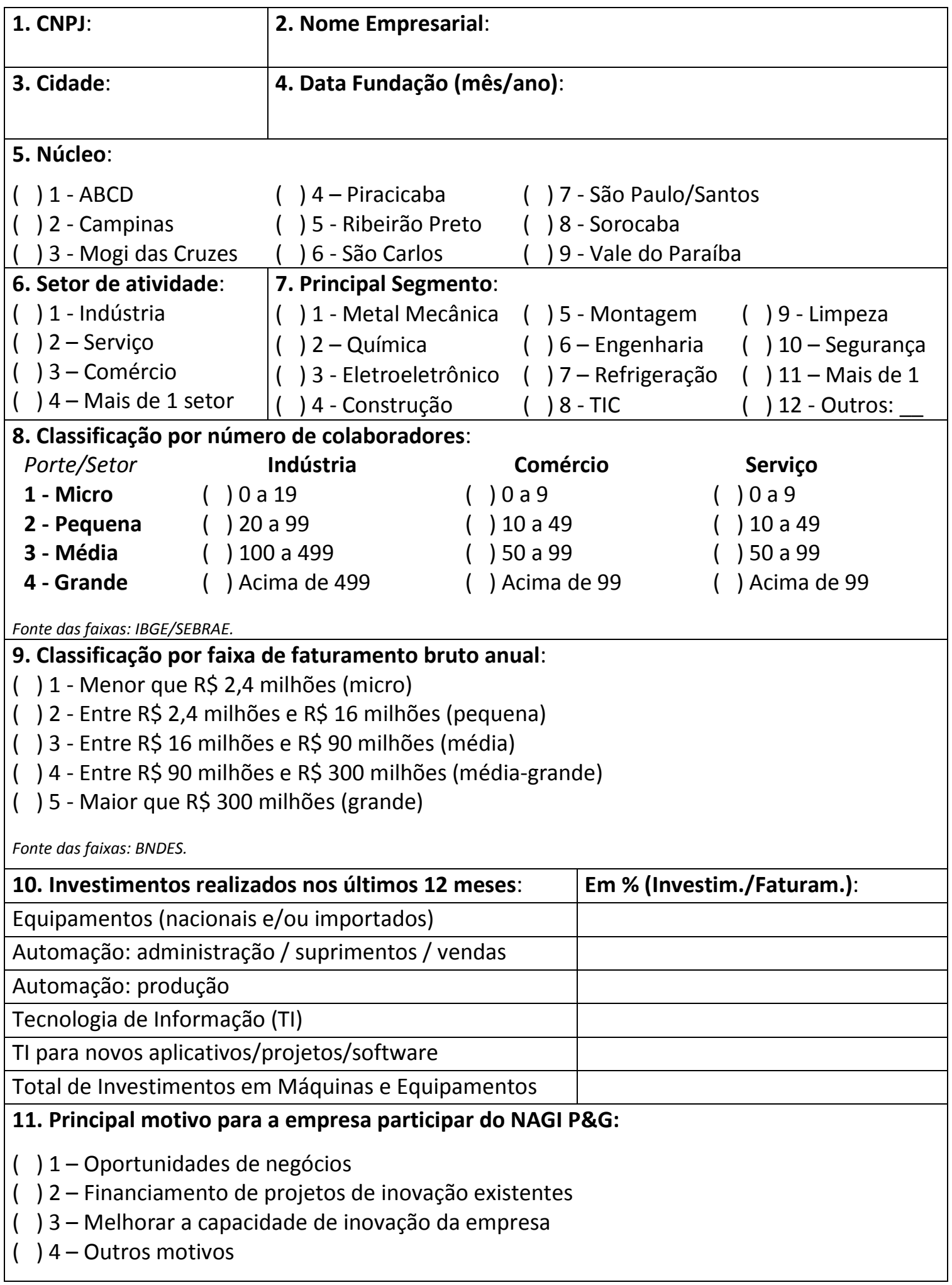


Seção III. AVALIAÇÃO DOS DETERMINANTES DA INOVAÇÃO

\section{Item 1. Níveis Hierárquicos}

A empresa possui hierarquia flexível e poucos níveis hierárquicos:

\section{Critérios de avaliação para orientação do entrevistador:}

Não - A empresa possui funções e regras formais e bem definidas (institucionalização), uma rede de relacionamento formal, um alto grau de departamentalização, tem muitos níveis se comparada ao seu tamanho (mais de 3 níveis verticais, segundo Robbins (2002)) e os gerentes possuem relativamente menos autoridade (menor amplitude administrativa).

Parcial - A empresa possui algumas funções e regras formais e definidas (institucionalização), uma rede de relacionamento informal, grau moderado de departamentalização e até 3 níveis hierárquicos.

Sim - A empresa possui um baixo nível de formalização em termos de funções, regras e rede de relacionamento, um baixo grau de departamentalização, hierarquia plana com poucos níveis hierárquicos em relação ao seu tamanho. (geralmente apenas 2 ou 3 níveis verticais, segundo Robbins (2002)) e gerentes possuem relativamente mais autoridade (maior amplitude administrativa).

\section{Evidências:}

(Exemplo, solicitar organograma para analisar o número de níveis de autoridade. Qual o número de subordinados das principais gerências?).

\section{Item 2. Tipo de Estrutura Organizacional}

A empresa possui o seguinte tipo de estrutura organizacional:

Funcional Matricial Projetizada

Critérios de avaliação para orientação do entrevistador:

Funcional - Estrutura mecanicista em que pessoas são agrupadas por atividades similares e trabalham em um grupo restrito de atividades, repetindo-as continuamente e tornando-se especialistas nessas atividades. A hierarquia é vertical e apresenta baixa interdependência entre as unidades.

Matricial - Estrutura orgânica com forma avançada de departamentalização em que há uma multiplicidade de comando (gerência funcional e gerência de produto/projeto). A hierarquia é horizontal no nível de produto/projeto e vertical no nível funcional (uso compartilhado e flexível de pessoal e equipamentos), apresentando alta interdependência entre as unidades.

Projetizada - Estrutura orgânica com forma avançada de departamentalização organizada a partir de equipes multifuncionais reunidas por projeto. Não há gerentes funcionais, nem pessoas alocadas por especialização, mas sim pessoas alocadas por projeto e ao gerente responsável para um determinado projeto.

Observação. De acordo com o PMBOK há basicamente três tipos de estruturas organizacionais: funcional, matricial e por projetos. 
Evidências:

(Exemplo, solicitar organograma).

\section{Item 3. Decisão Participativa}

\begin{tabular}{|l|l|l|l|}
\cline { 3 - 4 } \multicolumn{1}{c|}{} & Não & Parcial & Sim \\
\hline \\
decisão:
\end{tabular}

\section{Critérios de avaliação para orientação do entrevistador:}

Não - A empresa não possui um processo participativo de tomada de decisão.

Parcial - A empresa não possui um processo participativo de tomada de decisão, mas eventualmente coleta a opinião de alguns colaboradores.

Sim - A empresa possui um processo participativo sistemático de tomada de decisão sendo que o mecanismo permite coletar de forma ágil a opinião de uma diversidade de colaboradores em termos de número, nível hierárquico e departamento.

\section{Evidências:}

(Exemplo, qual o mecanismo para coleta de dados dos colaboradores: reuniões, intranet, sistema, comitê?).

\section{Item 4. Política de Autonomia}

A empresa possui política de autonomia de resolução de problemas:

\section{Critérios de avaliação para orientação do entrevistador:}

Não - A empresa não possui política formal de autonomia de resolução de problemas, sendo que todo problema deve passar pela diretoria que irá determinar a solução a ser executada (centralização).

Parcial - A empresa não possui política formal de autonomia de resolução de problemas, mas as áreas têm autonomia para resolver problemas específicos de baixo e médio impacto.

Sim - A empresa possui política formal de autonomia de resolução de problemas com limite de alçada em termos de responsabilidade e/ou valor, sendo que apenas problemas de grande impacto passam pela diretoria.

\section{Evidências:}

(Exemplo, solicitar o documento que defini os limites de responsabilidade. Entender, mapear e avaliar o processo de solução de problemas segundo a urgência, impacto, etc).

\section{Item 5. Coleta de Ideias}

A empresa possui um ambiente favorável de estímulo ao surgimento de ideais criativas e tem um sistema formal para colher sugestões dos colaboradores e implementar as melhores:

\begin{tabular}{|l|l|l|} 
Não & Parcial & Sim \\
\hline & & \\
& & \\
\hline
\end{tabular}


Critérios de avaliação para orientação do entrevistador:

Não - A empresa possui um ambiente desfavorável de estímulo ao surgimento de ideais criativas e não tem um sistema formal para colher sugestões dos colaboradores.

Parcial - A empresa possui um ambiente desfavorável de estímulo ao surgimento de ideais criativas, mas tem um sistema formal para colher sugestões dos colaboradores e implementar as melhores.

Sim - A empresa possui um ambiente favorável de estímulo ao surgimento de ideais criativas e tem um sistema formal para colher sugestões dos colaboradores e implementar as melhores.

\section{Evidências:}

(Exemplo, qual o sistema de coleta de ideias? São lançados desafios pontuais para estimular ideias direcionadas? Os colaboradores recebem feedback para as ideias que não foram implementadas?).

\section{Item 6. Sistema de Recompensa}

A empresa possui um sistema de recompensa formal para a prática da inovação (novas ideias):

\section{Critérios de avaliação para orientação do entrevistador:}

Não - A empresa não possui um sistema de recompensa formal para a prática da inovação (novas ideias).

Parcial - A empresa não possui um sistema de recompensa formal para a prática da inovação (novas ideias), mas eventualmente recompensa ideias que foram implementadas e geraram retorno para a empresa.

Sim - A empresa possui um sistema de recompensa formal para a prática da inovação (novas ideias).

\section{Evidências:}

(Exemplo, qual o sistema de recompensa adotado? Solicitar documento com regras do sistema de recompensa $e$ exemplos de situações em que o colaborador recebeu a recompensa).

\section{Item 7. Profissionais com Múltiplas Competências}

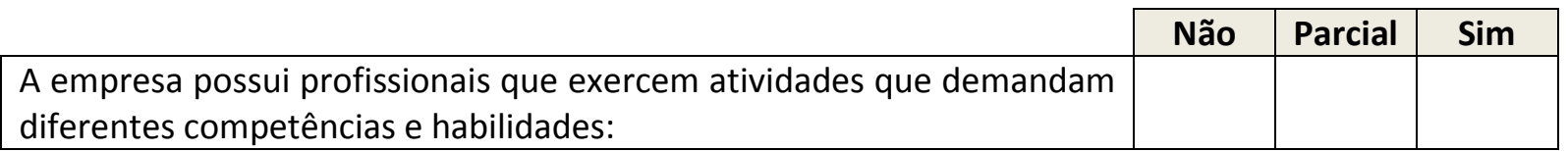

Critérios de avaliação para orientação do entrevistador:

Não - A empresa não possui profissionais que exercem atividades que demandam diferentes competências e habilidades (especialização).

Parcial - A empresa possui alguns profissionais que exercem atividades que demandam diferentes competências e habilidades.

Sim - A empresa possui profissionais que exercem atividades que demandam diferentes competências e habilidades. 
Evidências:

(Exemplo, solicitar tabela de cargos e analisar funções/atividades desempenhadas por quem ocupa o cargo. Empresa tem programa de job rotation?).

\section{Item 8. Tolerância ao Erro}

\begin{tabular}{|l|l|l|l|}
\cline { 3 - 4 } \multicolumn{1}{l|}{} & Não & Parcial & Sim \\
\hline $\begin{array}{l}\text { A liderança possui tolerância ao erro, valoriza o aprendizado e assume } \\
\text { riscos: }\end{array}$ & & & \\
\hline
\end{tabular}

\section{Critérios de avaliação para orientação do entrevistador:}

Não - A liderança não tolera erros, não valoriza o aprendizado em detrimento ao erro e não está disposta a assumir riscos.

Parcial - A liderança possui tolerância ao erro e valoriza o aprendizado, mas não assume riscos (conservadora).

Sim - A liderança possui tolerância ao erro, valoriza o aprendizado e assume riscos.

\section{Evidências:}

(Exemplo, como são apurados e conduzidos os erros na organização? Solicitar exemplos de casos concretos).

\section{Item 9. Times Multidisciplinares}

A liderança privilegia a formação de times multidisciplinares de forma rotineira:

\begin{tabular}{|l|l|l|}
\hline Não & Parcial & Sim \\
\hline & & \\
\hline
\end{tabular}

\section{Critérios de avaliação para orientação do entrevistador:}

Não - A liderança não privilegia a formação de times multidisciplinares.

Parcial - A liderança privilegia a formação de times multidisciplinares apenas em algumas situações específicas.

Sim - A liderança privilegia a formação de times multidisciplinares de forma rotineira.

\section{Evidências:}

(Exemplo, para quais atividades são formados times multidisciplinares? Com que frequência? Como são formados os times multidisciplinares? Há alguma regra ou determinação formal apoiando a formação de times multidisciplinares).

\section{Item 10. Apoio da Alta Administração}

A liderança apoia a experimentação planejada de novas ideias e estabelece condições práticas, com definição de responsabilidades e recursos para a implementação:

\begin{tabular}{|l|l|l|}
\hline Não & Parcial & Sim \\
\hline & & \\
& & \\
\hline
\end{tabular}

\section{Critérios de avaliação para orientação do entrevistador:}

Não - A liderança não apoia a experimentação planejada de novas ideias e não estabelece condições práticas, sem definição de responsabilidades e recursos para a implementação. 
Parcial - A liderança apoia a experimentação planejada de novas ideias e não estabelece condições práticas, sem definição de responsabilidades e recursos para a implementação.

Sim - A liderança apoia a experimentação planejada de novas ideias e estabelece condições práticas, com definição de responsabilidades e recursos para a implementação.

\section{Evidências:}

(Exemplo, como a liderança apoia a experimentação planejada das novas ideias: oferece recurso financeiro, recursos humanos, treinamento, permite dedicar parte do tempo de trabalho nesse projeto?).

\section{Item 11. Portfólio de Projetos de Inovação}

A empresa possui portfólio formal de projetos de inovação:

\begin{tabular}{|l|l|l|} 
Não & Parcial & Sim \\
\hline
\end{tabular}

\section{Critérios de avaliação para orientação do entrevistador:}

Não - A empresa não possui portfólio formal de projetos de inovação.

Parcial - A empresa não possui portfólio formal de projetos de inovação, mas possui alguma forma de avaliar o balanceamento dos projetos de inovação, analisar o alinhamento com a estratégia, listar os recursos necessários para executar os projetos e estabelecer um cronograma.

Sim - A empresa possui portfólio formal de projetos de inovação.

\section{Evidências:}

(Exemplo, solicitar o portfólio de projetos de inovação).

\section{Item 12. Controle e Acompanhamento}

\begin{tabular}{|l|l|l|l|}
\cline { 3 - 4 } \multicolumn{1}{c|}{} & Não & Parcial & Sim \\
\hline $\begin{array}{l}\text { A empresa acompanha de forma sistemática os esforços realizados } \\
\text { para inovação: }\end{array}$ & & & \\
\hline
\end{tabular}

\section{Critérios de avaliação para orientação do entrevistador:}

Não - Não são acompanhados os esforços realizados para inovação.

Parcial - São acompanhados de maneira informal os esforços realizados para inovação.

Sim - São acompanhados por meio de procedimentos formais os esforços realizados para inovação.

\section{Evidências:}

(Exemplo, qual o método de acompanhamento? A empresa possui um Comitê de Gestão da Inovação "CGI"? Empresa possui um PMO (solicitar organograma). Solicitar atas das reuniões do comitê).

\section{Item 13. Software ou Ferramentas de Gestão da Inovação}

A empresa adotou um software ou ferramenta para realizar a gestão da inovação (administrativa ou da produção), avaliando os resultados da inovação na empresa, nos últimos três anos:

\begin{tabular}{|l|l|l|} 
Não & Parcial & Sim \\
\hline & & \\
& & \\
\hline
\end{tabular}




\section{Critérios de avaliação para orientação do entrevistador:}

Não - Não, a empresa não adota qualquer software ou ferramenta de gestão da inovação, nem mensura seus resultados.

Parcial - Não, apenas utilizou um software ou ferramenta para realizar a gestão da inovação, sem avaliar seus resultados.

Sim - Sim, adotou um software ou ferramenta para realizar a gestão da inovação, avaliando os resultados da inovação na empresa.

\section{Evidências:}

(Exemplo, qual software/ferramenta utilizado(a): Funil da Inovação? Softwares como Teamwork, MS Project, entre outros? Possui base de dados de "lições aprendidas"? Quais os indicadores de avaliação dos resultados e benefícios são adotados?).

\section{Item 14. Comunicação Interna}

A empresa possui Certificação ISO 9001 (SGQ):

\begin{tabular}{l|l|l|} 
Não & Parcial & Sim \\
\hline
\end{tabular}

\section{Critérios de avaliação para orientação do entrevistador:}

Não - Não, a empresa não possui.

Parcial - Não, mas a empresa já adota as práticas do Manual da Qualidade.

Sim - Sim, possui a certificação ISO 9001.

\section{Evidências:}

(Exemplo, solicitar a certificação ou manual da qualidade. Solicitar o fluxo de comunicação interna. Existe uma intranet? Um repositório de documentos compartilhado com os colaboradores? Quadro de avisos? Reuniões?).

\section{Item 15. Competências Necessárias na Equipe}

São identificadas as competências necessárias na equipe e a partir delas é elaborado um plano para desenvolvê-las:

\begin{tabular}{|l|l|l|}
\hline Não & Parcial & Sim \\
& & \\
\hline
\end{tabular}

\section{Critérios de avaliação para orientação do entrevistador:}

Não - Não são identificadas as competências necessárias na equipe, nem há um plano para desenvolvê-las.

Parcial - São identificadas as competências necessárias na equipe, mas não há um plano para desenvolvê-las.

Sim - São identificadas as competências necessárias na equipe e a partir delas é elaborado um plano para desenvolvê-las.

\section{Evidências:}

(Exemplo, existe um plano de desenvolvimento pessoal (PDP) aprovado pelo gestor direto? Os cargos apresentam em seu descritivo as competências necessárias/requisitos? O PDP de um colaborador que ocupa determinando cargo está alinhado com as competências previstas no descritivo do cargo?). 


\section{Item 16. Política de Educação e Treinamento}

São adotadas políticas de educação e treinamento correspondentes a

essas competências:

\section{Critérios de avaliação para orientação do entrevistador:}

Não - Não são adotadas políticas de educação e treinamento correspondentes a essas competências.

Parcial - Não são adotadas políticas de educação e treinamento correspondentes a essas competências, mas a empresa eventualmente apoia a realização de cursos e treinamentos.

Sim - São adotadas políticas de educação e treinamento correspondentes a essas competências.

\section{Evidências:}

(Exemplo, solicitar o documento que prevê a política de treinamento. São realizados treinamentos internos? Externos? A empresa arca total ou parcial com os custos do treinamento/curso?).

\section{Item 17. Qualificação do Quadro Gerencial}

A empresa possui quadro técnico e gerencial qualificado:

\begin{tabular}{l|l|l|} 
Não & Parcial & Sim \\
\hline
\end{tabular}

\section{Critérios de avaliação para orientação do entrevistador:}

Não - A empresa não possui quadro técnico e gerencial qualificado.

Parcial - A empresa possui quadro técnico e gerencial parcialmente qualificado.

Sim - A empresa possui quadro técnico e gerencial qualificado.

\section{Evidências:}

(Exemplo, o processo de seleção assegura um quadro gerencial qualificado? Qual \% do quadro de colaboradores com doutorado, mestrado, superior completo, etc? A empresa tem quantos engenheiros? Avaliar o nível de educação formal dos colaboradores).

\section{Item 18. Avaliação de Desempenho}

São efetuadas avaliações de desempenho dos funcionários:

\begin{tabular}{|l|l|l|} 
Não & Parcial & Sim \\
\hline
\end{tabular}

Critérios de avaliação para orientação do entrevistador:

Não - Não são efetuadas avaliações de desempenho dos funcionários.

Parcial - Não são efetuadas avaliações de desempenho dos funcionários, mas eles recebem eventualmente feedbacks informais de seus gestores.

Sim - São efetuadas avaliações de desempenho dos funcionários.

\section{Evidências:}

(Exemplo, solicitar o documento de avaliação. Qual a frequência da avaliação? Qual o modelo: 360o?). 


\section{Item 19. Atividades de P\&D}

São executadas atividades de P\&D de forma sistemática:

Não $\quad$ Parcial $\quad$ Sim

Critérios de avaliação para orientação do entrevistador:

Não - Não são executadas atividades de P\&D na empresa.

Parcial - As atividades de P\&D são esporádicas, descentralizadas e executadas de maneira informal.

Sim - São executadas atividades de P\&D de forma sistemática.

\section{Evidências:}

(Exemplo, solicitar organograma. Há um departamento especifico que desenvolve atividades de P\&D? Essa área tem um "budget"/orçamento?).

\section{Item 20. Planejamento Estratégico}

A empresa possui um planejamento estratégico formal:

Não $\quad$ Parcial 1 Sim

Critérios de avaliação para orientação do entrevistador:

Não $\quad-$ A empresa não possui um planejamento estratégico formal.

Parcial - A empresa não possui um planejamento estratégico formal, mas a diretoria tem traçada algumas diretrizes para a empresa.

Sim - A empresa possui um planejamento estratégico formal.

\section{Evidências:}

(Exemplo, a empresa se reúne para realizar o planejamento estratégico? Qual a metodologia para realizar o planejamento estratégico? A empresa contrata alguém externo para apoiar no processo de formulação desse planejamento? Solicitar o modelo de planejamento estratégico).

\section{Item 21. Conceito e Estratégia de Inovação}

A empresa possui um conceito de inovação e visão de futuro definida e

formalizada que estão inseridos na estratégia:

\section{Critérios de avaliação para orientação do entrevistador:}

Não - A empresa não possui um conceito de inovação e nem insere inovação na estratégia (o tema inovação não faz parte da estratégia).

Parcial - A empresa possui um conceito de inovação e visão de futuro definida e formalizada, mas a inovação não está inserida na estratégia.

Sim - A empresa possui um conceito de inovação e visão de futuro definida e formalizada que estão inseridos na estratégia.

\section{Evidências:}

(Exemplo, solicitar o conceito de inovação adotado pela empresa. Esse conceito é divulgado internamente? Como? 0 planejamento estratégico contém a análise do mercado tecnológico? Qual a estratégia tecnológica da empresa: líder, seguidor rápido, seguidor lento?). 


\section{Item 22. Avaliação da Estratégia}

A empresa reavalia constantemente a estratégia:

\begin{tabular}{l|l|l|} 
Não & Parcial & Sim \\
\hline
\end{tabular}

\section{Critérios de avaliação para orientação do entrevistador:}

Não - A empresa não reavalia a estratégia.

Parcial - A empresa possui uma estratégia de inovação, mas é reavaliada eventualmente ou a empresa possui estratégia, mas não inclui o componente inovação.

Sim - A estratégia geral da empresa, inclusive de inovação é reavaliada constantemente.

\section{Evidências:}

(Exemplo, qual a frequência de reavaliação da estratégia: trimestral, semestral, anual? Quem são os participantes? Como são tomadas as eventuais ações corretivas? Quais informações servem de input para a avaliação?).

\section{Item 23. Indicadores Estratégicos}

A empresa possui indicadores estratégicos e inclusive indicadores específicos de inovação:

\begin{tabular}{|l|l|l|}
\hline Não & Parcial & Sim \\
& & \\
\end{tabular}

\section{Critérios de avaliação para orientação do entrevistador:}

Não - A empresa não possui indicadores estratégicos.

Parcial - A empresa possui indicadores estratégicos, mas não indicadores específicos para mensurar a inovação.

Sim - A empresa possui indicadores estratégicos e inclusive indicadores específicos de inovação.

\section{Evidências:}

(Exemplo, a empresa possui BSC? Os indicadores são divulgados na empresa: afixados em mural? O conjunto de indicadores inclui indicadores de inovação?).

\section{Item 24. Apoio Governamental}

A empresa já obteve apoio financeiro do governo para projetos de inovação e já utilizou algum incentivo fiscal para inovação:

\section{Critérios de avaliação para orientação do entrevistador:}

Não - A empresa nunca obteve apoio financeiro do governo para projetos de inovação, nem utilizou incentivo fiscal para inovação.

Parcial - A empresa já obteve apoio financeiro do governo para projetos de inovação, ou utilizou algum incentivo fiscal para inovação.

Sim - A empresa já obteve apoio financeiro do governo para projetos de inovação e utilizou algum incentivo fiscal para inovação. 
Evidências:

(Exemplo, solicitar contrato? Pleito aprovado? Lei do bem?).

\section{Item 25. Avaliação da Marca}

A empresa avalia a imagem de sua(s) marca(s), incluindo a imagem das marcas de seus produtos, de forma sistemática junto ao mercado, analisando os resultados e tomando ações corretivas ou realizando investimentos para melhoria da imagem, quando necessário:

\section{Critérios de avaliação para orientação do entrevistador:}

Não - A empresa não avalia a imagem de suas marcas.

Parcial - A empresa avalia a imagem de suas marcas esporadicamente, mesmo que informalmente.

Sim - A empresa avalia a imagem de sua(s) marca(s), incluindo a imagem das marcas de seus produtos, de forma sistemática junto ao mercado, analisando os resultados e tomando ações corretivas ou realizando investimentos para melhoria da imagem, quando necessário.

\section{Evidências:}

(Exemplo, qual o método (formal ou informal) utilizado? Citar exemplos de ações corretivas. Considera stakeholders "partes interessadas" nessa avaliação ou apenas um grupo específico, exemplo clientes).

\section{Item 26. Coleta de Manifestações dos Clientes}

A empresa tem uma sistemática (rotina) há pelo menos três anos para colher manifestações (sugestões, reclamações, etc.) dos clientes e utiliza-las para realizar melhorias:

\begin{tabular}{|l|l|l|}
\hline Não & Parcial & Sim \\
& & \\
& & \\
\hline
\end{tabular}

\section{Critérios de avaliação para orientação do entrevistador:}

Não - A empresa não tem uma sistemática (rotina) para colher informações e utiliza-las para realizar melhorias.

Parcial - A empresa não possui uma sistemática (rotina), mas identificou ao menos uma manifestação e promoveu melhorias.

Sim - A empresa tem uma sistemática (rotina) há pelo menos três anos para colher manifestações (sugestões, reclamações, etc.) dos clientes e utiliza-las para realizar melhorias.

\section{Evidências:}

(Exemplo, quais métodos: ouvidoria/fluxograma do processo de ouvidoria, pesquisa de satisfação, fale conosco, visita técnica, monitoramento das redes sociais? Citar exemplos de melhorias).

\section{Item 27. Uso das Manifestações dos Clientes (processo de inovação)}

A empresa possui uma sistemática para identificar e usar as manifestações dos clientes (sugestões, reclamações, etc.) para apoiar o 
processo de desenvolvimento de novos produtos/serviços e processos:

\section{Critérios de avaliação para orientação do entrevistador:}

Não - A empresa não identifica nem utiliza as manifestações para apoiar o desenvolvimento de novos produtos/serviços e processos.

Parcial - A empresa faz uso eventual das manifestações para apoiar o desenvolvimento de novos produtos/serviços e processos.

Sim - A empresa possui uma sistemática para identificar e usar as manifestações dos clientes (sugestões, reclamações, etc.) para apoiar o processo de desenvolvimento de novos produtos/serviços e processos.

\section{Evidências:}

(Exemplo, quais métodos: focus group, journey mapping? Processo de iteração por meio de projeto piloto com um grupo de clientes, teste de mercado com protótipo (visando tornar a inovação mais efetiva/assertiva)? Solicitar exemplo de desenvolvimento.)

\section{Item 28. Monitoramento do Mercado (lançamentos de produtos/serviços)}

A empresa tem uma sistemática (rotina) para monitorar o mercado e lançou mais de um novo produto/serviço, nos últimos 3 anos, em decorrência da identificação de oportunidades e necessidades de mercado:

\section{Critérios de avaliação para orientação do entrevistador:}

Não - A empresa não tem uma sistemática (rotina) para monitorar o mercado.

Parcial - A empresa não tem uma sistemática (rotina) para monitorar o mercado, mas lançou um novo produto/serviço nos últimos 3 anos em decorrência da identificação de oportunidades e necessidades de mercado.

Sim - A empresa tem uma sistemática (rotina) para monitorar o mercado e lançou mais de um novo produto/serviço nos últimos 3 anos em decorrência da identificação de oportunidades e necessidades de mercado.

\section{Evidências:}

(Exemplo, quais métodos: acompanhamento de editais, licitações, cotações? A empresa possui departamento de inteligência de mercado? Acompanha tecnologias do mercado no Brasil e no exterior? Acompanha pesquisas acadêmicas? Citar exemplos de necessidades identificadas e novos produtos/serviços). Surpreender o cliente

\section{Item 29. Relacionamento com os Clientes}

A empresa adotou mais de uma nova facilidade ou recurso, nos últimos três anos, para melhorar o relacionamento com os clientes:

\section{Critérios de avaliação para orientação do entrevistador:}

Não - A empresa não adotou uma nova facilidade ou recurso, nos últimos três anos, para melhorar o relacionamento com os clientes.

Parcial - A empresa adotou apenas uma nova facilidade ou recurso, nos últimos três anos, para melhorar o relacionamento com os clientes.

Sim - A empresa adotou mais de uma nova facilidade ou recurso, nos últimos três anos, para melhorar o relacionamento com os clientes. 


\section{Evidências:}

(Exemplo, citar o recurso e data de criação: CRM, redes sociais como canal no youtube, twitter, facebook, instagram, etc).

\section{Item 30. Diálogo com o Cliente}

A empresa adotou novas formas de falar com ou ouvir seus clientes (usando ou não tecnologia da informação), nos últimos três anos:

\section{Critérios de avaliação para orientação do entrevistador:}

Não - A empresa não adotou novas formas de falar com ou ouvir seus clientes (usando ou não tecnologia da informação), nos últimos três anos.

Parcial - A empresa adotou alguma forma de falar com ou ouvir seus clientes (usando ou não tecnologia da informação), nos últimos três anos

Sim - A empresa adotou novas formas de falar com ou ouvir seus clientes (usando ou não tecnologia da informação), nos últimos três anos.

\section{Evidências:}

(Exemplo, fale conosco, whatsapp, Skype, visita técnica, workshop, etc).

\section{Item 31. Pesquisa de Mercado}

\begin{tabular}{|l|l|l|l|}
\cline { 3 - 4 } \multicolumn{1}{c|}{$\begin{array}{l}\text { A empresa realiza pesquisa de mercado e utiliza os dados para o } \\
\text { processo de tomada de decisão: }\end{array}$} & & & \\
\hline
\end{tabular}

\section{Critérios de avaliação para orientação do entrevistador:}

Não - A empresa não realiza pesquisa de mercado, nem utiliza os dados de pesquisas de terceiros para o processo de tomada de decisão.

Parcial - A empresa não realiza pesquisa de mercado, mas utiliza os dados de pesquisas de terceiros para o processo de tomada de decisão.

Sim - A empresa realiza pesquisa de mercado e utiliza os dados para o processo de tomada de decisão.

\section{Evidências:}

(Exemplo, solicitar relatório de pesquisa de mercado. Realizado por equipe externa ou interna? Se for interno que ferramentas usa: surveymonkey, google form? Utiliza dados de pesquisa secundários, exemplo de sindicatos, associações, etc).

\section{Item 32. Parceria}

A empresa fez duas ou mais parcerias com outras organizações, para fornecer produtos/serviços melhores e mais completos, nos últimos três anos (Observação: exceto aquisição de tecnologia):

\begin{tabular}{|l|l|l|}
\hline Não & Parcial & Sim \\
\hline & & \\
& & \\
\hline
\end{tabular}


Critérios de avaliação para orientação do entrevistador:

Não - A empresa não fez nenhuma parceria com outras organizações, nos últimos três anos, para fornecer produtos/serviços melhores e mais completos.

Parcial - A empresa fez apenas uma parceria com outra organização, nos últimos três anos, para fornecer produtos/serviços melhores e mais completos.

Sim - A empresa fez duas ou mais parcerias com outras organizações, nos últimos três anos, para fornecer produtos/serviços melhores e mais completos.

\section{Evidências:}

(Exemplo, qual a empresa parceira: concorrente, empresa estrangeira? Qual o tipo de parceria (joint venture, codesenvolvimento, etc)? Qual o produto/serviço foco da parceria?).

\section{Item 33. Projeto Cooperado}

A empresa participou de algum projeto cooperado (com fornecedores, universidades ou clientes) para desenvolvimento de produtos/serviços, melhoria dos processos ou busca de novos mercados, nos últimos três anos:

\begin{tabular}{|l|l|l|}
\hline Não & Parcial & Sim \\
\hline & & \\
& & \\
\hline
\end{tabular}

\section{Critérios de avaliação para orientação do entrevistador:}

Não - A empresa não participou de nenhum projeto cooperado, nem adotou novas formas de trocar ideias, informações ou conhecimento com os fornecedores, universidades ou clientes, nos últimos três anos.

Parcial - A empresa não participou de nenhum projeto cooperado, mas adotou alguma nova forma de trocar ideias, informações ou conhecimento com os fornecedores, universidades ou clientes, nos últimos três anos.

Sim - A empresa participou de algum projeto cooperado (com fornecedores, universidades ou clientes) para desenvolvimento de produtos/serviços, melhoria dos processos ou busca de novos mercados, nos últimos três anos.

\section{Evidências:}

(Exemplo, qual o projeto cooperado? Qual produto/serviço ou processo desenvolvido? Qual o meio para trocar ideias e informações: EDI, e-mail, workshop, etc).

\section{Item 34. Relacionamento Externo (com Universidades)}

A empresa se comunica (troca ideias, informações ou conhecimento) com universidades de forma sistemática e é uma prática que faz parte da rotina:

\section{Critérios de avaliação para orientação do entrevistador:}

Não - A empresa não se comunica (troca ideias, informações ou conhecimento) com universidades (inexistente).

Parcial - A empresa se comunica (troca ideias, informações ou conhecimento) com universidades de forma esporádica, pois aconteceu algumas vezes (reativa).

Sim - A empresa se comunica (troca ideias, informações ou conhecimento) com universidades de forma sistemática e é uma prática que faz parte da rotina (proativa). 


\section{Evidências:}

(Exemplo, qual o método de interação ou troca de informação com a universidade? Qual a frequência? Com qual(is) universidade(s)? Quais os contatos?).

\section{Item 35. Relacionamento Externo (com Cadeia de Fornecimento)}

A empresa busca conhecimento ou novas tecnologias junto a fornecedores de forma proativa:

\begin{tabular}{|l|l|l|}
\hline Não & Parcial & Sim \\
& & \\
\hline
\end{tabular}

\section{Critérios de avaliação para orientação do entrevistador:}

Não - A empresa não busca conhecimento ou novas tecnologias junto a fornecedores de forma proativa, nem absorveu algum tipo de conhecimento ou tecnologia junto a fornecedores, nos últimos 3 anos (inexistente).

Parcial - A empresa não busca conhecimento ou novas tecnologias junto a fornecedores de forma proativa, mas absorveu, nos últimos 3 anos, algum tipo de conhecimento ou tecnologia junto a fornecedores (reativa)

Sim - A empresa busca conhecimento ou novas tecnologias junto a fornecedores de forma proativa.

\section{Evidências:}

(Exemplo, método de busca ou interação troca de informação, frequência, exemplos de solução/benefícios advindos da comunicação: para reduzir custo de transporte ou do estoque de matéria-prima, melhorar qualidade do produto/serviço).

\section{Item 36. Consultorias e Instituições de Apoio (Visão Externa)}

A empresa fez uso sistemático de consultorias ou do apoio de entidades ou de serviços tecnológicos, nos últimos três anos (Observação: pode haver contratação):

\section{Critérios de avaliação para orientação do entrevistador:}

Não - A empresa não fez uso de consultorias ou do apoio de entidades ou de serviços tecnológicos, nos últimos três anos.

Parcial - A empresa fez uso eventual de consultorias ou do apoio de entidades ou de serviços tecnológicos, nos últimos três anos

Sim - A empresa fez uso sistemático de consultorias ou do apoio de entidades ou de serviços tecnológicos, nos últimos três anos.

\section{Evidências:}

(Exemplo, SEBRAE, SESI, SENAI, Empresa Jr, Sindicatos Patronais, Consultorias privadas exemplo implantação de ISO, Institutos de Pesquisa etc. Qual a frequência? ).

\section{Item 37. Eventos e Associações}

A empresa busca de forma sistemática novas informações e tecnologias

\begin{tabular}{l|l|l} 
Não & Parcial & Sim \\
\hline
\end{tabular}


em eventos (seminários, congressos, etc.) e associações técnicas ou empresariais:

\section{Critérios de avaliação para orientação do entrevistador:}

Não - A empresa não busca novas informações e tecnologias em eventos (seminários, congressos, etc.) e associações técnicas ou empresariais

Parcial - A empresa busca de forma eventual novas informações e tecnologias em eventos (seminários, congressos, etc.) e associações técnicas ou empresariais

Sim - A empresa busca de forma sistemática novas informações e tecnologias em eventos (seminários, congressos, etc.) e associações técnicas ou empresariais.

\section{Evidências:}

(Exemplo, qual(is) o(s) nome(s) do(s) evento(s), datas de participação, exemplos de informações e tecnologias identificadas).

\section{Item 38. Aquisição de Patentes e Know-How (Conhecimento Técnico)}

\begin{tabular}{|l|l|l|l|}
\cline { 3 - 4 } \multicolumn{1}{c|}{} & Não & Parcial & Sim \\
\hline $\begin{array}{l}\text { A empresa adquiriu de forma sistemática novas informações técnicas, } \\
\text { áltimos te patentes ou knos: }\end{array}$ & & & \\
\hline
\end{tabular}

Critérios de avaliação para orientação do entrevistador:

Não - A empresa não adquiriu novas informações técnicas, através de patentes ou knowhow (conhecimento de terceiros), nos últimos três anos.

Parcial - A empresa adquiriu de forma eventual novas informações técnicas, através de patentes ou know-how (conhecimento de terceiros), nos últimos três anos.

Sim - A empresa adquiriu de forma sistemática as seguintes novas informações técnicas, através de patentes ou know-how (conhecimento de terceiros), nos últimos três anos.

\section{Evidências:}

(Exemplo, qual o tipo de patente: modelo de utilidade, desenho industrial adquirida? Qual o número do registro/ano?). 
Seção IV. AVALIAÇÃO DA CAPACIDADE DE INOVAÇÃO

\section{Item 1. Novos Produtos/Serviços}

A empresa lançou mais de um novo produto/serviço com sucesso no

mercado, nos últimos três anos:

\begin{tabular}{|l|l|l|}
\hline Não & Parcial & Sim \\
\hline
\end{tabular}

\section{Critérios de avaliação para orientação do entrevistador:}

Não - A empresa não lançou produto/serviço com sucesso no mercado, nos últimos três $\underline{\text { anos }}$

Parcial - A empresa lançou apenas um novo produto/serviço com sucesso no mercado, nos últimos três anos

Sim - A empresa lançou mais de um novo produto/serviço com sucesso no mercado, nos últimos três anos.

\section{Evidências:}

(Exemplo qual produto/serviço? Ano de lançamento? Solicitar catálogo e ficha técnica do produto. Quantos \% o novo produto/serviço representa do total do faturamento da empresa?).

\section{Item 2. Soluções Complementares (produtos)}

A empresa ofertou mais de um novo produto complementar a seus

clientes, nos últimos três anos, criando novas oportunidades de receita:

Critérios de avaliação para orientação do entrevistador:

Não - A empresa não ofertou um novo produto complementar a seus clientes, nos últimos três anos.

Parcial - A empresa ofertou apenas um novo produto complementar a seus clientes, nos últimos três anos, criando nova oportunidade de receita.

Sim - A empresa ofertou mais de um novo produto complementar a seus clientes, nos últimos três anos, criando novas oportunidades de receita.

Evidências:

(Exemplo, qual o produto/serviço e o produto complementar? Qual o ano de lançamento?).

\section{Item 3. Soluções Complementares (serviços)}

A empresa ofertou mais de um novo serviço complementar a seus clientes, nos últimos três anos, criando novas oportunidades de receita:

Critérios de avaliação para orientação do entrevistador:

Não - A empresa não ofertou um novo serviço complementar a seus clientes, nos últimos três anos. 
Parcial - A empresa ofertou apenas um novo serviço complementar a seus clientes, nos últimos três anos, criando nova oportunidade de receita.

Sim - A empresa ofertou mais de um novo serviço complementar a seus clientes, nos últimos três anos, criando novas oportunidades de receita.

\section{Evidências:}

(Exemplo, qual o produto/serviço e o serviço complementar? Qual o ano de lançamento?).

\section{Item 4. Sistema de Produção Flexível}

\begin{tabular}{|l|l|l|l|}
\cline { 2 - 4 } \multicolumn{1}{c|}{ A empresa modificou seu sistema de produção (linhas de produção) } & Não & Parcial & Sim \\
sistematicamente, nos últimos 3 anos, em busca de flexibilidade & & & \\
produtiva e seu sistema atende a mais de uma família de \\
produtos/serviços:
\end{tabular}

\section{Critérios de avaliação para orientação do entrevistador:}

Não - A empresa manteve seu sistema de produção (linhas de produção), nos últimos 3 anos, que atende a apenas um produto/serviço.

Parcial - A empresa fez algumas modificações em seu sistema de produção (linhas de produção), nos últimos 3 anos, em busca de flexibilidade produtiva e seu sistema atende a apenas uma família de produtos/serviços.

Sim - A empresa modificou seu sistema de produção (linhas de produção) sistematicamente, nos últimos 3 anos, em busca de flexibilidade produtiva e seu sistema atende a mais de uma família de produtos/serviços.

\section{Evidências:}

(Exemplo, como é o sistema de produção? Qual(is) produto(s)/serviço(s) e família(s) de produto(s) atendida(s) são atendidos por esse sistema de produção?).

\section{Item 5. Inovações em Processos}

A empresa modificou seus processos sistematicamente, nos últimos 3 anos, para obter maior eficiência, qualidade ou menor ciclo de produção:

\section{Critérios de avaliação para orientação do entrevistador:}

Não $\quad$ - A empresa não alterou seus processos, nos últimos 3 anos.

Parcial - A empresa alterou pelo menos um processo, nos últimos 3 anos, para obter maior eficiência, qualidade, flexibilidade produtiva ou menor ciclo de produção Sim - A empresa modificou seus processos sistematicamente, nos últimos 3 anos, para obter maior eficiência, qualidade ou menor ciclo de produção.

\section{Evidências:}

(Exemplo, qual o método de avaliação: lean manufactoring, melhoria contínua? Qual(is) modificação(ões) foram feitas e em que processos: exemplo compra ou aluga equipamentos diferentes dos usados normalmente? E qual melhoria: maior eficiência, qualidade, flexibilidade produtiva ou menor ciclo de produção). 


\section{Item 6. Sistemas de Gestão da Qualidade}

A empresa adotou mais de uma nova prática de gestão da qualidade, nos últimos três anos:

\section{Critérios de avaliação para orientação do entrevistador:}

Não - A empresa não adotou qualquer nova prática de gestão da qualidade, nos últimos três anos.

Parcial - A empresa adotou apenas uma nova prática de gestão da qualidade, nos últimos três anos.

Sim - A empresa adotou mais de uma nova prática de gestão da qualidade, nos últimos três anos.

\section{Evidências:}

(Exemplo, qual(is) prática(s) foi(ram) adotada(s): PCP, GQT, SCM, Kanban, Reengenharia, Just in Time, PNQ, Lean Manufactoring?).

\section{Item 7. Identificação de Novos Mercados}

A empresa tem uma sistemática (rotina) para encontrar novos mercados para seus produtos/serviços e identificou mais de dois mercados para seus produtos/serviços, nos últimos 3 anos:

\section{Critérios de avaliação para orientação do entrevistador:}

Não - A empresa não identificou novos mercados para seus produtos/serviços, nos últimos 3 anos.

Parcial - A empresa não possui uma sistemática, mas identificou um ou dois mercados para seus produtos/serviços, nos últimos 3 anos.

Sim - A empresa tem uma sistemática (rotina) para encontrar novos mercados para seus produtos/serviços e identificou mais de dois mercados para seus produtos/serviços, nos últimos 3 anos.

\section{Evidências:}

(Exemplo, qual o método (formal ou informal) utilizado? Quais os mercados identificados).

\section{Item 8. Inserção em Novos Mercados}

A empresa vendeu mais
nos últimos três anos:

Critérios de avaliação para orientação do entrevistador:

Não - A empresa não vendeu seus produtos/serviços em novos mercados, nos últimos três anos. 
Parcial - A empresa vendeu apenas um produto/serviço em novos mercados, nos últimos três anos.

Sim - A empresa vendeu mais de um produto/serviço em novos mercados, nos últimos três anos.

\section{Evidências:}

(Exemplo, qual novo mercado atingido com qual produto? Quantos \% do total do faturamento advém do(s) novo(s) mercado(s)? Solicitar exemplos de novos mercados com o ano de inserção). 


\section{APÊNDICE B - CONSTRUCTO CULTURA ORGANIZACIONAL}

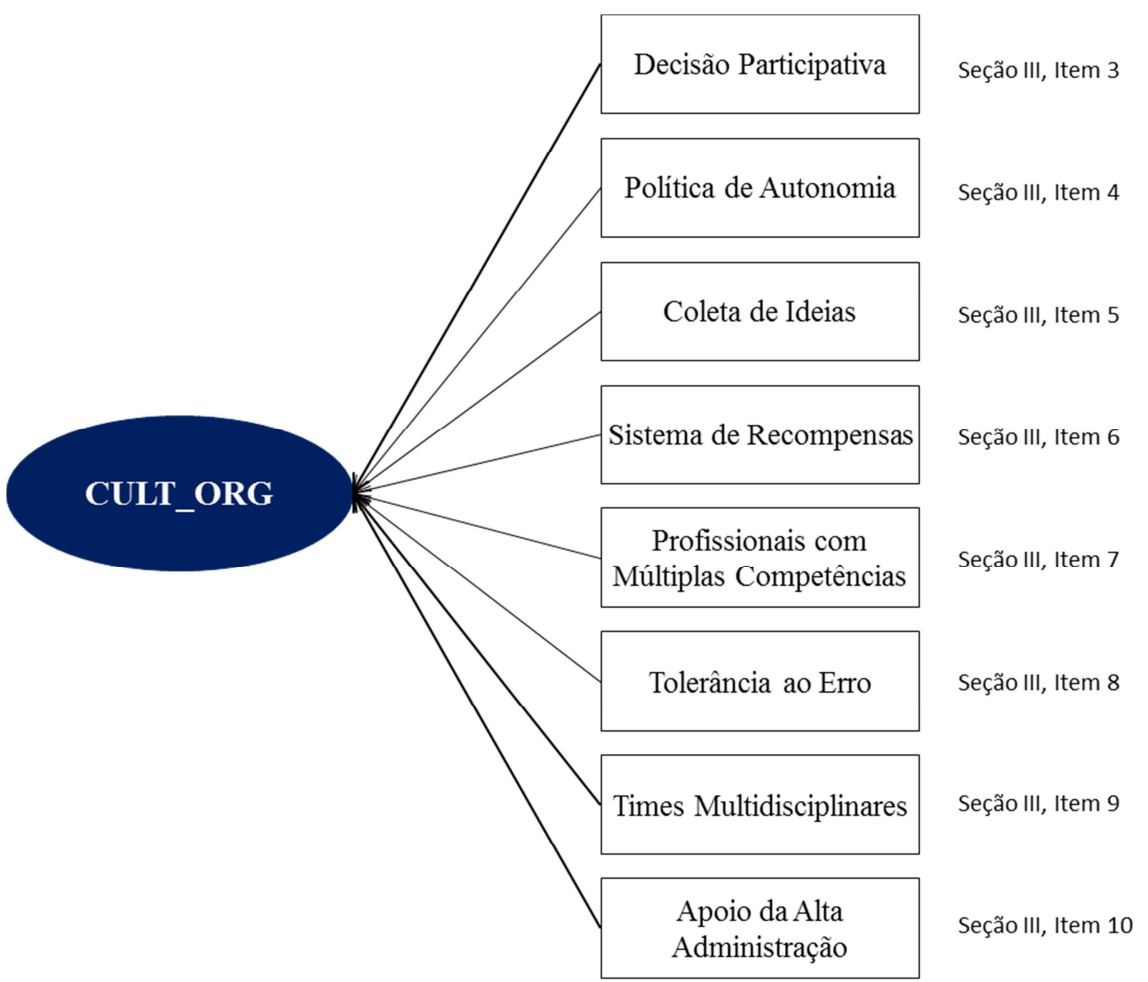




\section{APÊNDICE C - CONSTRUCTO CAPACIDADE DE GESTÃo DE PROJETOS}

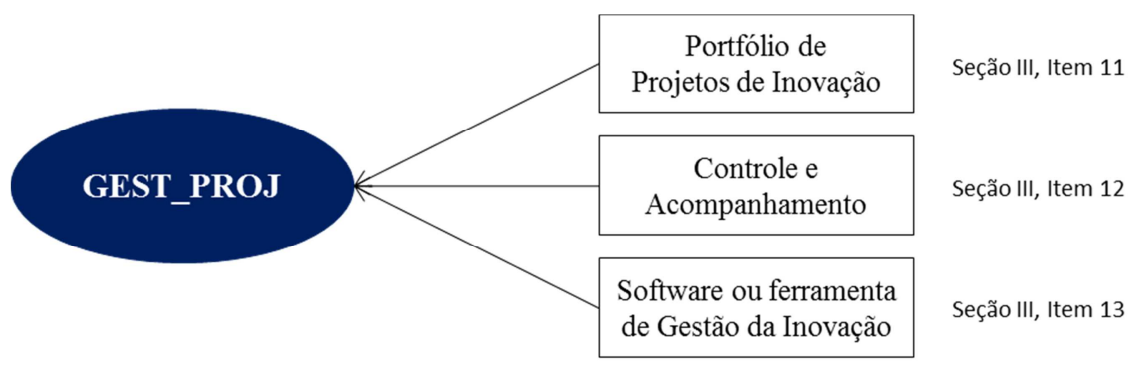




\section{APÊNDICE D - CONSTRUCTO BASE DE CONHECIMENTO INTERNO}

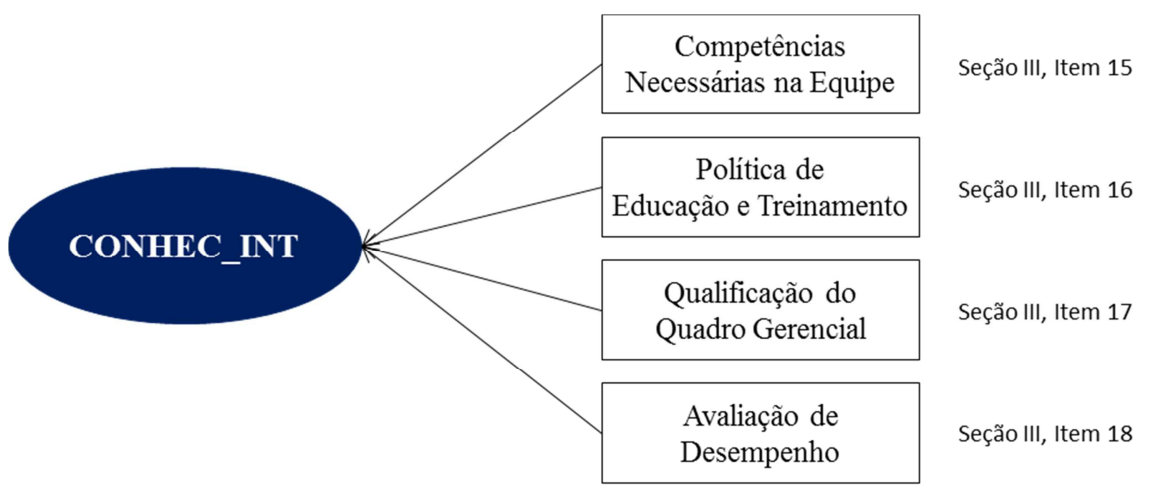




\section{APÊNDICE E - CONSTRUCTO ESTRATÉGIA}

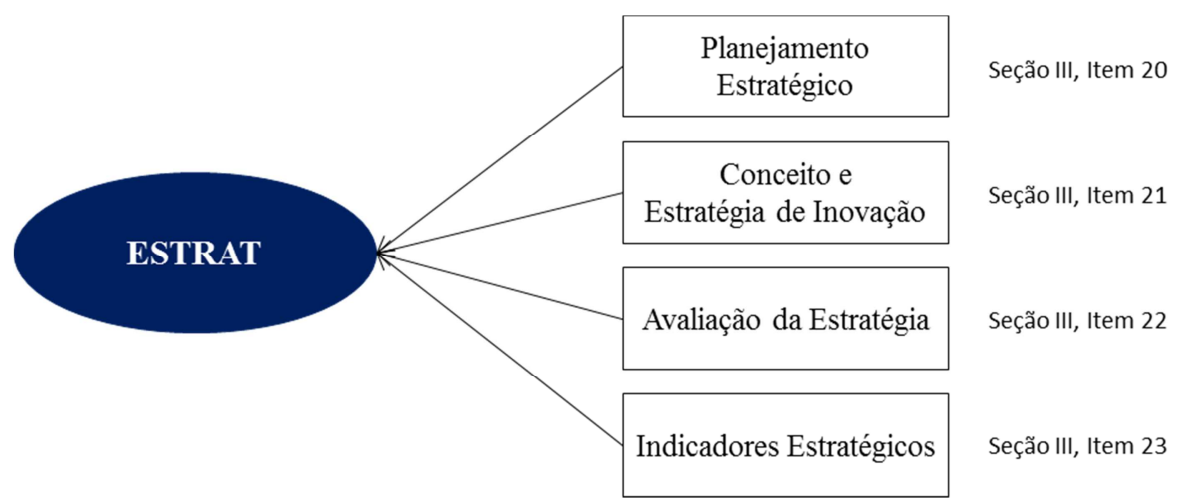




\section{APÊNDICE F - CONSTRUCTO ORIENTAÇÃO AO MERCADO}

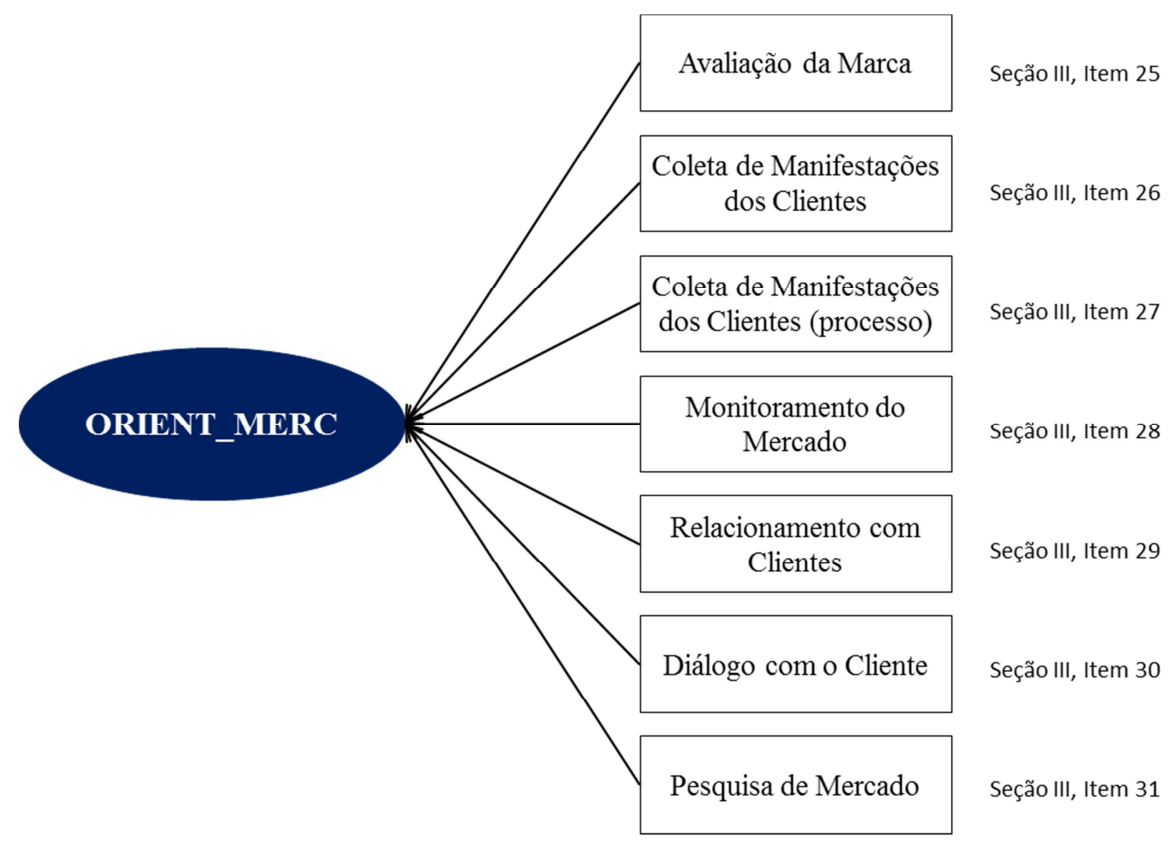




\section{APÊNDICE G - CONSTRUCTO BASE DE CONHECIMENTO EXTERNO}

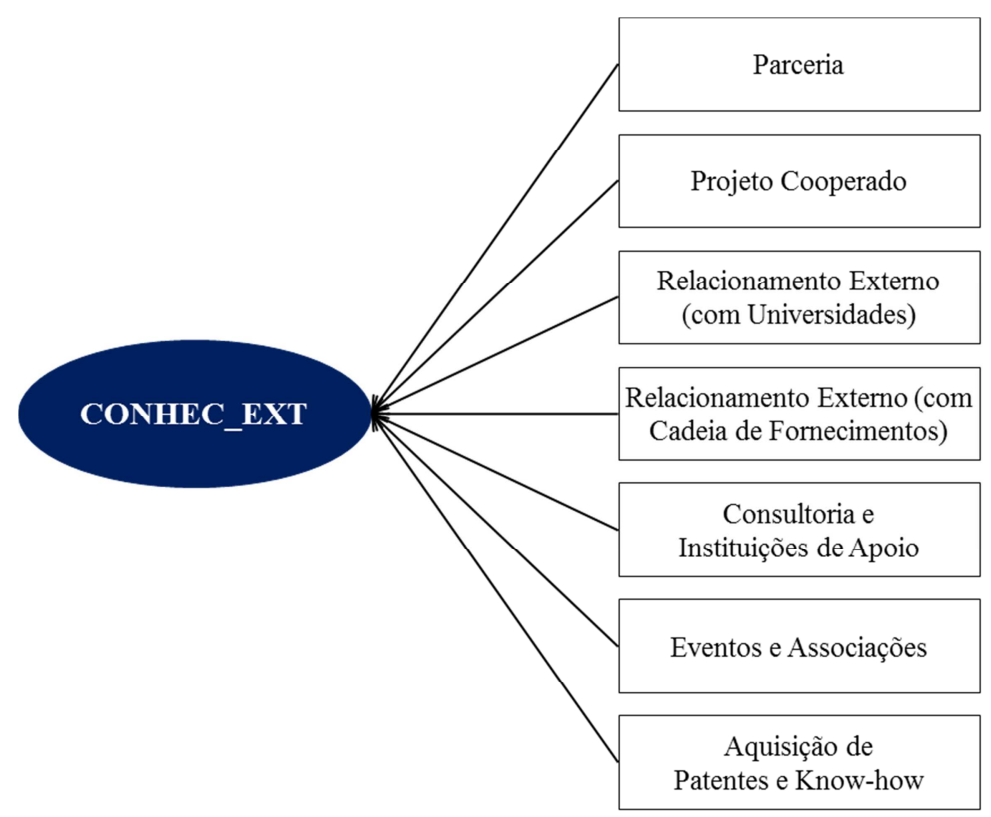

Seção III, Item 32

Seção III, Item 33

Seção III, Item 34

Seção III, Item 35

Seção III, Item 36

Seção III, Item 37

Seção III, Item 38 
APÊNDICE H - CONSTRUCTO CAPACIDADE DE INOVAÇÃO

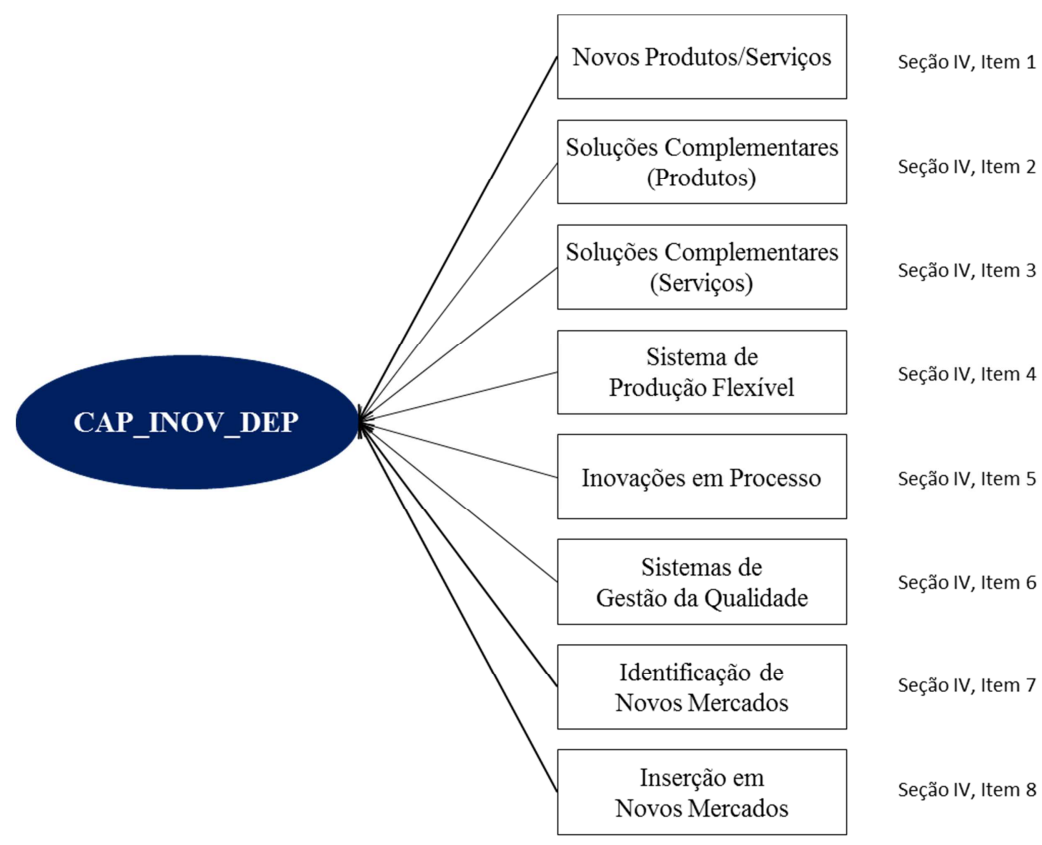

